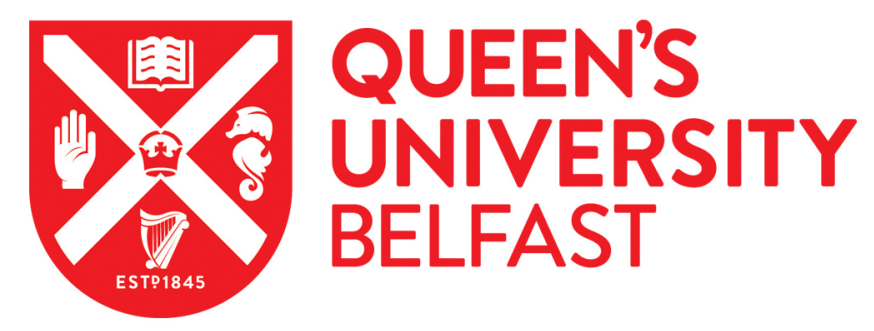

\title{
Diagnosing child sex abuse: A research challenge.
}

Duffy, K., Keenan, M., \& Dillenburger, K. (2006). Diagnosing child sex abuse: A research challenge. International Journal of Behavioral Consultation and Therapy, 2, 150-173.

Published in:

International Journal of Behavioral Consultation and Therapy

Queen's University Belfast - Research Portal:

Link to publication record in Queen's University Belfast Research Portal

\section{General rights}

Copyright for the publications made accessible via the Queen's University Belfast Research Portal is retained by the author(s) and / or other copyright owners and it is a condition of accessing these publications that users recognise and abide by the legal requirements associated with these rights.

Take down policy

The Research Portal is Queen's institutional repository that provides access to Queen's research output. Every effort has been made to ensure that content in the Research Portal does not infringe any person's rights, or applicable UK laws. If you discover content in the Research Portal that you believe breaches copyright or violates any law, please contact openaccess@qub.ac.uk. 


\section{International Journal}

\section{of \\ Behavioral and Consultation Therapy

\begin{tabular}{lll}
\hline Volume Number 2 & Spring, 2006 & Issue Number 2 \\
\hline ISSN $1555-7855$ &
\end{tabular}

\section{Table of Contents}

Page 141: Self-directed Behavioural Family Intervention - Alina Morawska and Matthew R Sanders

Page 150: Diagnosing Child Sex Abuse: A research challenge-Catrina Duffy, Mickey Keenan and Karola Dillenburger

Page 174: An Experimental Investigation of Responsibility and Reassurance: Relationships with Compulsive Checking - Chris L. Parrish and Adam S. Radomsky

Page 192: Behavior Analysis of Forgiveness in Couples Therapy - James Cordova, Ph.D., Joseph Cautilli, Ph.D., Corrina Simon

Page 215: A Treatment Study of Suicidal Adolescent with Personality Disorder or Traits: Mode Deactivation Therapy as compared to Treatment as Usual - Jack A Apsche, Christopher K. Bass, Alexander M. Siv

Page 225: Conjoint Behavioral Consultation: An Emerging and Effective Model for Developing Home-School Partnerships - Lee A. Wilkinson

Page 240: Alternate Forms Reliability of the Behavioral Relaxation Scale: Preliminary Results Duane A. Lundervold and Angel L. Dunlap

Page 246: The Effects of Learn Units on Student Performance in Two College Courses - Ara John Bahadourian, Kai Yung (Brian) Tam, R. Douglas Greer and Marilyn K. Rousseau

Page 266: Problem Solving Treatment for Intellectually Disabled Sex Offenders - Christine Maguth Nezu, Alicia A. Fiore \& Arthur M. Nezu

Page 277: A Treatment Study of Mode Deactivation Therapy in an Out Patient Community Setting - Jack A. Apsche, Christopher K. Bass and Alexander Siv

Page 286: Community Treatment Programs for Juveniles: A Best-Evidence Summary - Lee A. Underwood, Kara Sandor von Dresner \& Annie L. Phillips

Page 305: Dodo-Bird or Dressing up the Pig and the Politics of Psychotherapy: A Reply to Vandenberghe and de Sousa (2005) - Joseph Cautilli, Ph.D. 


\title{
International Journal of Behavioral and Consultation Therapy
}

\author{
VOLUME NO. 2, ISSUE NO. 2 \\ ISSN: 1555 - 7855 \\ Published: May 15, 2006

\section{PUBLISHER'S STATEMENT}

The International Journal of Behavioral and Consultation Therapy (IJBCT), is published quarterly by Joseph Cautilli. IJBCT is an online, electronic publication of general circulation to the scientific community. IJBCT's mission is to provide a focused view of behavioral consultation and therapy for the general behavioral intervention community.

Additionally, IJBCT hopes to highlight the importance of conducting clinical research from a strong theoretical base. IJBCT areas of interest include, but are not limited to: Clinical Behavior Analysis, Behavioral Therapy, Behavioral Consultation, Organizational Behavior Management, Human Performance Technology, and Cognitive Behavior Therapy. IJBCT is an independent publication and is in no way affiliated with any other publications.

The materials, articles, and information provided in this journal have been peer reviewed by the review board of IJBCT for informational purposes only. The information contained in this journal is not intended to create any kind of patient-therapist relationship or representation whatsoever. For a free subscription to The International Journal of Behavioral Consultation and Therapy, send the webmaster an e-mail at subscribe@behavior-analyst-today.com, containing your name, e-mail address, and the word "subscribe IJBCT" in the subject box, and you will be added to the subscription list. You will receive notice of publication of each new issue via e-mail that will contain a hyperlink to the latest edition.

\section{ADVERTISING IN THE \\ INTERNATIONAL JOURNAL OF BEHAVIORAL AND CONSULTATION THERAPY}

The prices for advertising in one issue are as follows:

1/4 Page: \$50.00 1/2 Page: \$100.00 vertical or horizontal Full Page: $\$ 200.00$

If you wish to run the same ad in multiple issues for the year, you are eligible for the following discount:

1/4 Pg.: \$40 - per issue

1/2 Pg.: \$75 - per issue -vertical or horizontal

Full Page: \$150.00-per issue

An additional one time layout/composition fee of \$25.00 is applicable

For more information, or to place an ad, contact Halina Dziewolska via e-mail at: halinadz@hotmail.com 


\section{International Journal of Behavioral and Consultation Therapy}

ISSN: 1555 - 7855

\section{Mission Statement}

The behavioral psychologies are major forces that influence many areas of human interest. These psychologies draw on various learning theories to produce change in clients and consultees performance and combine in an area known as Behavior Therapy. Behavior therapy is a broad area that often lacks integration and understanding between the theoretical and technological aspects of the field.

The International Journal of Behavioral Consultation and Therapy is committed to increasing the communication between various areas of behavioral consultation and therapy. As the massive body of behavioral research in psychology and education has been produced, the BAO group deemed that a new journal was needed to handle the ever increasing interest and ever fractionating field.

The International Journal of Behavioral Consultation and Therapy strives to be a high quality journal that also brings up to the minute information on current developments within the field to those who can benefit from those developments. Thus, the International Journal of Behavior Consultation and Therapy will continue to publish original research, reviews of the discipline, theoretical and conceptual work, applied research, program descriptions, research in organizations and the community, clinical work, and curriculum developments. Our vision is to become the voice of clinical behavior analysis and behavior therapy practices.

\section{Submissions}

Authors who wish to be considered for publication in IJBCT must submit a signed assignment of rights form with their article. The form can be downloaded from the IJBCT website on the submissions page.

The International Journal of Behavioral Consultation and Therapy (IJBCT) is wholly owned by Joseph Cautilli. IJBCT contributions are by invitation of the lead editor or the associate editors only. All submissions are peer-reviewed. After acceptance, all articles are copyedited.

\section{Peer Review}

All submitted manuscripts are reviewed initially by an IJBCT editor. Manuscripts with insufficient priority for publication are rejected promptly. Other manuscripts are sent to expert consultants for peer review. Information from submitted manuscripts may be systematically collected and analyzed as part of research to improve the quality of the editorial or peer review process. Identifying information will remain confidential. 


\section{Manuscripts}

Rejected manuscripts will be returned to authors when specifically requested in the cover letter. Print copies of original illustrations, photographs, and slides will be returned with the manuscript. In all cases, manuscripts must be submitted electronically saved in "rich text format" (.rtf) to Joseph Cautilli, Ph.D., BCBA.

\section{A Word about Abstracts}

In order to ensure that IJBCT will be accepted in the major psych databases, there are certain guidelines that must be followed for abstracts relating to our article and the Journal. The following guidelines are straight from the PsycINFO website:

http://www.apa.org/psycinfo/about/covinfo.html

\section{General Guidelines for Writing Effective Abstracts}

For use in PsycINFO and other databases, an abstract should not exceed 960 characters and spaces (approximately 120 words).

Characters may be conserved by:

- using digits for numbers (except at the beginning of sentences)

- using well-known abbreviations

- using the active voice

Begin with the most important information, but don't waste space by repeating the title. Include in the abstract only the four or five most important concepts, findings, or implications.

Embed as many key words and phrases in the abstract as possible; this will enhance the user's ability to find the citation for your article in a computer search. Include in the abstract only information that appears in the body of the paper.

Style:

Remember that not all people who read your abstract will have a high level of psychological knowledge.

Define all acronyms and abbreviations, except those for measurements.

- Spell out names of tests

- Use generic names for drugs (when possible)

- Define unique terms 
Use the present tense to describe results with continuing applicability or conclusions drawn and the past tense to describe variables manipulated or tests applied. As much as possible, use the third person, rather than the first person.

\title{
Abstracts for Empirical Studies:
}

Abstracts of an empirical study are generally about 100 - 120 words. Include the following information:

- problem under investigation (in one sentence)

- pertinent characteristics of subjects (number, type, age, sex, and genus and species)

- experimental method, including apparatus, data-gathering procedures, complete test

- names, and complete generic names and the dosage and routes of administration of any

drugs (particularly if the drugs are novel or important to the study)

- findings, including statistical significance levels

- conclusions and implications or applications

\section{Abstracts for Review/Theoretical Articles}

\author{
Abstracts for review or theoretical articles are generally about 75--100 \\ words. Include the following information: \\ - the topic in one sentence \\ - purpose, thesis, or organizing construct and the scope (comprehensive or selective) of the \\ article \\ - sources used (e.g., personal observation, published literature) \\ - conclusions
}

\section{Editing:}

Accepted manuscripts are copy edited according to APA format and returned to the author for approval. Authors are responsible for all statements made in their work, including changes made by the copy editor and authorized by the corresponding author. Please adhere to APA format and use "Times New Roman" font in 11 pt., single spaced throughout. In references, however, please italicize the places where APA format would have you underline.

\section{Additional requirements:}

To be published in any of the BAO journals, we have additional requirements that authors must adhere to. Our requirements supercede any requirements that conflict with APA requirements. 
* All articles must be created as one continuous document - no documents that are created in sections or sub documents.

* Authors must not insert their own headers, footers, or pagination.

* Graphics, figures, tables, etc., must be in jpg or bmp format. Graphics, figures, tables, etc., may be embedded in the text body of the article by the author. No Excel graphs will be accepted. If graphical materials are submitted as separate Word documents, they should be in portrait format and should be full page, or one half page or less only. Graphical materials larger than one page cause serious layout problems. If graphical materials are not inserted into the text portion of the article by the author, indicators must be placed in the text body so we know where the graphical materials belong.

* All articles should be single spaced, with one-inch margins all around.

* All abstracts must contain keywords.

* Full author contact information must be included in the article.

\section{Thank you!}

\section{The Behavior Analyst Online Journals Department}

\section{Message from the Editor:}

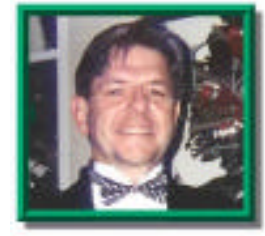

Dear Readers:

I want to take this opportunity clarify an error that occurred in IJBCT, Volume 1, No. 3, Summer, 2005. We inadvertently published an article that was published in the Journal of Forensic Psychology (see Nezu, C. M.., Greenberg, J. \& Nezu, A. M. (2006), Project STOP: Cognitive Behavioral Treatment for Intellectually Disabled Sex Offenders, Journal of Forensic Psychology Practice,6, 87-103.)

This was an accident that will be corrected in this issue as we publish the correct article: "Problem Solving Treatment for Intellectually Disabled Sex Offenders," by Christine Maguth Nezu, Alicia A. Fiore \& Arthur M. Nezu.

I am truly sorry to the authors and readers of IJBCT for this error.

I would also like to welcome Melissa Apsche as the newest member of the layout staff.

\section{J ack A psche}

Jack A. Apsche, Co-lead Editor 


\section{International Journal of Behavioral and Consultation Therapy}

ISSN : 1555 - 7855

\section{Co-Lead Editors:}

\section{Editorial Staff}

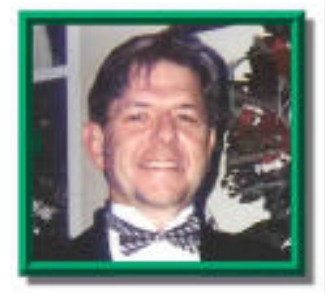

Jack Apsche, Ed.D, ABPP - Apsche Center, Yardley, PA

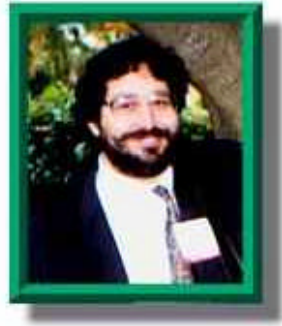

Joe Cautilli, Ph.D., M.Ed., BCBA-Children's Crisis Treatment Center - Philadelphia, PA

\section{Associate Editors}

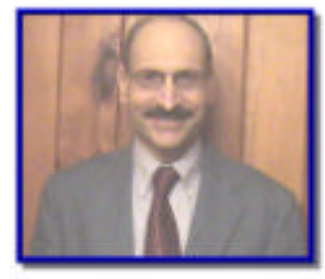

Michael Weinberg, Ph.D., BCBA - Orlando Behavioral Health, Orlando, FL

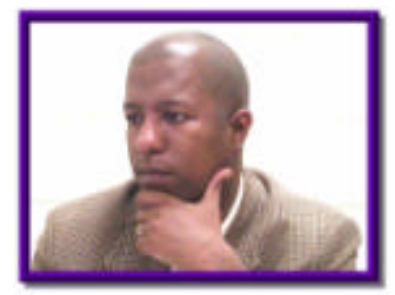

Christopher K. Bass, Ph.D. - Clark Atlanta University

NO PICTURES AVAILABLE

James K. Luiselli, Ed.D., ABPP, BCBA - May Institute

Ingo Bergsteinsson, Ph.D. - Behavior Change Resources 


\section{International Journal of Behavioral and Consultation Therapy}

\section{Editorial Board:}

John Austin, Ph.D. - Western Michigan University - USA

John Blackledge, Ph.D. - Spectrum Center (Berkeley, California) USA

Teri Burcroff, Ph.D. - East Strausburg University - USA

Ken Carpenter, Ph.D. - New York State Psychiatric Institute Division - CPMC - USA

Jim Connel, M.Ed. - Private Practice

Richard A.C. Dale, Ph.D. - Cornell University -USA

Simon Dymond, Ph.D., B.C.B.A. - University of Wales, Swansea - United Kingdom

Patrick Friman, Ph.D. - Boys Town, USA

Lee Kern, Ph.D. - Lehigh University -USA

Smita Mehta, Ph.D. - University of Texas - USA

Caio F. Miguel, Ph.D. - Western Michigan University - USA

Kevin Moore, Ph.D. - Oregon Social Learning Center - USA

Robert Kohlenberg, Ph.D. - University of Washington - USA

Cheryl McNeil, Ph.D. - West Virginia University - USA

Paul H. Pittman, Ph.D. - Indiana University Southwest - USA

Phil Reed, Ph.D. - University of Wales Swansea, United Kingdom

David M. Richman, Ph.D. - University of Maryland, Baltimore County - USA

Kimberly Schreck, Ph.D. - Penn State University - USA

James Snyder, Ph.D. - Wichata University - USA

Peter Sturmey, Ph.D. - Private Practice

Adam Weaver - Mississippi State University - USA

David Wilder, Ph.D. - University of Florida - USA

R.D Zettle, Ph.D. - Wichita University - USA 


\title{
Self-directed Behavioural Family Intervention
}

\author{
Alina Morawska \& Matthew R Sanders
}

\begin{abstract}
Behavioural family intervention is effective for the prevention and treatment of a wide range of emotional and behavioural problems in children. There is a growing need to address the accessibility of these services. This paper reviews the literature on self-directed interventions designed to help parents manage difficult child behaviours. Evidence regarding the efficacy of interventions is reviewed, and some of the difficulties associated with self-directed programs are discussed. The Selfdirected Triple P Program is highlighted as an example of an efficacious and effective behavioural family intervention fitting into a larger multi-level model of family intervention. The discussion of the efficacy and effectiveness of self-directed interventions has implications for service delivery of parenting programs.

Key words: self-directed, behavioural family intervention, parenting, children.
\end{abstract}

Parenting interventions attempt to enhance a parent's understanding of child behaviour management and the quality of the parent-child interactions, with the ultimate goal of optimising the child's developmental course (Cowan, Powell, \& Cowan, 1998). When parents are taught to use consistent, moderate, and firm discipline, their children exhibit fewer behaviour problems (Arnold \& O'Leary, 1997; Forehand, Wells, \& Griest, 1980; Webster-Stratton, Kolpacoff, \& Hollinsworth, 1988). Behavioural family interventions (BFI) aim to effect change in children's behaviour and adjustment by modifying aspects of the family environment that maintain and reinforce a child's problem behaviours (Sanders, 1992).

There is substantial evidence that BFI, particularly therapist-directed BFI, produces significant changes in both parents and children immediately following treatment (Forehand, Griest, \& Wells, 1979) and there is good maintenance of treatment gains and generalisation of these skills (Dadds, Sanders, \& James, 1983; Forehand \& Long, 1988). There is also evidence for the generalisation of intervention effects beyond the specific behaviours and settings addressed during treatment (Sanders \& Glynn, 1981; Serkettich \& Dumas, 1996). Furthermore, BFI has effects ranging beyond improvements in child behaviour. Effects have been shown for decreases in parental depression (Connell, Sanders, \& Markie Dadds, 1997; Forehand et al., 1980), anxiety, and stress (Connell et al., 1997). Finally, in general, parents report high levels of satisfaction with behavioural family interventions and find the programs socially acceptable (Forehand et al., 1980; McMahon \& Forehand, 1983; Webster-Stratton, 1989).

While there is significant evidence to support the efficacy of BFI, there are a number of factors that limit its dissemination at a community level. Firstly, very low numbers of parents participate in any form of parent education (Sanders et al., 1999) and there is generally low participation by parents of children who have significant behaviour problems (Zubrick et al., 1995) or whose children are believed to be at greatest risk of developing serious behaviour or emotional problems (Harachi, Catalano, \& Hawkins, 1997). In Australia, while approximately $18 \%$ of children experience an identifiable mental health problem, only $2 \%$ of children receive any form of treatment from specialist mental health practitioners (Zubrick \& Silburn, 1994) and only 10\% of parents participate in parenting education (Sanders et al., 1999). Secondly, there is a range of psychological and cultural implications to seeking help, with great stigma attached to perceived difficulties with coping (Cunningham, 1996). The logistics of attending sessions, either individual or group, such as work schedules, extracurricular activities, 
difficulties arranging childcare, travel time, and transport costs may prevent many parents from participating in interventions (Cunningham, 1996; Pavuluri, Luk, \& McGee, 1996; Spoth, Redmond, Hockaday, \& Shin, 1996). Finally, families may simply live in areas where there are no services, such as rural and remote regions. For these families, accessing services is very difficult, if not impossible. Indeed, research indicates that children from low-income families or rural/remote areas are less likely to receive psychological interventions (Hunsley, Aubry, \& Lee, 1997).

\section{Self-directed Interventions}

Self-directed interventions have been proposed as one effective way for addressing some of the limitations and access problems identified for traditional BFI and for increasing the reach of services (Sanders, 2000). Such interventions overcome many of the barriers associated with accessing face-to-face services, as there is lowered stigma and significantly reduced or eliminated cost, transport requirements, and timing difficulties. Families can complete self-directed programs in their own homes, in their own time, and at their own pace. Furthermore, self-administered interventions are often very cost-effective and their use can ease the financial burden of mental health on the community.

Self-administered interventions have also been proposed as forming part of a stepped-care approach, where they are used as the most basic and least intrusive level possible. It may be efficient to screen individuals and on the basis of a number of factors, assign them to either more or less intensive intervention. Clients could be offered a self-directed intervention, followed by more intensive intervention if required, allowing the clinician to build on skills and knowledge which have been acquired through the self-directed intervention (Sanders, Montgomery, \& Brechman-Touissant, 2000; Webster-Stratton, 1992).

There is limited research in the family intervention field focusing on self-directed interventions. Self-directed interventions have been used to target both specific problem behaviours, as well as broader behavioural difficulties. For example, self-directed interventions have been successful in improving child compliance (Gmeinder \& Kratochwill, 1998; Sloane, Endo, Hawkes, \& Jenson, 1990), in reducing child tantrums (Endo, Sloane, Hawkes, McLoughlin, \& Jenson, 1991), in reducing child sleep problems (Seymour, Brock, During, \& Poole, 1989), providing better outcomes in the treatment of ADHD (Long, Rickert, \& Ashcraft, 1993), treating nocturnal enuresis (van Londen, van Londden-Barensten, van Son, \& Mulder, 1993), and delaying adolescent smoking onset (Bauman et al., 2001).

The broader self-directed interventions focus on parents developing skills to monitor and remediate ineffective parenting techniques, determine their own goals and performance standards, and identify actions they can take to produce change in their child's behaviour. The work of Webster-Stratton and colleagues demonstrates an approach to examining self-directed programs with parents of young children. For example, Webster-Stratton, Kolpacoff, and Hollinsworth (1988) found that a selfadministered video modelling intervention was comparable to a group discussion video modelling intervention. The self-administered approach was found more effective when families accessed two brief consultations with a therapist during the course of the program (Webster-Stratton, 1990), suggesting that therapist involvement is an important element of therapeutic effectiveness.

Self-directed programs have also been found to have comparable effects to therapist directed programs. For example, Nicholson and Sanders (1999) compared therapist directed BFI to a self-directed BFI intervention for parents of 7 to 12-year-old children with significant oppositional or conduct problems. Both intervention conditions led to equivalent improvements, compared to a wait-list control; however, there was more satisfaction with therapy in the therapist directed condition. Similarly, Sanders, Markie-Dadds, Tully, and Bor (2000) conducted a large scale clinical trial of 305 families with a 3-year- 
old child comparing two therapist-assisted versions of BFI and a self-directed BFI condition. Families completing any version of the program showed significant improvements on a variety of self-report and observational measures compared to a wait-list control group, however, there was more improvement in the therapist directed versions of the program, compared to the self-directed version. At 1-year follow-up families in the self-directed group continued to show improvements and were more comparable to the other two groups.

The empirical support for brief, self-directed interventions is hampered by methodological limitations. Most include some kind of practitioner support (e.g., Endo, Sloane, Hawkes, \& Jenson, 1991; Hansen, Tisdelle, \& O'Dell, 1984), small sample sizes (e.g., Connell et al., 1997; Gmeinder \& Kratochwill, 1998; Hansen et al., 1984), an absence of control groups (e.g., Hunt \& Adams, 1989), an absence of child behaviour outcome measures (Flanagan, Adams, \& Forehand, 1979; Hansen et al., 1984), and an absence of independent observations of child and parent behaviours (Connell et al., 1997).

Overall, Elgar and McGrath (2003) in a review of self-administered treatments for children and families concluded that there is some evidence to support the use of self-administered interventions. However, more randomised controlled trials addressing various problem areas, long term effects, populations, and media need to be conducted. The authors emphasised the need to conduct effectiveness trials in naturalistic settings, in order to promote integration of programs into health care settings. Furthermore, they recommended that the role of therapist assistance in self-administered treatments needs to be clarified.

\section{Triple P - Positive Parenting Program}

Triple P is an example of an empirically supported BFI (e.g., Sanders, Markie-Dadds et al., 2000), which was developed at the University of Queensland and has a considerable history of research and clinical application. It is a program that emphasises parental self-regulation as a means of achieving long-term change in child behaviour.

Triple $\mathrm{P}$ is a multi-level, preventively oriented parenting and family support strategy. It aims to prevent behavioural, emotional and developmental problems in children by enhancing the knowledge, skills, and confidence of parents. Triple P incorporates five levels of intervention on a tiered continuum of strength. Triple $\mathrm{P}$ is a behavioural family intervention based on social learning principles aiming to: (a) enhance the knowledge, skills, confidence, self-sufficiency and resourcefulness of parents; (b) promote more nurturing, safe, engaging, non-violent and low conflict environments for children, and; (c) promote children's social, emotional, language, intellectual and behavioural competencies through positive parenting practices (Sanders, 1999). The distinguishing features of Triple P are program sufficiency, flexible tailoring to identified risk and protective factors, varied delivery modalities, wide potential reach, and a multidisciplinary approach.

\section{Self-directed Triple $\mathbf{P}$}

There is considerable research evidence for variants of Triple $\mathrm{P}$, and the technological aspects of selfdirected intervention have been examined. Specifically, the research has examined the role of therapist involvement in enhancing the efficacy of self-directed behavioural family interventions. Self-directed Triple $\mathrm{P}$ with no practitioner support has been found to have comparable effects to therapist directed programs (Nicholson \& Sanders, 1999; Sanders, Markie-Dadds et al., 2000), however, in general parents were more satisfied with the intervention when they received practitioner support. 
Connell et al. (1997) provided a self-directed BFI intervention to 24 parents of preschoolers in regional areas, which included a parent book and workbook, as well as weekly telephone consultations with a therapist. In addition to providing specific advice and support, the telephone consultations also served to promote responsibility for changing parents' own and their child's behaviour. The self-directed program was effective in reducing levels of disruptive child behaviour, based on self-report measures and changes were maintained at 4 months follow-up. There were also improvements in mothers' parenting practices at post-intervention and follow-up and there was greater satisfaction and competence in parenting skills and lower levels of dysfunctional parenting practices, compared to a wait-list control. Finally, mothers in the self-directed group also reported lower levels of depression, anxiety and stress following the intervention compared to the control group. This study demonstrated the efficacy of a therapist-assisted self-directed approach, however, it did not provide information about the minimally sufficient level of intervention required for change. It also did not provide information about the importance or otherwise of the telephones consultations with parents.

Markie-Dadds and Sanders (2006b) randomly assigned 63 families to a self-directed BFI or a wait list group. Compared to the wait list group mothers in the self-directed BFI condition reported lower levels of child disruptive behaviour, lower levels of harsh authoritarian discipline and higher levels of satisfaction and parenting efficacy, and these gains were maintained at 6-month follow-up. Similarly, Markie-Dadds and Sanders (2006a) showed a tiered intervention effect in comparing a self-directed intervention to an enhanced version with weekly telephone consultations with a practitioner. At post intervention, children in the enhanced version showed lower levels of problem behaviours compared to the standard program, which in turn showed lower levels of problem behaviour than the wait list group. Similarly, mothers showed higher levels of parenting efficacy, while there were no changes in parental adjustment or relationship conflict. However, the differences between the two intervention groups were not maintained at 6-month follow-up, with the standard group catching up to the enhanced group.

In order to address these limitations, Morawska and Sanders (2006b) compared a self-directed BFI (SD-BFI) for parents of toddlers, to a telephone-assisted self-directed (TASD-BFI) version and a wait-list control. There were significant short- and long-term effects of the self-directed intervention in terms of child behaviour problems and maternal parenting style, confidence and anger. However, while participants in the SD-BFI condition made similar statistical gains to the TASD-BFI condition, the TASD-BFI conditions led to clearly superior outcomes in clinical terms. Participants in the TASD-BFI condition changed more reliably and there was a signific ant shift away from the clinical range for this group. While participants in the SD-BFI also made some gains, these were not as clinically meaningful as those in the TASD-BFI condition. These effects were maintained over a period of six-months. Finally, parents in the TASD-BFI group were more satisfied with the program than those in the SD-BFI condition.

A unique aspect of this study was that using a stringent methodological approach, it demonstrated that self-administered interventions can provide significant benefits in terms of child behaviour and parenting confidence and skills. Furthermore, it was also demonstrated that a tiered effect was evident, where parents who received a small amount of clinical input were able to make more significant, clinically meaningful improvements. It is important to note that the clinician input in this study was relatively minimal. Telephone consultations lasted an average of approximately 10 minutes, and overall on average each participant in the TASD-BFI received just over an hour of clinical input over the course of the program. What makes this hour unique, is that it is designed to enhance parents' self-regulatory skills - that is, enable them to make their own changes and be able to generalise these changes over time and situations. Parents set the agenda for these sessions and they are guided to solve their difficulties or concerns using the resources that have been provided to them, rather than the clinician providing advice or solutions. 
The combined results of these studies provide strong support for the use of telephone assisted self-directed versions of Triple $\mathrm{P}$ as a low cost, clinically effective intervention for children of all ages. The self-directed Triple $\mathrm{P}$ interventions led to results that were not only statistically significant, but also clinically meaningful. These effects were evident particularly for the telephone-assisted versions of the program. The studies provide a strong evidence base for self-directed interventions, which form an effective part of a behavioural family intervention suite that allows tailoring of strength of intervention to individual problems and families. Furthermore, there is clear evidence for the important role of therapist involvement and support.

Sanders, Markie-Dadds, Tully, and Bor (2000) conducted a large scale clinical trial of 305 families with a 3-year-old child comparing two therapist-assisted versions of BFI and a self-directed BFI condition. Families completing any version of the program showed significant improvements on a variety of self-report and observational measures compared to a wait-list control group, however, there was more improvement in the therapist directed versions of the program, compared to the self-directed version. At 1-year follow-up families in the self-directed group continued to show improvements and were more comparable to the other two groups, and these results were maintained at 3-year follow-up (Sanders, Bor, \& Morawska, 2006).

Finally, Sanders, Montgomery et al. (2000) demonstrated that a self-directed minimal intervention, delivered in the format of a television series with accompanying parent tip sheets for each episode, significantly reduced parental perceptions of child behaviour problems and increased selfreported maternal parenting competence, compared to a wait-list control.

There is also evidence that a BFI based on a self-regulatory model, delivered by trained telephone counsellors can have significant effects across a range of measures of family functioning (Morawska \& Sanders, 2006a). The intervention led to reductions in parental reports of child behaviour problems, reductions in dysfunctional parenting for mothers, and increases in parenting efficacy and confidence for both parents. There were also reductions in parental conflict over parenting and maternal stress. These effects were evident not only in statistical terms, but also in clinical terms with a shift in the population norm towards lower levels of risk. Importantly, the effects were also maintained at follow-up, indicating that the intervention has not only immediate effects, but benefits continue over time.

\section{Conclusions and Implications}

The review presented here indicates that there is a paucity of research on methodologically sound, structured self-directed intervention approaches. At the same time, there is a growing need to increase access to efficacious parenting interventions for parents who find it difficult to access traditional services. Triple $\mathrm{P}$ is a behavioural family intervention with significant empirical support, and the studies reviewed here provide considerable evidence for the efficacy of self-directed versions of the program. Furthermore, the studies provide support for the importance of some therapist involvement in promoting clinically meaningful and reliable change in child behaviour and family functioning. It was a clear finding that therapist assistance in completing a self-directed parenting program led to greater positive change for families. While this therapist involvement was clearly important, it was very minimal and was focused on enhancing parents' self-regulatory skills. This emphasis on self-regulation enables parents to make successful, enduring changes for their children and families, and provides them with the structure and skills necessary to effectively problem-solve future difficulties.

There is growing evidence that self-directed behavioural family interventions based on a selfregulatory model provide a low-cost, effective intervention for families in the treatment of a range of behavioural difficulties across childhood. They allow parents who cannot access traditional services to 
access high quality evidence-based interventions. They also have the potential to form a valuable role in a multi-level intervention model, for example, when parents are on waiting lists for services. A therapistassisted intervention socialises parents to the self-regulatory framework and key strategies that may be refined later in individual therapy if necessary, reducing demands on services. This review has provided evidence that therapist involvement is important and has considerable impact on the outcomes of behavioural family interventions across the spectrum of child development. While parents are able to make changes on their own, their ability to implement strategies and maintain these in the longer term is affected by whether or not they are supported in doing so. Parents who receive therapist support make greater changes in their parenting and thus report increased levels of improvement in their child's behaviour. An area for future research is to consider the mechanisms involved in this effect. We posit that the self-regulatory framework utilised by therapists is key to better outcomes for families participating in a self-directed program. In addition, a motivational effect may also play a role in increasing parents' implementation of strategies. Clarification of the mechanisms involved would be important to specify the nature of therapist involvement, the training therapists need to conduct telephone-consultations and thus, the most efficient way of delivering support to families.

\section{References}

Arnold, E. H., \& O'Leary, S. G. (1997). Mother's and fathers' discipline of hard to manage toddlers. Child and Family Behavior Therapy, 19(3), 1-11.

Bauman, K. E., Foshee, V. A., Ennett, S. T., Pemberton, M., Hicks, K. A., King, T. S., et al. (2001). The influence of a family program on adolescent tobacco and alcohol use. American Journal of Public Health, 91, 604-610.

Connell, S., Sanders, M. R., \& Markie-Dadds, C. (1997). Self-directed behavioral family intervention for parents of oppositional children in rural and remote areas. Behavior Modification, 21, 379-408.

Cowan, P. A., Powell, D., \& Cowan, C. P. (1998). Parenting interventions: A family systems perspective. In I.E. Sigel \& K. A. Renninger (Eds.), Handbook of child psychology: Volume 4 - Child psychology in practice (5th ed., pp. 3-172). New York: Wiley.

Cunningham, C. E. (1996). Improving availability, utilization, and cost efficacy of parent training programs for children with disruptive behaviour disorders. In R. D. Peters \& R. J. McMahon (Eds.), Preventing childhood disorders, substance abuse and delinquency (pp. 144-160). Thousand Oaks, California: Sage Publications.

Dadds, M., Sanders, M. R., \& James, J. E. (1983). Enhancing generalisation effects in parent training: The role of planned activities and social support. Behavioral Psychotherapy, 15, 289-313.

Elgar, F. J., \& McGrath, P. J. (2003). Self-administered psychosocial treatments for children and families. Journal of Clinical Psychology, 59, 321-339.

Endo, G. T., Sloane, H. N., Hawkes, T. W., \& Jenson, W. R. (1991). Reducing child whining through self-instructional parent training materials. Child and Family Behavior Therapy, 13(3), 41-58.

Endo, G. T., Sloane, H. N., Hawkes, T. W., McLoughlin, C., \& Jenson, W. R. (1991). Reducing child tantrums through self-instructional parent training materials. School Psychology International, 12, 95-109. 
Flanagan, S., Adams, H. E., \& Forehand, R. (1979). A comparison of four instructional techniques for teaching parents to use time-out. Behavior Therapy, 10, 94-102.

Forehand, R., Griest, D. L., \& Wells, D. C. (1979). Parent behavioral training: An analysis of the relationship amongst multiple outcome measures. Journal of Abnormal Child Psychology, 7, 229242.

Forehand, R., \& Long, N. (1988). Outpatie nt treatment of the acting-out child: Procedures, long-term follow-up data and clinical problems. Advances in Behavior Research and Therapy, 10, 129-177.

Forehand, R., Wells, K. C., \& Griest, D. L. (1980). An examination of the social validity of a parent training program. Behavior Therapy, 11, 488-502.

Gmeinder, K. L., \& Kratochwill, T. R. (1998). Short-term, home-based intervention for child noncompliance using behavioral consultation and a self-help manual. Journal of Educational and Psychological Consultation, 9, 91-117.

Hansen, D. J., Tisdelle, D. A., \& O'Dell, S. L. (1984). Teaching parents time out with media materials: The importance of observation and feedback. Child and Adolescent Psychotherapy, 1, 20-25.

Harachi, T. W., Catalano, R. F., \& Hawkins, J. D. (1997). Effective recruitment for parenting programs within ethnic minorities. Child and Adolescent Social Work Journal, 14(1), 23-39.

Hunsley, J., Aubry, T., \& Lee, C. L. (1997). A profile of Canadian consumers of psychological services. Ottawa: Canadian Psychological Association.

Hunt, S., \& Adams, M. (1989). Bibliotherapy-based dry bed training: A pilot study. Behavioural Psychotherapy, 17, 290-302.

Long, N., Rickert, V. I., \& Ashcraft, E. W. (1993). Bibliotherapy as an adjunct to stimulant medication in the treatment of attention-deficit hyperactivity disorder. Journal of Pediatric Health Care, 7, 8288 .

Markie-Dadds, C., \& Sanders, M. R. (2006a). An evaluation of an enhanced self-directed behavioural family intervention for parents of children with conduct problems in rural and remote areas. In Press: Behavior Change.

Markie-Dadds, C., \& Sanders, M. R. (2006b). Self-directed Triple P (Positive Parenting Program) for mothers with children at-risk of developing conduct problems. In Press: Behavioural and Cognitive Psychotherapy.

McMahon, R. J., \& Forehand, R. L. (1983). Consumer satisfaction in behavioral treatment of children: Types, issues and recommendations. Behavior Therapy, 14, 209-225.

Morawska, A., \& Sanders, M. R. (2006a). Self-administered behavioural family intervention for parents of toddlers: Effectiveness and dissemination. In Press: Behavior Research and Therapy.

Morawska, A., \& Sanders, M. R. (2006b). Self-administered behavioural family intervention for parents of toddlers: Part I - Efficacy. In press: Journal of Consulting and Clinical Psychology. 
Nicholson, J. M., \& Sanders, M. R. (1999). Randomized controlled trial of behavioural family intervention for the treatment of child behaviour problems in step-families. Journal of Divorce and Remarriage, 30(3/4), 1-23.

Pavuluri, M. N., Luk, S. L., \& McGee, R. (1996). Help-seeking for behavior problems by parents of preschool children: A community study. Journal of the American Academy of Child and Adolescent Psychiatry, 35(2), 215-222.

Sanders, M. R. (1992). Enhancing the impact of behavioural family intervention with children: Emerging perspectives. Behaviour Change, 9, 115-119.

Sanders, M. R. (1999). Triple P-Positive Parenting Program: Towards an empirically validated multilevel parenting and family support strategy for the prevention of behavior and emotional problems in children. Clinical Child and Family Psychology Review, 2, 71-90.

Sanders, M. R. (2000). Community-based parenting and family support interventions and the prevention of drug abuse. Addictive Behaviors, 25, 929-942.

Sanders, M. R., Bor, W., \& Morawska, A. (2006). Long term maintenance effects of three variants of the Triple P-Positive Parenting Program for early onset conduct problems. Submitted for publication.

Sanders, M. R., \& Glynn, T. (1981). Training parents in behavioural self-management: An analysis of generalisation and maintenance. Journal of Applied Behaviour Analysis, 14, 223-237.

Sanders, M. R., Markie-Dadds, C., Tully, L. A., \& Bor, W. (2000). The Triple P - Positive Parenting Program: A comparison of enhanced, standard and self-directed behavioural family intervention for parents of children with early onset conduct problems. Journal of Consulting and Clinical Psychology, 68, 624-640.

Sanders, M. R., Montgomery, D. T., \& Brechman-Touissant, M. L. (2000). The mass media and the prevention of child behaviour problems: The evaluation of a television series to promote positive outcomes for parents and their children. Journal of Child Psychology and Psychiatry, 41, 939948.

Sanders, M. R., Tully, L. A., Baade, P. D., Lynch, M. E., Heywood, A. H., Pollard, G. E., et al. (1999). A survey of parenting practices in Queensland: Implications for mental health promotion. Health Promotion Journal of Australia, 9, 112-121.

Serkettich, W. J., \& Dumas, J. E. (1996). The effectiveness of behavioral parent training to modify antisocial behavior in children: A meta-analysis. Behavior Therapy, 27, 171-186.

Seymour, F. W., Brock, P., During, M., \& Poole, G. (1989). Reducing sleep disruptions in young children: Evaluation of therapist-guided and written information approaches: A brief report. Journal of Child Psychology and Psychiatry, 30, 913-918.

Sloane, H. N., Endo, G. T., Hawkes, T. W., \& Jenson, W. R. (1990). Improving child compliance through self-instructional parent training materials. Child and Family Behavior Therapy, 12(4), 39-64. 
Spoth, R., Redmond, C., Hockaday, C., \& Shin, C. Y. (1996). Barriers to participation in family skills preventive interventions and their evaluations: A replication and extension. Family Relations, 45, 247-254.

van Londen, A., van Londden-Barensten, M. W., van Son, M. J., \& Mulder, G. A. (1993). Arousal training for children suffering from nocturnal enuresis. Behavior Research and Therapy, 31, 613615.

Webster-Stratton, C. (1989). Systematic comparison of consumer satisfaction of three cost-effective parent training programs for conduct problem children. Behavior Therapy, 20, 103-115.

Webster-Stratton, C. (1990). Enhancing the effectiveness of self-administered videotape parent training for families with conduct-problem children. Journal of Abnormal Child Psychology, 18, 479-492.

Webster-Stratton, C. (1992). Individually administered videotape parent training: A comparison study. Journal of Consulting and Clinical Psychology, 62, 583-593.

Webster-Stratton, C., Kolpacoff, M., \& Hollinsworth, T. (1988). Self-administered videotape therapy for families with conduct problem children: Comparison with two cost-effective treatments and a control group. Journal of Consulting and Clinical Psychology, 56, 558-566.

Zubrick, S. R., \& Silburn, S. (1994). Western Australian Child Health Survey. Perth: Australian Bureau of Statistics and Institute for Child Health Research.

Zubrick, S. R., Silburn, S. R., Garton, A., Burton, P., Dalby, R., Carlton, J., et al. (1995). Western Australia Child Health Survey: Developing health and well-being in the nineties. Perth, Western Australia: Australian Bureau of Statistics and the Institute for Child Health Research.

\title{
Author Contact Information:
}

\author{
Alina Morawska, PhD \\ Parenting and Family Support Centre \\ School of Psychology \\ University of Queensland \\ St Lucia 4072 \\ Australia \\ Ph: +61 733657304 \\ Fax: +61 733656724
}

Email: alina@psy.uq.edu.au 


\section{Advertisement}

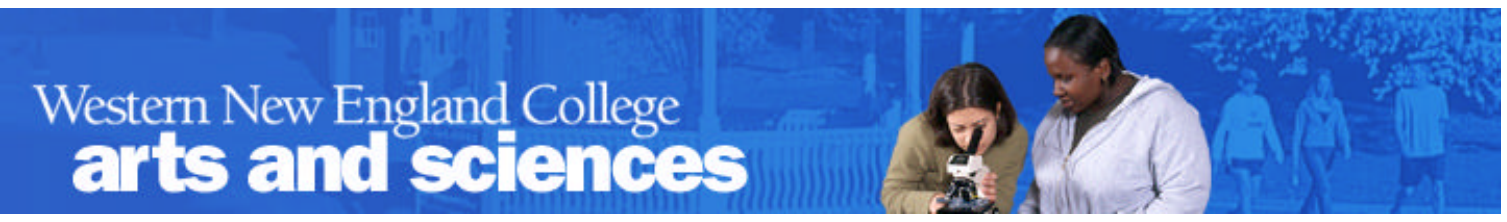

Director/Professor, Ph.D. program in Psychology: The Department of Psychology at Western New England College and the New England Center for Children (NECC) invite applicants for an anticipated Ph.D. Program Director/tenure-track or tenured faculty position at the associate professor or professor level, beginning in August, 2007. Candidates are expected to have earned a Ph.D. prior to appointment and should also have BCBA certification. Terms and conditions of appointment depend on the candidate's qualifications and experience. The ideal candidate will also have both academic and clinical experience with PDD populations and a record of excellence in teaching. The Program Director will coordinate Program Committees (Recruitment and Marketing, Admissions, Student Evaluation, Program Evaluation, and individual Dissertation Committees) for an Applied Behavior Analysis Ph.D. program.

Job responsibilities will also include teaching 2 courses per semester. We are particularly interested in candidates who can teach advanced courses in Experimental or Applied Behavior Analysis. In addition, the ideal candidate would have an active research profile and display a strong commitment to involving students in their research.

The deadline for applicants is December $1^{\text {st }}, 2006$.

Candidates should send a letter of interest, curriculum vitae, a statement on teaching philosophy and research interests, student evaluations, official or unofficial copies of transcripts, and three letters of recommendation to:

Jessica Carlson, Ph.D., Search Committee Chair

C/O Dr. Saeed Ghahramani, Dean

School of Arts and Sciences

Western New England College

1215 Wilbraham Road

Springfield, MA 01119

Visit our website at: $\underline{\text { www.wnec.edu }}$

Western New England College is an Equal Opportunity Employer. 


\title{
Diagnosing Child Sex Abuse: A research challenge
}

\author{
Catrina Duffy, Mickey Keenan \& Karola Dillenburger
}

\begin{abstract}
Child sex abuse increasingly is recognised as a societal problem that can no longer be ignored. In this paper definitions, prevalence, trends, assessment, and available diagnostic procedures are described and critically evaluated. It is argued that the lack of reliable diagnostic procedures remains one of the main difficulties in dealing effectively with the detrimental effects of CSA on the child or adult. The research challenge to find effective alternative procedures is outlined. Key words: child sex abuse (CSA), diagnosis, disclosure, assessment.
\end{abstract}

\section{Introduction}

Child Sex Abuse (CSA) is a social problem that demands vigorous scrutiny and formal investigation. Although some form of incest taboo has existed across most cultures, the sexual abuse of children has been denied, condoned, and sanctioned throughout history. Over the last decade research in the area of CSA has increased exponentially and has attracted increasing attention not only from health professionals (Miller \& Veltkamp, 1995) but also from public, legal, and media interest. Issues surrounding CSA include the veracity of the reports, the extent of the short-term and long-term negative effects on the child, and the controversy over therapeutic interventions to help overcome the long-term negative effects of CSA.

Sexual abuse of children includes many types of sexual trauma, from single attacks by strangers to long-term incestuous relationships with a parent or close relative. In this paper, the term sexual abuse will be used to denote all types of sexual victimization, whereas incest will be used only with respect to sexual experiences between individuals related by blood or by marriage, with whom such activity is prohibited by virtue of societal taboos.

\section{Problems with definitions}

Despite efforts to promote a uniform criterion for defining CSA, there are still variations in the definitions adopted by professionals and researchers working in the field. The definition of CSA varies on several dimensions, for example, the level of physical contact, the age of the victim, the age of the perpetrator, the age difference between the victim and the perpetrator, and issues to do with consent. Legally CSA may be defined as "... any activity, before the age of legal consent, for sexual gratification of an adult or significantly older child" (Rappley \& Woolford, 1998, p. 49), while most commonly CSA is defined as:

... the involvement of dependent and immature children or adolescents in sexual activities they do not fully understand and to which they are unable to give informed consent, and which violate social taboos of family roles. (Helfer \& Kempe, 1976, p.60).

By-and-large researchers agree that the definition of CSA should not be confined to actual physical violation of a child by rape, as this will adversely affect reported cases. Importantly definitional differences can markedly affect prevalence rates (Haugaard \& Emery, 1989; Russell, 1984; Wyatt, 1985; Wyatt \& Peters 1986). In the Irish context, Ward (1997) extended the definition of sexual abuse to include exposure to pornography, sexual exhibitionism, 
perverse activities, and viewing of sexual acts. Also included is a range of sexual contact between adults and children from fondling, oralgenital contact, digital penetration, (all of which do not leave any physically detectable traces), to intercourse.

Furthermore, it is widely agreed that any definition of CSA should include the use of power over the child, for example, threats and/or exploitation of relationships that include an authority differential or some kind of dependence, no matter what the age of the abuser or abused. Once all these factors are included in the definition a different picture of prevalence rates emerges.

\section{Prevalence}

Over the last two decades the United Kingdom and Ireland, like most other countries worldwide, have witnessed a substantial increase in the number of reported incidents of CSA (Benedeck \& Schetky, 1987; Dammeyer, 1998; Haugaard \& Emery, 1989; Lamb, 1994; Wood, Orsak, Murphy, Cross, 1996). It is unclear whether this increase in the number of reported cases reflect a real increase in the incidence of CSA, increasing awareness of the problem, increased willingness to report CSA to authorities, or a combination of these factors. Whatever the reason, the number of reported cases is quite startling.

In the United Kingdom recent statistics show increases from 3,700 new substantiated cases $(.034 \%)$ in 1991 to 4,200 new substantiated cases (.037\%) in 1992 (Lamb 1994). In the last two decades an enormous increase in the awareness and reporting of CSA took place in Ireland, specifically in 1982, when the Department of Health compiled national statistical frequencies on child abuse referrals (Department of Health, 1995). For example, the number of notifications for alleged sexual abuse in Ireland rose from 88 in 1984 to 1,242 in 1989 (Department of Health, 1996a). The earliest epidemiological investigation of CSA in Ireland conducted in 1987 by the Market Research Bureau of Ireland (MRBI) reported that in a sample of five hundred adults in the Dublin area, $5 \%$ of males and $7 \%$ of females reported that they had been sexually abused as a child (MRBI, 1987). This was followed by a succession of high profile CSA cases, which became public throughout the mid-1990s; for example, the X case (Holden, 1994), the Kilkenny Incest Case (Lalor, 2001), the Brendan Smyth Affair (Moore, 1995), the Madonna House Affair (Department of Health, 1996b), and the Sophia McCologan case (McKay, 1998). Following this succession of high profile cases, 970 cases of CSA were reported in 1996 in the Eastern Health Board region of Ireland alone (Eastern Health Board, 1996).

In 1993 the Irish Society for the Prevention of Cruelty to Children (ISPCC) conducted a survey of 1,001 members of the general population. The results obtained from this study elaborate on the picture of CSA that was described in the earlier MRBI (1987) survey. A total of 160 (16\% per cent) respondents reported having experienced CSA. In a survey of 247 students of the Dublin Institute of Technology, Lalor (1999) reported the highest rate of CSA recorded so far; $31.8 \%$ of females in the sample reporting an unwanted sexual experience before the age of sixteen. In Northern Ireland, MacKenzie, Blaney, Chivers and Vincent (1993) examined reported cases of CSA in the year 1987 and estimated that the epidemiology lay between 0.9 and 1.87 cases per 1,000 children. Jenny (1997) thought that the prevalence of incest might even be as high as one in eight children.

There is overwhelming evidence that more girls suffer CSA than boys. For example, Finkelhor and Berliner (1995) examined research from 19 different countries and concluded that girls were abused 1.5 - 3 times more often than were boys in the general population. Similarly, 
Dobash, Carnie, and Waterhouse (1993) reported that girls made up 74\% of the CSA population in the UK.

However, it is becoming more and more evident that the sexual abuse of boys is vastly under-reported (Briggs \& Hawkins, 1995; Cermak \& Molidor, 1996; Violato \& Genuis, 1993; Watkins \& Bentovim, 1992). Lamb and Edgar-Smith (1994), DeVoe and Faller (1999), and Gries, Goh, and Cavanaugh (1996) reported that proportionately more girls disclosed their abuse to an interviewer than did boys. The statistics outlined above are based upon official reports to child protective services and are undoubtedly a substantial underestimation of the true incidence and prevalence of CSA both in Ireland and Britain and, in fact, probably represent only the tip of the iceberg (Mordock, 2001).

There are several reasons for the underestimation in prevalence rates including the variation in the definition of CSA employed (Glaser \& Frosh, 1993; Haugaard \& Emery, 1989; Kelly, Regan, \& Burton, 1995; Kempe \& Kempe, 1984), the sample not being representative of the general public (The Research Team, 1990), methodological differences in data collection (interviews versus questionnaires), survey response rates (Haugaard \& Emery, 1989), or the fact that sexual abuse is a social taboo and as such is underreported (MacFarlane, Waterman, Conerly, Damon, Durfee, \& Long, 1988).

Disclosure

It is generally accepted that the crime constituting CSA is intertwined with the issue of "victim by secrecy" (Finkelor, 1986; Glaser \& Frosh, 1993; The Research Team, 1990), with only the victim and the perpetrator witnessing the crime, thus making it more difficult for the child to "disclose" the actual events. Fears of retribution and abandonment from the family, feelings of complicity, embarrassment, guilt, and shame all conspire to silence children and inhibit their voluntary disclosure of CSA. The fear of negative consequences of disclosure usually is particular salient in cases of incest, because children fear the abusing parent, relative, or sibling will be punished. Children also may fear that, by disclosing the abuse, they will create a disruption in the family (Lawson \& Chaffin, 1992).

An additional factor is that it is difficult for the child to understand that the abuse is wrong when the perpetrator is a trusted member of the family. Consequently, children who are abused by a family member are more ambivalence about disclosing the abuse oftentimes because they have mixed feelings toward the perpetrator, including feelings of loyalty, injustice, guilt, trust, dependence, mixed up with the love and incomprehension. Empirical research suggests that $53 \%$ of children who are victims of interfamilial CSA never disclose the abuse (Arata, 1998; DiPietro, Runyan \& Fredrickson 1997; Mian, Wehrspann, Klajner-Diamond, LeBaron, \& Winder, 1986; Sas, 1993; Saunzier, 1989; Smith, Letourneau, Saunders, Kilpatrick, Resnick \& Best 2000; Wyatt \& Newcomb, 1990).

Because there is often little if any physical evidence of sexual abuse, intervention depends heavily on children's voluntary disclosure (Saunzier, 1989). By not disclosing, children may be subjected to longer or repeated abuse and may not receive treatment for psychologically damaging sequel. Non-disclosure also precludes protection from further abuse, prevents the child from obtaining therapy, and may even put other children in danger of being sexually abused. Thus, sexually abused children face a serious dilemma in deciding whether or not to disclose. In the remainer of this paper we outline why much more research is needed on ways to help victims 
of CSA to disclose and on identifying factors that may alleviate the tremendous pressures placed on children to maintain the silence so often associated with CSA.

Reasons for non-disclosure

There are various reasons children do not disclose abuse immediately, but one of the main reasons is that the abuse usually occurs at an early age and many victims of sexual abuse are too young to verbalise such information. Developmental factors, particularly cognitive limitations, may inhibit disclosure in young children (DeYoung, 1987; DiPietro, Runyan, \& Fredrickson, 1997; Gries, Goh, \& Cavanaugh, 1996; Keary \& Fitzpatrick, 1994). For example, as concluded by Goodman-Brown, Edelsrein, Goodman, Jones, and Gordon (2003), young children's lack of sexual knowledge may hinder their voluntary disclosure of sexual abuse. Similarly, very young children and children with developmental delays have limited knowledge about societal sexual taboos, which may in turn inhibit their verbal reports.

Research suggests that interfamilial abuse is associated with increased perceptions by the child of at least partial responsibility for the abuse (Kendall-Tackett, Williams, \& Finkelhor, 1993; Quas, Goodman, \& Jones, 2003). Consistent with the notion of perceived responsibility, Hazzard, Celano, Gould, Lawry, and Webb (1995) reported that among female CSA victims, younger children were more likely to blame themselves for the occurrence of CSA.

Reasons why male victims of CSA are more reluctant to disclose abuse may include the stigma attached to being sexually abused by another male, for example, being labeled as "queer" or "homosexual" (Goldman, 2000), being stigmatised as a victim (Mordock, 2001), or in the case of a female abuser, that the unwanted sexual experience with an older female is something to be proud of. Additionally, medical findings are very often not as apparent in boys as in girls. If tears to the anal tissue do occur, they heal so rapidly (10-14 days) that there may be no trace of CSA when the abuse is finally disclosed (McCann, Voris, \& Simon, 1992). Finally, the low incidence figures for male victims of CSA reported in the research literature and by legal and social organisations may also be attributed to the problem of definition highlighted above.

\section{Recovered versus False Memories}

The past decade has seen a proliferation of reports of childhood sexual abuse based on memories that emerge in adulthood (Melchert \& Parker, 1997). However, there has been considerable controversy regarding the emergence of recovered versus false memories, and in particular the use of hypnosis to access and process such memories. Some argue that the prevalence of early CSA may be underreported because retrospective memories of early abuse can be dissociated or repressed from memory (Briere \& Conte, 1993; Davies \& Frawley 1994). Others believe that some childhood sexual trauma can be forgotten and emerge later in adulthood (Chaffin, Lawson, Selby, \& Wherry, 1997; Herman \& Schatzow, 1987; Williams, 1995).

For example, Feldman-Summers and Pope (1994) asked a national sample of psychologists whether they had been sexually abused as children and, if so, whether they had ever forgotten some or all of the abuse. Both sexually abused and non- abused subjects reported to have experienced a period of forgetting the events in their childhood. The most frequently reported factor correlating with recall of CSA was being in therapy. Approximately $50 \%$ of participants who reported forgetting also reported corroboration of the abuse, and reported forgetting was related to severity of the abuse. 
There are those who contend that instances of delayed recall of traumatic memories are predominantly falsely remembered events (Wakefield \& Underwager, 1992) which may be falsely created in response to various sources of suggestion, including books, the media, and some therapists who use highly suggestive memory recovery techniques such as hypnotic age regression and guided imagery (Bottoms \& Davis, 1997; Lindsay \& Read, 1995). For example, in surveys of certified therapists in the United States and Great Britain, 14.7\% used techniques such as hypnosis and dream interpretation to help patients recall CSA. Harold (1996) states that it is important to recall memories of CSA for effective treatment. The assumption relating to patients who deny a history of abuse is that these patients have hidden memories of CSA.

Epstein and Bottoms (1998) reported that, prior to entering therapy, 31\% of partic ipants had only partial memories of abuse that existed before participating in any therapy. Three percent of participants had no memory of sexual abuse before entering therapy and subsequently recalled such memories during therapy.

Critics of repressed or recovered memory do not deny the possibility that actual abuse could be forgotten and then later recalled in adulthood. Instead, they argue that there is little scientific evidence supporting the classic psychoanalytic concept of repression (Lindsay \& Read, 1994) and that common cognitive processes may account for forgetting and subsequent recall of childhood sexual abuse (Epstein \& Bottoms, 1998). In fact, the validity of repressed memory theory has been questioned and the outpouring of memories has been considered as "false memory syndrome" (Yamini, 1996). For example, Ney (1995) argues that clients can be convinced that they have a memory of a traumatic event that never actually happened to them.

Both sides in this debate suggest that repressed or recovered memory is a wide spread phenomenon, with one side of the debate asserting that the recovered memories are genuine, and the other side maintaining that they are false. Neither of these two arguments is supported by scientific evidence. Research into recovered or repressed memory is still in its infancy, and therefore prevalence rates are unknown.

The clinical and legal implications of embracing false memories of CSA are serious. Individuals have come to believe that they have suffered terrible CSA that never actually occurred. Innocent individuals have been falsely accused of having perpetrated CSA and convicted of crimes they never committed. On the other hand, maligning the credibility of victims who actually experienced abuse and thereby contraindicating their clinical recovery and legal retribution is an equally troubling prospect. Professionals in the field of CSA must develop diagnostic procedures to minimize the likelihood of creating a false memory in CSA victims.

One of the most difficult problems for investigators of CSA is deciding whether or not a child's accusations are truthful. There are indications that false accusations of incest and other forms of sexual abuse by children are relatively rare, usually ranging between $2 \%$ and $8 \%$ (Corwin, Berliner, Goodman, Goodwin, \& White, 1987; Everson \& Boat, 1989; Goodwin, Sahd, \& Rada, 1982; Jones \& McCraw, 1987). However, others advocate that false allegations are relatively frequent (Benedeck \& Schetky, 1987) leading most professionals in the field of CSA to treat accusations with suspicion.

The perception that memories of CSA are frequently fabricated is rooted principally in early Freudian theories. Initially, Freud thought that the origin of a variety of neurotic symptoms including hysterical neuroses could be traced to early sexual traumas experienced by young girls perpetrated by their fathers. By 1897, however, Freud renounced this "seduction theory" in favor 
of "drive theory" and "Oedipal complex". Many current psychoanaly tic writers believe that Freud's shift in focus from seduction theory to Oedipal theory served to minimise the role of actual CSA in the etiology of neurosis and psychopathology (Krull 1986; Lerman, 1988; Masson, 1984; Miller, 1984) and, in the early 1980s, a child-centered philosophy of "believe the child" or "children never lie" emerged (Faller, 1984; McCarty, 1981).

Today it is known that false allegations occur most often in the context of custodial or visitation-access disputes (Furniss, 1991; Ney, 1995). Everson and Boat (1989) assert that about one third of all reported allegations in a custody dispute context might be false. In cases where allegations are deemed false, they are more likely to emanate from adults or involve misinterpretations of the child, rather than deliberate fabrications (Berliner \& Conte, 1993). It has been suggested that the rates of false allegations of CSA in custodial disputes have risen (Everson \& Boat, 1989; Green, 1992; Jones \& McGraw, 1987; Theonnes \& Tjaden, 1990; Wood, Orsak, Murphy, Cross, 1996), however actual prevalence rates are unknown. These issues are accentuated if the child is question has special needs.

\section{Special Needs}

There is ample evidence that the prevalence of CSA is high for children with developmental disabilities and that these children constitute a particularly vulnerable group of people with regard to CSA (Dunne \& Power, 1990; Brown, Stein, \& Turk, 1995). It is difficult to know how prevalent abuse is among people with developmental disabilities because of the limited number of studies and the underreporting of abuse to proper authorities. However, in the last twenty years estimates have been substantiated that children with developmental disabilities are sexually abused at a rate 4 to 10 times higher than that of children in the general population, and prevalence rates vary from $3 \%$ to $70 \%$ (Baladerian, 1990). The difficulties in ensuring accurate disclosure and preventing false memories are heightened in special needs children and the percentage of false allegation rates made by people with developmental disabilities remains unknown (Ahlgrim-Delzell \& Dudley, 2001).

As is true with the majority of CSA victims, the perpetrators of children with developmental disabilities are most likely to be family members or people known to and trusted by the victim, such as teachers, residential care providers, and aides (Baladerian, 1990). In fact, it has been reported that as many as $99 \%$ of perpetrators were well known to and trusted by their victims with developmental disabilities (Baladerian, 1990).

Children with developmental disabilities commonly have communication difficulties, leading to an increased vulnerability, and may be less able to defend themselves, have less knowledge about their own bodies and what may be considered as normal sexuality, and finally but most importantly, they may be dependent upon the abuser. These are circumstances that an adult may misuse, and thus severely developmentally disabled children constitute the real risk group (Hoggs, Campell, Cullen, \& Hudson, 2001). Males with developmental disabilities appear to be more susceptible to abuse in general (Zirpoli, Snell, \& Lloyd, 1987), whereas females with developmental disabilities appear to be more susceptible to CSA (Ahlgrim-Delzell, \& Dudley, 2001).

Difficulties in disclosure may be attributed to several factors. First, the child may not be able to verbally communicate. Like all victims of CSA, children with developmental disabilities will give non-verbal signals when they have been a victim of CSA, such as loss of appetite, sleeping problems, crying, nightmares, rage or introverted behaviour. When such behaviour 
occurs, caretakers of children with developmental delays generally link these to bullying, wrong medication, fear of future hospitalization, or even view the behaviour problems as 'symptoms' of the disability (Kvam, 2000). Consequently, sexual assault is not disclosed until it is much more obviously evident.

In $43 \%$ of cases involving disabled children, compared to $11 \%$ of cases involving nondisabled children close family and/or guardians knew about the abuse but did not acknowledge the sexual abuse because the child had a disability (Kvam, 2000). One reason for this may be that CSA may be regarded as less severe for a child with developmental delays and therefore is ignored for longer. However, there is ample evidence that psychological reactions of people with developmental disabilities are similar if not more pronounced than in typically developing children (Cruz, Price-Williams, \& Andron, 1988; Tharinger, Horton, \& Millea, 1990).

In CSA cases of children with disabilities who are in institutional care and who are abused by a care worker, institutions have at times tried to handle the situation "in house" (Kvam, 2000), for example, through job termination of the alleged abuser. Oftentimes no formal legal action is taken, the offender will leave the institution, and if no background checks are conducted, he/she can seek new employment in other institutions where they might perpetrate further abuse (Sobsey \& Doe, 1991). As a result, rather than protecting children from CSA, some institutions are inadvertently perpetuating the problem of CSA.

Other reasons why CSA is not always reported may be lack of faith in the existing judicial system, the parents' or caretaker's belief that a trial would probably not lead to conviction, and therefore their decision not to further violate the child with a medical examination that may be necessary for criminal conviction. Kvam (2000) stated that :

...convictions of offenders were rare in spite of the chronic and severe nature of abuse... Ironically, many who fail to report abuse indicated that they lacked the faith in the justice system to secure convictions. This appeared to become a self-fulfilling prophecy, as crimes that go unreported cannot be punished. (p. 79).

\section{Assessment Tools}

Documenting that CSA has taken place can be extremely challenging, particularly when the current literature indicates that no specific syndrome exists among CSA victims (Berliner, 1991; Berliner \& Conte, 1993; Lamb, 1994; Mannarino, Cohen, \& Gregor, 1989). Not all sexually abused children show identifiable syndromes in reaction to their sexual victimisation (Finkelhor \& Berliner, 1995) and many non-abused children show behaviours that are thought to be indicative of CSA (Kendall-Tackett, Williams, \& Finkelhor, 1993). For example, Cohen and Mannarino (1988) and Mannarino, Cohen, and Gregor (1989) suggest that sexually abused children and children with psychiatric diagnoses but with no history of CSA show no significant differences in sexual behaviour (Cohen \& Mannarino, 1988).

As reports of CSA have risen dramatically in the last two decades, tremendous attention has been focused on how professionals in the field of CSA evaluate allegations of abuse (Conte, 1992; Corwin \& Olafson, 1993), which has subsequently lead to the development of a wide array of assessment tools. The most commonly used assessment methods include interviews (Berliner \& Conte, 1993), medical examinations (Cantwell, 1983; 1987; Muram, 1989), human figure and family drawings (Hibbard \& Hartman, 1990), the use of fables (Miller \& Veltkamp, 1989a;b), the use of anatomically detailed dolls (Boat \& Everson, 1988; Britton \& O'Keefe, 1991; Jampole \& 
Weber, 1987; Kendall-Tackett \& Watson, 1992; Lie \& Inman, 1991; Sivan, Schor, Koeppl, \& Noble, 1988; Sirnkins \& Reiner, 1996; White, Strom, Santilli \& Halpin, 1986), direct

observations of behaviour or behaviour check lists (The Research Team, 1990), and behaviour analytic procedures (McGlinchey, Keenan, \& Dillenburger, 2000).

\section{Interviews}

The validity of information obtained in CSA interviews is currently an area of highly visible public, professional, and legal concern. It is generally accepted that a child's interview is a critical source of information (Lamb, 1994). In fact, many professionals believe the child's report is among one of best indicators in deciding whether or not abuse took place (Berliner \& Conte, 1993; Conte, 1992; Lamb, 1994).

Assumptions that interview statements are always valid indicators of a history of CSA have been challenged (Rawls, 1994) and there are indications that a child's reports may be "suggestively induced" (Ceci \& Bruck, 1993). A semi-structured interview approach is often the preferred method for assessment of children as they are quite flexible. Highly structured formats are inflexible and may not allow for the interviewer to accommodate developmental factors such as attention span and motivation (Wood, Orsak, Murphy, \& Cross 1996).

Despite concerted efforts to avoid repeated interviewing in suspected cases of CSA (National Criminal Justice Reference Service, 2004), all too often children still are exposed to repeated questioning to elicit more detailed information. Repetitive questioning by law enforcement and social care professionals and concerned parents may significantly alter or distort a child's original story. Young children may come to believe that because they are asked the same questions repeatedly, their original answers were not correct and they should provide a different response. If so, changes in children's answers, resulting from the social demands of the interview situation, may negatively affect the consistency and accuracy of their reports (Mordock, 2001).

Perhaps the most serious challenge to the accuracy of children's reports of CSA involves the issue of suggestibility. While most experts agree that even young children can provide accurate experimental accounts (Berliner \& Conte, 1993; Lamb, 1994, Keenan, McGlinchey, Fairhurst, \& Dillenburger 2000), there is considerable evidence to suggest that children are highly susceptible. It is well documented that during certain interview conditions adults, especially those in authority can lead children to report highly persuasive accounts of fictitious events (Ceci $\&$ Bruck, 1993) especially between the ages of $4-9$ years of age (Cole \& Loftus, 1987). Young children when interviewed can be susceptible to social pressure to say what they think those in authority want to hear (Ceci, Ross, \& Toglia, 1989; Myers, 1996).

Lepore and Sesco (1994) demonstrated how personal biases impacts on the assessment process. They reported that intervie wers who were purposely misled about children's experiences prior to an interview elicited more inaccurate information from the children than those who did not receive inaccurate information. Based on the conclusions above, it is evident that interviews alone cannot be relied on as sole indicators of CSA.

Medical Examination

Considerable progress has been made in the last decade in the evaluation of the medical examination of children in suspected cases of CSA (Paradise, 1989). Regardless of this progress, 
medical evidence exists in only a fraction of cases (Finkel \& De Jong, 1994) providing conclusive evidence in less than 30\% of cases (Adams, 1992). This makes CSA one of the most difficult crimes to detect and legally prosecute. Three studies of sexually abused children showed that $77 \%$ of CSA victims had normal or nonspecific medical findings. Even where there was strong evidence of vaginal penetration and in cases where the perpetrator had admitted to CSA medical evidence remained inconclusive (Muram, 1989; DeJong \& Rose, 1991).

The Committee on Child Abuse and Neglect of the American Academy of Pediatrics (American Academy of Pediatrics, 1991) concluded, "The diagnosis of CSA is made on the basis of a child's history. Physical examination alone is infrequently diagnostic in the absence of a history and/or specific laboratory findings" (p. 256). Strong medical indicators of CSA include urinary tract infections, perineal bruises and tears, pharyngeal infections, venereal disease, and pregnancy in young adolescents. Physicians have recently expressed concern about the overemphasis on, and limitations of, the physical examinations in the detection of CSA (Sinal, Lawless, Rainey, Everett, Runyan, Frothingham, \& Herman-Giddens, 1997). One major proble m when using medical evidence as an indicator of abuse is that in most cases there are no physical signs, e.g., when the abuse involved touching, fondling, oratgenital contact, or rubbing of the hand or penis against the genital area.

Human figure and family drawings

Drawings have been used as assessment tools, interviewing aids or props, and communication tool in a range of clinical areas (Cohen-Liebman, 1995). Thomas and Silk (1990) found that a child's innermost feelings can be portrayed in drawings and that therefore drawings may be employed as an effective medium of communication. This can be especially true for children whose language is developmentally delayed (Veltman \& Brown, 2001) and who therefore may not be able to describe in detail what has happened to them.

While several studies indicate a significant difference between sexually abused and nonabused children regarding the drawing of genitalia, very few sexually abused children draw genitalia. Waterman and Lusk (1993) found that only $7 \%$ of a sample of ritualistically abused children drew genitalia, although none of the non-abused children did so. Hibbard and Hartman (1990) reported no significant difference in the drawings of a sample of abused children compared to non-abused children and concluded that the drawing of genitalia is not conclusive for diagnosis CSA.

More recently, Butler, Gross, and Hayne (1995) reported that the opportunity to draw during an interview facilitated 3- to 6-year-old children's verbal reports of a past event up to one month later, especially in response to direct questioning. The effect of drawings on children's recall is not restricted to experimentally contrived events but has been shown to generalise to actual clinical contexts. Gross and Hayne $(1998 ; 1999)$ found that 3- to 9-year-old children who were given the opportunity to draw and verbally report their emotional experiences reported more than twice as much information as children asked merely to verbally report their experience.

Hibbard, Roghman, and Hoekelman (1987) caution that drawings alone should not be over-interpreted and sexual abuse should not be inferred exclusively from drawings alone, specifically because conclusions derived from a child's drawings are based on the subjective interpretation of the individual assessor (Thomas \& Silk, 1990). At best drawings should be used as a demonstration aid to facilitate verbal disclosure. 


\section{Fables}

An alternative methodology that has yielded considerable clinical information has been the use of fables as a means of allowing the child to identify with a particular situation and to generate, through metaphor, their comprehension of the issues involved in stressful life events, such as CSA. As early as 1943, Despert first proposed the use of fables and incomplete stories to evoke children to disclose and talk about various affective themes (Miller, \& Veltkamp, 1989a). Today, story-telling techniques are used as projective technique designed for psychiatric assessment of children and adolescents to determine areas of emotional conflict, including physical trauma and CSA (Miller, \& Veltkamp, 1995). However, imaginative stories are open to misinterpretation and therefore cannot be used as a sole conclusive indicator in the diagnosis of CSA.

\section{Family Dolls and Anatomically Detailed Dolls ( $A D$ dolls)}

The use of family dolls and the introduction of role-play can enable the evaluator to assess the level and nature of interactions between the child and their parents or siblings (Miller \& Velkamp, 1989a; 1989b). Doll houses and family dolls are commonly employed in therapeutic interventions with CSA victims (O' Connor \& Braverman, 1997). However, similar to the use of drawings and fables, interpretation remains problematic and renders assessment through family dolls insufficient for a diagnosis of CSA (Faller, 1984).

Anatomically detailed dolls are used extensively as assessment tools in CSA investigations. Recent work by Everson and Boat (1990) indicates that, in a sample of 223 children aged 2 - 5 years of age who were screened for the presence or absence of CSA, physical touching and exploration of AD dolls genitalia were common behaviours, occurring in over 50\% of the sample. Six per cent of the sample demonstrated explicit sexual play in the form of apparent demonstrations of vaginal, oral, or anal intercourse, for example, penile insertion, sexual placement with what is described as "humping" motions, or "mouthing" a dolls genitals.

There are no clear evidence-based guidelines and no consensus among professionals regarding what constitutes normal, questionable, and abnormal doll play (Ney, 1995). While some view anatomically detailed dolls as a symbolic medium through which children can more easily communicate and re-enact events (Everson \& Boat, 1994), others fear that exposure to anatomically detailed dolls will promote sexual fantasy and suggestibility (Ceci \& Bruck, 1993; Mordock, 2001). Presently, the most reliable use of AD dolls is for demonstration of the child's knowledge of various body parts and to aid verbal disclosure more clearly. In short, there is no scientific evidence that suggests $\mathrm{AD}$ doll play provides reliable validity for detection of CSA.

\section{Direct Observations and Behavioural Checklists}

In response to the need to identify children who have been sexually abused, many professionals have employed the use of traditional assessment methods, which use behavioural signs that are apparently indicative of sexually abused children. A broad range of behavioral symptoms that have been identified as indictors of sexual abuse in children, include sleep disturbances, nightmares, enuresis, depression, frequent bathing, crying with no provocation, staying indoors, anxiety, and regressive behaviours such as, finger sucking or clinging (Ney, 1995). While these behaviours may well be associated with children who have being sexually victimised, they are common behaviours in children who have experienced general stress or trauma rather than specifically CSA. 
The one behavioural sign that may be of some discriminative value in CSA investigations is inappropriate sexualised behaviour. Empirical research suggests that children who have been sexually abused often show an increase in their sexual behaviours (Deblinger, McLeer, Atkins, Ralphe, \& Foe, 1989; Friedrich, 1993; Friedrich, Beilke, \& Urquiza, 1988; Friedrich, Grambsch, Broughton, Kuiper, \& Beilke, 1991; Gale, Thompson, Moran, \& Sack, 1988; Kolko, Moser, \& Weldy, 1988; White, Halpin, Strom, \& Santilli, 1988). Poole and Lindsay (1998) concluded the following:

While the sexually abused children studied exhibited significantly more indicators of emotional and behavioral disturbance that did comparison groups of 'normal' children, when compared to non-sexually abused children receiving psychiatric services only one discriminating variable emerged. These studies empirically support the growing impression among clinicians that overt sexual behaviour, inappropriate for age, is an indication of sexual abuse. (pp. 488-489)

Overtly sexual behaviour includes open and compulsive masturbation, precocious sex play, sexualised play with dolls, seductive behaviour and age-inappropriate sexual knowledge (Dubowitz, Black, Harrington, \& Verschoore, 1993; Chaffin, Lawson, Selby, \& Wherry, 1997; Gale, Thompson, Moran, \& Sack 1988; Wells, McCann, Adams, Voris, \& Ensign, 1995). Sexual aggression, that is, coercing others to repeat and re-enact the sexual victimisation, is considered to be among the most salient indicators of CSA (Cosentino, Meyer-Bahlburg, Alpert, Weinberg, \& Gaines, 1995; Friedrich, Beilke \& Urquiza, 1988; Gale, Thompson, Moran, \& Sack, 1988; Kolko, Moses, \& Weldy, 1988; Yates, 1991).

The Children's Sexual Behavior Inventory (CSBI) (Friedrich, Grambsch, Broughton, Kuipers, \& Beilke, 1991) reflects an attempt to clearly define and operationalise sexualised behaviour so as to allow for a discrimination between sexually abused and non-abused children. Friedrich and colleagues used this inventory with a sample of 276 children (aged , 2-12 years) with a confirmed history of CSA and a sample of 880 non-abused children of the same age. Friedrich (1993) suggested that the CSBI demonstrated greatest sensitivity for classifying sexualised behaviours in 2-6-year old males (0.92), and the lowest overall sensitivity for 7-12 year-old females (0.70), who had a confirmed history of CSA. Behaviours such as "puts mouth on sex parts, asks to engage in sex acts, masturbates with object, inserts object in vagina/anus, imitates intercourse, imitates sexual sounds, and French kisses" were among some of the more powerful discriminating behaviours (Friedrich, Eeilke, \& Urquiza (1988). Cash (2002) examined the frequency of sexual behaviour among a sample of preschool children and confirmed that levels of sexualised behaviours on the CSBI as well as levels of sleep disturbance significantly differentiated "probably abused" from "probably not abused".

The CSBI represents a promising line of research however, like other traditional diagnostic indicators of CSA, it is difficult to draw firm conclusions. As noted by Lamb (1994), familial and cultural factors may influence what is defined as sexualised behaviour, thus making it extremely difficult to define a standard for what constitutes overtly sexualised behaviour. Exposure to certain television shows may be responsible for the presence of sexualised behaviour rather than direct sexual victimisation. In conclusion, while the presence of inappropriate sexualised behaviour in children may provide some evidence that CSA has occurred, and may point to a need for further investigation it cannot be relied upon solely in the diagnosis of CSA.

\section{Behaviour Analytic Procedures}


Inspired by Rawls (1994), Keenan and colleagues (McGlinchey, Keenan, \& Dillenburger, 2000; Keenan, McGlinchey, Fairhurst, \& Dillenburger, 2000) initiated the development of behaviour analytic procedures that avoid a range of the problems with traditional diagnostic procedures. Their work builds on procedures developed within the stimulus equivalence paradigm (Sidman \& Tailby, 1982) that have been used to explore complex behaviours such as concept development (McGuigan \& Keenan, 2002) and creativity (McVeigh \& Keenan, 2002). In general, these procedures entail training participants using a matching-to-sample discrimination procedure and then testing responses to new combinations of stimuli. The general logic of the procedures can be seen in a related study by Watt, Keenan, Barnes, and Cairns (1991). Although not a study on CSA, the procedure was designed to address a question that is relevant to the goals of assessment in CSA. Put simply, the study investigated whether it was possible to distinguish between two groups of subjects in terms of prior social learning. Participants were trained to match three traditionally Northern Irish Catholic names (stimuli A1, A2, \& A3) to three 3-letter nonsense syllables (stimuli B1, B2, \& B3), and subsequently to match these nonsense syllables to three traditionally Protestant symbols (stimulus $\mathrm{C} 1, \mathrm{C} 2, \& \mathrm{C} 3$ ). When arbitrary stimuli are used in match-to-sample training like this the result is the establishment of three 3-member equivalence classes (i.e., A1B1C1, A2B2C2, \& A3B3C3). In the Watt et al study, however, there was a departure from the traditional equivalence assessment procedure. Normally the stimuli from class $\mathrm{C}$ would be used as samples and the stimuli from class A only would be used as the comparisons from which a selection is made. During their equivalence testing phase, Watt et al presented participants with Protestant symbols (class C) as the sample stimuli but the comparison stimuli were two of the Catholic names employed during training (class A) and novel Protestant names (N1, N2 or N3). The inclusion the of socially loaded stimuli as novel stimuli in the testing procedure disrupted equivalence responding in twelve of the nineteen Northern Irish subjects; they selected the novel Protestant stimuli (either in N1, N2, or N3) in the presence of the Protestant sample stimulus ( $\mathrm{C} 1, \mathrm{C} 2$, or $\mathrm{C} 3$ respectively) instead of the expected A1, A2 or A3 stimuli. In other words, these participants failed to demonstrate the expected laboratory-induced equivalence responding. In contrast, all of the English subjects responded equivalently by selecting the Catholic names in the presence of the Protestant symbols. The general conclusion from this study is that pre-experimentally established social relations were incongruous with the experimentally induced discriminations and thus controlled participants' performance on the equivalence test. These results have been replicated using a number of different social experiences and participants, including children (McGlinchey \& Keenan, 1997).

McGlinchey, Keenan, and Dillenburger (2000) argued that using the logic of Watt et al's study "it might be possible to differentiate between abused and nonabused children by examining the extent to which normal equivalence responding can be disrupted by [the inclusion of] socially loaded stimuli" (p. 729). Keenan, McGlinchey, Fairhurst, and Dillenburger (2000) continued this line of research and were able to increase the accuracy in verbal reporting of social experiences. This is a prominsing line of research, not only because it might lead to reliable diagnostic tools in the area of CSA, but also because it uses well established conceptual foundations related to learning, thus offering parismony for the development of screening procedures for CSA. In effect, this line of research calls for a return to more basic experimental investigations aimed at assessing the extent to which we can discriminate between children based on prior social experiences. If we can control those experiences, then we should be able to develop assessment procedures that map on to those experiences. This is precisely the goal in the development of screeening tests for CSA. What makes it difficult, though, is that the assessment protocol must be designed in a context where we don't know which stimuli are the appropriate stimuli to use. The varities of abuse and the varities of locations in which the abuse may have taken place present a significant challenge to the whole endeavour. 


\section{Conclusion}

Concerns about accuracy of allegations have resulted in an increased interest in the reliability and validity of the CSA assessment process (American Professional Society on the Abuse of Children (APSAC),1995; Faller, 2003). Inaccurately assessed allegations have serious repercussions for the individuals involved (Bradley \& Wood, 1996). Victims of CSA who have been abused may not be taken seriously and may continue to be subjected to abuse and thus exposed to additional unnecessary psychological trauma (Brown, Palmer, and Rae-Grant, 1994; Robin, 1991). It has been said, that one of the biggest factors in false allegations, has generally been the lack of expertise and training of those professionals assigned to conduct the investigation and interview. (Ney, 1995, pp. 27-28).

In response to this it could be argued that investigators must be adequately trained if the systemic response to child abuse is to be effective (Ney, 1995). However, this solution only makes sense if we have effective screening procedures.

In this paper we have highlighted the fact that the key issue in the diagnosis of CSA is that as yet there is no generally accepted, scientifically valid way to determine whether an abuse report is true or false. While traditional assessment methods continue to be used as indicators of abuse, none are conclusive in their utility to reliably diagnose CSA (Berliner \& Conte, 1993; Lamb, 1994; Goodman, Emery, \& Haugarrd 1998). This point was eloquently expressed by Poole and Lindsay (1998):

The clinical assessment processes which have been used in assessing allegations of sexual abuse have regularly and ambitiously raced ahead of the experimental and empirical foundations which would warrant their use as valid, and reliable methods. (p.15).

Clearly what is needed is the development of covert assessment procedures that are reliable and unintrusive, and that at the same time do not falling prey to the problems associated with traditional assessment methods. This is a difficult research challenge but one that will reap enormous benefits for all concerned.

\section{References}

Adams, J. (1992). Significance of medical findings in suspected sexual abuse: Moving towards consensus. Journal of Child Sexual Abuse, 1, 91-99.

Ahlgrim-Delzell, L., \& Dudley, J. R., (2001) Confirmed, unconfirmed, and false allegations of abuse made by adults with mental retardation who are members of a class action lawsuit. Child Abuse \& Neglect 25, 1121-1132.

American Academy of Pediatrics. (1991). Committee on Child Abuse and Neglect: Public disclosure of private information about victims of abuse. Pediatrics, 87(2), 254-261.

American Professional Society on the Abuse of Children (APSAC) (1995). Practice guidelines: Psychosocial evaluation of suspected sexual abuse in young children. Chicago, IL: American Professional Society on the Abuse of Children. 
Arata, C, M. (1998). To tell or not to tell: Current functioning of child sexual abuse survivors who disclose their victimisation. Child Maltreatment, 3, 63-71.

Baladerian, N. J. (1990). Sexual and physical abuse of developmentally disabled people. Available from Mental Health Consultants, P. O. Box "T," Culver City, CA 90230.

Benedeck, E. P., \& Schetky, D. H. (1987). Problems in validating allegations of sexual abuse. Part 2: Clinical evaluation. Journal of the American Academy of Child and Adolescent Psychiatry, 26, 916-921.

Berliner, L. (1991). Effects of sexual abuse on children. Violence Update, 1, 1-11.

Berliner, L., \& Conte, J. R. (1993). Sexual abuse evaluations: Conceptual and empirical obstacles. Child Abuse \& Neglect, 17, 111-125.

Boat, B. W., \& Everson, M. D. (1988). Use of anatomical dolls among professionals in sexual abuse evaluations. Child Abuse \& Neglect, 12, 171-179.

Bottoms, B. L., \& Davis, S. L. (1997). The creation of satanic ritual abuse. Journal of Social and Clinical Psychology, 16, 112-132.

Bradley, A. R., \& Wood, J. M. (1996). How do children tell? The disclosure process in child sexual abuse. Child Abuse \& Neglect, 9, 881-891.

Briere, J., \& Conte, J. (1993). Self-reported amnesia for abuse in adults molested as children . Journal of Traumatic Stress, 6, 21-31.

Briggs, F., \& Hawkins, R. M. F. (1995). Protecting boys from the risk of sexual abuse. Early Child Development and Care, 110, 19-32.

Britton, H. L., \& O'Keefe, M. A. (1991). Use of nonanatomical dolls in the sexual abuse interview. Child Abuse \& Neglect, 15, 567-573.

Brown, R., Palmer, S., \& Rae-Grant, N. (1994). Preliminary findings of the long term effects of childhood abuse: A study of survivors. In T. Ney (Ed.), True and false allegations of child abuse, assessment and case management. New York: Brunner/Mazel.

Brown, H., Stein, J., \& Turk, V., (1995). Report of a second two year incidence survey on the reported sexual abuse of adults with learning disabilities: 1991 and 1992. Mental Handicap Research, 8, 1-22.

Butler, S., Gross, J., \& Hayne, H. (1995). The effect of drawing on memory performance in young children. Developmental Psychology, 31, 597-608.

Cantwell, H. B. (1983). Vaginal inspection as it relates to child sexual abuse in girls under 13. Child Abuse \& Neglect, 7, 171-176.

Cantwell, H. B., (1987). Update on vaginal inspection as it relates to child sexual abuse in girls under 13. Child Abuse \& Neglect, 4, 545-546. 
Carpenter, Mary Chapin. (1992). "Come On, Come On”. Sony Music.

Cash, R. O., (2002). Predicting sexual abuse status among preschool-aged children using the Child Sexual Behavior Inventory. Child Abuse \& Neglect, 63, 317-324.

Ceci, S. J., \& Bruck, M. (1993) Child witnesses: Translating research into policy. Social Policy Report, 20, 34-38.

Ceci, S. J., Ross. D. F., \& Toglia, M. (1989). Age difference in suggestibility: Psycholegal implications. Journal of Experimental Psychology: General, 117, 38-49.

Cermak, P., \& Molidor, C. (1996). Male victims of child sexual abuse. Child and Adolescent Social Work, 13, 385-400.

Chaffin, M., Lawson, L., Selby, A., \& Wherry, J, N. (1997). False negatives in sexual abuse interviews: Preliminary investigation of a relationship to dissociation. Journal of Child Sexual Abuse, 6, 15-29.

Cohen-Liebman, M.S. (1995). Drawings as judiciary aids in child sexual abuse litigation: A composite list of indicators. The Arts In Psychotherapy, 22, 475-483.

Cohen, J. A., \& Mannarino, A. P. (1988). Psychological symptoms in sexually abused girls. Child Abuse \& Neglect, 12, 571-577.

Cole, C. B. \& Loftus, E. (1987). The memory of children. In S. J. Ceci, M. P. Toglia, \& D. F. Ross (Eds.), Children's eyewitness memory. (pp. 178-208) New York: Springer-Verlag.

Conte, J. R. (1992). Has this child been sexually abuse? Dilemmas for the mental health professional who seeks the answer. Criminal Justice and Behavior, 19, 54-73.

Corwin, D. L., Berliner, L., Goodman, G., Goodwin, J., \& White, S. (1987). Child sexual abuse and custody disputes: No easy answers. Journal of Interpersonal Violence, 2, 91 105.

Corwin, D. L., \& Olafson, E. (1993). Overview: Clinical identification of sexually abused children. Child Abuse \& Neglect, 17, 3-5.

Cosentino, C., Meyer-Bahlburg, H., Alpert, J., Weinberg, S., \& Gaines, R. (1995). Sexual behavior problems psychopathology symptoms in sexually abused girls. Journal of the American Academy of Child Adolescent Psychiatry, 34, 1033-1042.

Cruz, V. K., Price-Williams, D., \& Andron, L. (1988). Developmentally disabled women who were molested as children. Social Casework: The Journal of Contemporary Social Work, 69, 411-419.

Dammeyer, M. D., (1998). The assessment of child sexual abuse allegations: Using research to guide clinical decision making. Behavioral Science and the Law, 16, 21-34.

Davies, J. M. \& Frawley, M G. (1994) Treating the adult survivor of childhood sexual abuse. 
Book. New York.

Deblinger, E., McLeer, S. V., Atkins, M. S., Ralphe, D., \& Foa, E. (1989). Post-traumatic stress in sexually abused, physically abused, and nonabused children. Child Abuse \& Neglect, 13, 403-408.

DeJong, A. R., \& Rose, M. (1991). Legal proof of child sexual abuse in the absence of physical findings. Pediatrics, 88, 506-511.

Department of Health (1995). Notification and reporting of suspected cases of child abuse. Dublin: Stationary Office.

Department of Health. (1996a). Putting children first. Discussion document on mandatory reporting. Dublin: Department of Health.

Department of Health. (1996b). Report on the inquiry into the operation of Madonna House. Dublin: Government Publications Office.

DeVoe, E. R., \& Faller, K. C. (1999). The characteristics of disclosure among children who may have been sexually abused. Child Maltreatment, 4, 217-227.

DeYoung, M. (1987). Disclosing sexual abuse: The impact of developmental variables. Child Welfare, 66, 217-223.

DiPietro, E. K., Runyan, D. K., \& Fredrickson, D. D. (1997). Predicators of disclosure during medical evaluation for suspected sexual abuse. Journal of Sexual Abuse, 6, 133-142.

Dobash, R. P., Carnie, J., \& Waterhouse, L. (1993). Child sexual abusers: Recognition and response. In L. Waterhouse (ED.), Child abuse and child abusers (pp. 113-135). London: Jessica Kingsley Publishers.

Dubowitz, H., Black, M., Harrington, D., \& Verschoore, A. (1993). A follow-up study of behavior problems associated with child sexual abuse. Child Abuse \& Neglect, 17, 743754.

Dunne, T. P., \& Power, A., (1990). Sexual abuse and mental handicap: preliminary findings of a community based study. Mental Handicap Research, 3, 111-125.

Eastern Health Board (1996). Child care and family support services in 1996: Review of adequacy, Dublin: Eastern Health Board.

Epstein, M., \& Bottoms, B. L., (1998). Memories of Childhood Sexual Abuse: A Survey of Young Adults. Child Abuse \& Neglect, 22, 1217-1238.

Everson, M., \& Boat, B. (1989). False allegations of sexual abuse by children and adolescents. Journal of the American Academy of Child and Adolescent Psychiatry, 28, 230-235.

Everson, M., \& Boat, B. (1990). Sexualized doll play among children: Implications for the 
use of anatomical dolls in sexual abuse evaluations. Journal of the American Academy of Child and Adolescent Psychiatry, 29, 736-742.

Everson, M. D., \& Boat, B. W. (1994). Putting the anatomical doll controversy in perspective: An examination of the major uses and criticisms of the dolls in child sexual abuse evaluations. Child Abuse \& Neglect, 18, 113-130.

Faller, K. C. (1984). Is the child victim of sexual abuse telling the truth? Child Abuse \& Neglect, 8, 473-481.

Faller, K. C. (2003). Understanding and assessing child sexual maltreatment. Thousand Oaks: Sage.

Feldman-Summers, S. \& Pope, K. S. (1994). The experience of "forgetting" childhood abuse: A national survey of psychologists. Journal of Consulting and Clinical Psychology, 62, 636-639.

Finkel, M. A., \& DeJong, A. R. (1994). Medical findings in child sexual abuse. In R. M. Reece (Ed.), Child abuse: Medical diagnosis and management (pp. 185-247). Philadelphia, PA: Lea \& Febiger.

Finkelhor, D. (1986). A sourcebook on child sexual abuse. London: Sage.

Finkelhor, D., \& Berliner, L., (1995). Research on the treatment of sexually abused children: A review and recommendations. Journal of the American Academy of Child and Adolescent Psychiatry, 34, 1408-1423.

Friedrich, W. N., (1993). Sexual victimization and sexual behavior in children: A review of recent literature. Child Abuse \& Neglect, 17, 59-66.

Friedrich, W., Eeilke, R., \& Urquiza, A. (1988). Behavior problems in young sexually abused boys. Journal of Interpersonal Violence, 3, 21-27.

Friedrich, W., Grambash, P., Broughton, D., Kuipers, J., \& Beilke, R .L. (1991). Normative sexual behavior in children. Pediatrics, 88, 456-464.

Furniss, T. (1991). The multi-professional handbook of child sexual abuse: Integrated management, therapy and legal intervention (pp. 342-346). London: Routledge.

Gale, J., Thompson, R. J., Moran, T., \& Sack, W. H. (1988). Sexual abuse in young children: Its clinical presentation and characteristic patterns. Child Abuse \& Neglect, 12, 163-170.

Glaser, D. \& Frosh, S. (1993). Child sexual abuse ( $2^{\text {nd }}$ ed.). Hong Kong: Macmillan.

Goldman, J. D. (2000) Some methodological Problems in Estimating Incidence and Prevalence in Child Sexual Abuse Research. Journal of Sex Research, 6, 1-17.

Goodman, G. S., Emery, R. E., \& Hauggard, J. J. (1998). Development psychology and law: 
Divorce, child maltreatment, foster care, and adoption. In W. Damon (Series Ed.) \& I. Sigel \& A. Renninger (Vol. Eds.), Handbook of child psychology: Vol. 4. Child psychology in practice ( $5 \mathrm{t}^{\mathrm{h}}$ ed., pp. 775-876). New York: Wiley.

Goodman-Brown, T., Edelsrein, R., Goodman, G., Jones, D., \& Gordon, D (2003). Why children tell: A model of children's disclosure of sexual abuse. Child Abuse \& Neglect, $27,525-540$.

Goodwin, J., Sahd, D., \& Rada, R.T. (1982). False accusations and false denials of incest: Clinical myths and clinical realities. In J. Goodwin (Ed.), Sexual abuse: Incest victims and their families (pp. 17-26). London: John Wright.

Green, A. (1992). Factors contributing to false allegations of child sex abuse in custody disputes. In M. Robin (Ed.), Assessing child maltreated reports: The problem of false allegations (pp. 177-189). New York: Haworth Press.

Gries, L. T., Goh, D. S., \& Cavanaugh, J. (1996). Factors associated with disclosure during child sexual abuse assessment. Journal of Child Sexual Abuse, 5, 1-19.

Gross, J., \& Hayne, H. (1998). Drawing facilitates children's verbal reports of emotionally laden events. Journal of Experimental Psychology: Applied, 4, 163-179.

Gross, J., \& Hayne, H., (1999). Drawing facilitates children's verbal reports after long delays. Journal of Experimental Psychology: Applied, 5, 265-283.

Harold, H., (1996). Ethical Issues in the search for repressed memories. American Journal of Psychotherapy, 50, 323-335.

Haugaard, J J., \& Emery, R. E, (1989). Methodological issues in child sexual abuse. Child Abuse \& Neglect, 13, 89-100.

Hazzard, A., Celano, M., Gould, J., Lawry, S., \& Webb, C. (1995). Predicting symptomatology and self-blame among child sex abuse victims. Child Abuse \& Neglect, 19, 707-714.

Helfer, R. \& Kempe, C. (1976), Child Abuse \& Neglect: The family and the community. Cambridge, Mass., Ballinger.

Herman, J. L., \& Schatzow, E. (1987). Recovery and verification of memories of childhood sexual trauma. Psychoanalytic Psychology, 4, 1-14.

Hibbard, R. A., \& Hartman, G. L., (1990). Emotional indicators in human figure drawings of sexually victimised and nonabused children. Journal of Clinical Psychology, 46, 211219.

Hibbard, R. A., Roghmann, K., \& Hoekelman, R. A., (1987). Genitalia in children's drawings: An association with sexual abuse. Pediatrics, 79 (1), 129-137.

Holden, W. (1994). Unlawful Carnal Knowledge: The True Story of the X Case. London: Harper Collins. 
Hoggs, J., Campell, M., Cullen, C., \& Hudson, W (2001). Evaluation of the Effect of an Open Learning Course on Staff Knowledge and Attitudes Towards the Sexual Abuse of Adults with Learning Disabilities. Journal of Applied Research in Intellectual Disabilities, 14, 12-29.

Jampole, L., \& Weber, M. K. (1987). An assessment of the behavior of sexually abused and nonsexually abused children with anatomically correct dolls. Child Abuse \& Neglect, 11, 187-192.

Jenny, C., X., (1997). Pediatrics and child sexual abuse: where we've been where we're going. Pediatrics Annual, 26, 284-286.

Jones, D. P. H., \& McGraw, J. M. (1987). Reliable and fictitious accounts of sexual abuse to children. Journal of Interpersonal Violence, 2, 27-45.

Keary K, \& Fitzpatrick, C., (1994). Children's Disclosure of Sexual Abuse during formal investigation. Child Abuse and Neglect, 18, 543-548.

Keenan, M., McGlinchey, A., Fairhurst, C., Dillenburger, K. (2000). Accuracy of Disclosure and Contextual Control in Child Abuse: Developing Procedures within the Stimulus Equivalence Paradigm. Behaviour and Social Issues, 10, 1-17.

Kelly, L., Regan, L., \& Burton, S. (1995). An exploratory study of the prevalence of sexual abuse in a sample of 16-21 year olds. London: HMSO.

Kempe, H.C. \& Kempe, R.S. (1984). The common secret: sexual abuse of children and adolescents. New York: W. H. Freeman.

Kendell-Tackett, K. A. \& Watson, M. W. (1992). Use of anatomical dolls by Boston-area professionals. Child Abuse \& Neglect, 16, 423-428.

Kendall-Tackett, K. A., Williams, L. M., \& Finkelhor, D. (1993). Impact of sexual abuse on children: A review and synthesis of recent empirical studies. Psychological Bulletin, 113, 164-180.

Kolko, D. J., Moser, J. T., \& Weldy, S. R. (1988). Behavioral/emotional indicators of child sexual abuse in child psychiatric inpatients: A controlled comparison with physical abuse. Child Abuse \& Neglect, 12, 529.

Krull, M. (1986). Freud and His Father. New York: W. W. Norton \& Co.

Kvam, M. H., (2000). Is sexual abuse of children with disabilities disclosed? A retrospective analysis of child disability and the likelihood of sexual abuse among those attending Norwegian hospitals. Child Abuse \& Neglect, 24, 1084-2000.

Lalor, K. (1999). The incidence of unwanted childhood sexual experiences amongst a sample of third level students. Irish Journal of Psychology, 20 (1), 15-28.

Lalor, K. (2001). The end of innocence: Child sex abuse in Ireland. Oak Tree Press. 
Techman Ltd.

Lamb, M. E. (1994). The investigation of child sexual abuse: An interdisciplinary consensus statement. Child Abuse \& Neglect, Vol. 18, 1021-1028.

Lamb, S., \& Edgar-Smith, S. (1994). Aspects of disclosure: Mediators of outcome of childhood sexual abuse. Journal of Interpersonal Violence, 9, 307-326.

Lawson, L., \& Chaffin, M. (1992). False negatives in sexual abuse disclosure interviews. Journal of Interpersonal Violence, 7, 532-542.

Lerman, H. (1988). The psychoanalytic legacy: From whence we came. In L. E. A. Walker. Handbook of sexual abuse of children. (pp. 37-57). New York: Springer.

Lepore, J., S.,\& Sesco, B., (1994). Distorting children's reports and interpretations of events through suggestion. Journal of Applied Psychology, 79, 108-120.

Lie, G., \& Inman, A. (1991). The use of anatomical dolls as assessment and evidentiary tools. Social Work, 36, 396-399.

Lindsay, D. S., \& Read, J. D., (1994). Psychotherapy and memories of childhood sexual abuse: A cognitive perspective. Applied Cognitive Psychology, 8, 281-338.

MacFarlane, K., Waterman, J., Conerly, S., Damon, L., Durfee, M., \& Long, S. (1988). Sexual abuse of young children: Evaluation and treatment. London: Cassell.

MacKenzie, G., Blaney, R., Chivers, A., \& Vincent, O. (1993). The Incidence of Child Sexual Abuse in Northern Ireland. International Journal of Epidemiology, 22, 299-305.

Mannarino, A. P., Cohen, J. A., \& Gregor, M. (1989). Emotional and behavioral difficulties in sexually abused girls. Journal of Interpersonal Violence, 4, 437-451.

Masson, J. M. (1984). The Assault on truth: Freud's suppression of the seduction theory. New York: Farrar, Straus \& Giroux.

McCann, J., \& Voris, J., \& Simon, M. (1992). Genital injuries resulting from sexual abuse: A longitudinal study. Pediatrics, 89, 307-317.

McCarty, L. (1981). Investigation of incest: Opportunity to motivate families to seek help. Child Welfare, 60, 679-689.

McGlinchey, A., \& Keenan, M. (1997). Stimulus equivalence and social categorization in Northern Ireland. Behavior and Social Issues, 7, 113-128.

McGlinchey, A., Keenan, M., \& Dillenburger, K. (2000). Outline for the development of a screening procedure for children who have been sexually abused. Research on Social Work Practice, 10, 722-747.

McKay, S., (1998). Sophia’s Story. Dublin: Gill \& Macmillan. 
McGuigan, S. \& Keenan, M. (2002). Rule following in functional equivalence classes. European Journal of Behavior Analysis, 1, 21-29.

McVeigh, B. \& Keenan, M. (2002) The effects of multiple functions within equivalence classes. Experimental Analysis of Behaviour Group. Annual conference, London (March).

Melchert, T. P., \& Parker, R. L., (1997). Different forms of childhood abuse and memory. Child Abuse \& Neglect, 2, 125-135.

Mian, M., Wehrspann, W., Kaljner-Diamond, H., LeBaron, D., \& Winder, J. (1986). Review of 125 children 6 years of age and under who were sexually abused. Child Abuse \& Neglect, 10, 223-229.

Miller, A. (1984). Thou shalt not be aware: Society's betrayal of the child. New York: Farrar, Straus \& Giroux.

Miller, T. W. \& Veltkamp, L. J., (1989a). Assessment of child sexual abuse: Clinical use of fables. Child Psychiatry and Human Development, 20, 123-133.

Miller, T. W., \& Veltkamp, L. J. (1989b). Use of fables in clinical assessment of contested child custody. Child Psychiatry and Human Development, 16, 274-284.

Miller, T. W., \& Veltkamp, L. J. (1995). Assessment of sexual abuse and trauma: Clinical measures. Child Psychiatry and Human Development, 26, 3-10.

Moore. C. (1995). Betrayal of trust: The Father Brendan Smyth affair and the Catholic church. Dublin: Marino.

Mordock, J. B. (2001). Interviewing abused and traumatized children. Clinical Child Psychology and Psychiatry, 6, 271-291.

MRBI. (1987). Child sexual abuse in Dublin: Pilot survey report. Dublin: Market Research Bureau of Ireland Ltd.

Muram D. (1989). Child sexual abuse. Relationship between sexual acts and genital findings. Child Abuse \& Neglect, 13, 211-216.

Myers, J. E. B. (1996). Taint hearings to attack investigative interviews: A further assault on children's credibility. Child Maltreatment, 1, 213-222.

National Criminal Justice Reference Service (2004). Child sexual abuse investigations. A joint investigative approach combining the expertise of mental health and law enforcement professionals. Retrieved from http://www.prevent-abusenow.com/news3a.htm\#Invest on 17 Nov.

Ney, T. (1995). True and false allegations of child sexual abuse assessment and case management. New York: Brunner/Mazel Publishers.

Paradise, J. E., (1989). Predictive accuracy and the diagnosis of sexual abuse. A big issue 
about a little tissue. Child Abuse \& Neglect, 13, 169-176.

Poole, D. A., \& Lindsay, D, S., (1998). Assessing the accuracy of young children's reports: Lessons from the investigation of child sexual abuse. Applied \& Preventive Psychology, 26, 1-26.

Quas, J. A., Goodman, G. S., \& Jones, D. P. H. (2003). Predicators of attributions of self blame and internalising behaviour problems in sexually abused children. Journal of Child Psychology and Psychiatry, 44, 1-14.

Rappley, M. D., \& Woolford, M. D., (1998). Abuse and neglect of children III: Sexual abuse. Psychiatrists Update, 3, 35-50.

Rawls, J. M. (1994). What difference does the interview format make to children's disclosures? Interviewing young children who had secrets to keep. Paper presented at the Association of Behavior Analysis Convention, Atlanta, Georgia (May).

Robin, M. (1991) Assessing child maltreated reports: The problem of false allegations. New York: Haworth Press.Russell, D. (1984). The incidence and prevalence of interfamilial and extrafamilial sexual abuse of female children. Child Abuse \& Neglect, 7, 133-146.

Sas, L. (1993). Three years after the verdict. London, Ont., Canada: London Family Court Clinic Inc.

Saunzier, M. (1989). Disclosure of child sexual abuse: For better or for worse. Psychiatric Clinics of North America, 12, 455-469.

Sidman, M. \& Tailby, W. (1982). Conditional discrimination vs. matching to sample: An expansion of the testing paradigm. Journal of the Experimental Analysis of Behavior, 37, $5-22$.

Sinal, S. H., Lawless, M. R., Rainey, D. Y., Everett, V. D., Runyan, D. K., Frothingham, T., \& Herman-Giddens, M (1997). Clinician agreement on physical findings in child sexual abuse cases. Archives Pediatric Adolescent Medicine, 151, 497-501.

Sirnkins, L., \& Renier, A. (1996). An analytic review of the empirical literature on children's play with anatomically detailed dolls. Journal of Child Sex Abuse, 5, 21-45.

Sivan, A. B., Schor, D. P., Koeppl, G. K., \& Noble, L. D. (1988). Interaction of normal children with anatomical dolls. Child Abuse \& Neglect, 12, 295-304.

Smith, D. W., Letourneau, E. J., Saunders, B. E., Kilpatrick, D. G., Resnick, H. S., \& Best, C. L. (2000). Delay in disclosure of childhood rape: Results from a national survey. Child Abuse \& Neglect, 2, 273-287.

Sobsey, D., \& Doe, T. (1991). Patterns of sexual abuse and assault. Sexuality and Disability, 9, 243-259.

Tharinger, D., Horton, C. B., \& Millea, S. (1990). Sexual abuse and exploitation of children 
and adults with mental retardation and other handicaps. Child Abuse \& Neglect, 14, 301312.

The Research Team (1990). Child sexual abuse in Northern Ireland: A research study of incidence. Greystone Books, Antrim.

Theonnes, N., \& Tjaden, P.G. (1990). The extent, nature and validity of sexual abuse allegations in custody disputes. Child Abuse \& Neglect, 14, 151-163.

Thomas, G. V., \& Silk, A. M. J. (1990). An introduction to the psychology of children's drawings. Hemel Hempstead: Harvester Wheatsheaf.

Veltman, M. W., \& Browne, K, D., (2001). Identifying childhood abuse through favorite kind of day and kinetic family drawings. The Arts in Psychotherapy, 28, 251-259.

Violato, C., \& Genuis, M. (1993). Problems of research in male child sexual abuse: A review. Journal of Child Sexual Abuse, 2, 33-54.

Wakefield, H., \& Underwager, R. (1992). Recovered memories of alleged sexual abuse: Lawsuits against parents. Behavioral Sciences and the Law, 10, 483-507.

Ward, P. (1997). The Child Care Act, 1991. Dublin: Round Hall Press.

Waterman, J., \& Lusk, R. (1993). Psychological testing in evaluation of child sexual abuse. Child Abuse \& Neglect, 17, 145-159.

Watkins, B., \& Bentovim, A. (1992). The sexual abuse of male children and adolescents: A review of current research. Journal of Child Psychology and Psychiatry, 33, 197-248.

Watt, A., Keenan, M., Barnes, D., \& Cairns, E. (1991). Social categorization and stimulus equivalence. The Psychological Record, 41, 33-50.

Wells, R. D., McCann, J., Adams, J., Voris, J., \& Ensign, J. (1995). Emotional, behavioral, and physical symptoms reported by parents of sexually abused, nonabused, and allegedly abused prepubescent females. Child Abuse \& Neglect, 19, 155-163.

White, S., Halpin, B. M., Strom, G. A., \& Santilli, G. (1988). Behavioral comparison of young sexually abused, neglected, and nonreferred children. Journal of Clinical Child Psychology, 17, 53-61.

White, S., Strom, G. A., Santilli, G., \& Halpin, B. M. (1986). Interviewing young sexual abuse victims with anatomically correct dolls. Child Abuse \& Neglect, 10, 519-529.

Williams, L. (1995). Recovered memories of abuse in women with documented child sexual victimization histories. Journal of Traumatic Stress, 8, 649-674.

Wood, B., Orsak, C., Murphy, M., \& Cross, H., (1996). Semi-structured child sexual abuse interviews: Interview and child characteristics related to credibility of disclosure. Child Abuse \& Neglect, 20, 81-92. 
Wyatt, G. E., (1985). The sexual abuse of Afro-American and White-American women in childhood. Child Abuse \& Neglect, 9, 507-519.

Wyatt, G. E., \& Newcomb, M.D. (1990). Internal and external mediators of women's sexual abuse in childhood. Journal of Consulting and clinical Psychology, 58, 758-767.

Wyatt, G. E., \& Peters, S. D (1986). Issues in the definition of child abuse in the prevalence research. Child Abuse \& Neglect, 10, 231-241.

Yamini, R. J., (1996). Repressed and recovered memories of child sexual abuse: The accused as "Direct victim". Hastings Law Journal 47, 551-580.

Yates, A. (1991). Differentiating hypererotic states in the evaluation of sexual abuse. Journal of the American Academy of Child Adolescent Psychiatry. 30, 791-795.

Zirpoli, T., Snell, M., \& Lloyd, B. (1987). Characteristics of persons with mental retardation who have been abused by care givers. The Journal of Special Education, 21 (2), 31-41.

\section{Author Contact Information:}

\section{Catrina Duffy}

Samplings Project

Kill, Kildare,

Ireland

Mickey Keenan

School of Psychology

University of Ulster at Coleraine

Coleraine BT52 1SA

Northern Ireland

\section{Karola Dillenburger}

School of Sociology, Social Policy, and Social Work

Queen's University of Belfast

Belfast BT9 5BY

Northern Ireland 


\title{
Second Annual \\ Functional Analytic Psychotherapy (FAP) Summer Conference
}

\section{At the University of Washington, Seattle Friday, June 30 - Sunday, July 2}

\author{
Presenters include: \\ Madelon Bolling, Ph.D. \\ Glenn Callahan, Ph.D. \\ William Follette, Ph.D. \\ Jonathan Kanter, Ph.D. \\ Robert Kohlenberg, Ph.D. \\ Kirk Newring, Ph.D. \\ Mavis Tsai, Ph.D. \\ and more...
}

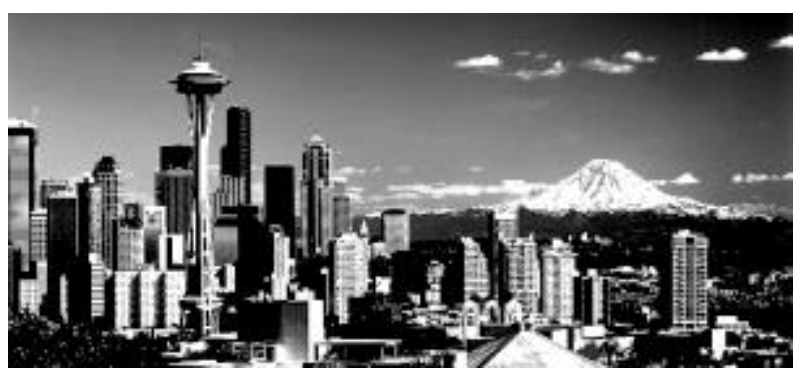

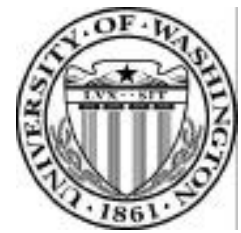

6/30: Intro Workshop 7/1-7/2: Intermediate Workshops

Up to 16 CE credits

\section{What is FAP?}

Considered one of the new generation innovative Cognitive Behavior Therapies identified as "Third Wave," FAP is integrative, and provides a conceptual and practical framework that will help super-charge the therapy session. FAP utilizes emotional intimacy in the therapist-client relationship to shape clients' problematic behavior occurring in the therapy session. FAP has been applied to depression, anxiety, intimacy difficulties, personality disorders, problems of the self, substance abuse, and couples work.

For more information and to register, visit www.faptherapy.com or call Amanda Patrick at (206) 543-6511

Advertisement

\section{Behavior Analyst Online}

\author{
www.Behavior-Analyst-Online.org
}

The Behavior Analyst Online organization (BAO) develops and deploys new resources for behavior analysts and makes them available on the Internet free of charge to the public. These resources are dedicated to educating the public about behavior analysis as well as serving as a resource for professionals involved in the field of behavior analysis.

The BAO organization is responsible to its membership to develop resources that the membership will find useful in everyday research, education, and application of the science of behavior analysis.

The BAO organization offers may perks to its members, including a Web Forum and the ABAPRO Mailing List. In addition, the organization publishes several major free e-journals of interest to the behavior analysis community:

The Behavior Analyst Today

The Journal of Early and Intensive Behavior Intervention

The International Journal of Behavioral Consultation and Therapy

The Journal of Speech and Language Pathology - Applied Behavior Analysis

Membership in the BAO organization is free. For details, visit our website at 


\title{
An Experimental Investigation of Responsibility and Reassurance: Relationships with Compulsive Checking
}

\author{
Chris L. Parrish and Adam S. Radomsky
}

\begin{abstract}
Inflated perceptions of responsibility are hypothesized to contribute to compulsive checking. Reassurance seeking, proposed to be a form of checking, may exacerbate checking behaviour in the long run. A sample of non-clinical participants $(N=100)$ performed a complex manual classification task under 1 of 4 experimental conditions: high responsibility-high reassurance, high responsibility-low reassurance, low responsibility-high reassurance, or low responsibility-low reassurance, and provided ratings of anxiety, urges to check, urges to seek reassurance, and confidence both before and after experimental manipulations were employed. Higher levels of perceived responsibility were associated with the maintenance of compulsive urges and doubt. Results are discussed in terms of cognitive and behavioural models of obsessive-compulsive disorder, and in terms of directions for future research. Key words: Obsessive-compulsive disorder, OCD, Responsibility, Reassurance, Checking, Neutralization.
\end{abstract}

Obsessive-compulsive disorder (OCD) is characterized by recurrent obsessions and/or compulsions that are time-consuming (lasting at least one hour per day) and which cause marked distress or significant impairment in functioning (American Psychiatric Association, 2000). Cognitive conceptualizations of OCD (e.g., Rachman, 1976, 1993; Salkovskis, 1985, 1999) emphasize the fundamental role of perceived responsibility in promoting obsessional phenomena. Responsibility, in this context, refers to "the belief that one possesses pivotal power to provoke or prevent subjectively crucial negative outcomes" (Salkovskis, Rachman, Ladouceur, \& Freeston, 1992). The centrality of this construct was first highlighted in Salkovskis's (1985) cognitive theory of obsessions, which states that a primary distinction between non-clinical and clinical (i.e., OCD) populations is the manner in which they interpret and appraise intrusive phenomena. This theory helped to explain two critical findings from early research on OCD-related cognitions: (i) 'normal' individuals routinely experience intrusions whose content resembles that of clinical obsessions (Rachman \& De Silva, 1978; Salkovskis \& Harrison, 1984), and (ii) unlike OCD sufferers, non-clinical populations can easily dismiss cognitive intrusions as senseless and trivial events (Salkovskis \& Harrison, 1984). Salkovskis $(1985,1999)$ suggested that obsessionals frequently (mis)interpret their intrusive thoughts, images, and impulses as indicating that danger is imminent, and that they feel personally responsible for preventing any potential harm that might occur as a result of this threat. It was also hypothesized that OCD sufferers' negative interpretations of their intrusions would lead to discomfort which, in turn, would increase their subsequent urges to engage in various forms of anxiety-neutralizing behaviour (e.g., checking, reassurance seeking, washing, thought suppression, distraction, mental ritualization, etc.). Thus, an inflated sense of perceived responsibility has been hypothesized to increase both the occurrence of obsessions and the use of counter-productive neutralization strategies (Salkovskis et al., 2000).

Several authors (e.g., Ladouceur et al., 1995; Lopatka \& Rachman, 1995; Rachman, 1976, 2002; Rachman \& Hodgson, 1980; Rhéaume, Ladouceur, Freeston, \& Letarte, 1995) have suggested that an exaggerated sense of responsibility for preventing harm may be particularly relevant to individuals with checking compulsions. For example, an individual pre-occupied with images of their children trapped in a fire might repeatedly check the stove, gas taps, etc., to ensure that they have been properly shut off. However, a number of other factors, including exaggerated perceptions of threat and impaired metamemory, may also contribute to doubting and checking activities (Rachman, 2002). 
Rachman's (2002) recent model of compulsive checking provides an outline of the mechanisms purported to be involved in the onset and maintenance of this behaviour. According to this model, repeated checking is precipitated by increases in anxiety/discomfort and urges to check, which result from the presence of three "cognitive multipliers", namely, perceived responsibility for harm, perceived probability of harm and perceived seriousness of harm. Rachman notes that compulsive checking is usually intended to prevent future harm from occurring as a result of a perceived threat. However, perceived threats are often hypothetical, vague, and never-ending (e.g., "the failure to check properly might lead to harm coming to a family member"), thus individuals plagued with harm-related obsessions are often compelled to continue checking repeatedly, in order to temporarily alleviate their feelings of anxiety. In addition, because compulsive checking can prevent the disconfirmation of negative beliefs (e.g., "If I do not check, disaster is certain to occur"), it serves to maintain these beliefs, thereby increasing the likelihood of further compulsions and safety behaviours. Rachman's theory also stipulates that a "self-perpetuating mechanism" acts to maintain compulsive checking once it has begun. The act of repeated checking itself is purported to paradoxically increase one's sense of personal responsibility for harm, as well as one's estimation of threat, while also impairing meta-memory (Coles, Radomsky, \& Horng, in press; Hout \& Kindt, 2004; Radomsky, Gilchrist, \& Dussault, in press). Thus, an exaggerated sense of responsibility for preventing harm (in conjunction with a bias towards increased perceptions of threat) is thought to play a critical role in both the onset and maintenance of compulsive checking behaviour.

Research examining the relationships between perceived responsibility and compulsive checking has generally supported this theory. For instance, Lopatka \& Rachman (1995) asked a group of clinical checkers to perform an anxiety-provoking exposure task in their own homes under conditions of high and low responsibility, and a "no manipulation" control condition. Lower perceived responsibility was associated with significant reductions in participants' subjective anxiety/discomfort, urges to check, and perceived likelihood and severity of harm (i.e., threat estimation), while higher perceived responsibility did not lead to a significant increase in any of these variables, relative to the control condition. In a related study, Ladouceur et al. (1995) had non-clinical students perform a manual classification task (e.g., sorting pills) under conditions of high and low responsibility/threat. Higher levels of perceived responsibility/threat were associated with significantly greater checking behaviour and hesitations. However, similar to Lopatka and Rachman's (1995) findings, participants in the high responsibility group did not demonstrate significantly higher levels of doubt or urges to check, relative to participants in the low responsibility group. More recently, Shafran (1997) manipulated responsibility indirectly in a sample of OCD patients, by varying whether the experimenter was present (low responsibility condition), or absent (high responsibility condition), during an idiographically designed exposure task. Participants reported significantly higher levels of perceived threat, discomfort, and urges to neutralize in the high responsibility condition, relative to the low responsibility condition.

Thus, the majority of empirical and anecdotal evidence suggests that an inflated sense of responsibility for preventing harm contributes to doubting and checking behaviour. Yet, the precise manner in which responsibility affects these variables remains unclear, as the effects of manipulating responsibility were not entirely uniform across these studies. Whereas Ladouceur et al. (1995) found that increases in perceived responsibility were associated with increased checking behaviour, Lopatka and Rachman (1995) found that decreases, but not increases in perceived responsibility significantly affected anxiety and compulsive urges. In addition, because Shafran's (1997) study did not include a 'baseline' condition, it is not clear whether the significant group differences found in this experiment reflect an increase in OCD-related cognitions in the high responsibility group, a decrease in these cognitions in the low responsibility group, or a combination of both. Thus, one objective of the current study is to clarify these issues, by investigating both the nature and direction of responsibility and threat manipulations in a non-clinical group of participants. 
Another focus of the current investigation was to examine the effects of repeated reassurance on various factors purported to exacerbate checking and related behaviours. Repeated requests for reassurance are common in OCD, particularly among individuals with checking compulsions (Rachman, 2002; Rachman \& Hodgson, 1980; Salkovskis, 1985, 1999). This behaviour has been conceptualized as a form of checking "by proxy" (Rachman, 2002), in which the individual seeks to disperse responsibility for harm to others (Salkovskis, 1985, 1999). In fact, Rachman (2002) proposes that excessive reassurance-seeking, compulsive checking, and other forms of OCD-related neutralization behaviour can all be construed as anxiety-reduction techniques aimed at exerting influence over negative outcomes (i.e., reducing "threat"), and reducing one's perceived responsibility for such outcomes. However, similar to effects observed in compulsive checking, the hypothesized reductions in anxiety and perceived responsibility that follow repeated reassurance are thought to be temporary (Hout \& Kindt, 2004; Rachman, 2002; Rachman \& Hodgson, 1980). Thus, both the functions and the long-term consequences of reassurance seeking and compulsive checking in OCD are purported to be similar.

Prior research has demonstrated a number of long-term detrimental effects associated with excessive reassurance seeking in the context of other emotional disorders, such as health anxiety (or hypochondriasis) (Hadjistavropoulos, Craig, \& Hadjistavropoulos, 1998; Salkovskis \& Warwick, 1986) and depression (Joiner \& Schmidt, 1998; Joiner, Alfano, \& Metalsky, 1992). Among individuals with health anxiety, requests for reassurance tend to focus on health status (e.g., "Do I have a disease?", "Is this spot cancerous?"), whereas depressed individuals tend to seek reassurance regarding issues related to self-worth (e.g., "Do you really care about me?"). In these contexts, excessive reassurance seeking has been shown to contribute to interpersonal difficulties (e.g., causing others to become frustrated with repeated demands for reassurance; Joiner et al., 1992), unnecessary health costs (e.g., due to increased and unnecessary medical consultation in the case of health anxiety; Salkovskis \& Warwick, 1986), and the long-term exacerbation of compulsive behaviour (e.g., increased demands for additional reassurance; Hadjistavropoulos et al., 1998; Salkovskis \& Warwick, 1986). Furthermore, the manner in which other individuals respond to repeated requests for reassurance seems to be an important factor in determining the long-term consequences of this behaviour. Repeated provisions of reassurance can be counterproductive, leading to subsequent and further increases in reassurance seeking (Hallam, 1974; Salkovskis \& Warwick, 1986; Tolin, 2001). Given that a common underlying purpose for soliciting reassurance in each of the above-described circumstances may be to achieve rapid (albeit temporary) reductions in anxiety, it is reasonable to hypothesize that excessive reassurance seeking in OCD may have long-term consequences that resemble those described above. Therefore, an investigation of this behaviour, particularly in the context of compulsive checking, is warranted.

Accordingly, the present investigation was designed to address the following questions: (i) Do manipulations of perceived responsibility and threat during a complex and potentially threatening task affect participants' subjective ratings of anxiety, compulsive urges (to check and to seek reassurance), performance-related doubt (e.g., confidence in outcome), and/or memory accuracy (e.g., their ability to recall recently-performed actions), and (ii) Are the above-listed phenomena affected by repeated provisions of reassurance?

To examine these issues, the current study used a protocol similar to that employed by Ladouceur et al. (1995). In their study, non-clinical participants were asked to perform a manual classification task (i.e., sorting pharmaceutical capsules into a row of small containers according to their colour) under conditions of either high or low responsibility. In the high responsibility condition, participants were told that the results of their individual performance would have important implications for the health and safety of inhabitants of a developing country. In contrast, participants in the low responsibility condition were told that the purpose of the experiment was to examine colour perception, and that the sorting trials they were asked to complete were only "practice" before the real experiment began. The current study 
also included a reassurance manipulation, in order to determine whether reassurance might interact with perceived responsibility to exacerbate OCD-related cognitions and distress.

\section{Hypotheses}

It was hypothesized that participants assigned to high responsibility conditions would demonstrate subsequent increases in: i) subjective anxiety, ii) urges to check, and iii) urges to seek additional reassurance, relative to participants in low responsibility conditions. It was also hypothesized that increases in perceived responsibility would act to decrease participants' confidence in their performance accuracy. In addition, it was hypothesized that providing repeated reassurance to participants regarding their performance during the experimental task would amplify the effects of increased responsibility, relative to conditions in which no reassurance was offered. Finally, memory accuracy (i.e., participants' ability to recall specific details of the sorting procedure) was not expected to be influenced by manipulations of either responsibility or reassurance.

\section{Method}

\section{Participants}

One hundred twenty-four volunteer undergraduate students participated in this study. In order to preserve the credibility of the experiment, Psychology majors were not recruited for participation. Participants' mean age was 22.57 ( $S D=4.80$, range $=17-43$ ) years, and $73.0 \%$ of participants were female. Participants were compensated for their time with course credit, or entry in a draw for a cash prize. Participant characteristics are displayed in Table 1.

Table 1

Participants' Scores on the VOCI, OBQ-44, BAI, and BDI-II

\begin{tabular}{llllll}
\hline Measure & $M$ & $S D$ & Min. & Max. & Max.
\end{tabular}

\section{$\mathrm{VOCI}^{\mathrm{a}}$}

$\begin{array}{lccccc}\text { Total } & 43.10 & 36.24 & 0.00 & 153.00 & 220.00 \\ \text { HResp-HRsre } & 37.04 & 30.90 & 0.00 & 104.00 & 220.00 \\ \text { HResp-LRsre } & 53.74 & 42.42 & 0.00 & 117.00 & 220.00 \\ \text { LResp-HRsre } & 33.04 & 29.52 & 0.00 & 112.00 & 220.00 \\ \text { LResp-LRsre } & 49.11 & 39.04 & 1.00 & 153.00 & 220.00 \\ -44^{\text {a }} & & & & & \end{array}$




$\begin{array}{lccccc}\text { Total } & 141.96 & 44.80 & 56.00 & 250.00 & 308.00 \\ \text { HResp-HRsre } & 137.62 & 49.00 & 56.00 & 250.00 & 308.00 \\ \text { HResp-LRsre } & 147.56 & 44.50 & 78.00 & 237.00 & 308.00 \\ \text { LResp-HRsre } & 139.02 & 42.72 & 57.00 & 243.00 & 308.00 \\ \text { LResp-LRsre } & 143.88 & 45.04 & 67.00 & 244.00 & 308.00\end{array}$

BAI

$\begin{array}{lccccc}\text { Total } & 11.92 & 9.98 & 0.00 & 42.00 & 63.00 \\ \text { HResp-HRsre } & 9.25 & 7.60 & 0.00 & 28.00 & 63.00 \\ \text { HResp-LRsre } & 15.39 & 11.09 & 0.00 & 38.00 & 63.00 \\ \text { LResp-HRsre } & 9.42 & 8.98 & 0.00 & 42.00 & 63.00 \\ \text { LResp-LRsre } & 13.74 & 10.95 & 0.00 & 37.00 & 63.00\end{array}$

Table 1 (continued)

Participants' Scores on the VOCI, OBQ-44, BAI, and BDI-II

\begin{tabular}{|c|c|c|c|c|c|}
\hline Measure & $M$ & $S D$ & Min. & Max. & $\begin{array}{l}\text { Max. } \\
\text { possible }\end{array}$ \\
\hline
\end{tabular}

BDI-II

$\begin{array}{lccccc}\text { Total } & 12.33 & 9.84 & 0.00 & 45.00 & 63.00 \\ \text { HResp-HRsre } & 10.71 & 7.25 & 0.00 & 32.00 & 63.00 \\ \text { HResp-LRsre } & 13.35 & 11.23 & 0.00 & 34.00 & 63.00 \\ \text { LResp-HRsre } & 11.73 & 10.08 & 1.00 & 45.00 & 63.00 \\ \text { LResp-LRsre } & 13.48 & 10.62 & 1.00 & 43.00 & 63.00\end{array}$

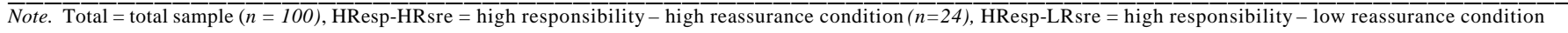
$(n=23)$, LResp-HRsre = low responsibility - high reassurance condition $(n=26)$, LResp-HRsre $=$ low responsibility - high reassurance $\operatorname{condition}(n=27)$.

' participants' mean scale scores were substituted for missing values.
} 


\section{Measures}

\section{Vancouver Obsessional Compulsive Inventory}

The Vancouver Obsessional Compulsive Inventory (VOCI; Thordarson et al., 2004) is a 55-item self-report measure designed to assess a broad range of OCD symptoms.

A factor analysis revealed 6 easily interpretable factors, which comprise the VOCI's 6 component subscales: checking, contamination, obsessions, hoarding, "just right", and indecisiveness. The VOCI possesses good inter-item reliability in student, community, OCD, and clinical control populations (Cronbach's $\alpha=.96, .90, .94$, and .98 respectively). Test-retest reliability for the VOCI total score is high in clinical populations (Pearson's $\mathrm{r}=.96, \mathrm{p}<0.001$ ) (Thordarson et al., 2004), as well as in student samples (Pearson's $r=.91, p<0.001$ ) (Parrish, Ouimet, Ashbaugh, Radomsky, \& O'Connor, 2004).

\section{Obsessional Beliefs Questionnaire - 44}

The Obsessional Beliefs Questionnaire - 44 (OBQ; Obsessive-Compulsive Cognitions Working Group [OCCWG], 2005) is a 44-item scale that measures the presence and strength of various beliefs that are common among OCD sufferers.

A recent analysis conducted on a previous 87-item version of the OBQ revealed three empirically derived factors that correspond to cognitive constructs hypothesized to be highly relevant to OCD: 1) responsibility and threat estimation, 2) perfectionism and intolerance for uncertainty, and 3) importance and control of thoughts (OCCWG, 2005). As a result of this analysis, the shorter, 44-item version of the OBQ was created. This abbreviated version possesses excellent internal consistency among OCD patients (Cronbach's $\alpha=.95$ ), and evidence supports the criterion validity of this measure (OCCWG, 2005).

\section{Beck Anxiety Inventory}

The Beck Anxiety Inventory (BAI; Beck \& Steer, 1990) is a 21-item self-report measure designed to assess the severity of primarily somatic anxiety symptoms experienced by respondents during the previous week. The BAI has been shown to be highly reliable and valid (Beck \& Steer, 1990).

\section{Beck Depression Inventory-II}

The Beck Depression Inventory-II (BDI; Beck, Steer, \& Brown, 1996) is a 21-item self-report measure that assesses the severity of depressive symptoms experienced by respondents over the course of the previous two weeks. The BDI has been shown to be a highly reliable and valid assessment tool (Beck, Steer, \& Brown, 1996).

\section{Anxiety (Subjective units of distress scale [SUDS])}

Participants were asked to rate their subjective anxiety on a 0-100 scale, where 0 was anchored by "not-at-all anxious", and 100 was anchored by "extremely anxious."

\section{Urge to check}

Participants were asked to rate their urge to check their performance on a 0-100 scale, where 0 was anchored by "no urge whatsoever", and 100 was anchored by "extreme urge to check". 


\section{Urge to seek reassurance}

Participants were asked to rate their urge to receive additional reassurance on a 0-100 scale, where 0 was anchored by "no urge whatsoever", and 100 was anchored by "extreme urge to be reassured."

\section{Confidence in outcome}

Participants were asked to rate how confident they were that they had sorted the pills accurately on a $0-100$ scale, where 0 was anchored by "not-at-all confident", and 100 was anchored by "completely confident."

\section{Memory accuracy}

To assess memory accuracy, participants completed a multiple-choice memory test (see Appendix), which measured their ability to remember the pill combinations they had been asked to place in each bottle during the sorting task.

\section{Procedure}

The study employed a 2 (time) x 2 (responsibility condition) x 2 (reassurance condition) mixed design, in which both perceived responsibility and the provision of reassurance were experimentally manipulated. Thus, four conditions (high responsibility-high reassurance [HResp-HRsre], high responsibility-low reassurance [HResp-LRsre], low responsibility-high reassurance [LResp-HRsre], and low responsibility-low reassurance [LResp-LRsre]) across two assessment points comprised the experimental design.

After providing informed consent, participants were seated in a small testing room where the experimenter provided initial verbal instructions and a detailed standardized demonstration of the pillsorting task that they would be asked to perform. Participants were presented with an assortment of ten different pill types (including various shapes, colours and sizes) in two large ceramic bowls, and were subsequently asked to perform a series of sorting trials during the experiment. Each trial involved sorting the pills into a row of seven opaque pharmaceutical bottles, one pill at a time, using seven pre-determined four-pill combinations. Participants were instructed not to look into the bottles while sorting.

Participants were not initially informed of the purpose of the sorting task; however, they were instructed to sort the pills as quickly and accurately as possible. Participants were asked to wear a pair of latex gloves while sorting the pills, and were informed that the experimenter would record the time taken to complete each trial.

Following each of the first three trials, participants received identical feedback regarding the accuracy of their performance. After the first trial, all participants were told that they had made a mistake while sorting the pills (regardless of their actual performance). This potentially false feedback was meant to increase participants' uncertainty about their ability to perform the sorting task correctly and quickly, and is consistent with the procedure employed by Hout \& Kindt (2003a, 2003b) in their investigations of repeated checking. However, to ensure that participants believed that they were also capable of performing the task correctly, they were assured that they had sorted the pills correctly following the second trial (again, regardless of their actual performance). Participants were not given feedback following their third trial. Instead, they were led to a different room, where they were asked to provide the subjective ratings outlined above (i.e., anxiety, urges to check, urges to seek reassurance, confidence in outcome), as well as to complete the test of memory accuracy. 


\section{Responsibility manipulation}

In the high responsibility condition, participants were told that our laboratory had been asked by a charitable organization to determine whether pills of various shapes, sizes and colours could be sorted quickly and accurately by hand. Participants were also told that the results of their individual performance would be important for developing a safe and efficient means of sorting and distributing vitamins and medications in a third-world country. To maximize credibility and increase participants' perceived responsibility and threat in this condition, the experimenter wore a lab coat throughout the experiment, and a poster from a charitable organization was displayed on the wall of the testing room. Conversely, participants in the low responsibility condition were told that the present study had been designed to investigate colour and shape perception, and that our laboratory was interested in determining how quickly and accurately people were able to sort pills according to their colour and shape. The experimenter did not wear a lab coat in this condition, nor were any additional props (e.g., posters) included. All participants (regardless of responsibility condition) were told that we were also interested in determining how task repetition would affect their mood.

\section{Reassurance manipulation}

Following the responsibility manipulation, each participant performed two more sorting trials (trials \#4 and \#5). In between these trials, a brief series of task-irrelevant questionnaires was administered to participants in an adjacent room. Members of the low reassurance groups did not receive any feedback regarding their performance following the fourth and fifth trials, while members of the "high-reassurance" groups were provided with three standardized bouts of reassurance following the fourth trial. These reassurances involved three discrete statements of positive performance-related feedback: (i) "That's great, I've checked every pill in each bottle, and you've sorted them exactly right. Let me reassure you that your performance was satisfactory. However, to be sure, we use a standardized procedure for checking your performance, so I am now going to take this tray of pills to our data entry person for her to check", (ii) "Our data entry person has just checked your last trial and also found that you sorted the pills exactly right. She will now enter your last trial into our database which will provide another means of checking your performance", and (iii) "Our computer database has also verified that you sorted the pills correctly on your last trial". These reassurance provisions were spread out over a 15-minute time period, during which the above-mentioned questionnaires were completed. Participants did not receive any performance-related feedback following the fifth trial, regardless of reassurance condition.

After completing the fifth trial, participants were asked to provide a second set of subjective ratings (i.e., anxiety, urge to check, urge to seek reassurance, confidence in outcome). They were also asked to complete the multiple-choice memory accuracy test once more. In addition, as a manipulation check, participants were asked to rate (scale $0-100$ ) the level of perceived responsibility/threat that they associated with the experimental task.

\section{Results}

Analyses were conducted excluding cases with incomplete data $(n=24)$. As a result, the overall sample size was reduced from 124 to 100 participants (HResp-HRsre group: $n=24$, HResp-LRsre group: $n=23$, LResp-HRsre group: $n=26$, LResp-LRsre group: $n=27$ ).

\section{Participant characteristics}

Participants in the four experimental groups did not differ with respect to age, $F(3,96)=1.75$, $n . s$. , nor did they differ in terms of their mean total scores on the BDI, $F(3,96)=.45$, n.s., the BAI, $F(3,96)=2.44, n . s$., the VOCI, $F(3,96)=1.85, n . s$., or the OBQ, $F(3,96)=.24$, n.s. (see Table 1 for descriptive statistics). 


\section{Sex comparisons}

A chi-squared analysis revealed that sex was not equally distributed across the experimental groups $\left(?^{2}[3, \mathrm{~N}=100]=8.37, p=.04\right)$. There were fewer males in the "high responsibility" groups than in the "low responsibility" groups (19.1\% vs. $34.0 \%$, respectively), and fewer males in the HResp-HRsre group compared to the other three groups $(4.2 \%$ vs. $34.8 \%, 34.6 \%$, and $33.3 \%$ respectively). However, independent samples t-tests revealed that males and females did not differ with respect to the number of error-free sorting trials they performed, $t(98)=1.65$, n.s. $(M=2.59[S D=1.37] v s .3 .10[S D=1.34]$ errorfree trials for males and females, respectively). Furthermore, there were no significant differences between males and females on pre-manipulation ratings of anxiety, $t(98)=.35, n . s$., urges to check, $t(98)$ $=.34$, n.s., urges to seek reassurance, $t(98)=-.45, n . s$., or confidence in outcome, $t(98)=-.63$, n.s. Likewise, there were no significant sex differences on post-manipulation ratings of anxiety, $t(98)=.48, p$ $=n . s$., urges to check, $t(98)=-.30, n . s$., urges to seek reassurance, $t(98)=.15, n . s$., or confidence in outcome, $t(98)=-.53$, n.s. Males and females also did not differ in terms of their memory accuracy prior to, $t(98)=-.27, n . s .$, or following, $t(98)=.01, n . s$. , the experimental manipulations.

\section{Manipulation check}

Following the last pill-sorting trial, participants rated (on a scale from $0-100$ ) the extent to which they felt their performance would affect the well-being of others. Participants in the high responsibility groups reported a significantly greater amount of perceived responsibility/threat associated with the experimental task than participants in the low responsibility groups, $F(1,96)=12.47, p<0.01(M=$ $46.68[S D=27.32] v s .27 .81[S D=26.50]$, respectively), indicating that the responsibility manipulation was effective.

\section{Main dependent variables}

A repeated-measures ANOVA was conducted, in which time and scale were treated as withinparticipants factors, while responsibility and reassurance conditions served as between-participants factors. Significant main effects of time, $F(1,288)=6.90, p=.01$ (Cohen's $d=.31$ ) and scale, $F(3,288)=$ $57.53, p<.001$ (Cohen's $d=.89$ ) were found, indicating that participants' ratings differed according to the scale being measured and the time of measurement. In addition, results revealed a significant 3-way (time $\mathrm{x}$ scale $\mathrm{x}$ responsibility condition) interaction, $F(3,288)=3.23, p=.02$ (Cohen's $d=.21$ ), indicating that participants' ratings for each of the above-mentioned scales were differentially influenced by manipulations of perceived responsibility across time. In contrast, the interaction between time, scale, and reassurance condition was not statistically significant, $F(3,288)=.60, n$.s., nor was the 4-way interaction between time, scale, responsibility condition, and reassurance condition, $F(3,288)=1.13$, n.s.

To determine which scales were affected by the interaction between time of measurement and responsibility condition, four separate $2 \times 2 \times 2$ repeated measures ANOVAs were conducted (one for each scale) using the poole d error term from the original analysis (see Howell, 1987). Subsequent to these analyses, the simple effects of time were examined at both levels of responsibility for each scale, and pairwise comparisons were conducted to clarify significant results.

\section{Table 2}

Participants' Subjective Ratings (scale 0-100) at Time1 and Time2.

$\begin{array}{lll}\text { Group } & \text { Time 1 } & \text { Time 2 }\end{array}$


$\begin{array}{lllll}\text { Rating } & M & (S D) & M & (S D)\end{array}$

High responsibility $(n=47)$

$\begin{array}{lcccc}\text { Anxiety } & 33.83 & 25.45 & 28.57 & 24.75 \\ \text { Urge to check } & 42.23 & 32.32 & 41.00 & 34.54 \\ \text { Urge to seek reassurance } & 40.26 & 32.40 & 39.62 & 33.65 \\ \text { Confidence } & 72.13 & 23.10 & 71.21 & 29.45\end{array}$

Low responsibility $(n=53)$

$\begin{array}{lcccc}\text { Anxiety } & 35.68 & 26.53 & 30.09 & 25.23 \\ \text { Urge to check } & 50.34 & 33.51 & 38.77 & 34.49 \\ \text { Urge to seek reassurance } & 49.25 & 32.19 & 39.40 & 32.23 \\ \text { Confidence } & 69.32 & 28.33 & 77.17 & 24.64\end{array}$

\section{Anxiety}

The interaction between time and responsibility condition was not significant with respect to participants' anxiety ratings, $F(1,288)=.01$, n.s. Furthermore, simple effects tests revealed that participants' anxiety ratings did not differ significantly from time 1 to time 2 in either the high responsibility groups, $F(1,288)=2.11$, n.s., or the low responsibility groups, $F(1,288)=2.69$, n.s.

\section{Urges to check}

The interaction between time and responsibility condition was statistically significant for participants" "urge to check" ratings, $F(1,288)=4.27, p=.04$, (Cohen's $d=.24$ ). Participants in the low responsibility conditions demonstrated a decrease in urges to check from time 1 to time $2, F(1,288)=$ $11.52, p<.001$ (Cohen's $d=.40$ ), whereas participants in the high responsibility conditions did not demonstrate this decrease in urges to check, $F(1,288)=.12$, n.s.

\section{Urges to seek reassurance}

An examination of participants" "urge to seek reassurance" ratings revealed a marginally significant trend for the interaction between time and responsibility condition, $F(1,288)=3.40, p=.07$ (Cohen's $d=.22$ ). Under conditions of low responsibility, participants' urges to seek reassurance decreased from time 1 to time $2, F(1,288)=8.36, p<.01$ (Cohen's $d=.34$ ), while participants in the high responsibility conditions did not demonstrate this decrease, $F(1,288)=.03$, n.s.

\section{Confidence in outcome}


A trend was found for the interaction between time and responsibility condition when examining participants' ratings of confidence in outcome, $F(1,288)=3.22, p=.07$ (Cohen's $d=.21$ ). Participants in the low responsibility conditions demonstrated a significant increase in confidence from time 1 to time 2 , $F(1,288)=5.30, p=.02$, whereas participants in the high responsibility conditions did not demonstrate this increase in confidence, $F(1,288)=.06, n . s$.

It was important to assess whether these findings might have resulted from greater performance accuracy among participants in the low responsibility conditions. To determine whether participants in each responsibility condition differed in terms of their actual performance, an independent samples t-test was performed, in which the number of incorrectly performed trials served as the dependent variable. The responsibility groups did not differ with respect to the number of trials performed incorrectly, $t(98)=$ -.569 , n.s. $(M=1.96[S D=1.40] v s .2 .11[S D=1.34]$ for high $v s$. low responsibility groups, respectively).

\section{Memory accuracy}

A separate $2 \times 2 \times 2$ repeated measures ANOVA was performed to assess whether participants' memory accuracy differed by time of measurement or experimental condition. The effects of time, $F(1,96)=.75$, n.s., responsibility condition, $F(1,96)=.69$, n.s., and reassurance condition $F(1,96)=.06$, n.s., were not statistically significant. Similarly, the responsibility by reassurance condition interaction, $F(1,96)=1.16, n . s$., the time by responsibility condition interaction, $F(1,96)=.08, n . s$., and the time by reassurance condition interaction $F(1,96)=.16, n . s$., were not significant. In contrast, a significant 3-way interaction was found between time, responsibility condition and reassurance condition, $F(1,96)=4.18, p$ $=.04$ (Cohen's $d=.42$ ). However, simple effects tests revealed that participants' memory accuracy did not differ significantly as a function of time in the high responsibility conditions, $F(1,46)=.18$, n.s., the low responsibility conditions, $F(1,52)=.74$, n.s., the high reassurance conditions, $F(1,49)=.07$, n.s., or the low reassurance conditions, $F(1,49)=1.07$, n.s. Notwithstanding this result, pairwise comparisons revealed a trend towards increased memory accuracy in the LResp-LRsre group from time 1 to time 2, $F(1,96)=3.50, p=.06$, whereas none of the other experimental groups demonstrated a significant change in memory accuracy following the experimental manipulations.

\section{Trial completion time}

To assess whether the experimental manipulations of reassurance and responsibility affected the amount of time participants spent performing the final sorting trial, a two-way ANOVA was conducted. The amount of time spent sorting on the final trial did not differ significantly between responsibility conditions, $F(1,96)=.02$, n.s., or reassurance conditions, $F(1,96)=.02$, n.s. Also, the responsibility condition by reassurance condition interaction was not statistically significant, $F(1,96)=.19$, n.s.

\section{Discussion}

The results of the current study provided mixed support for our hypotheses. As predicted, manipulations of perceived responsibility/threat had a significant impact upon participants' urges to check, their urges to seek reassurance, and their confidence in outcome. Specifically, participants in the low responsibility conditions reported significant decreases in their urges to check and to seek reassurance, as well as an increase in confidence, following the responsibility manipulation that was employed in this study. In contrast, these effects were not apparent among participants assigned to the high responsibility conditions. Thus, higher levels of perceived responsibility/threat were associated with the maintenance of compulsive urges and performance-related doubt following the completion of a complex experimental task. Also, as predicted, neither manipulations of responsibility/threat, nor manipulations of reassurance affected memory accuracy. These findings are generally consistent with previous research in this domain (e.g., Ladouceur et al., 1995; Lopatka \& Rachman, 1995; Shafran, 
1997), and they provide additional support for leading cognitive-behavioural models of OCD which emphasize the importance of perceived responsibility and threat perception in maintaining obsessional thinking (e.g., Rachman, 1976, 2002; Rachman \& Hodgson, 1980; Salkovskis, 1985, 1999).

Notwithstanding these results, manipulations of perceived responsibility/threat did not affect participants' reported levels of anxiety, despite the fact that participants in the low responsibility group displayed a post-manipulation decrease in compulsive urges. Contrary to predictions set forth by anxietyreduction theories of compulsive behaviour (e.g., see Rachman, de Silva, \& Roper, 1976; Rachman \& Hodgson, 1980; Salkovskis, 1999), these results seem to suggest that reductions in compulsive urges might occur independently of reductions in anxiety. However, because participants were asked to indicate their general level of anxiety following the two experimental trials, rather than their specific (i.e., performance-related) anxiety, it is possible that some participants may have interpreted this question in a more global fashion, and rated their anxiety accordingly. Therefore, these findings must be interpreted with caution. Future investigations would benefit from the inclusion of several, perhaps differently focused, measures of anxiety, in addition to other potentially distressing emotions (e.g., worry, guilt, etc.).

In this study, decreases in perceived responsibility led to greater change in participants' ratings of compulsive urges and confidence than did increases in responsibility. Participants reported moderately high levels of doubt (i.e., low confidence) and compulsive urges prior to the experimental manipulation, which subsequently decreased in the low responsibility conditions only. Consistent with results reported by Lopatka \& Rachman (1995), and Ladouceur et al. (1995), increases in perceived responsibility did not lead to significant increases in compulsive urges or to a significant decrease in confidence. This suggests that it may be common for individuals to experience relatively high levels of performance-related doubt and compulsive urges when performing a complex and unfamiliar task. However, whereas non-clinical populations would be expected to demonstrate a decrease in compulsive urges and doubt as they gain familiarity with the task, individuals with an inflated sense of responsibility may be hindered from processing information that would decrease their (mis)appraisals of threat, thus maintaining high levels of performance-related doubt, and consequent urges to check. Further investigation is warranted to test this hypothesis.

Hypotheses regarding the effects of repeated reassurance on anxiety, compulsive urges, and confidence in outcome were not supported by the current investigation. However, a number of issues related to the experimental protocol may have compromised our ability to test a valid analogue of real-life reassurance-seeking behaviour, thereby limiting our results.

Firstly, efforts to standardize the provision of reassurance in the present experiment might have reduced the credibility of this feedback. All participants were given identical feedback following their first two sorting trials, regardless of their actual performance. Consequently, a number of participants received false reassurance during these initial trials (e.g., some were told they had sorted the pills correctly when they had in fact made a mistake and vice versa). While very few participants exhibited any signs of disbelief as a result of this potentially false information, our use of deception may have raised suspicion in a number of participants, thereby reducing the impact of subsequent reassurance. Moreover, as a result of standardization, reassurance provisions may have been perceived as somewhat artificial, stereotypic and excessive. Thus, the internal validity of our reassurance manipulation may have been compromised by the standardization of this procedure.

Second, the performance-related feedback provided to participants in our study might not have fully resembled the "type" of feedback typically received by individuals who persistently seek reassurance from others. The feedback given to participants in this study was detailed, precise, and unambiguous (e.g., 'Good. I've checked every pill in every bottle, and you've sorted them exactly correctly"). Conversely, individuals who repeatedly request reassurance from others are probably more 
likely to receive ambiguous and imprecise feedback (e.g., "Yes dear, I'm sure it's OK"), as a result of frustration over repeated requests. Such ambiguity is likely to increase uncertainty, thereby perpetuating one's urges to seek further reassurance. Therefore, future investigations of reassurance-seeking behaviour might attempt to incorporate ambiguity in experimental reassurance provisions to increase the ecological validity of this manipulation.

Finally, our efforts to develop an analogue to reassurance seeking in OCD may have been compromised by the fact that participants did not actively seek reassurance in the present study. Given that a number of previous studies (e.g., Coles, Radomsky, \& Horng, in press; Hout \& Kindt, 2003a, 2003b, 2004; Radomsky et al., in press) used forced task repetition as an analogue for reallife checking, it was theorized that providing unsolicited reassurance would act as a valid analogue for real-life responses to excessive reassurance seeking. However, repeatedly providing unsolicited reassurance may differ substantially from repeatedly granting active requests for reassurance. In fact, many of the cognitive-behavioural processes purported to exacerbate reassurance-seeking behaviour in OCD may remain relatively inactive until, or unless, the individual feels compelled to actively solicit reassurance. For example, it is presumed that obsessional beliefs are common among individuals who actively seek reassurance (e.g., "I have to do everything I can to prevent disaster, or something bad will surely happen"), and that repeatedly granting an individual's requests for reassurance prevents them from disconfirming these beliefs. However, such processes might not occur among individuals receiving unsolicited feedback, as they may have never endorsed such beliefs in the first place. Furthermore, individuals who actively solicit reassurance are hypothesized to experience short-term benefits (e.g., temporary reductions in anxiety and compulsive urges) as a result of this feedback, thereby activating a vicious cycle of compulsive behaviour that is maintained by negative reinforcement. In this manner, requests for reassurance which are followed by temporary decreases in anxiety/discomfort would be expected to lead to subsequent increases in reassurance-seeking behaviour. However, it is reasonable to suspect that this self-perpetuating mechanism might not become activated in individuals who do not solicit reassurance. Indeed, in the absence of clear evidence of urge-related distress, it is difficult to ascertain whether or not participants experienced any of the maladaptive cognitive processes that are hypothesized to contribute to increased checking and reassurance seeking behaviour.

There were a number of other limitations in this study. First, it was not entirely clear whether our responsibility manipulation affected participants' sense of responsibility for preventing harm, or their predictions of risk (i.e., threat). While our responsibility manipulation was designed to incorporate both components of Salkovskis et al.'s (1992) definition of responsibility (i.e., participants' "pivotal role" in preventing harm, and the "crucial" nature of the task), it is possible that participants' perceptions of threat were more influenced by our manipulation than their perceptions of personal influence over outcome. Also, the experimenter was present while participants completed the pill sorting task, which may have led participants to feel less responsible for potential negative outcomes due to responsibility sharing or displacement (Rachman, 1976; Shafran, 1997). Furthermore, because we collected participants' responsibility ratings only after the experimental manipulation was introduced, we could not assess whether post-manipulation group differences in responsibility occurred as a result of increases in perceived responsibility in the high responsibility condition, decreases in perceived responsibility in the low responsibility condition, or a combination of both (relative to baseline). Lastly, the failure to include a clinical group in this study might limit the generalizability of our results.

Future investigations aimed at examining the relationships between responsibility and checking behaviour might attempt to determine whether individuals with checking compulsions demonstrate an impaired ability to process information that is inconsistent with their responsibility perceptions. Also, future studies might attempt to manipulate perceived responsibility more explicitly (e.g., using a 'responsibility contract') within a high-threat paradigm, in order to tease apart the effects of threat and responsibility on individuals' cognitions and behaviour. 
Lastly, to increase our understanding of the mechanisms involved in excessive reassurance seeking, further efforts must be made to develop valid methods of examining this potentially distressing behaviour through empirical means. A preliminary step in this process might involve building on knowledge gained from the current investigation to design methods of enquiry in which methodological problems from the current study are addressed. This will likely include the development of an experimental protocol in which participants are able to actively solicit reassurance under different conditions of perceived responsibility/threat.

Once researchers establish reliable and effective methods of studying reassurance-seeking behaviour, they can begin to make significant progress in examining issues that are relevant to this behaviour. For example, future investigations might evaluate the apparent inability/unwillingness of some individuals diagnosed with OCD to inhibit their compulsive urges to seek reassurance, as well as to determine whether a link exists between certain belief domains (e.g., intolerance of uncertainty, worry) and excessive reassurance seeking. It is expected that such investigations will provide a great deal of insight for researchers and clinicians who are interested in being better able to understand (and treat) this potentially distressing and complex compulsive behaviour.

\section{References}

American Psychiatric Association (2000). Diagnostic and statistical manual of mental disorders ( $4^{\text {th }}$ ed: Text Revision). Washington, DC: American Psychiatric Press.

Beck, A.T., \& Steer, R.A. (1990). Beck anxiety inventory manual. Toronto: Psychological Corporation.

Beck, A.T., Steer, R.A., \& Brown, G.K. (1996). Manual for the Beck Depression Inventory-II. San Antonio, TX: Psychological Corp.

Coles, M.E., Radomsky, A.S., \& Horng, B. (in press). Exploring the boundaries of memory distrust from repeated checking: Increasing external validity and examining thresholds. Behaviour Research and Therapy.

Hadjistavropoulos, H.D., Craig, K.D., \& Hadjistavropoulos, T. (1998). Cognitive and behavioural responses to illness information: The role of health anxiety. Behaviour Research and Therapy, $36,149-164$.

Hallam, R.S. (1974). Extinction of ruminations: a case study. Behavior Therapy, 5, 565-568.

Hout, M. van den \& Kindt, M. (2003a). Repeated checking causes memory distrust. Behaviour Research and Therapy, 41, 301-316.

Hout, M. van den, \& Kindt, M. (2003b). Phenomenological validity of an OCD-memory model and the remember/know distinction. Behaviour Research and Therapy, 41(3), 369-378.

Hout, M. van den, \& Kindt, M. (2004). Obsessive-compulsive disorder and the paradoxical effects of perseverative behaviour on experienced uncertainty. Journal of Behaviour Therapy and Experimental Psychiatry, 35, 165-181.

Howell, D.C. (1987). Statistical methods for psychology ( $2^{\text {nd }}$ ed.). Boston: PWS-KENT.

Joiner, T.E., Alfano, M.S., \& Metalsky, G.I. (1992). When depression breeds contempt: Reassurance seeking, self-esteem, and rejection of depressed colle ge students by their roommates. Journal of Abnormal Psychology, 101(1), 165-173. 
Joiner, T.E., \& Schmidt, N.B. (1998). Excessive reassurance-seeking predicts depressive but not anxious reactions to acute stress. Journal of Abnormal Psychology, 107(3), 533-537.

Ladouceur, R., Rheaume, J., Freeston, M.H., Aublet, F., Jean, K., Lachance, S., Langlois, F., \& de Pokomandy-Morin, K. (1995). Experimental manipulations of responsibility: an analogue test for models of obsessive-compulsive disorder. Behaviour Research and Therapy, 33(8), 937-946.

Lopatka, C., \& Rachman, S. (1995). Perceived responsibility and compulsive checking: an experimental analysis. Behaviour Research and Therapy, 33(6), 673-684.

Obsessive Compulsive Cognitions Working Group (OCCWG) (2005). Psychometric validation of the Obsessive Belief Questionnaire and Interpretation of Intrusions Inventory: Part 2, Factor analyses and testing of a brief version. Behaviour Research and Therapy, 43(11), 1527-1542.

Parrish, C.L., Ouimet, A.J., Ashbaugh, A.R., Radomsky, A.S., \& O’Connor, K.P. (2004, September). Psychometric properties of the Vancouver Obsessional-Compulsive Inventory and the Symmetry, Ordering, and Arranging Questionnaire: French translations. Posterpresented at the European \& British Associations of Behavioural and Cognitive Psychotherapies Joint Conference, Manchester, UK.

Rachman, S. (1976). Obsessional-compulsive checking. Behaviour Research and Therapy, 14, 269-277.

Rachman, S. (1993). Obsessions, responsibility, and guilt. Behaviour Research and Therapy, 31(2), 149154.

Rachman, S. (2002). A cognitive theory of compulsive checking. Behaviour Research and Therapy, 40, 625-639.

Rachman, S., \& De Silva, P. (1978). Abnormal and normal obsessions. Behaviour Research and Therapy, 16, 233-248.

Rachman, S., De Silva, P., \& Roper, G. (1976). The spontaneous decay of compulsive urges. Behaviour Research and Therapy, 14, 445-453.

Rachman, S., \& Hodgson, R. (1980). Obsessions and compulsions. Englewood Cliffs, NJ: Prentice Hall.

Radomsky, A.S., Gilchrist, P.T., \& Dussault, D.D. (in press). Repeated checking really does cause memory distrust. Behaviour Research and Therapy.

Rhéaume, J., Ladouceur, R., Freeston, M.H., \& Letarte, H. (1995). Inflated responsibility in obsessivecompulsive disorder: Validation of an operational definition. Behaviour Research and Therapy, 33(2), 159-169.

Salkovskis, P.M. (1985). Obsessional-compulsive problems: A cognitive-behavioural analysis. Behaviour Research and Therapy, 23(5), 571-583.

Salkovskis, P.M. (1999). Understanding and treating obsessive-compulsive disorder. Behaviour Research and Therapy, 37, S29-S52.

Salkovskis, P.M., \& Harrison, J. (1984). Abnormal and normal obsessions - A replication. Behaviour Research and Therapy, 22(5), 549-552. 
Salkovskis, P.M., Rachman, S., Ladouceur, R., \& Freeston, M. (1992). The definition of 'responsibility'. Paper presented at the World Congress of Behavioural and Cognitive Psychotherapies, Toronto, Canada.

Salkovskis, P.M., \& Warwick, H.M.C. (1986). Morbid preoccupations, health anxiety and reassurance: a cognitive-behavioural approach to hypochondriasis. Behaviour Research and Therapy, 24(5), 597-602.

Salkovskis, P.M., Wroe, A.L., Gledhill, A., Morrison, N., Forrester, E., Richards, C., et al. (2000). Responsibility attitudes and interpretations are characteristic of obsessive compulsive disorder. Behaviour Research and Therapy, 38, 347-372.

Shafran, R. (1997). The manipulation of responsibility in obsessive-compulsive disorder. British Journal of Clinical Psychology, 36(3), 397-407.

Thordarson, D., Radomsky, A.S., Rachman, S., Shafran, R., Sawchuk, C.N., \& Hakstian, H.R. (2004). The Vancouver Obsessional Compulsive Inventory (VOCI). Behaviour Research and Therapy, 42(11), 1289-1314.

Tolin, D.F. (2001). Bibliotherapy and extinction treatment of obsessive-compulsive disorder in a 5-yearold boy. Journal of the American Academy of Child and Adolescent Psychiatry, 40(9), 11111114.

Tolin, D.F., Abramowitz, J.S., Brigidi, B.D., Amir, N., Street, G.P., \& Foa, E.B. (2001). Memory and memory confidence in obsessive-compulsive disorder. Behaviour Research and Therapy, 39, 913-927.

Author Contact Information:

Adam S. Radomsky

Department of Psychology,

Concordia University

7141 Sherbrooke St.

West, Montréal, QC, H4B 1R6, CANADA

Email: adam.radomsky@ concordia.ca

Appendix

Please circle the best answer for each of the following. Do not spend too much time on any one item; if unsure of an answer, simply put your best guess.

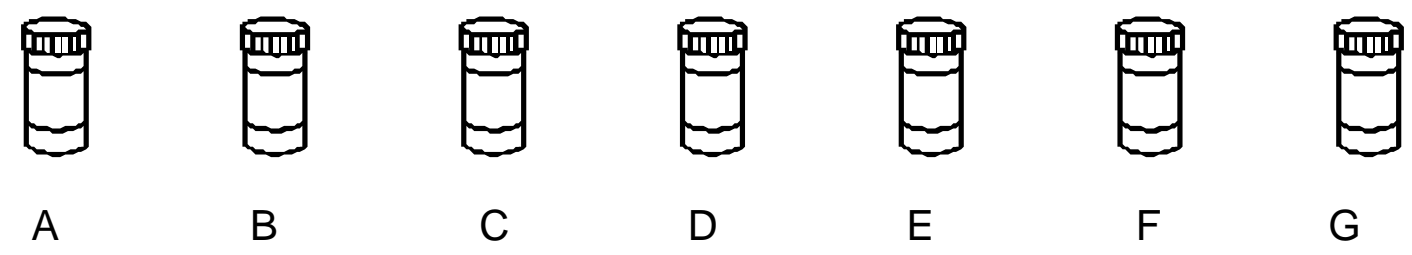

1. In which bottles did pill \# 1 go?: $\quad$ a) A, D, and E

b) B, and $G$ 
c) A, B, and D

2. In which bottles did pill \# 2 go?:
a) C, F, and G
b) $\mathrm{C}, \mathrm{D}$, and $\mathrm{F}$
c) B, F, and G

3. In which bottles did pill \# 3 go?:
a) A, D, E, and G
b) A, E, and G
c) B, C, D, and E

4. In which bottles did pill \# 4 go?:
a) A, D, and F
b) A, C, and G
c) B, C, and F

5. In which bottles did pill \# 5 go?:
a) A, and $\mathrm{E}$
b) B, and F
d) B, and E

** please continue with questions on next page

Please circle the best answer for each of the following. Do not spend too much time on any one item; if unsure of an answer, simply put your best guess.

$\mathrm{A}_{\mathrm{B}} \quad \mathrm{C} \quad \mathrm{D}_{\mathrm{E}}$

6. In which bottles did pill \# 6 go?:
a) A, B, and G
b) B, D, and F
c) B, F, and G

7. In which bottles did pill \# 7 go?:
a) D, E, and G
b) B, D, and E
c) B, D, and G 

8. In which bottles did pill \# 8 go?:
a) B, E, and G
b) $\mathrm{C}$, and $\mathrm{E}$
c) $\mathrm{B}$ and $\mathrm{F}$

9. In which bottles did pill \# 9 go?:
a) B, C, and E
b) A, D, and G
c) B, D, and F

10. In which bottles did pill \# 10 go?:
a) $\mathrm{C}$, and $\mathrm{F}$
b) $\mathrm{E}$, and $\mathrm{F}$
c) $\mathrm{C}, \mathrm{E}$, and $\mathrm{F}$

Author notes

This research was supported in part by a Natural Sciences and Engineering Research Council of Canada (NSERC) PGS-A Award held by the first author and by an NSERC Operating Grant and a CIHR New Investigator Award held by the second author.

Portions of this data were presented at the 2004 European Association for Behavioural and Cognitive Therapies conference in Manchester, England, and at the 2004 Anxiety Disorders Special Interest Group Exposition at the Association for the Advancement of Behavior Therapy conference in New Orleans.

The authors are grateful to Monique Lahoud and Christine Senn for their help with data collection and entry. We are also grateful to Drs. Bill Bukowski and Michel Dugas for their contributions to the design of this study, as well as to Naomi Koerner for her helpful suggestions on earlier drafts of this manuscript.

\section{Author contact information:}

Chris L. Parrish /Adam S. Radomsky

Department of Psychology

Concordia University

7141 Sherbrooke St.

West, Montréal, QC, H4B 1R6, CANADA

Email: adam.radomsky@concordia.ca 


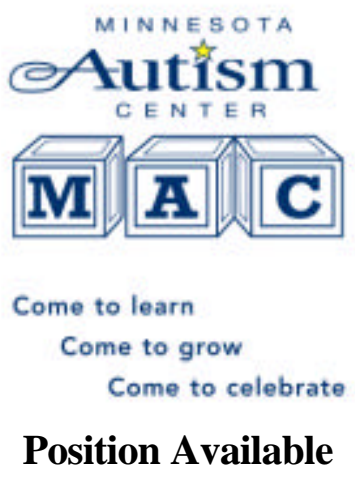

\section{LICENSED PSYCHOLOGIST EXPERIENCED IN AUTISM}

The Minnesota Autism Center is seeking a full time Psychologist, Ph.D. or Psy.D licensed or license eligible in the state of Minnesota.

Minnesota Autism Center (MAC) is a Minneapolis based non profit organization serving children and youth with Autism Spectrum Disorders. (ASD) The successful candidate will have training and an understanding of Applied Behavior Analysis (ABA), knowledge of primary treatments such as team provided home based behavior therapy, incidental teaching, functional language and discrete trial intervention. Experience conducting and supervising functional assessments and designing and supervising behavioral interventions to promote communication and social skills as well as reducing behavioral challenges is ideal. Experience with standardized psychological assessment of children with ASD is preferred.

Our current team of Psychologist supervises Clinicians who deliver services with a team of highly qualified and trained Mental Health Practioners who oversee day to day services to the children and their family members. Our services include Assessment and Brief Intervention, Intensive Early Intervention, School Age Programs, Family support and Speech and Communication.

Our compensation and benefit package is competitive with a starting salary of $\$ 70,000$.

If you are interested in this great opportunity please contact:

Minnesota Autism Center

Attention: Director of Human Resources

3001 Broadway NE Suite 185

Minneapolis, MN 55413

Email interest to: penny.swanson@mnautism.org

Call 612-767-4209 with questions / interest

or fax resume to 612-767-4211 


\title{
Behavior Analysis of Forgiveness in Couples Therapy
}

\author{
James Cordova, Ph.D., Joseph Cautilli, Ph.D., Corrina Simon and Robin Axelrod Sabag
}

\begin{abstract}
Behavioral couples' therapy has a long history of success with couples and is an empirically validated treatment for marital discord (Task Force on Promotion and Dissemination of Psychological Procedures, 1995). However, only about 50\% of all couples in treatment experience long-term change ( 2 years). One of the founders of behavioral couples' therapy called for the therapy to return to its original roots in functional analysis (Jacobson, 1997). This produced integrative behavioral couples' therapy. As behavioral couples' therapy attempts to reach the maximum number of couples possible, we believe further attention to behavior analytic principles will continue to contribute to advances in the field. We propose that an operational analysis of forgiveness will help to strengthen behavioral couples' therapy by creating a direct module to handle some of the most entrenched situations, those commonly referred to as betrayal. Key words: Couples therapy, forgiveness, betrayal, intimacy, behavior training, self control training.
\end{abstract}

\section{Introduction}

"Never does the human soul appear so strong as when it foregoes revenge and dares to forgive an injury". -Confucius

Traditional Behavioral Couples therapy (TBCT; Jacobson \& Margolin, 1979) is the oldest and most researched approach to couples therapy. It was developed more than 20 years ago, and is still widely used. In TBCT partners learn to be nicer to each other, communicate better and improve their conflict-resolution skills. TBCT is listed as a well-established treatment for marital discord (Task Force on Promotion and Dissemination of Psychological Procedures, 1995). Meta-analytic results show that TBCT is a well-established treatment for marital discord; however, only about $50 \%$ of the couples experience long-term change (Christensen, Jacobson, \& Babcock, 1995; Jacobson \& Christensen, 1996; Shadish, \& Baldwin, 2005).

Integrative behavioral couples therapy was formulated in an attempt to improve traditional behavioral couples therapy. Christensen and colleagues (1995) viewed IBCT as couples therapy's return to its radical behavioral roots and away from more cognitive interpretations of stress. This movement, as Jacobson (1997) described it, was a move away from task analysis of skills that couples needed to perform to a more intensive focus on the functions of behaviors in the relational context. TBCT focused on training couple through the implementation of rule-governed behavior with little focus on the controlling variables in the relationship. More specifically, Jacobson (1997) urged a greater reliance on functional analysis and on techniques to disrupt faulty rule control. Faulty rule control was seen as rules that inadequately tact behavior and environment relationships. This may allow IJBCT some unique strengths in dealing with couples problems such as betrayal.

Taking Skinner's (1969) focus on rule-governed behavior, Jacobson and Christenson (1996) developed several techniques to disrupt faulty rule control. These included empathic joining and unified detachment (turning the problem into an "it"). In addition, they created a greater focus on lessening the negativity of disruptive stimuli with an exposure technique similar 
to desensitization called tolerance building. Finally, they focused on creating a self-care focus to help people better tolerate negative behavior on the partner's behalf.

IBCT has been shown to increase the effectiveness of Behavioral Couples Therapy. Jacobson, Christensen, Prince, Cordova, and Eldrige (2000) found that approximately $80 \%$ of couples responded to normal functioning in the IBCT group. On follow up, $67 \%$ of couples significantly improved their relationships for two years (Christensen, Atkins, Berns, Wheeler, Baucom, \& Simpson, 2004). While $67 \%$ of couples in therapy experiencing clinically significant reliable change are a powerful effect, IBCT continues to refine its tenets and its treatment formulations. It is hoped that as this process continues, IBCT will be able to reach more and more of the remaining distressed couples. Recent research studies have placed IBCT as a likely efficacious treatment for couples' distress (Chapman \& Compton, 2003).

In this vein, IBCT has recently attempted to observe its effectiveness with couples in which an extramarital affair is present (Atkins, Baucom, Eldridge, Christensen, 2005; Gordon, Baucom, \& Snyder, 2000, 2004) and in recovery from an affair (Gordon, Baucom, \& Snyder, $2000,2004)$. We believe that an operant analysis will lead to an assessment process of when such a technology might be useful in a couple's relationship.

\section{Why is forgiveness important?}

This is so, principally because people tend to cause each other hurt, and paradoxically, the more emotionally close people are to each other the more vulnerable they are to being hurt. In addition to diminishing the probability that we will cause each other and ourselves harm, the goal of behavioral clinicians is to minimize the harm caused by how people react to the common hurts of day-to-day life. In this context, forgiveness plays a vitally important role, particularly in the background of intimate relationships, a context in which some exposure to hurt is inevitable.

Forgiveness is fast becoming a central topic of concern for clinical scientists. A great deal of both basic and applied research has been conducted in the past decade. Forgiveness interventions have been developed and implemented for populations from self-forgiveness (Enright, \& The Human Development Study Group, 1996) to undergraduates struggling to forgive emotionally distant parents, through couples recovering from the betrayal of a sexual affair or men when a partner has an abortion (Coyle \& Enright, 1997), to survivors of ethnic cleansing struggling for truth and reconciliation with their former neighborsShriver, 1995; Weine, 2000).

Healthy couples who have survived years of marriage rate forgiveness as one of the top ten factors of a long-term first marriage (Fenell, 1993). Literature supporting the use of techniques to foster forgiveness will be reviewed and integrated into the new IJBCT model that we are proposing. More importantly than the term being important to clinicians, interventions fostering forgiveness appears to have a strong psychological impact on an individual's emotional adjustment (Baskin \& Enright, 2004). While the standard treatment effect size across traditional psychotherapies is approximately .82 (Bergin, 1994), the meta-analytic results show forgiveness interventions have an effect size of 1.42 (Baskin \& Enright, 2004). Thus, as an intervention, forgiveness seems to be more effective than traditional psychotherapy. In addition, Bergin and Enright's (2004) meta-analysis demonstrates that the cognitive decision making model of forgiveness places its effect size no greater then that of the control groups. This seems to indicate that deciding to forgive (a cognitive approach) is not, alone, effective in producing a clinical effect. All these factors seem to set the stage for an operant analysis of forgiveness. Within that broad array of contexts, this paper is centrally concerned with forgiveness in intimate 
relationships, but we hope that our attempt to conceptualize the forgiveness process from a behavior analytic framework will be useful across all contexts of forgiveness.

Our goal in this paper is to explore the utility of applying a behavior analytic framework to the phenomenon of forgiveness. The potential benefits of applying such a framework are twofold. First, applied behavior analytic conceptualizations strive to take maximum advantage of empirically demonstrated principles of behavior as explanatory processes. Second, as a philosophy ${ }^{1}$ behavior analysis remains uniquely rigorous in terms of adherence to a thoroughgoing explanatory system that is decidedly different from how we, in the culture, commonly think about the causes of human behavior. As such, it offers the potential to open up new perspectives on commonly discussed psychological phenomenon that might not otherwise be readily revealed.

\section{Operational Analysis of Psychological Terms}

A behavioral version of deconstruction of words- the functional analysis of verbal behavior began in 1945 with the publication of the Harvard Symposium on Operationalism in Psychological Review. B.F. Skinner's paper "The Operational Analysis of Psychological Terms" argued that by observing the contingencies and setting conditions under which a verbal community typically used the ordinary language terms, the listener could interpret the terms in a descriptive, functional assessment. This approach is critical to the scientific investigation of events that, on the surface, do not appear to be readily available to a behavioral interpretation or applied research (Leigland, 1996). Leigland (1996) lamented that behaviorally oriented clinicians did little research on terms that have been important to non-behavioral clinicians. This is largely do to the small behavioral community choosing to use resources in some areas and not in others. However, many of these areas such as forgiveness are critical to clinicians.

On the other hand, non-behavioral clinicians have been stymied with presenting a rationale for the use of forgiveness interventions and have lacked a model for why such interventions would be effective. Third generation behavior therapy has attempted to reconcile this problem by becoming a source to integrate psychotherapies (Hayes, 2004, Kohlenberg, Boiling, Kanter \& Parker, 2002). By applying a functional analysis of terms and placing emphasis on the function of such terms in the client's life, third generation behavior therapy is a progressive force in integrating diverse therapeutic approaches. One term, that appears to have importance to traditional clinicians, is that of forgiveness. Several accounts of forgiveness exist. These vary from cognitive-behavioral (Gordon, Baucom, \& Snyder, 2000, 2004) and motivational accounts (McCullough et al., 1997) to diverse clinical orientations such as spiritual self-help groups (Alcoholic Anonymous, 1976) to solution-orie nted therapists (PotterEffron \& Potter-Effron, 1991) to forgiveness based therapies such as Ferch (1998) and Fitzgibbons (1986).

When we speak of forgiveness, it is important to recognize that we do so as an intrapersonal process as well as an interpersonal process. It occurs at the molecular level in the sense of feeling behavior, individual acts, and rules. It also occurs at the molar level as well as an extended process over time. We can see that forgiveness is operant behavior and that operant behavior is choice. When we speak of "forgiveness," it is important to realize that we are speaking of several levels of operants under the same category:

\footnotetext{
${ }^{1}$ A behavior analytic philosophy tries to link cause with environmental events. In behavior, whole person and environment interactions represent analysis cause. Thus, behavior analyst seeks to create a technology of environmental manipulation to explain, predict and control events.
} 


\section{Molecular Views:}

1. The $t a c t^{2}$ "I forgive"- the focus here is a mixture of the feelings of acceptance of hurt, empathy and care for self and another person. Skinner $(1945,1974)$ discussed feelings as private events. In his argument, what is felt is the body. Applied to forgiveness, we can speak of feeling "forgiving." That is, we have reached a point in a given moment, where our bodies are less in touch with the pain of the betrayal and more in touch with the acceptance of the person and the action. In traditional terms this could be considered the affective response of forgiveness but probably has broader history implications.

2. The second is the tact of the rule as defined "Because I forgive, I give up my right to retaliate." Skinner (1957) defined forgiveness in the following way, "...Forgiveness is the reduction of conditioned aversive stimulus or threat after a response has been made." (pp. 168-169). Thus, one facet of forgiveness appears to involve rule-governed behavior characterized as a decision to forgive, or letting go of one's right to hurt another in return for being hurt. Forgiveness appears to require following a set of rules that indicate the personal and interpersonal benefits of "letting it go" and the letting go of the rule ${ }^{3}$ "I resent person $\mathrm{X}$ for $\mathrm{Y}$ and must retaliate against or withdraw from him or her." It is based on the dismissal of the rule to seek retaliation for harm suffered. To the listener, forgiveness serves as discriminative stimuli that the speaker will no longer seek retribution. In addition, it may signal to the listener that some of the previous rewarding contingencies of the relationship may return. This path to forgiveness seems to suggest in some ways the need to let go of the experiential avoidance that we experience in feeling the pain of betrayal.

\section{Molar View:}

3. The third is the molar ongoing act in context of forgiving. In this view, forgiveness is a pattern of action extended over time. In a molar analysis, forgiveness would represent nothing more than a summary statement for what actually occurs. When we view the problem of forgiveness from this scale, we see that the ongoing act of forgiveness is not an act of forgiveness. If we were to create a summary statement, the ongoing act is intimacy with forgiveness serving as a momentary course adjustment after an act of betrayal to return to intimacyAt this level of analysis, our view of forgiveness is similar but not the same as the integrated behavioral exchange/interdependency theory model of forgiveness (Rusbult, Hannon, Stocker, \& Finkel, 2005).

\footnotetext{
2 Tact is a term that emerged from Skinner's (1957) analysis of verbal behavior to describe an episode of stimulus control as it enters into the verbal domain.

${ }^{3}$ For our analysis, rules are antecedent stimuli those tact functional relations in the environment. Rules maybe acquired as either tacts or intraverbals and can lead to failure to contact environmental contingencies. Rules can change the function of other environmental stimuli. Often a person can generate his or her own rules about situations (see Kohlenberg \& Tsai, 1991).

${ }^{4}$ This may be akin to Gottman's concept of Q-Space. At the same time, while there is a "Q-space" quality to forgiveness in that there is a point at which the experience flips from "I haven't forgiven you yet" to "I have forgiven you," following the "stages of change" model, there is certainly a period of time where individuals are actively working in the direction of forgiveness. So, like Gottman's P-space Q-space model, people labor bit-by-bit toward accumulating the experiences that allow for the dichotomous tipping point from non-forgiveness to forgiveness.
} 


\section{Context of forgiveness: Betrayal}

"When something bad happens all you want to do is get your old life back. So you build a wall around your old life. But it is not your old life at all but your new life with a wall around it."

- From Stephen Speilberg's "Taken"

Forgiveness is particularly important in the treatment of couples where betrayal has occurred $^{5}$ Betrayal in intimate relationships is often a difficult problem for partners to overcome. Often these couples will seek out therapeutic intervention. Recent advances in the behavioral assessment of intimacy have led to innovative techniques and interventions. However, it is difficult for clinicians to assist in the process of restoring healthy relationships after a betrayal.

When betrayal occurs, it serves as an establishing operation or setting event for a large number of behaviors possibly occurring. One possible behavior is forgiveness. Forgiveness can be seen as a person emitting a statement that he or she will not retaliate against a partner. Forgiveness has two components: 1) a reduction or avoidance of engaging in future hostile action to the partner and 2) an increase in acceptance of the partner and a sense of "benevolence" or increased sense of intimacy with the partner. In addition, forgiveness was shown to be a factor in conflict resolution. Fincham, Beach, and Davila (2004) found that when couples forgave each other, they were less likely to use hostile statements about the incident in future conflict bouts. Thus, couples able to forgive showed fewer automatic and negative responses in future conflicts.

Forgiveness is clearly operant behavior. As operant behavior, forgiveness is choice behavior. Choice is selected by the distribution of operant behavior among alternative sources of reinforcement (Hernstein, 1961, 1970). As with most choice behavior, momentary attempts to maximize reinforcement often fail to lead to overall maximization. It seems that from the matching analysis, forgiveness and its opposite unforgiveness represent two separate choices. Applied to forgiveness and unforgiveness, the matching law suggests the relative frequency of unforgiveness behavior compared to forgiveness behavior is proportional to the relative value provided for forgiving compared to unforgiving (McDowell, 1982). For example, holding the partner as "unforgiven" may be a good way to gain power over the partner in other arguments. Plainly speaking, persistent unforgiveness may occur because (a) reinforcement available for forgiving is low or nonexistent (the case of the estranged couple) and/or (b) unforgiveness produces relatively high rates of positive and/or negative reinforcement and/or (c) punishment for forgiveness is high. Since reinforcement can occur at an unaware level (Cautilli, Tillman, Axelrod, \& Hineline, 2005a), the matching law would hold that the reinforcement value that shapes forgiveness or unforgiveness may be processes that the client is not directly aware of experiencing.

Setting events are events that set the stage for the occurrence of behavior (Walher, 2002). Intimacy is a setting event for forgiveness in the sense that when partners have a close and intimate relationship, they are more likely to forgive. Partners in close and intimate relationships are also likely to report a higher sense of commitment to the relationship. Commitment is a form of rule-governed behavior that also serves as a factor to predict forgiveness (Bui, Peplau, \& Hill,

${ }^{5}$ For example, when one person in the couple is having an affair or negligence on the part of one of the members of a couple leading to the death of a child. Betrayal can be a small matter such as one partner continually taking the side of a child or another person, such as an in-law, in the relationship against the other person in the relationship. 
1996; Finkel, Rusbult, Kumashiro, \& Hannon, 2002). Commitment is also choice behavior and is affected by alternatives that a person has in the environment. People who have fewer choices are more likely to commit and forgive. Bui and colleagues (1996) observed couples for 15 years. They found support for the Rusbult's (1990) social exchange model of commitment and stability, especially to the extent that the theory successfully predicted long-term relationship stability in couples. The path analysis that they developed from the data showed a good fit to the model. In addition, they found that the model was equally applicable for both men and women. Finally, Bui and colleagues study found evidence for more complex patterns than identified by Rusbult, such as an association between the quality of one person's alternatives and the partner's commitment.

Hurt and forgiveness are additive processes. Over time, partners become both discriminative stimuli for reinforcement and generalized reinforcers themselves through conditioning histories. Becoming a generalized conditioned reinforcer occurs when the intimacy behaviors of one are strengthened by events that have an effect through a history of reinforcement. Intimacy based behaviors represent a very large response class. In this, intimacy based behaviors include hundreds of discrete behaviors from gently caressing the partners' face to a shared smile to the buying of flowers and attending movies together. Betrayal is a conditioned punisher. As such, it suppresses the entire response class of intimate behaviors. In addition, punishment has side effects and through even one trial respondent conditioning, a formerly salient discriminative stimulus can now serve as a setting event for the pain of the betrayal. This contaminant effect can be very powerful. Often it can be witnessed or experienced by the couple as a couple engaging in a formerly enjoyable activity where one partner becomes triggered and deeply upset over the past betrayal.

It is important to note that some punishment occurs in even the healthiest relationships. Gottman (1994) discussed a five to one ratio of reinforcement to punishment as being a predictor of a stable marriage. So sometimes, the partner is a discriminative stimulus for reinforcement, but at other times - even under the most favorable conditions- is a partial punisher. Gottman (1994) argues that this ratio is the key for stable couples, even if couples are conflict avoidant or conflict seeking. Cordova (2003) argued that couples either reinforce patterns of intimacy with each other or they do not. Couples who shape intimacy are more likely to forgive (Rusbult, Hannon, Stocker, $\&$ Finkel, 2005). Intimacy sets the stage for forgiveness and, as a setting event, makes it more likely that forgiveness will occur. Rusbult's work is based on interdependence theory but has remarkable behavioral characteristics.

\section{A Behavior Analytic Conceptualization of the Forgiveness Process in Intimate Relationships}

Intimacy itself develops as one partner reinforces the interpersonally vulnerable behavior of the other. In other words, intimacy develops out of those moments when we make ourselves vulnerable with a partner and that partner responds in ways that honor that vulnerability. The exact behaviors that make each of us interpersonally vulnerable, however, vary from individual to individual depending on our different learning histories. Although what makes us each vulnerable varies, the predictable outcomes of the intimacy process are universal. First, intimate events in which vulnerability is reinforced create momentum. Reinforcing vulnerable expressions increases the probability of future expressions of vulnerability toward that partner. Second, the experience of feeling safe being vulnerable with our intimate partners is a predictable outcome when expressions of vulnerability are predic tably more often reinforcing than punishing. In other words, if our partner usually responds well when we make ourselves vulnerable, then we learn over time that we are safe being vulnerable with that partner. Third, given the degree and depth of vulnerability exposed in intimate relationships, it is inevitable that our intimate partners will hurt 
us from time to time, intentionally or not. It is on these inevitable occasions that forgiveness and unforgiveness become of paramount importance.

The forgiveness process can be conceptualized as an ongoing act in context composed of the following events with their attendant qualities. The first quality to attend to in following the arch of a forgiveness event is the initial stimulus value of the partner and how that stimulus value changes as a result of the aversive experiences. In other words, we are concerned with the quality of the intimate relationship between the two individuals before the hurtful event. The stimulus value of the partner can range from very appetitive to very aversive, depending on whether vulnerable behavior in the relationship has been mostly reinforced or too frequently punished. These values are often particularly strong, specifically because they are inevitably a product of a combination of both appetitive and aversive responses to interpersonal vulnerability (Weissman, 1998).

Second, beginning with this preexisting relationship ${ }^{6}$, some event occurs that adds aversive stimulus qualities to the value of the target person such that that aversive stimulus value saliently competes with the pre-existing appetitive stimulus value. This addition is experienced in a variety of ways, most commonly labeled, or tacted, as hurt. The operative question at this stage is: What additive event caused a shift toward aversion? The main point is that not all aversive events in an intimate relationship require that we engage in a process of forgiveness, because not all aversive events result in a shift in the overall stimulus value of the partner from appetitive to aversive.

Thus, third, the stimulus value of the addition can itself vary from extremely aversive (e.g., an affair) to only aversive enough to begin to saliently compete with the appetitive stimulus value of the target. People are rarely moved to say, for example, "I forgive you for forgetting to turn on the dishwasher last night." Minor annoyances and hurts are absorbed into the ongoing stream of interactions between intimate partners with little or no loss of intimate momentum. The type of event that we are concerned with here is one that shifts the entire stimulus value of the intimate partner from appetitive and safe to aversive and unsafe. We are talking about the kind of dichotomous, catastrophic changes that Gottman (1994) describes as changes in Q-space; those changes that represent that dichotomous shift in perception from safe to unsafe, as opposed to a gradual shift in perception. Gradual shifts in perception of intimate safety do not as readily lend themselves to the language of forgiveness, whereas dichotomous shifts epitomize the event setting the stage for forgiveness or unforgiveness. When our partner says something deeply hurtful, then we are moved to pursue forgiveness as a means of getting intimacy back on track. If forgiveness is not achieved, then intimacy is substantially derailed.

An additional issue is that there will be individual variability at this stage with regard to vulnerability to experiencing hurt (see Cordova \& Scott, 2001 for a discussion of vulnerability). The operative question at this second stage is how aversive was the addition? The forgiveness literature discusses the intrapersonal facet of hurt as rejection sensitivity. From our perspective, how easily a specific event hurts a person is a product of his or her learning history with regard to that event in an interpersonal context and will vary from individual to individual. For example, for some partners, name-calling is experienced as a normal expression of anger. For other partners, name-calling is experienced as a serious and hurtful breach of trust.

\footnotetext{
${ }^{6}$ We can refer to this as the context or setting event. Often the vernacular refers to this as a "trusting" or "intimate" relationship.
} 
Also, included at this point is the repertoire shift that accompanies the shift from appetitive to aversive. Partners become both discriminative stimuli for reinforcement and generalized reinforcers themselves through conditioning histories. Intimacy based vulnerable behaviors represent a very large response class. In this, intimacy based vulnerable behaviors include hundreds of discrete behaviors from gently caressing the partners face to a shared smile to the buying of flowers and attending movies together. Betrayal serves as a conditioned punisher. As such it suppresses the entire response class of intimacy behaviors. In addition, punishment has side effects and through one trial respondent conditioning a formerly salient discriminative stimuli can now serve as a conditioned stimulus for and setting event for the pain of the betrayal. This contaminant effect can be very powerful and can be witnessed as a couple engaging in a formerly enjoyable activity and one partner becoming upset over the past betrayal.

Fourth, the individual reacts to the increased aversiveness. This step has to do with how the individual enacts aversion or how the individual enacts hurt (Cordova, et al. 2005). How individuals react to hurt inevitably determines whether intimacy will continue unabated or will be undermined and undone. There will be variability at this stage as different people enact hurt differently. The most common behavior elicited will be intense emotional reactions. In addition, for low level "hurt," some form of fight or flight behavior is either overtly or covertly acted out. The most commonly emitted behavior for overwhelming "hurt" is escape or avoidance, either covert or overt. This is the experience of unforgiveness and, whether overt or covert, it is operant behavior. The operative question here is, "how does the person 'do' hurt?" It can include retaliation, withdrawal, problem solving, expressions of hurt, or other repertoires for enacting hurt.

The existing forgiveness literature makes an explicit distinction between forgiveness and unforgiveness, stating that forgiveness is not simply the opposite of unforgiveness. If seen as large functional response classes, some of the behaviors in these classes have opposite overlap but others do not. In fact, Wade and Worthington (2003), provide compelling data showing that although "comple te forgiveness" is associated with little variability in the experience of unforgiveness (following complete forgiveness, virtually no one remains motivated to retaliate or withdraw), "no forgiveness" is associated with a great deal of variability in unforgiveness (some people will seek retaliation or withdrawal whereas others will not). In other words, you might be a long way from forgiving someone without necessarily being motivated to retaliate against or withdraw from him or her. This fits very well with what we are saying here about variability in terms of how people enact hurt. Although many people have learned to enact hurt through retaliation seeking and withdrawal, many other people have learned to enact hurt in quite different ways, including actively seeking reconciliation.

There is a distinction between the respondent experience of hurt (the emotion) and the operant enactment of unforgiveness (as well as the operant enactment of forgiveness). From our perspective, there is some utility to limiting the definition of unforgiveness to operant behavior, because the respondent experience of hurt when re-exposed to the hurtful event (e.g., memories of the affair) may never completely remit, even when all other conditions for forgiveness have been met $^{7}$. In this sense, our view is similar to the cognitive view of betrayal as a trauma to the couple (Gordon, Baucom, \& Snyder, 2000, 2004); however, we would not describe the trauma as being "processed away" but instead would describe a process of adding new experiences to the couple's history together. Forgiveness researchers and therapists (e.g., Gordon, Baucom, \& Synder, 2000) note that "distress tolerance" is a necessary ingredient in successful forgiveness

\footnotetext{
${ }^{7}$ This could create some difficulty practically for the therapist because one person's expression of the pain could be an aversive event to the partner in the relationship or could take on functional qualities.
} 
work. Distress tolerance (Linehan \& Kehrer, 1993) in this context is thought of as the ability of the hurt partner to tolerate contact with the partner despite the hurtful events, as well as to tolerate contact with the painful thoughts and feelings associated with memories of the hurtful event. In treating couples for the trauma of infidelity, it is thought that memories of the affair and the devastation caused to the relationship may always be painful to the couple. Given that forgiveness involves both partners developing tolerance for those painful memories as part of the price of a renewed intimate partnership.

Fifth, the process of forgiveness begins (and/or the lessening of unforgiveness). The operative question here is, what stimulus additions serve to re-weight the stimulus value of the target(s)? It is important to be clear that there may be multiple intervention targets at this stage. The most obvious target is the target person who caused the hurt. In addition, however, the experience of "hurt" thoughts and feelings may also become important targets requiring interventions to decrease fight or flight responses elicited by contact with those thoughts and feelings. Other sequelae likely become legitimate sources of aversion and thus targets of intervention. A main point here being that both the offender and offended may have to learn to accept that some residual experiencing of hurt may never resolve, as well as to commit to not making sharing of those experiences damaging to intimacy or functional in the sense or retaliation. In addition, it is possible for the experience of forgiveness itself to be experienced as aversive and become a legitimate target of intervention to increase its appetitive stimulus value. In some cases, forgiveness can be equated by the person with condoning injustice or weakness and will not in that context be regarded as a valued goal.

There exists an important functional distinction between intrapersonal forgiveness and interpersonal forgiveness. In the case of intrapersonal forgiveness, the individual who caused the hurt does not participate (or does not participate effectively) in setting the stage for forgiveness and yet, the experience of forgiveness is achieved and experienced as involving a "letting go" of unforgiveness and acceptance of the hurtful event and possibly acceptance of the hurtful person. The important point is that forgiveness can be pursued and achieved without the participation of the hurtful partner and without reconciliation as the final outcome. Interpersonal forgiveness, on the other hand, does explicitly involve participation by the person who caused the hurt in setting the stage for the experience of forgiveness and does target reconciliation between the partners as the goal.

Fleshing out the effective stimulus additions and their targets points us at existing forgiveness interventions and the unique contributions to forgiveness intervention provided by a behavior analytic conceptualization. For example, a behavior analytic framework highlights the central role played by experiential avoidance in perpetuating unforgiveness and, thus, the necessity of exposure procedures for facilitating forgiveness. Techniques for increasing radical acceptance of the thoughts and feelings associated with the hurtful event, for both parties, can be derived from third wave behavior therapies such as IBCT, FAP, ACT, and DBT. The hurt individual and/or the couple often require help scaffolding contact with the source of aversion that is ultimately to be the target of forgiveness. Although not every detail of an affair, for example, need necessarily be discussed in detail, contact with the betraying partner and with the accompanying painful thoughts and feelings is necessary in order to begin the process of forgiveness. As noted, in the behavior therapy literature, this is often discussed as supporting distress tole rance.

Next, procedures for adding appetitive content to the stimulus value of the original target have to be specified. To date, these seem to mostly involve empathy promotion, uncovering the understandable reasons and the soft emotions of the target, perspective taking, remembering when 
you needed forgiveness, and other techniques that function to increase the appetitive value of enacting forgiveness and/or increasing the appetitive value of the person that caused the hurt. Specific procedures will be detailed in the following section concerning the contributions of third wave behavior therapies to the promotion of forgiveness in couple's therapy.

Finally, there remains a question about whether enough appetitive stimulus value can be added to re-weight the stimulus value of the original target person back toward appetitive. Here we see the inclusion of behavioral activation interventions as critical to help couples begin to rekindle their relationship and redefine "intimacy." In other words, reconciliation should be considered a legitimate point on the forgiveness continuum, even if circumstances may preclude approaching reconciliation as a feasible goal for any particular couple. This "should" is because it is possible to re-weight the stimulus for the original target person to the extent that he or she (or they) reemerge as a source of mostly appetitive stimulus control. At the same time, it should be acknowledged that there are circumstances in which reconciliation either cannot be a goal (the source of the hurt is no longer available or will not cooperate) or is a goal that cannot be achieved (the hurt or betrayal is simply too powerful to overcome).

\section{Forgiveness as a Special Case of Acceptance}

Following from the above, we would argue that forgiveness is a special case of the broader phenomenon of acceptance as it is defined and pursued in behavior therapy (Cordova, 2001). Acceptance can be defined in behavior analytic terms as a change in the behavior evoked by a stimulus from that functioning to avoid, escape, or destroy to behavior functioning to maintain or pursue contact (Cordova, 2001). In the case of acceptance, the source of aversion can be something that has been around for some time and does not necessarily involve the type of dichotomous shift from appetitive/neutral to aversive that characterizes the sort of event that sets the stage for the necessity of forgiveness. For example, in couple's therapy, one can work toward accepting some characteristic of his/her partner that has always been an aspect of his/her character, such as a partner's greater desire for independence than might be optimally comfortable for their partner. That "alone time" can be experienced as aversive and set the stage for destructive struggles in the relationship. Acceptance interventions in couples' therapy can help partners to accept fundamental differences between them in terms of their desire for closeness versus independence. As each partner comes to accept these fundamental differences more, instances of destructive conflict diminish ${ }^{8}$. In acceptance terms, the source of the initial aversion (the difference between partners needs for alone time) does not necessarily change, but the stimulus value of that source does change such that contact with it no longer evokes aversion, but instead evokes behavior functioning to maintain or pursue relationship health.

What appears to distinguish forgiveness as a special case of acceptance is the occurrence of the injurious event that causes the dichotomous shift from appetitive to aversive experiencing of the partner. Because the injurious event cannot be changed (given that experience is additive), acceptance is the only viable therapeutic option. Acceptance in this context means coming to terms with the injurious event in a way that either maintains intimacy development in the relationship or that diminishes active aversion ("letting go") such that the time and energy previously dedicated to aversion is freed for other, more psychologically healthy, activities (whether the relationship continues or is terminated).

\footnotetext{
${ }^{8}$ It may become important to distinguish between acceptance of partner's frailty and letting go of the relationship - estrangement and other forms of escape.
} 
Conceptualizing forgiveness as a special case of acceptance facilitates our thinking about forgiveness as existing on the same continuum as acceptance. The acceptance continuum is anchored on one end by total aversion (non-acceptance), moves through a mid-point of tolerance and is anchored at the other end by embracing acceptance (largely appetitive; see Figure 1). In the case of forgiveness, the injurious event causes a shift from appetitive to aversive. The forgiveness continuum therefore is anchored on one end by total unforgiveness, experienced as total aversion and characterized by any or all of the three main types of aversion, namely avoidance, aggression (e.g., revenge-seeking), or withdrawal. The midpoint of forgiveness would be tolerance of the stimuli associated with the injurious event, characterized by diminishment of aversion and/or an increase in behavior that maintains and/or pursues contact. It is at this mid-point that forgiveness researchers and clinicians are drawing the distinction between forgiveness and reconciliation because it is at this mid-point that one might be able to say that one has forgiven someone but is no longer interested in maintaining a relationship with that person. Forgiveness at this point on the continuum is most clearly characterized by the diminishment of unforgiveness or in our terms, the diminishment of aversion behavior. This is the "letting go" that people refer to when they talk about forgiveness at this level. Letting go involves no longer engaging in such aversion behaviors as withdrawal, avoidance, or aggression. The psychological benefit of forgiveness at this level stems from the freeing up of resources previously dedicated to aversion, which makes those resources available for healthier pursuits.

At the other end, the forgiveness continuum is anchored by embracing forgiveness, characterized by an experiencing of the partner as mostly appetitive and perhaps by a sense of "glorifying the struggle" (Gottman, 1994) in which the partners can talk about the injurious event in a way that communicates a sense that they have become a stronger couple as a result of having worked through the trauma. Between tolerance and embracing forgiveness is an entire section of the continuum in which the partners are working toward what the forgiveness literature is conceptualizing as "reconciliation." The benefit of highlighting this section of the continuum is that it draws our attention to the distance that must be traveled by the couple from the beginning of tolerance to a place on the continuum where real intimacy can continue unimpeded by the aftereffects of the injurious event.

Conceptualizing forgiveness as a special case of the acceptance continuum also highlights several other facets of forgiveness. Beginning to move from the total aversion end of the continuum involves a "stages of change" process beginning with precontemplation (not even considering forgiveness), moving on to contemplation (considering that forgiveness might be worthwhile), dedication (deciding to forgive), action (making efforts to move in the direction of forgiveness), and maintenance (working to maintain forgiveness) or relapse (falling back into unforgiveness). This highlights that the decision to forgive is not in and of itself forgiveness, but is most often simply the decision to dedicate time and effort to the pursuit of forgiveness.

As one approaches the midpoint on the continuum, one enters a moment when the appetitive and aversive qualities of the relationship are roughly in balance, allowing, as noted above, forgiveness without reconciliation. Finally, as one moves past tolerance toward embracing the balance of the stimulus value of the partner begins to tilt toward appetitive (satisfying and safe).

Considering forgiveness as a special case of acceptance also provides a framework for organizing interventions based on whether the target of the intention is (a) the discriminative stimulus quality of the partner/event, (b) the behavior of aversion, or (c) the consequences of aversion versus acceptance (Cordova, 2001). In the following section, we will explore the contributions of third wave behavior therapies to promotion of forgiveness in couple therapy. 


\title{
Contributions of Third Wave Behavior Therapies to the Promotion of Forgiveness in Couple Therapy
}

\author{
Let all bitterness and wrath and anger and clamor and slander be put away from you, \\ along with all malice. Ephesians 4:31
}

\section{Targeting the Discriminative Stimulus Functions of the Injurious Partner/Event}

One of the principal targets of forgiveness intervention is the discriminative stimulus function of the injurious partner or event. In other words, efforts are specifically made to facilitate a different experience of the event or partner such that she or he is no longer experienced as completely aversive, but instead are experienced as forgivable. Within Integrative Behavioral Couple Therapy, techniques such as eliciting soft emotional expression and highlighting the understandable reasons for undesirable behavior/events are designed to take advantage of a transfer of function such that the partner or injurious event comes to take on some of the stimulus functions of the soft emotions or understandable reasons. For example, initial contact with a partner who has had an affair (or contact with thoughts about the affair) is experienced as totally aversive and elicits some form of aversive behavior (withdrawal, avoidance, or attack). Promoting empathy often occurs through the offending partner's expressions of soft emotions such as his or her genuine sorrow at having caused his or her partner such terrible pain, and/or other soft emotions such as deep regret, heartfelt love for the partner and anguished fear of losing him or her. Such expressions allow for stimulus transfer such that the intimacy promoting qualities of these softer emotions enter into the person's experience of the offending partner and thoughts about the event. Following such interventions, the victim no longer experiences the partner/event as simply aversive, but instead experiences the partner/event as a complicated mix of aversive stimuli and intimacy-promoting stimuli, moving him or her further up the acceptanceforgiveness continuum. In short, any in-session intervention that plausibly pairs the partner-whohas-offended with experiences that elicit compassionate understanding should promote movement along the forgiveness continuum. As noted earlier, this movement does not always progress past the midpoint of tolerance or forgiveness-without-reconciliation. For a more comprehensive explanation of the relational frame theory underlying this approach in an acceptance context, see Cordova (2001).

Acceptance and Commitment Therapy (ACT) shares a common theoretical base to IBCT, and thus is easy to integrate (Chapman \& Compton, 2003). ACT is less relationally reliant than is IBCT and focuses more on the use of paradoxical statements to reduce faulty rule control. Omer (1981) proposed that paradoxes alter the context in which behavior occurs. They achieve this through: (a) changing the stimulus context (b) creating alternative associations for a behavior and (c) altering the consequences the behavior normally receives in the environment. Commitment has a critical role in couple's relationships, especially in avoiding affairs. Johnson and Rusbult, (1989) taking a social exchange perspective argued that those committed to their relationships (because of high rewards, low costs, high investments, and poor alternatives) are likely to "avoid temptation and maintain stable involvement by derogating alternative partners" (p. 194). Interestingly enough, both correlational and experimental studies provide evidence that this is the case. Highly committed individuals in couples, who are committed because they have rewarding and satisfying relationships in which they are invested, have a tendency to derogate attractive, available alternatives (Johnson \& Rusbult, 1989; Simpson, Gangestad, \& Lerma, 1990).

The decline of couples with unannounced affairs in Atkins et al (2005) may demonstrate a role for commitment and self-control in preventing participants in the relationship from 
attempting to maximize reinforcement outside the relationship. This maximization could be an affair, another relationship (such as devoting oneself to a child in the relationship), or to work and career. This analysis also suggests that one needs to view the self-care exercises as having the potential to cause further harm in the relationship.

\section{Targeting Unforgiveness Behavior}

Targeting unforgiveness from a behavioral perspective has two rationales. First, forgiveness can also be promoted by targeting the aversive behavior of unforgiveness directly. This process is directly akin to exposure and response prevention in the treatment of simple phobias. Treatment involves exposure to the offense by talking about it and its aftermath in the session. Response prevention involves creating a safe environment in the session where avoidance, withdrawal, and retaliation are not available options. The partners learn through experience that contact with these painful topics does not in and of itself result in further injury, while at the same time providing an opportunity to engage in more intimacy conducive behavior. For example, a partner can talk about feeling betrayed with genuine sorrow and without seeking revenge or escape. The other partner can talk about feeling defensive and wanting to run away without defending himself or running away. That partner can also talk about powerful feelings of regret at having hurt his partner that seem to coexist with a strong desire to defend himself. Intimacy is promoted through the non-punitive sharing of vulnerability while the therapeutic context works to minimize acting out feelings of withdrawal and retaliation. Like exposure therapies for panic attacks, the clients learn that exposure to the feared stimuli can be tolerated in the service of deeply valued goals. Second, targeting unforgiveness fits with a matching analysis of function in which an attempt is made to decrease the reinforcement value on the problem behavior to increase the rate of the alternative behavior (see McDowell, 1982).

\section{Behavioral Activation:}

Behavioral activation theory holds to a matching analysis of client behavior. It holds that clients do not forgive because there is more reinforcement (at least immediately) for not forgiving, not enough reinforcement for forgiving, or the threat of punishment for forgiving (Hopko, Lejuez, LePage, Hopko, \& McNeil, 2003) Behavioral activation is an effective long term technique because it engages in rewarding activities and people lessen their depression. The philosophy of behavioral activation is that the focus on modifying environmental contingencies is the healing force of therapy (Hopko, Lejuez, LePage, Hopko, \& McNeil, 2003). Behavioral activation is listed as a well-established treatment for depression (Chamberless, Baker, Baucom, Beutler, et al, 1998). The primary contingencies of a couple's relationship are in the hands of the partners. Thus, it seems that couples need to struggle to come together. John Gottman spoke of the "glorifying the struggle" as being important to the couples healing (Gottman, 1994). On the individual level and couples level, activation can be seen as similar to the Greek concept of Pathos. Pathos is the experience of virtuous struggle and suffering for redemption. After betrayal, couples need to struggle together to work at their relationship. Many therapists will tell that the best couples therapy sessions that they have had were the ones that began with one partner saying something to the effect of "our relationship really sucks and it does not have to be this way." Early on, behavioral couples therapy explored the building of collaborative sets with couples (Jacobson \& Margolin, 1979). Once the couple agrees to work on their relationship, exercises can be developed to lessen alienation.

\section{Targeting the Consequences of Forgiveness and Unforgiveness}


Finally, acceptance can be promoted by targeting the consequence of aversion versus movement toward forgiveness. This involves the therapist providing reinforcement for behavior that maintains contact while discouraging behavior that avoids or diminishes contact. This is an approach advocated within Functional Analytic Psychotherapy (FAP) as a treatment for difficulty with intimate relationships.

The therapeutic relationship is a rich source of contingencies (Kohlenberg \& Tsai, Cautilli, Riley-Tillman, Axelrod, \& Hineline, 2005a). This is as true for couple's therapy as it is for individual therapy. These contingencies can help couples by reinforcing movement toward progress or haphazardly move couples toward escape and disaster. Maximizing these contingencies and a careful functional analysis of resistance (e.g., Cautilli, Tillman, Axelrod, \& Hineline, 2005b) can reduce therapeutic failure. It is critical that therapists be trained to recognize clinically relevant behavior of the couple as it occurs in session (Kohlenberg \& Tsai, 1991). In the context of forgiveness therapy, the therapist must attend to both those clinically relevant behaviors that maintain positive contact in order to increase the frequency of that behavior and to those behaviors that are acts of unforgiveness in order to decrease the frequency of that behavior. For example, talking about wanting to escape without actually moving to escape both maintains positive contact and replaces active aversion. The therapist can reinforce that behavior by responding with genuine attention and augmenting his or her positive emotional response to the client (e.g. 'I think what you're doing shows such strength and commitment. Wanting to run away, saying that out loud, and yet staying here engaged in this therapeutic process feels very powerful to me.").

Taking a functional analytic psychotherapy perspective (Kohlenberg \& Tsai, 1991), in the therapeutic relationship clinically relevant behavior emerges (CRB). This clinically relevant behavior can represent the problem occurring in session (CRB1) or improvement occurring in session (CRB 2). The therapist's job is to reinforce with natural reinforcers CRB $2 \mathrm{~s}$ and disrupt and call attention to CBR1s as they occur in session.

\section{Methods from Traditional (First and Second Generation) Behavior Therapy Self-Control Training}

Chambless, and colleagues (1998) list self-control training as a probably efficacious treatment for depression. Early research on self-control training from an operant perspective was very promising for treating depression (Fuch \& Rehm, 1977; Thomas, Petry, \& Goldman, 1987).

Fuch and Rehm's program emphasized monitoring one's own behavior, evaluation of performance against stated goals and objectives, and the use of systematic reinforcement for achieving long-term goals. Fuch and Rehm (1977) found their approach superior to supportive therapy for expression treatment. Rehm and Plakosh, (1975) showed that for depressed individuals a distinct preference for immediate versus delayed rewards. Thomas, Petry, and Goldman (1987) compared the behavioral self- control program to cognitive therapy for depression and found the two approaches to be equally effective both during treatment and at a six week follow up. Self-control can help the individual to give up the momentary reinforcer of unforgiveness and/or overcome the momentary punishment associated with forgiving to meet the long-term goal of relational intimacy.

The self-control programs teach clients to give up small immediate rewards for more long- term gains. This can be very helpful for couples struggling to find peace after a betrayal. Recognizing the triggers to sarcastic and biting statements can help the couple to begin rebuilding their relationship. 
Behavioral self-control also has a role in avoiding damaging affairs. Not placing oneself in situations of temptation is important to ensuring a healthy relationship.

\section{Treating Seeing as Operant Behavior}

Skinner (1974) held that seeing is operant behavior and is thus capable of being shaped. One way to impress this on clients is through the hard eyes/soft eyes technique (Potter-Efron \& Potter-Efron, 1991). In this technique, first the individuals are told to look into a mirror and to view themselves in the most critical and judgmental way. They are told to "make their eyes hard" are then asked to share what they see in the mirror. The therapist listens and notes what he or she hears. Next, the person is told to relax and soften their eyes and too look with non-critical (i.e., curious, accepting) eyes in the mirror. The therapist then asks them what they see and notes the difference. After this is done, the therapist discusses what he did to make his eyes softer or harder. The therapist asks them how they would prefer to see themselves and how they would prefer others to see them. Next, the therapist brings the couple together for the same activity. When the couple is brought together for the activity they are taught to look at each other first with hard eyes then soft eyes. They then share what they say and how they would prefer to be seen.

\section{Therapist autoclitics}

Skinner defined autoclitic behavior as behavior engaged in by the speaker to change the behavior of the listener. Stories, metaphors and similes are common autoclitics used by the therapist to enhance couples therapy. The therapist should use autoclitics that are meaningful to the clients' learning history. If the clients watch television, common television shows could be used to discuss how conflicts are handled. If clients use a lot of religious themes, then common religious comments could help. Stories are an excellent way to leave couples with a rulegoverned understanding of their situation. A common one for the additive nature of the relationship is the story of the child who hurts others. The story goes like this: there was a child who cursed and hurt others. She was very aggressive. So one day, her mother told her each time she hit someone or cursed, she needed to go into the yard and put a nail in the fence. After several days of this intervention, her rate of hitting and cursing dropped to near zero. After a few more days, it reached zero and so her mother told her that for each day she did not curse or hit others, she could remove a nail from the fence. After several weeks, all of the nails were removed. Her mother went to her and said "Excellent job, all the nails are gone." The girl looked at the fence and felt proud to see all the nails gone. But then she felt sad because she saw all of the holes in the fence. She said "but mommy look at all the holes" and her mother said to her "Well sometimes once things are done, there is no way to fix them."

\section{Communication and Problem Solving Training}

Communication and problem solving training while not the major focus of the intervention is important to help couples create a space that is safe to discuss the hurt event. This approach can have a powerful effect for couples struggling with the event (see Atkins, Baucom, Eldridge, \& Christenson, 2003). Couples are taught methods to reflectively listen to the partner and to allow the partner to express the problem as they see it and in a manner that is heard. Next the therapist encourages the couple to go through a formal process of problem solving around the issue

\section{Suggestions for Intervention}


Figure 1- Change model and Interventions

\begin{tabular}{|c|c|c|c|c|}
\hline $\begin{array}{l}\text { Phase } \\
\text { Number and } \\
\text { Description }\end{array}$ & $\begin{array}{l}\text { Therapist and } \\
\text { Couples goals }\end{array}$ & $\begin{array}{l}\text { Intervention techniques } \\
\text { that may help }\end{array}$ & $\begin{array}{l}\text { Clinically } \\
\text { relevant } \\
\text { behavior to } \\
\text { look for in } \\
\text { session }\end{array}$ & $\begin{array}{l}\text { Clinically relevant } \\
\text { behavior that the } \\
\text { therapist may emit } \\
\text { that suggests they } \\
\text { need to seek } \\
\text { supervision }\end{array}$ \\
\hline $\begin{array}{l}\text { Phase 1- } \\
\text { Looking at } \\
\text { the context } \\
\text { before the } \\
\text { hurt. } \\
\text { Recognizing } \\
\text { what was lost } \\
\text { from the hurt. }\end{array}$ & $\begin{array}{l}\text { a. Looking at the } \\
\text { relationship before } \\
\text { the hurt/Betrayal } \\
\text { b. Looking at the } \\
\text { relationship after } \\
\text { the hurt/betrayal } \\
\text { c. Patterns of } \\
\text { intimacy }\end{array}$ & $\begin{array}{ll}\text { a. } & \text { Communication } \\
\text { training } \\
\text { b. Empathic joining }\end{array}$ & $\begin{array}{l}\text { Possible CRB } \\
\text { 1s } \\
\text { "I don't forgive } \\
\text { because I am } \\
\text { bad." } \\
\text { "I don't forgive } \\
\text { because I want } \\
\text { to hurt you." } \\
\text { "I hurt myself } \\
\text { to hurt you." } \\
\text { "I don't forgive } \\
\text { because I am } \\
\text { disgusted" } \\
\text { CBR2s "I don't } \\
\text { forgive because } \\
\text { I am afraid" } \\
\text { "I don't forgive } \\
\text { because I am } \\
\text { ashamed" }\end{array}$ & $\begin{array}{l}\text { The therapist feels } \\
\text { frustrated } \\
\text { The therapist feels } \\
\text { helpless }\end{array}$ \\
\hline $\begin{array}{l}\text { Phase } 2 \text { - } \\
\text { Recognizing } \\
\text { the context of } \\
\text { hurt. Placing } \\
\text { the couples } \\
\text { relationship } \\
\text { in context }\end{array}$ & $\begin{array}{ll}\text { a. } & \text { Fostering } \\
& \text { acceptance } \\
\text { b. } & \text { Lessening } \\
& \text { experiential } \\
& \text { avoidance }\end{array}$ & $\begin{array}{l}\text { a. Shaping softer eyes } \\
\text { b. Jacobson's turning the } \\
\text { problem into an it } \\
\text { c. Empathic joining } \\
\text { techniques } \\
\text { d. Using } \\
\text { contingencies in the } \\
\text { therapeutic } \\
\text { relationship to } \\
\text { reinforce accepting } \\
\text { statements and } \\
\text { rules of acceptance }\end{array}$ & $\begin{array}{l}\text { CRB1s - } \\
\text { Couple misses } \\
\text { sessions. } \\
\text { CRB2s- } \\
\text { Couples attend } \\
\text { sessions and } \\
\text { discuss pain } \\
\text { openly. }\end{array}$ & $\begin{array}{l}\text { Therapist misses } \\
\text { clients expressions of } \\
\text { hurt and anger } \\
\text { Therapist feels angry } \\
\text { or moral revulsion or } \\
\text { disgust. } \\
\text { Therapist feels an } \\
\text { urge to rush in and } \\
\text { save or protect the } \\
\text { couple or a member } \\
\text { of the couple }\end{array}$ \\
\hline $\begin{array}{l}\text { Phase } 3 \text { - } \\
\text { Accepting } \\
\text { the } \\
\text { hurt/betrayal } \\
\text { Breaking } \\
\text { away from } \\
\text { experiential } \\
\text { avoidance- } \\
\text { disrupting the } \\
\text { rules for } \\
\text { avoidance }\end{array}$ & $\begin{array}{l}\text { a. Fostering } \\
\text { increased } \\
\text { acceptance }\end{array}$ & $\begin{array}{l}\text { a. Feeling the pain together } \\
\text { (empathic joining) } \\
\text { b. Exploring the couples } \\
\text { values around pain and the } \\
\text { betrayal } \\
\text { c. Increasing self-care } \\
\text { activities }\end{array}$ & $\begin{array}{l}\text { CRB1s - } \\
\text { Couples avoid } \\
\text { speaking of the } \\
\text { affair, couples } \\
\text { create other } \\
\text { issues to work } \\
\text { on in therapy. } \\
\text { CRB2s- } \\
\text { couples speak } \\
\text { of the pain } \\
\text { openly and } \\
\text { make verbal } \\
\text { commitment to }\end{array}$ & $\begin{array}{l}\text { Therapist finds } \\
\text { himself or herself } \\
\text { "selling the } \\
\text { program." } \\
\text { Therapist finds } \\
\text { themselves equating } \\
\text { couples health with } \\
\text { freedom from } \\
\text { emotions } \\
\text { Therapist finds } \\
\text { themselves allying } \\
\text { with less angry client }\end{array}$ \\
\hline
\end{tabular}




\begin{tabular}{|c|c|c|c|c|c|}
\hline & & & & $\begin{array}{l}\text { working on the } \\
\text { pain. }\end{array}$ & \\
\hline $\begin{array}{l}\text { Phase } 4 \text { - } \\
\text { Committing } \\
\text { to Forgive }\end{array}$ & $\begin{array}{l}\text { a. Having the } \\
\text { client } \\
\text { commit to } \\
\text { living life } \\
\text { in accords } \\
\text { with their } \\
\text { values. } \\
\text { b. Having } \\
\text { client } \\
\text { commit to } \\
\text { the process } \\
\text { of } \\
\text { forgiving. }\end{array}$ & $\begin{array}{l}\text { a. } \\
\text { in } \\
\text { c. } \\
\end{array}$ & $\begin{array}{l}\text { A } \\
\text { functional analysis } \\
\text { of factors blocking } \\
\text { forgiveness (looking } \\
\text { at triggers for } \\
\text { moments of } \\
\text { unforgiveness, look } \\
\text { at consequence } \\
\text { factors for moments } \\
\text { of unforgiveness, } \\
\text { increased attention } \\
\text { in the moment, a } \\
\text { strong suppressive } \\
\text { punisher when the } \\
\text { partner says } \\
\text { something that the } \\
\text { person does not like, } \\
\text { etc). } \\
\quad \text { Rule } \\
\text { governed factors for } \\
\text { unforgiveness } \\
\text { (immediate reward- } \\
\text { temporary power } \\
\text { over partner- and } \\
\text { long term death of } \\
\text { relationship) } \\
\text { A teaching the } \\
\text { individual a } \\
\text { behavioral self- } \\
\text { control and } \\
\text { acceptance tactics } \\
\text { for when triggers } \\
\text { arises as a couple. } \\
\text { (i.e., keeping track } \\
\text { of the umber of } \\
\text { disgusted or critical } \\
\text { statements made } \\
\text { and what triggered } \\
\text { them and what was } \\
\text { the payoff for their } \\
\text { comments- look at } \\
\text { the effects of } \\
\text { overlearning). } \\
\text { Problem solving } \\
\text { training }\end{array}$ & $\begin{array}{l}\text { CRB1- couple } \\
\text { blocks making } \\
\text { statements } \\
\text { about } \\
\text { commitment } \\
\text { CRB2- couple } \\
\text { states it can not } \\
\text { commit at this } \\
\text { time or } \\
\text { commits to } \\
\text { activities }\end{array}$ & $\begin{array}{l}\text { Therapist feels used } \\
\text { by clients } \\
\text { Therapist has moral } \\
\text { problems with } \\
\text { commitment } \\
\text { Therapist finds that } \\
\text { they are getting into } \\
\text { power struggles with } \\
\text { the client } \\
\text { Therapist finds } \\
\text { himself or herself } \\
\text { rushing in to make } \\
\text { things peaceful. }\end{array}$ \\
\hline $\begin{array}{l}\text { Phase 5- } \\
\text { Behavioral A } \\
\text { ctivation to } \\
\text { achieve }\end{array}$ & $\begin{array}{l}\text { a. Engaging in } \\
\text { exercises to forgive }\end{array}$ & & $\begin{array}{ll}\text { a. } & \text { Contracting } \\
\text { b. } & \text { Activity } \\
& \text { scheduling }\end{array}$ & $\begin{array}{l}\text { CRB1- couples } \\
\text { do not do } \\
\text { homework or } \\
\text { activity }\end{array}$ & $\begin{array}{l}\text { Therapist finds } \\
\text { themselves with a } \\
\text { lack of energy to see } \\
\text { the couple }\end{array}$ \\
\hline
\end{tabular}




\begin{tabular}{|l|l|l|l|}
\hline forgiveness & & schedule & \\
& & CRB2- couples & \\
& complete \\
homework and & \\
& discuss events & \\
& freely. & \\
\hline
\end{tabular}

\section{Conclusion}

A behavior analysis of forgiveness offers insight into the therapeutic processes that may help couples overcome hurt and betrayal. This conceptualization allows the therapist to draw from both second and third generation behavioral technologies in a manner that may maximize the therapeutic outcome. Thus, the process is a balanced mixture of acceptance and change based on the idiographic histories of the couple in therapy. We have taken this process to lie out a broad model of interventions that the therapist may use to meet unique needs that develop through the case conceptualization process.

\section{References}

Alcoholics Anonymous (1976)(3rd Ed.). New York: A.A. World Services.

Atkins, D.C., Baucom, D.H. Eldridge, K.A., \& Christenson, A. (2003) Infidelity and behavioral couples therapy: Optimism in the face of betrayal. Journal of Consulting and Clinical Psychology, 73, 144-150.

Baskin, T.W. \& Enright, R.D. (2004). Intervention studies on forgiveness: A meta -Analysis. Journal of Counseling and Development, 82, 79-90.

Bergin, A.E. (1988). Three contributions of a spiritual perspective to counseling, psychotherapy, and behavior change. Counseling and values, 33, 21-31.

Bui, Khanh-Van T.; Peplau, Letitia A.; \& Hill, Charles T. (1996). Testing the Rusbult Model of relationship commitment and stability in a 15-year study of heterosexual couples. Personality and Social Psychology Bulletin, 22(12), 1244-1257.

Cautilli, J.D., Verbal Conditioning in Third Generation Behavior Therapy. The Behavior Analyst Today, 6.(2), 138-144. www.behavior-analyst-online.org.

Cautilli, J.D., Riley-Tillman, T.C., Axelrod, S. \& Hineline, P. (2005b). Current Behavioral Models of Client and Consultee Resistance: A Critical Review - IJBCT, 1. (2), 147-155. www.behavior-analyst-online.org.

Cordova, J. (2003). Behavior analysis and the scientific study of couples. The Behavior Analyst Today, 3 (4), 412-415. www.behavior-analyst-online.org.

Chapman, A. \& Compton, B. (2003) From Traditional Behavioral Couples Therapy to Integrative Behavioral Couple Therapy: New Research Directions. The Behavior Analyst Today, 4 (1), 17-24. www.behavior-analyst-online.org. 
Chapman, A.I. \& Compton, J.S. (2003). From traditional behavioral couples therapy to integrative behavioral couples therapy: New research directions. The Behavior Analyst Today, 4, 17-25. www.behavior-analyst-online.org.

Chambless, D.L., Baker, M.J., Baucom, D.H et al. (1998). Update on empirically validated therapies II. The Clinical Psychologist, 51, 3-16.

Christensen , A., Jacobson, N.S., \& Babcock, J.C. (1999). Integrative behavioral couples therapy. In N.S. Jacobson \& A.S. Gurman (Eds), Clinical Handbookc for Couples Therapy (pp. 31-64). New York: Guildford Press.

Christensen, A., Atkins, D. C., Berns, S., Wheeler, J., Baucom, D. H. \& Simpson, L. E.(2004). Traditional versus integrative behavioral couple therapy for significantly and chronically distressed married couples. Journal of Consulting and Clinical Psychology, 72, 176-191.

Coyle, C.T. \& Enright, R.D. (1997). Forgiveness Intervention with Postabortion Men. Journal of Consulting and Clinical Psychology, 65,(6), 1042-1046.

Enright, R.D. \& The Human Development Study Group (1996). Counseling within the forgiveness triad: On forgiving, receiving forgiveness, and self-forgiveness. Counseling and Values, 40, 107-146.

Fenell, D. L. (1993). Characteristics of longer-term first marriages. Journal of Mental Health and Counseling, 15, 446-460.

Ferch, S.R. (1998). Intentional forgiving as a counseling intervention. Journal of Counseling \& Development, 76, 261-270.

Fincham, F. D. Beach, S.R.H. \& Davila, J. (2004). Forgiveness and conflict resolution in marriage. Journal of Family Psychology, 18, 72-81.

Fitzgibbons, R.P. (1986). The cognitive and emotive use of forgiveness in the treatment of anger. Psychotherapy, 23, 629-633

Fuch, C.Z. \& Rehm, L.P. (1977). A self-control behavior therapy program for depression. Journal of Consulting and Clinical Psychology, 45, 206-214.

Gordon, K.C., Baucom, D.H., \& Snyder, D.K. (2000). The use of forgiveness in martial therapy. In M.E. McCullough, K.I. Pargament, \& C.E. Thoresen (Eds.), Forgiveness: Theory, research, and practice (pp. 203-227). New York: Guilford Press.

Gordon, K.C., Baucom, D.H., \& Snyder, D.K. (2004). An integrative intervention for promoting recovery from extramarital affairs. Journal of Martial and Family Therapy, 30, 1-12.

Gottman, J. (1994). Why Marriages Succeed or Fail. New York: Simon and Schuster. 
Hayes, S.C.(2004). Acceptance and commitment therapy, relational frame theory, and the third wave of behavioral and cognitive therapies. Behavior Therapy, 35(4), 639666.

Hayes, S.C., Masuda, A., Bissett, R., Luoma, J., \& Guerrero, L.F. (2004). DBT, FAP, and ACT: How empirically oriented are the new behavior therapy technologies. Behavior Therapy, $35,35-54$.

Herrnstein, R.J. (1961). Relative and absolute strength of a response as a function of the frequency of reinforcement. Journal of the Experimental Analysis of Behavior, 4, $267-$ 272.

Herrnstein, R.J. (1970). On the law of effect. Journal of the Experimental Analysis of Behavior, $13,243-266$.

Herrstein, R.J. \& Loveland, D.H. (1975). Maximizing and matching on concurrent ratio schedules. Journal of the Experimental Analysis of Behavior, 24, 107-116.

Hopko, D.R., Lejuez, C.W., LePage, J.P., Hopko, S.D. \& McNeil, D.W. (2003). A brief behavioral activation treatment for depression: A randomized pilot trial within an inpatient psychiatric hospital. Behavior Modification, 27, 458-469.

Jacobson, N.S. (1997). Can contextualism help? Behavior Therapy, 28, 435-443.

Jacobson, N.S. \& Christenson, A. (1996). Integrative couples therapy. New York: W.W. Norton.

Jacobson, N.S., Christensen, A., Prince, S.E., Cordova, J. \& Eldrige (2000). Integrative behavioral couples therapy: An acceptance-based promising new treatment for marital discord. Journal of Consulting and Clinical Psychology, 68, 351-355.

Johnson, D. J., \& Rusbult, C. F. (1989). Resisting temptation: Devaluation of alternative partners as a means of maintaining commitment in close relationships. Journal of Personality and Social Psychology, 57, 967-980

Kanter, J. W., Callaghan, G. M. , Landes, S. J. Busch, A. M. and Brown K.R. (2004). Behavior analytic conceptualization and treatment of depression: traditional models and recent advances. The Behavior Analyst Today, 5.(3), Page 255-265

Kanter, J.W., Cautilli, J.D., Busch, A.M., \& Baruch, D.E.(2005). Toward a comprehensive functional analysis of depressive behavior: Five environmental factors plus a possible sixth and seventh. The Behavior Analyst Today, 6(1), 65-72. www.behavior-analyst-online.org.

Keller, K. (1974). The role of elicited responding in behavioral contrast. Journal of the Experimental Analysis of Behavior, 21, 249-257.

Kohlenberg, R.J, Boiling, M., Kanter, J.R., \& Parker, C. (2002) Clinical behavior analysis: Where it went wrong, how it was made good again, and why its future is so bright. The Behavior Analyst Today, 3 (3), 248-256. www.behavior-analyst-online.org. 
Krumboltz, J.D. \& Thoresen, C.E. (1969). Behavioral Counseling. New York: Holt, Rinehart and Winston.

Leigland, S.(1996). The functional analysis of psychological terms: In defense of a research program. The Analysis of Verbal Behavior, 13, 105-123.

Martell, C.R., Addis, M.E., \& Jacobson, N.S. (2001). Depression in context: Strategies for guided action. New York: W.W. Norton.

McCullough, M. E., Exline, J. J., \& Baumeister, R. E (1998a). An annotated bibliography of research on forgiveness and related concepts. In E. L. Worthington, Jr. (Ed.), Dimensions of forgiveness: Psychological research and theological perspectives (pp. 193-318). Philadelphia: Templeton Foundation.

McCullough, M. E., Rachal, K. C., Sandage, S. J., Worthington, E. L., Jr., Brown, S. W., \& Hight, T. L. (1998b). Interpersonal forgiving in close relationships. 11. Theoretical elaboration and measurement. Journal of Personality and Social Psychology, 75, 15861603.

McCullough, M. E., \& Worthington, E. L., Jr. (1994). Encouraging clients to forgive people who have hurt them: Review, critique, and research prospectus. Journal of Psychology and Theology, 22, 3-20.

McCullough, M. E., \& Worthington, E. L., Jr. (1995). Promoting forgiveness: The comparison of two brief psychoeducational interventions with a waiting-list control. Counseling and Values, 40, 55-68.

McCullough, M. E., Worthington, E. L., Jr., \& Rachal, K. C. (1997). Interpersonal forgiving in close relationships. Journal of Personality and Social Psychology, 73, 321-336.

McDowell, J.J. (1982). The importance of Herrnstein's mathematical statement of the law of effect for behavior therapy. American Psychologist, 37, 771-779.

Omer, H. (1981). Paradoxical treatments: A unified concept. Psychotherapy: Theory, Research, and Practice, 18, 320-324.

Potter-Efron, R.T \& Potter-Efron, P.S. (1991a). Anger: Alcoholism and addiction: Treating individuals, couples, and families. Norton

Potter-Efron, R.T \& Potter-Efron, P.S. (1991b). Ending our resentments. Center City, MN: Hazelden Press.

Rehm, L.P., \& Plakosh, P. (1975). Preference for immediate reinforcement in depression. Journal of Behavior Therapy and Experimental Psychiatry, 6, 101-106.

Reynolds, G.S. (1961). Behavioral contrast. Journal of the Experimental Analysis of Behavior, 4, 57-71.

Riley-Tillman, T.C., Axelrod, S. \& Hineline, P. (2005a). The Role of 
Verbal Conditioning in Third Generation Behavior Therapy. The Behavior Analyst Today, 6.(2), 138-144.www.behavior-analyst-online.org

Rusbult, C. E. (1980). Commitment and satisfaction in romantic associations: A test of the investment model. Journal of Experimental Social Psychology, 16, 172-186.

Rusbult, C. E. (1983). A longitudinal test of the investment model: The development (and deterioration) of satisfaction and commitment in heterosexual involvements. Journal of Personality and Social Psychology, 43, 101-117.

Rusbult, C. E., \& Buunk, B. R. (1993). Commitment processes in close relationships: An interdependence analysis. Journal of Social and Personal Relationships, 10, 175-204.

Rusbult, C. E., Drigotas, S. M., \& Verette, J. (1994). The Investment model: An interdependence analysis of commitment processes and relationship maintenance phenomena. In D. Canary \& L. Stafford (Eds.), Communication and relational maintenance (pp. 115-139). San Diego, CA: Sage.

Rusbult, C.E., Hannon, P.A., Stocker, S.L. \& Finkel, E.J. (2005). Forgiveness and relational repair. In E.L. Worthington's Handbook of Forgiveness (pp 185-202). New York.:Brunner: Rutledge.

Rusbult, C. E., Verette, J., Whitney, G. A., Slovik, L. F., \& Lipkus, I. (1991). Accommodation processes in close relationships: Theory and preliminary empirical evidence. Journal of Personality and Social Psychology, 60, 53-78.

Rusbult, C. E., Zembrodt, I. M., \& Gunn, L. K. (1982). Exit, voice, loyalty, and neglect: Responses to dissatisfaction in romantic involvements. Journal of Personality and Social Psychology, 43, 1230-1242.

Shadish, W.R., \& Baldwin, S.A. (2005). The effects of behavioral marital therapy: A meta-analysis of randomized controlled trials. Journal of Consulting and Clinical Psychology, 73(1), 6-14.

Shriver, D. (1995) An Ethic for Enemies: Forgiveness in Politics. Oxford University Press.

Simpson, J. A., Gangestad, S. W., \& Lerma, M. (1990). Perception of physical attractiveness: Mechanisms involved in the maintenance of romantic relationships. Journal of Personality and Social Psychology, 59, 1192-1201.

Skinner, B.F. (1945). The operational analysis of psychological terms. Psychological Review, 52 270-277.

Skinner, B.F. (1957). Verbal behavior. New York: Appleton-Century-Croft.

Skinner, B.F.(1969). An operant analysis of problem-solving. In B.F. Skinner's Contingencies of reinforcement (pp. 133-157). New York: Appleton-Century-Croft. Task Force on Promotion and Dissemination of Psychological Procedures (1995). Training in and dissemination of empirically validated psychological treatments. The Clinical Psychologist, 48, 3-23. 
Thomas, J.R, Petry, R.A. \& Goldman, J.R.(1987). Comparison of cognitive and behavioral treatment of depression. Psychological Reports, 60, 975-982.

Weine, S. M. (2000). Lives and Memories of Ethnic Cleansing in Bosnia-Herzegovina. Rutgers University Press.

Zettle, R.D. (2005). The Evolution of a Contextual Approach to Therapy: From Comprehensive Distancing to ACT - IJBCT, 1.(2), Page 77-84.

Author contact information:

Joseph Cautilli, Ph.D.

Children Crisis Treatment Center

1823 Callowhill St.

Philadelphia, PA 19130

jcautilli@cctckids.com

James V. Cordova, Ph.D.

Associate Professor

Director of Clinical Training

Department of Psychology

Clark University

950 Main St

Worcestor, MA 01610-1477

(508) 793-7268 Phone

(508) 793- 7265 Fax

Corrina Simon

Department of Psychology

C;ark University

950 Main St.

Worcestor, MA 0110-1477

Robin Axelrod Sabag

Project Director

Philadelphia Safe and Sound

1835 Market Street

Suite 420

Philadelphia, PA 19103

Phone: 215-568-0620

Fax: 215-568-0745 


\title{
A Treatment Study of Suicidal Adolescent with Personality Disorder or Traits: Mode Deactivation Therapy as compared to Treatment as Usual
}

\author{
Jack A Apsche, Christopher K. Bass, Alexander M. Siv
}

\begin{abstract}
This treatment research compares Mode Deactivation Therapy(MDT) to Treatment as Usual (TAU) with suicidal adolescents. This treatment research study examines the effects of MDT vs. TAU on adolescents who had co-morbid mental health issues as well as, personality disorders and traits. MDT was shown to be more effective in reducing suicidal thoughts and behavior as measured by the Beck Depression Inventory II and the Reynolds SIQ-HS.

Key words: Mode Deactivation Therapy, Suicidal Adolescents, Treatment as Ususal.
\end{abstract}

\section{Introduction}

Adolescent suicides continue to be a leading cause of death in North America (Links, Gould, Ratnayake (2003). Links et. al. report a 5 to 1 ratio of males to females of suicide in adolescents in Canada. Arnett (1999), reports that adolescents have the highest prevalence of risk behaviors including lethal suicides. Peters, Kochenek and Murphy (1998) report that completed suicide for adolescents between the ages of 15 and 19 rose $24.5 \%$ between 1956 and 1994. During the past 30 years there has been an increase in the number of incidences of suicide in adolescents ages, 15-19 years of age, and data has shown important ethnic variations as well. The rate of adolescent suicides in males has risen from just under 6 per 100,000 to 17.8 per 100,000 in 1992 (Shaffer, Gould, \& Hicks 1994). Between the ages of 15 and 9, suicide is the second leading cause of death for white males and the third leading cause of death among African American males (Shaffer and Hicks, 1993). The rates of suicide among adolescents is rising at an alarming rate over the past ten years according to (Shaffer, et. al., 1994).

Marttunen, Aro, Henriksson, Lonnqist $(1991,1994)$ found that $17 \%$ of adolescents aged 13 to 19 years met criteria for conduct disorder or antisocial personality disorder (APD). When Marttunen et. al. (1994) studied non lethal suicide attempts they found that $45 \%$ of the males had significant symptoms of APD.

Adolescents with borderline personality disorder (BPD) represent $9 \%$ to $33 \%$ of all suicides, (Runesson, Beskow (1991). Narcissistic personality disorder (NPD) or traits was found in 14\% of lethal suicides in a 15 year study of suicide by Stone (1989).

Apsche and Siv (2005) completed a case study with an adolescent male with conduct and personality disorders who was actively suicidal. They found in this case study that MDT was effective in reducing suicidal attempts, thoughts and ideation in this adolescent. This study is the first attempt to test the effectiveness of MDT on suicidal adolescents in a larger group setting.

A history of suicidal behavior is found in $55 \%$ to $70 \%$ of individuals with personality disorders (Gunderson (1984); Kjellander, Bonger, King (1998); Links, Gould, Ratnayake, (2003)). The recent study compared adolescents who had many of these personality disorder or traits. This study examines the effects of Mode Deactivation Therapy (Apsche, Bass, Siv $(2005 ; 2006)$ on a population of 
adolescents with a variety of personality traits, a decrease in their suicidal ideation and cognition are measured by the Beck Depression Inventory II and the Reynolds Suicidal Ideation Questionnaire.

\section{Characteristics and Results}

The sample comprised of 20 male adolescent residential patients. All subjects were referred to the same residential treatment facility for the treatment of aggression. In this study, subjects were randomly assigned to one of the two treatment conditions at the time of admission based on available openings in the caseload of the participating clinicians. The two treatment conditions showed similarity in terms of the frequency of Axis I and Axis II diagnoses, age, and racial background. To ensure consistency in the delivery of the two respective treatments, therapists were specifically trained in one of the three treatment curriculums/methods. The average length of residential treatment across all conditions was one year.

Treatment As Usual (TAU): A total of ten male adolescents were assigned to the TAU condition. The group was comprised of 4 African Americans, 3 European Americans, 1 Hispanic American and 1 Asian American with an average age of 15.3. The principal Axis I diagnoses for this group included Conduct Disorder (4), Oppositional Defiant Disorder (3), and Post Traumatic Stress Disorder (7). Axis II diagnoses for the group included Mixed Personality Disorder (3), Borderline Personality Disorder (3), Narcissistic Personality Disorder (1) and Dependent Personality Disorder (1).

TAU consisted of a bi-weekly psychodynamic psychotherapy group or Dialectical Behavioral Therapy (DBT) skills group, individual psychodynamic psychotherapy or individual DBT at least once per week, Psychoeducational oriented milieu based on “The Boys and Girls Town's Psychoeducational Model". Seven of the ten TAU group patients participated in DBT. Individual Components of this psychoeducational treatment curriculum included daily recording of training in social skills placed on point card sheets. All clinicians were trained in adolescent psychodynamic therapy. The TAU team met regularly to discuss treatment concerns.

Mode Deactivation Therapy (MDT): A total of ten male adolescents were assigned to the MDT condition. The group was comprised of 5 African Americans, 3 European Americans and 2 Hispanic Americans with an average age of 15.7. The principal Axis I dia gnoses for this group included Conduct Disorder (5), Oppositional Defiant Disorder (3), Post Traumatic Stress Disorder (7), and Major Depressive Disorder, primary or secondary (2). Axis II diagnoses for the group included Mixed Personality Disorder (6), Borderline Personality Traits (3), and Narcissistic Personality Traits (2). The MDT condition used the methodology described earlier in this paper.

TABLE 1. Composition of both treatment groups

\begin{tabular}{|c|c|c|}
\hline Axis I & TAU & MDT \\
\hline Conduct Disorder & 6 & 8 \\
\hline Oppositional Defiant Disorder & 3 & 3 \\
\hline Post Traumatic Stress Disorder & 7 & 7 \\
\hline Major Depression & 0 & 2 \\
\hline Axis II & 3 & 6 \\
\hline Mixed Personality Disorder & 3 & 3 \\
\hline Borderline Personality Traits & 1 & 2 \\
\hline Narcissistic Personality Traits &
\end{tabular}




\begin{tabular}{|l|c|c|}
\hline Dependent Personality Traits & 1 & 0 \\
\hline Avoidant Personality Traits & 0 & 0 \\
\hline Race & 4 & 5 \\
\hline African American & 4 & 3 \\
\hline European American & 1 & 2 \\
\hline Hispanic/Latino American & 1 & 0 \\
\hline Asian American & 10 & 10 \\
\hline Total & 15.3 & 15.7 \\
\hline Average Age & & \\
\hline
\end{tabular}

TABLE 1

Means and Standard Deviations on Assessment Measures at Three Time Points By Treatment Groups

\begin{tabular}{|c|c|c|c|c|c|c|c|c|c|c|c|c|}
\hline & \multicolumn{6}{|c|}{ MDT } & \multicolumn{6}{|c|}{ TAU } \\
\hline & \multicolumn{2}{|c|}{ Baseline } & \multicolumn{2}{|c|}{3 Months } & \multicolumn{2}{|c|}{6 Months } & \multicolumn{2}{|c|}{ Baseline } & \multicolumn{2}{|c|}{3 Months } & \multicolumn{2}{|c|}{6 Months } \\
\hline & $\mathbf{M}$ & SD & $\mathbf{M}$ & SD & $\mathbf{M}$ & SD & $\mathbf{M}$ & SD & $\mathbf{M}$ & SD & $\mathbf{M}$ & SD \\
\hline BDI-II & 34.2 & 14.65 & 14.6 & 9.54 & 9.9 & 6.18 & 26.8 & 20.62 & 17.5 & 14.37 & 12.7 & 12.91 \\
\hline $\begin{array}{l}\text { SIQ- } \\
\text { HS }\end{array}$ & 57.2 & 29.29 & 10.9 & 14.43 & 7.2 & 7.37 & 55.4 & 49.34 & 18.6 & 18.90 & 12.9 & 13.66 \\
\hline
\end{tabular}

BDI-II = Beck Depression Inventory $2^{\text {nd }}$ Edition; SIQ-HS = Suicidal Ideation Questionnaire High School Form; MDT $=$ Mode Deactivation Therapy; TAU= Treatment as usual

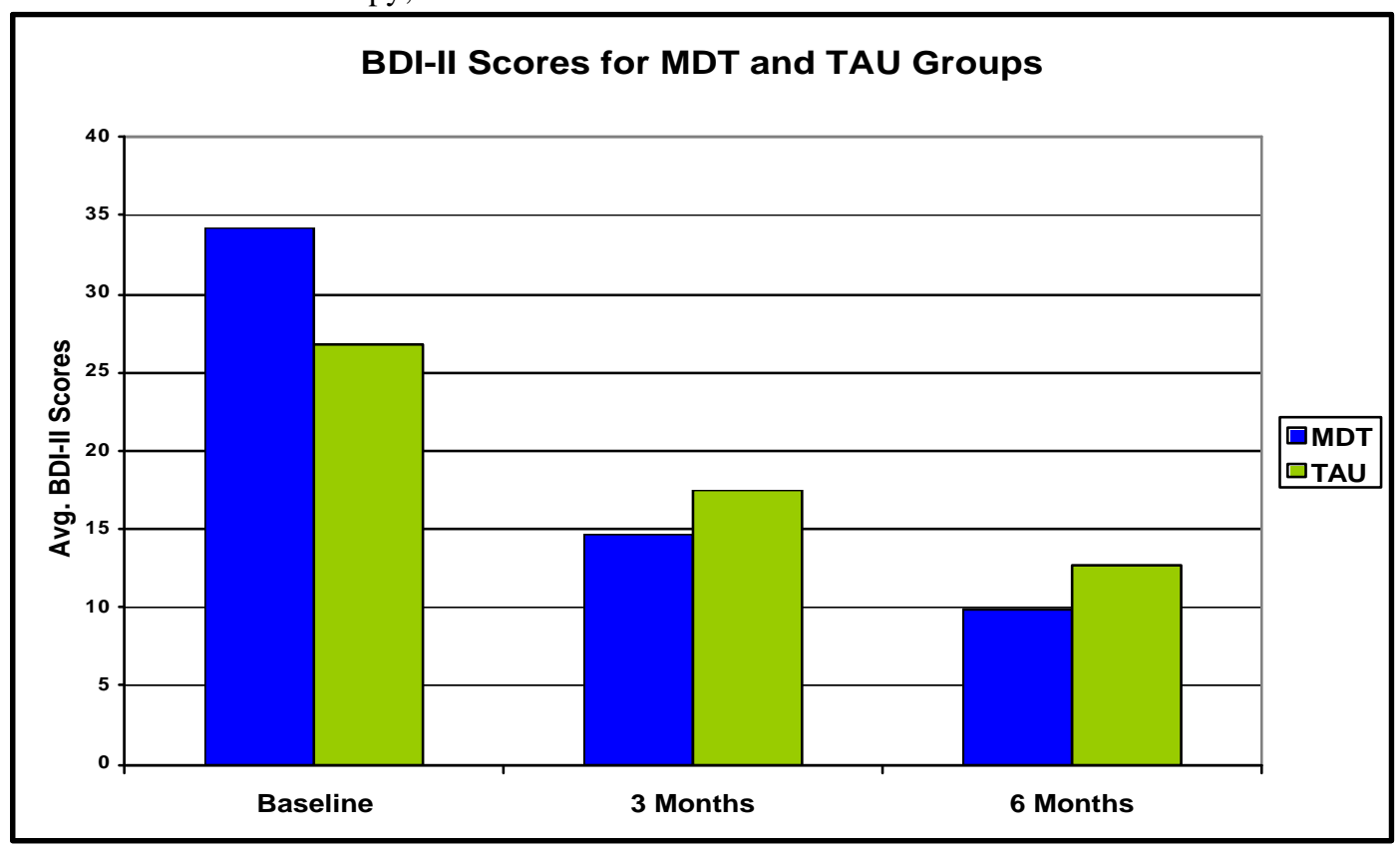

Figure 1: Means scores for BDI- II at three time points. Note: All baseline comparisons between groups were nonsignificant $(\mathrm{p}>.05) \mathrm{BDI}-\mathrm{II}=$ Beck Depression Inventory $2^{\text {nd }}$ Edition; MDT $=$ Mode Deactivation Therapy; TAU= Treatment as usual 


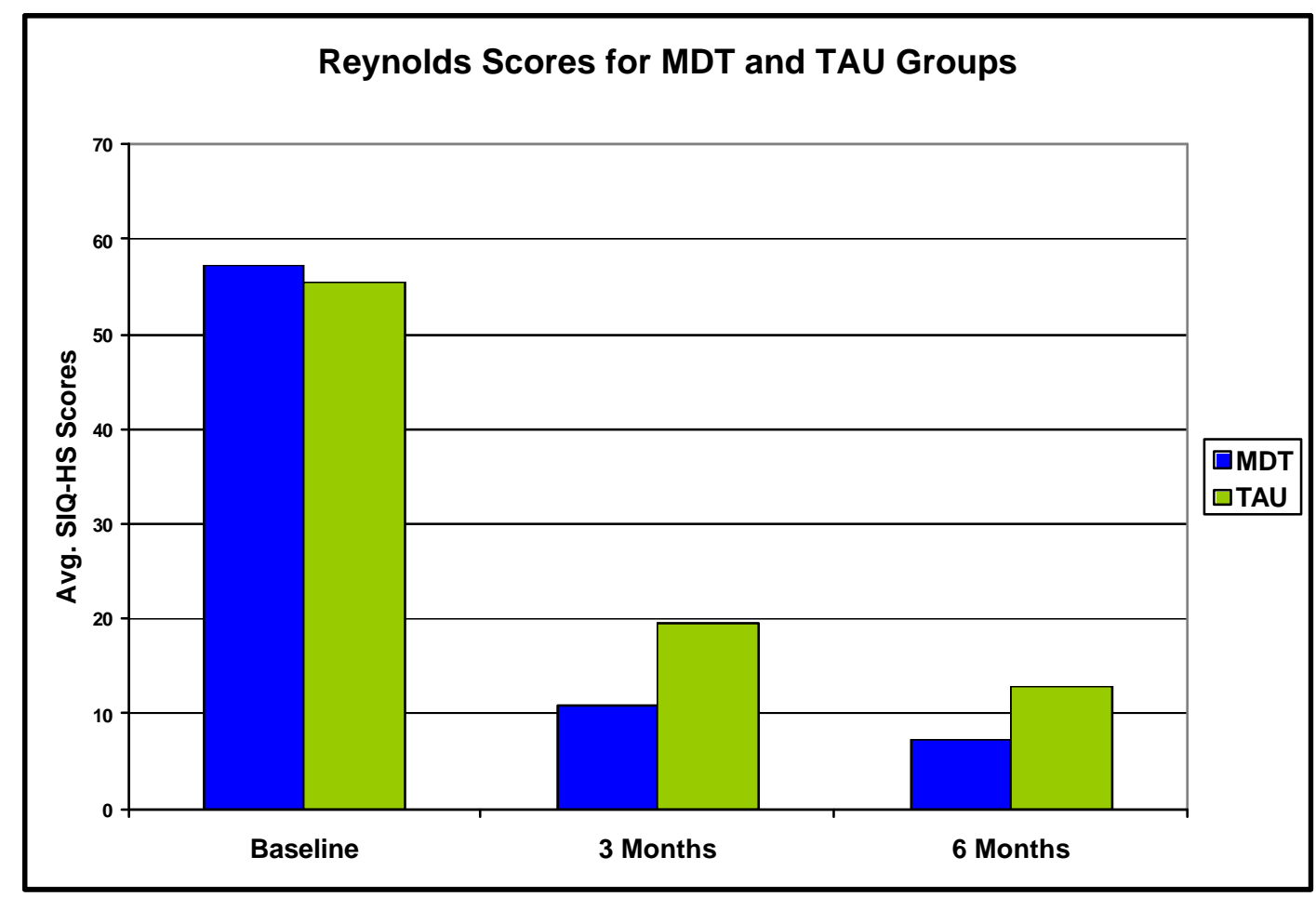

Figure 2: Mean Scores for SIQ-HS at three time points. Note: All baseline comparisons between groups were nonsignificant $(\mathrm{p}>$.05) SIQ-HS= Suicidal Ideation Questionnaire High School Form; MDT= Mode Deactivation Therapy; TAU $=$ Treatment as usual

Because the clinicians followed protocol of MDT, the fidelity was measured by review of video typed session and with the MDT clinician and the client's workbook. The MDT group achieved a $98 \%$ score of adherence by these measures.

\section{Summary}

MDT has shown evidence of promise as a effective treatment in adolescents with conduct disorder, and personality disorder or traits (Apsche et. al. 2004, 2005, 2006). This study suggests that MDT might be effective in treating these adolescent with suicidal ideation, cognitions or beliefs.

\section{Discussion}

It appears that MDT reduces the suicidal risk in this study as measured by the BDI-II and SIQHS assessments. MDT's effectiveness might be effective because it addresses both the personality disorder or traits and the axis I disorders. MDT was significantly more effective then TAU by over 1 SD per category.

These data suggest that MDT might be an effective methodology in reducing suicidal beliefs or traits in adolescents with axis I disorders, and personality disorders or traits.

There were several limits to this study. First as all of the MDT studies thus far, it was completed in a clinical residential setting, although all assignments to caseloads are random by assignments these are limits in this randomization, although the limits are also the strengths. The effects of MDT in less controlled setting suggest that the fidelity to the model might be more effective than more controlled studies. 
There are several limits to any clinical study that must be identified. Random assignments were made as openings occurred within the therapists caseloads. These openings were often more controlled by the availability of aftercare services arranged by the referral source, than by the specific skills of the individual therapists.

The authors hope that this treatment research might lead to another possible treatment of suicidal adolescents in the future.

\section{References}

Achenbach, T.M. (1991). Manual for the Child Behavior Checklist and 1991 profile. Burlington, VT: University of Vermont Department of Psychiatry.

Achenbach, T.M. (1991). Child Behavior Checklist, Assessment. Burlington, VT: University of Vermont Department of Psychiatry.

Alford, B.A. and Beck, A.T. (1997). The integrative power of cognitive therapy. New York: Guilford Press.

Apsche, J.A. (2005). Beck's theory of modes. International Journal of Behavioral Consultation and Therapy, 1(1), pp. 27-45.

Apsche, J.A. Theory of Modes and Impulses. Journal of Early and Intensive Behavior Intervention. 2. (1), pp. 14-18.

Apsche, J.A. (1999). Thought Change Workbook. Portsmouth, VA: Alternative Behavioral services.

Apsche, J.A., Bass, C.K. (2006). A Treatment Study of Mode Deactivation Therapy in an Out Patient Community Setting. International Journal of Behavior Consultation and Therapy. 2. (1). pp. 86-94.

Apsche,J.A., Bass,C.K., Jennings, J.L., Murphy,C.J., Hunter, L.A., and Siv, A. (2005). An empirical study of behavior: A comparison of Mode Deactivation Therapy, Cognitive Behavior Therapy and Social Skills Training. International Journal of Behavior Consultation and Therapy. 1. (2), pp. 113-132.

Apsche, J.A., Bass, C.K., Jennings, C.J., Siv, A.M. (2005). An empirical comparison between two treatments for adolescent males with conduct and personality disorders: Cognitive Behavior Therapy and Mode Deactivation Therapy. International Journal of Behavior Consultation and Therapy. 1. (1), pp. 27- 45.

Apsche, J.A., Bass, C.K., Murphy, C.J., (2004). A comparison of the effectiveness of Mode deactivation therapy, Cognitive behavior therapy in adolescents with conduct disorders. : The Journal of Behavior Analyst Today. Vol.5. No. 4. Winter.

Apsche, J.A., Bass, C.K., Siv, A.M. (2006). Summary of Mode Deactivation Therapy, Cognitive Behavior Therapy and Social Skills Training with Two Year Post Treatment Results. International Journal of Behavior Consultation and Therapy. 2. (1). pp. 29-44. 
Apsche, J.A., Bass, C.K., Siv, A.M. (2005). A review and empirical comparison of three treatments for adolescent males with conduct and personality disorder. International Journal of Behavior Consultation and Therapy. 1. (4). Pp. 312-322.

Apsche, J.A., Bass, C.K., Siv, A.M., Matteson, S.C. (2005). An empirical "Real World" comparison of two treatments with aggressive adolescent males. International Journal of Behavior Consultation and Therapy. 1. (3) pp. 239-251

Apsche, J.A., Siv, A.M (2005). Theoretical Case Analysis on a suicidal adolescent. International Journal of Behavior Consultation and Treatment. 1. (2), pp. 130-146.

Apsche, J.A., Siv, A.M., Bass, C.K. (2005). A Case Analysis of MDT with an Adolescent with Conduct and Personality Disorder. International Journal of Behavior Consultation and Therapy. 1. (4) pp. $312-322$.

Apsche, J.A., Siv, A.M., Matteson, S.C. (2005). A comparison of MDT and DBT: A case study and analysis. International Journal of Behavior Consultation and Therapy. 1, (3) pp. 205-215

Apsche, J.A. and Ward Bailey, S.R. (2003). Mode deactivation therapy: A theoretical case analysis (Part I). The Behavior Analyst Today, 4(3), 342-353.

Apsche, J.A. and Ward Bailey, S.R. (2004a). Mode Deactivation Therapy: Cognitive-behavioural therapy for young people with reactive conduct disorders or personality disorders or traits who sexually abuse. In M.C. Calder (Ed.), Children and Young People who Sexually Abuse: New Theory, Research and Practice Developments, pp. 263-287. Lyme Regis, UK: Russell House Publishing.

Apsche, J.A. and Ward Bailey, S.R. (2004b). Mode deactivation therapy: A theoretical case analysis (Part II). The Behavior Analyst Today, 5(1), 395-434.

Apsche, J.A. and Ward Bailey, S.R. (2004c). Mode deactivation therapy: A theoretical case analysis (Part III). The Behavior Analyst Today, 5(3), 314-332.

Arnett, J.J. (1999). Adolescent storm and stress, reconsidered. American Psychologist, Vol. 54, pp. 317326

Beck, A.T. (1996). Beyond belief: A theory of modes, personality and psychopathology. In P.M. Salkovaskis (Ed.), Frontiers of cognitive therapy, (pp. 1-25). New York: Guilford Press.

Beck, A.T., Beck R.W. (1972). Screening depressed patients in family practice: a rapid technique. Postgrad Med 52: 81-85

Beck, A.T. and Freeman, A. (1990). Cognitive therapy of personality disorders. New York: Guilford Press.

Beck, A.T., Freeman, A., Davis, D.D. and Associates. (1994). Cognitive Therapy of Personality Disorders. New York, Guilford Press.

Beck, A.T., Freeman, A., Davis, D.D. and Associates. (2004). Cognitive Therapy of Personality Disorders. New York, Guilford Press. 
Beck, A.T., Ward C., Mendelson M., Mock J., Erbaugh J. (1961). An Inventory for measuring depression. Arch Gen Psych 4: 53-63

Boesky, L.M. (2002). Juvenile offenders with mental health disorders: Who are they and what do we do with them? Lanham, MD: American Correctional Association.

Dodge, K.A., Lochman, J.E., Harnish, J.D., Petti, G.S. (1997). Reactive and proactive aggression in school children and psychiatrically impaired chronically assaultive youth. Journal of Abnormal Psychology, 106 (1), 37-51.

Freeman, A., Pretzer, J., Fleming, B., and Simon, K.M. (1990). Clinical applications of cognitive therapy. New York: Plenum.

Gunderson, J.G. (1984). Borderline personality disorder. Washington (DC). American Psychiatric Press.

Henggeler, S.W., Schoenwald, S.K., Borduin, C.M., Rowland, M.D. and Cunningham, P.B. (1998). Multisystemic treatment of antisocial behavior in children and adolescents. New York: Guilford Press.

Johnson, J.G., Cohen, P., Brown, J., Smailes, E.M., and Bernstein, D.P. (1999). Associations between four types of childhood neglect and personality disorder symptoms during adolescence and early adulthood: Findings of a community-based longitudinal study. Archives of General Psychiatry, 14, 171-120.

Kazdin, A.E. and Weisz, J.R. (2003). Evidenced-based psychotherapies for children and adolescents. New York: Guilford Press.

Kjellander, C., Bonger, B., King A. (1998). Suicidality in borderline personality disorder. Crisis: vol. 19 pp. 125-134

Koenigsberg, H.W., Harvey, P.D., Mitropoulou, V., Antonia, N.S., Goodman, M., Silverman, J., Serby, M., Schopick, F. and Siever, L. (2001). Are the interpersonal and identity disturbances in the borderline personality disorder criteria linked to the traits of affective instability and impulsivity? Journal of Personality, 15(4), 358-370.

Kohlenberg, R.J. and Tsai, M. (1993). Functional Analytic Psychotherapy: A behavioral approach to intensive treatment. In W. O'Donahue and L. Krasner (Ed.), Theories of behavior therapy: Exploring behavior change (pp. 638-640). Washington, D.C.: American Psychological Association.

Links, P.S., Gould, B., Ratnayake, R. (2003). Assessing suicidal youth with antisocial, borderline, or narcissistic personality disorder. The Canadian Journal of Psychiatry.

Linehan, M.M. (1993). Treating Borderline Personality disorder: The dialectical approach. New York: Guilford Press.

Marttunen, M.J., Aro, H.M., Henriksson, M.M., Lonnqvist, J.K. (1994). Antisocial behaviour in adolescent suicide. Acta Psychiatr Scand: vol. 89, pp. 167- 173 
Marttunen, M.J., Aro, H.M., Henriksson, M.M., Lonnqvist, J.K. (1991). Mental disorders in adolescents DSM-III-R Axes I and II among 13 to 19 year olds. Arch Gen Psychiatry: vol. 48, pp. 834- 839

Naglieri, J.A., LeBuffe, P.A. \& Pfeiffer, S.I. (1994). Devereux scales of mental disorder. San Antonio: The Devereux Foundation.

Naglieri, J.A., LeBuffe, P.A. \& Pfeiffer, S.I. (1994). Manual of the Devereux scales of mental disorder. San Antonio: The Devereux Foundation.

Nezu, A.M., Nezu, C.M., Friedman, S.H. and Haynes, S.N. (1998). Case formulation in behavior therapy: Problem-solving and Functional Analytic strategies. In T.D. Eells (Ed.), Handbook of psychotherapy case formulation. New York: Guilford Press.

Peters, K.D., Kochanek, K.D., \& Murphy, S.L. (1998). Deaths: Final data for 1996. National Vital Statistics Report, 49(9). Also available: Hyattsville, MD: National Center for Health Statistics, DHHS (pp.70 table 24)

Reynolds, W.M. (1988). Suicidal Ideation Questionnaire, Professional Manual Odessa, FL: Psychological Assessment Resources.

Runesson, B., Beskow, J. (1991). Borderline personality disorder in young Swedish suicides. J Nerv Mental Dis: vol. 179, pp. 153- 156

Shaffer, D., Could, M. \& Hicks, R. (1994). Worsening suicide reate in black teenagers. American Journal of Psychiatry: vol.151, pp. 1810 - 1812

Shaffer, D., Hicks, R. (1993). The epidemiology f child and adolescent suicide. In B. Press (Ed.). The Epidemiology of Childhood Disorders. New York: Oxford University Press.

Stone, M. (1989). Long-term follow-up of narcissistic personality disorder. Psychiatry Clinical North America: vol. 12, pp. 621-641

Swenson, C.C., Henggeler, S.W., Schoenwald, S.K., Kaufman, K.L., and Randall, J. (1998). Changing the social ecologies of adolescent sexual offenders: Implications of the success of multisystemic therapy in treating serious antisocial behavior in adolescents. Child Maltreatment, 3, 330-339.

Young, J.E., Klosko, J.S. and Weishaar, M.E. (2003). Schema therapy: A practitioner's guide. New York: Guilford Press.

Author contact information:

Jack A Apsche, Ed.D., ABPP

Apsche Center for Evidenced Based Psychotherapy

111 South Main Street

Yardley, PA 19067

jackmdt@aol.com

Christopher K. Bass, Ph.D.

Dept of Psychology 
Clark Atlanta University

207 Knowles Hall

Atlanta, GA 30313

cbass@cau.edu

Alexander M. Siv, MA, CAGS

Capital Academy

1770 Mt. Ephraim Ave.

Camden, NJ 08104

alexmsiv@hotmail.com

\section{ADVERTISING IN THE INTERNATIONAL JOURNAL OF BEHAVIORAL AND CONSULTATION THERAPY}

The prices for advertising in one issue are as follows:

1/4 Page: $\$ 50.00 \quad 1 / 2$ Page: $\$ 100.00$ vertical or horizontal Full Page: $\$ 200.00$

If you wish to run the same ad in multiple issues for the year, you are eligible for the

following discount:

1/4 Pg.: \$40 - per issue

1/2 Pg.: \$75 - per issue -vertical or horizontal

Full Page: \$150.00-per issue

An additional one time layout/composition fee of $\$ 25.00$ is applicable

For more information, or to place an ad, contact Halina Dziewolska via e-mail at: halinadz@hotmail.com 


\title{
Conjoint Behavioral Consultation: An Emerging and Effective Model for Developing Home-School Partnerships
}

\author{
Lee A. Wilkinson
}

\begin{abstract}
Conjoint Behavioral Consultation (CBC) is discussed as an emerging and effective model of home-school collaboration and shared problem solving. A case study is presented to demonstrate how practitioners can use $\mathrm{CBC}$ to deliver high quality consultation and intervention services to students, teachers, and parents in a real world setting. An evidence-based intervention (EBI) was implemented in the context of $\mathrm{CBC}$ to enhance the on-task and compliant behavior of a student referred for consultation. Results indicated a significant increase in teacher ratings of behavioral control (on-task and compliant behavior) following consultation. Positive treatment effects were maintained at a 4-week follow-up. Norm referenced measures produced statistically reliable and clinically meaningful changes in teacher perception of externalizing problem behavior. Consultees validated CBC as an acceptable and effective model of service delivery across home and school contexts. Limitations, future research, and implications for evidence-based practice are discussed.

Keywords: behavioral consultation, ecologicalsystems theory, home-school partnerships, selfmanagement.
\end{abstract}

The role of consultation in clinical and educational practice has expanded significantly over the past two decades. Consultation has become an important component in the shift from traditional assessment-driven structures to an ecological and problem solving paradigm of practice (Kratochwill \& Stoiber, 2000; Sheridan \& Gutkin, 2000). Research has established a preference for behavioral consultation (BC: Kratochwill \& Bergan, 1990) among consumers and practitioners of psychological services, as well as the efficacy of this approach when compared to other consultation models (e.g., mental health, instructional, organizational). Reviews, meta-analyses, and case studies (e.g., Bramlett \& Murphy, 1998; Kratochwill, Elliott, \& Busse, 1995; McLeod, Jones, Sommers, \& Havey, 2001; Medway \& Updyke, 1985; Sheridan, Welch, \& Orme, 1996; Wilkinson, 1997, 2003) have consistently documented the effectiveness of behavioral consultation as a vehicle for delivering interventions to students with a wide variety of learning and behavioral problems. The model is considered a powerful tool in remediating children's learning and behavioral problems and for delivering preventive interventions in general education settings.

Family-School Mesosystem

The empirical support for developing home-school relationships is quite strong. The benefits of parental involvement in the educational process are unequivocal (Sheridan and Gutkin, 2000). Two decades of research clearly indicate that students benefit when families are involved in collaborative relationships with educators and that a strong home-school partnership maximizes the potential for children's success in the classroom (Christenson, 1990). Active parent participation is related to positive student outcomes such as increased student achievement and less discipline problems in the school and at home (Christenson, 1995; Christenson, Rounds, \& Franklin, 1992). Moreover, positive interactions between parents and school personnel based on a common interest enhance the likelihood that behavioral 
interventions will be effective (Clark \& Fiedler, 2003). Gains in student performance are greatest when interventions focus on the reciprocal relationship between home and school rather than focusing only on the classroom or home environment (Christenson \& Sheridan, 2001).

\section{Conjoint Behavioral Consultation}

Despite the support for collaborative home-school efforts, few structured models of parent consultation are available. For example, traditional behavioral consultation involves the psychologist as consultant and teacher as consultee. The model does not typically include parents or caregivers in the behavior change process, thus omitting a valuable resource and opportunity to improve treatment generalization. Yet, the validation and use of systematic and empirically documented models of parentteacher consultation are especially important for children whose disruptive behavior extends across home and school settings, as these problems have far reaching implications for children's future adjustment. Conjoint rather than parallel consultation is necessary in order to provide the structure and support for teachers and parents to address the behavioral needs of children at home and in the classroom (Sheridan, Kratochwill, \& Bergan, 1996).

\section{Theoretical Framework}

$\mathrm{CBC}$ is an emerging model of consultation that provides a solution-oriented focus in which educators and parents are linked in a collaborative problem-solving process to address the academic, social, or behavioral needs of a student for whom all parties assume some responsibility (Sheridan \& Kratochwill, 1992; Sheridan et al., 1996). CBC incorporates the problem-solving stages and objectives of traditional behavioral consultation (problem identification, problem analysis, treatment implementation, treatment evaluation) and conceptually extends the model by focusing on the interacting systems in a child's life (home and school). Parents and teachers work cooperatively to identify and operationally define a problem, analyze behavioral data and develop a treatment plan, implement an intervention across settings, and conjointly evaluate the success of the treatment.

CBC is based on an integration of ecologicalsystems and behavior theory (Sheridan et al., 1996). The model is grounded on the assumption that behaviors are learned as a function of their interaction with the environment. The problem-solving process is guided by an examination of antecedent, situation, and consequent conditions in an effort to generate evidence-based interventions. However, unlike behavioral consultation in which a problem is analyzed molecularly, CBC considers the broader context in which behavior occurs (Sheridan et al., 1996). This conceptual framework recognizes the importance of the interrelations and linkages among a child's primary environments and the reciprocal influences of the home-school mesosystem on a child's behavior and learning (Bronfenbrenner, 1992; Sheridan, 1997). The child is considered a part of a system or network of systems. These systems overlap, and what occurs in one system affects the child's behavior in the other system. Moreover, problems do not reside exclusively within the child, or solely within his or her environments. Behavior is considered a function of the interaction of the system components in a child's life. CBC's theoretical perspective assumes that (a) change agents focus on observable behavior and not the underlying causes of behavior, (b) intervention strategies are based on learning principles, (c) interconnections between systems (home and school) in a child's life have a significant impact on behavior, and (d) problem resolution is shared between these systems (Sheridan, 1997; Sheridan et al., 1996). Thus, CBC combines the conceptual advantages of ecologicalsystems theory and the empirically validated structured approach of behavioral consultation to provide a potentially powerful model for intervention. 


\section{CBC Process}

CBC engages the parent and teacher in a collaborative problem-solving process with the assistance of a consultant, wherein the interconnections between home and school systems are considered critically important. Figure 1 depicts the interactive process in which the consultant joins the parent and teacher in a cooperative partnership with shared ownership of the problem. This process assumes that collaborative problem solving among all parties will afford the greatest benefits. Each person is recognized as possessing important knowledge and skills. Parents and teachers share information, value each another's input and incorporate their insights into intervention plans. Pooling resources, developing a clearer conceptualization of problems, and increasing the range of possible solutions are among the primary objectives of the CBC problem-solving process (Sheridan et al., 1996). A detailed description of CBC's process and outcome goals can be found in Sheridan et al., 1996.

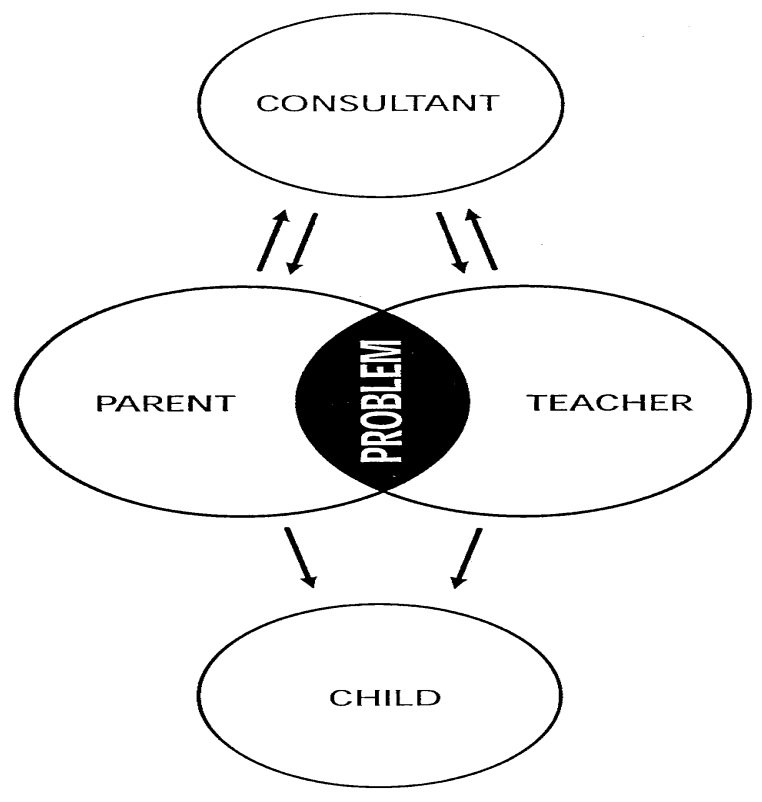

CBC Research

Figure 1. Model of Conjoint Consultation

The extant research on $\mathrm{CBC}$ is promising and suggests that the model can be an effective strategy for delivering evidenced-based interventions (EBIs) to students with diverse problems such as social skills deficits, attention-deficit/hyperactivity disorder (ADHD), academic underachievement, and disruptive behavior disorders (Colton \& Sheridan, 1998; Galloway \& Sheridan, 1994; Sheridan, Eagle, Cowan, \& Mickelson, 2001; Sheridan, Kratochwill, \& Elliott, 1990; Weiner, Sheridan, \& Jenson, 1998; Wilkinson, 2005a). Research also suggests that empirically supported treatments delivered via the CBC 
model result in greater behavior change than interventions implemented solely by teachers or parents (e.g., Galloway \& Sheridan, 1994; Sheridan et al., 1990). Likewise, survey research indicates that CBC is more acceptable to parents, teachers, and school psychologists than parent-only or teacher-only consultation for implementing interventions for students with academic, behavior, and social/emotional problems (Freer \& Watson, 1999; Sheridan \& Steck, 1995).

\section{Case Study Example}

A case study example is presented here to demonstrate how practitioners can apply CBC and partner with parents and educators to address the learning and behavioral needs of children in a real world context. Application of the CBC model was informed by the strong empirical foundation for parent involvement and applied research indicating the importance of the family-school mesosystem when intervening with children's problems. CBC was used to structure and deliver positive behavioral support for a student referred for consultation. An evidence-based intervention (EBI) consisting of selfmanagement, goal setting, and contingency reinforcement across settings was delivered via the consultation process to address the student's off-task and noncompliant behavior. Ratings of classroom behavior and an empirically based measure of externalizing problem behavior served as primary outcome measures. Assessment of social validity included teacher and parent subjective ratings of CBC's acceptability and effectiveness.

\section{Participants}

Participant selection for this case vignette was based on teacher concerns and perceptions of classroom behavior. The primary reason for student referral was disruptive behavior that interfered with ability to complete tasks and comply with classroom rules. Selection criteria included (a) teacher referral, (b) verified disruptive behavior disorder through the Diagnostic and Statistical Manual of Mental Disorders (DSM-IV TR; American Psychiatric Association, 2000) classification system, (c) general education placement, (d) informed written consent, and (e) a clinically significant rating on the broad based Externalizing scale of the Child Behavior Checklist - Teacher's Report Form (CBCL-TRF; Achenbach \& Rescorla, 2001).

Mark.

Mark was an 11-year old fifth grade student identified with attention-deficit/hyperactivity disorder (ADHD) and oppositional defiant disorder (ODD) who fully included in his general education classroom with 27 classmates. He demonstrated chronic behavioral control problems characterized by significant impulsivity and noncompliance across settings. Parent and teacher reported high levels of attention problems, poor peer relationships, and oppositional behavior that interfered with learning and adjustment. Teacher ratings indicated that he was behaving and learning much less than same age peers and had marked difficulty regulating emotional and behavioral responses. Mark's cognitive and academic skills were considered to be within normal limits according to norm-referenced measures. TRF syndrome (Social Problems, Attention Problems, and Aggressive Behavior) and broad-based externalizing scale scores were elevated and indicated significantly more behavior problems than typically reported by teachers of students of a comparable age and gender. Teacher endorsements included: Argues a lot; Impulsive, acts without thinking; Not liked by other students; Can't sit still, restless; Disturbs other students; and Fails to carry out assigned tasks. Mark's mother and teacher, an educator with 17 years of classroom experience, served as joint consultees.

\section{Consultation Phases}


The consultant and consultees participated jointly in 3 structured interviews: a conjoint problem identification interview (CPII), conjoint problem analysis interview (CPAI), and conjoint treatment evaluation interview (CTEI). The consultant incorporated a conjoint treatment monitoring interview (CTMI) as part of the CBC process to enhance fidelity to the intervention plan (treatment integrity). All interviews were conducted in the school's conference room at mutually convenient times and ranged from 60 to 90 minutes in length. The consultation phases were completed over a 6-week time period.

Problem Identification Interview. A conjoint problem identification interview (CPII) were conducted with consultees to (a) establish rapport and a climate of shared responsibility, (b) share information about the goals of CBC, (c) establish agreement about roles and responsibilities, (d) operationally define target behaviors, and (e) discuss data collection procedures. Consistent with $\mathrm{CBC}$, the consultation team reviewed the referral information and reached a consensus regarding the nature of the problem and the desired outcomes off consultation. The consultation team identified off-task behavior and noncompliance with teacher requests/classroom rules as the primary targets for classroom intervention. Off-task behavior was operationally defined as behaviors where the student, after initiating the appropriate task-relevant behavior, attends to stimuli other than the assigned work. Noncompliance was defined as failure on the part of the student to initiate appropriate behavior in response to an adult request or classroom rule. These target behaviors were considered appropriate as they were rated as the most problematic across school and home settings.

An observational ratings recording method was selected as the most convenient and efficient method of documenting Mark's challenging classroom behavior. Ratings recording provide a solution to the dilemma of balancing the need for an accurate measure of behavior with the demands of time, resources, and expertise available to the classroom teacher. This method has been shown to be an accurate, reliable, and efficient strategy for assessing the more global aspects of problem behavior in authentic classroom settings (Abidin \& Robinson, 2002; Sattler, 2002; Steege, Davin, \& Hathaway, 2001).

Mark's behavior was rated by his teacher two or three times weekly following 50-minute observational periods that included both independent and small-group instructional activities. This reduced the time demands required for observation but still provided a reasonable sample of student behavior with which to evaluate the intervention. The target behaviors of off-task behavior and noncompliant behavior were aggregated under the global category of "disruptive off-task behavior" (Hoff \& DuPaul, 1998; Wilkinson, 1997). Ratings were made on a 9-point Likert-type scale with 1 indicating a high rate of problem behavior occurrence and 9 indicating a low rate of problem behavior occurrence (e.g., 1 to $3=$ poor; 4 to $6=$ needs improvement; 7 to $9=$ good).

Prior to data collection, the consultant didactically trained Mark's teacher to: (a) observe the student and identify target behaviors, (b) review the Likert scale, and (c) practice observing and recording the corresponding numerical rating. During the practice sessions, the consultant independently rated the student's behavior until interrater agreement reached $80 \%$. Behavioral ratings data were collected throughout all phases of consultation (baseline, treatment implementation, and follow-up) and used as time-series data to document the effectiveness of the intervention plan.

Problem Analysis Interview. A conjoint problem analysis interview (CPAI) was conducted following the baseline phase of consultation. The consultation team analyzed the behavioral data, explored alternative intervention strategies, agreed upon a goal for behavioral change, and discussed implementation of a behavior intervention plan. A conditions analysis review of the baseline data revealed consistently high 
ratings of target problem behavior (noncompliance and off-task behavior) during unstructured activities such as independent and small group classroom instruction. Mark was most often oppositional and off-task when given a teacher/parent directive or when he desired individual attention and social control. He demonstrated considerable difficulty regulating his own behavior in these situations and relied on adults and other external contingencies to direct and maintain appropriate behavior. Traditional teacher managed contingency strategies were only minimally successful in reducing Mark's problematic behavior.

Following a discussion of intervention strategies with empirically validated acceptability and efficacy, and a closeness of match with home and school ecosystems, the consultant recommended a self-

management package consisting of self-monitoring, goal setting, and home-school contingency reinforcement as the CBC-based treatment plan. Self-management interventions have strong empirical support for improving a wide range of academic and behavioral outcomes for students (e.g., Cole \& Bambara, 2000; Hoff \& DuPaul, 1998; McDougall, 1998; Shapiro \& Cole, 1994; Stage \& Quiroz, 1997; Wilkinson, 2005b). The mutually agreed upon goal of the intervention was to reduce Mark's challenging behavior by applying a self-monitoring procedure in the classroom and contingent reinforcement across home and school settings. This technique afforded the student an opportunity to develop the strategies needed to increase prosocial behaviors and reduce his reliance on adults and teacher-managed contingencies. Parent and teacher were asked to involve Mark in the selection of incentives and develop a reinforcement menu of tangible and activity rewards to ensure he received positive reinforcement in school and at home.

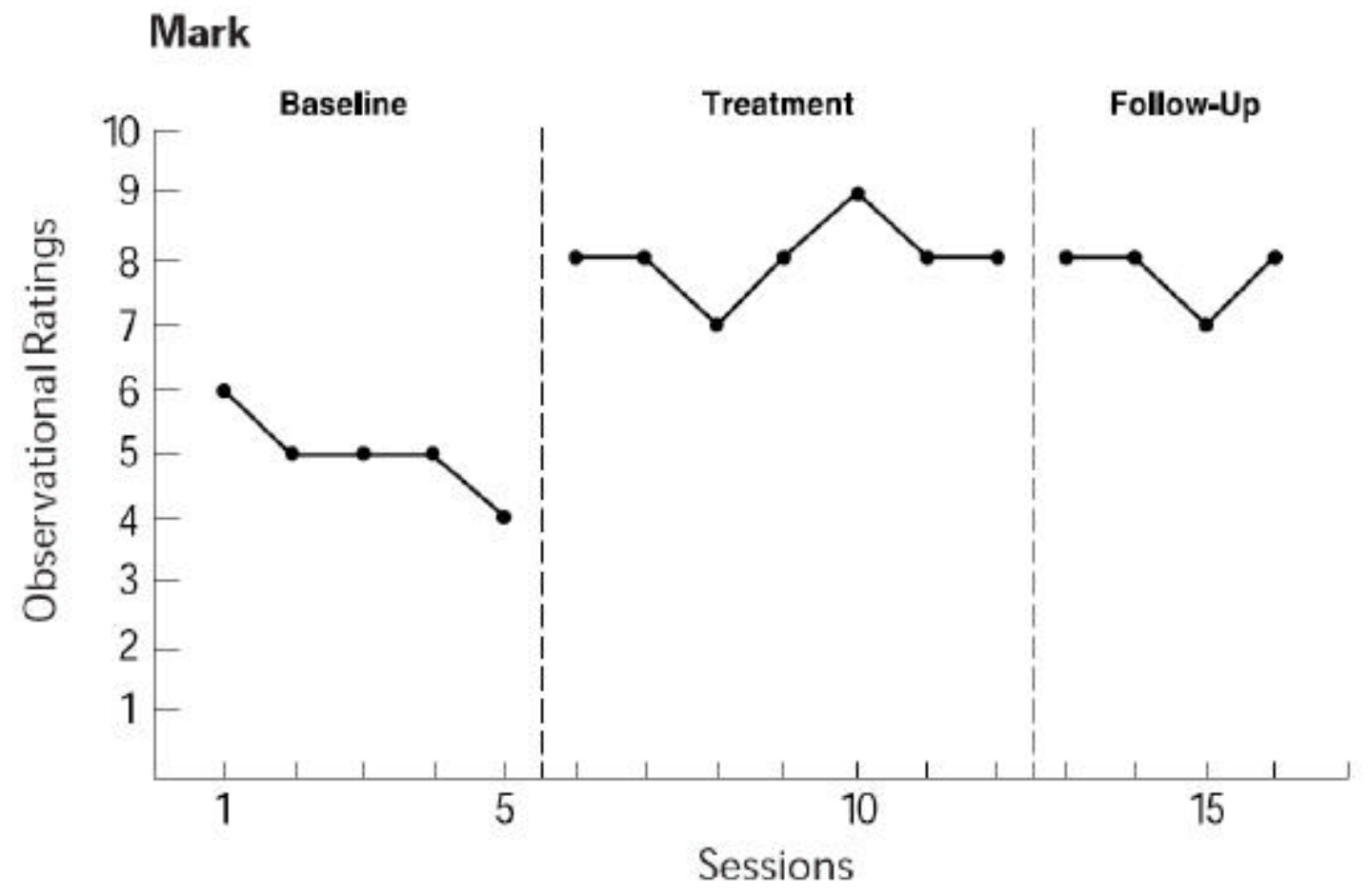


Treatment (Plan) Implementation. The self-management intervention was delivered to Mark during the treatment implementation phase of $\mathrm{CBC}$. Two primary components were involved in the procedure: (a) self-assessment and (b) self-recording. Self-assessment involved the covert questioning of behavior (e.g., Was I paying attention?) and self-recording the overt documentation of the response to the self-assessment question on a recording form. Mark was told "self-management means accepting responsibility for managing and controlling your own behavior so that you can accomplish the things you want in school and at home." He was also given positive and negative examples of the behavioral cycle and a definition of the target behaviors to be self-monitored. On-task behavior was defined as (a) seated at own desk, (b) eyes on the teacher, board, or seatwork, (c) work materials on desk, and (d) reading or working on an assignment. Compliant behavior was defined as following classroom rules by (a) asking relevant questions of teacher and neighbor, (b) raising hand and waiting turn before responding, (c) interacting appropriately with other students, and (d) complying with teacher instructions/directives. Mark's teacher modeled the on-task behaviors and described classroom scenarios indicative of appropriate behavior. The self-management procedure was also demonstrated to ensure the student's understanding of the self-assessment and self-recording components of the intervention.

Following 2 days of practice, Mark self-monitored his behavior on a daily basis for a 3-week period. This timeframe was considered sufficient to observe a change in behavioral functioning. A selfrecording sheet was taped to the upper right hand corner of the student's desk. Because he was the only student who was self-monitoring in the classroom and other students might be disturbed by an auditory cue, Mark's teacher physically cued him to self-monitor by tapping the corner of the desk, on average, every 10 minutes during approximately 50 minutes of independent and small-group classroom instruction. (Cole, Marder, \& McCann, 2000; Shapiro, Durnan, Post, \& Skibitsky Levinson, 2002). When cued, Mark asked himself "Was I on task?" and "Was I following directions/classroom rules?" He then marked the self-recording sheet with a "plus" (yes) or "minus" (no), indicating the response to the self-assessment questions. Daily goals were set at equal to or greater than $80 \%$ positive responses for on-task and compliant behavior. Mark's teacher held a brief meeting with him each day to review ratings, determine whether behavioral goals were met, and sign the self-recording sheet. When his daily goals were met, Mark could make a selection from a group of incentives such as additional computer time, access to a preferred game or activity, extra recess time, etc. Because home-school communication was an essential feature of consultation and treatment, the self-recording sheet was sent home each day for parent signature so that Mark's mother could review her child's behavior and provide rewards contingent on meeting behavioral goals. The self-management intervention continued for a minimum of 15 school days after which the procedure was faded by increasing the intervals between self-monitoring cues. The goal was to have Mark self-monitor his behavior independently.

Treatment monitoring interview. Mark's teacher continued to collect observational data during the treatment implementation phase of consultation. The consultant checked data collection, visited the classroom, and conducted a conjoint treatment monitoring interview (CTMI) to (a) identify barriers and obstacles to plan implementation, (b) evaluate the extent to which the self-monitoring steps were completed, and (c) examine permanent products such as Mark's self-monitoring sheets, home-school notes, and consultees' behavioral reports/summaries. A performance review was then completed and social praise provided for accurate implementation of the intervention plan across settings. The primary objective of the CTMI was to facilitate consultees' cooperation by providing direct support and performance feedback, thus minimizing resistance and increasing the strength of the intervention plan 
(Butler, Weaver, Doggett, \& Watson, 2002; Jones, Wickstrom \& Friman, 1997; Noell, Duhon, Gatti, \& Connell, 2002).

Treatment Evaluation Interview. A conjoint treatment evaluation interview (CTEI) was conducted following treatment implementation to discuss progress towards consultation goals, modifications to the treatment plan, and to determine whether the intervention plan was effective. A judgment of the congruence between consultation objectives and performance was based on the comparison of the data collected during the baseline and treatment phases of CBC. Parent and teacher were asked whether consultation services should be kept in place, modified or terminated. Because consultees were generally satisfied with the improvement in Mark's behavior, the self-monitoring intervention plan was faded. Consultees agreed to continue their home-school communication via a daily report of student behavior. Mark's teacher completed 4 observational ratings sessions approximately one month later to determine maintenance of treatment effects.

\section{Results}

\section{Observational Ratings}

Figure 1 graphically displays the observational ratings scale data for Mark across consultation phases. Visual analysis indicates a stable baseline and an immediate effect on his challenging behavior with the introduction of the treatment plan. Calculation of the magnitude of behavioral change produced a large treatment effect size $(E S=4.61)$. The behavioral trend was positive with $100 \%$ nonoverlapping data points $(P N D)$ from baseline to treatment. Mark's behavioral control (on-task behavior and compliance) increased $60 \%$ over the baseline phase of consultation. Mean teacher ratings improved from $5.00(S D=$ $0.66)$ at baseline to $8.21(S D=0.69)$ during treatment implementation. Behavior rating data collected at a 4-week follow-up reflects maintenance of positive treatment effects, Mark's behavior control remaining 42 $\%$ above baseline conditions.

\section{Behavioral Checklist}

The Teacher's Report Form (TRF; Achenbach \& Rescorla, 2001) was administered at baseline and following consultation to determine perceived changes in challenging behavior. The TRF is among the most frequently used empirically-based instruments for quantifying children's internalizing and externalizing behavior problems. The reliable change index (RC) was used to determine whether Mark's TRF scale scores were significantly reduced following treatment (Gresham \& Noell, 1993; Jacobson, Follette, \& Revenstorf, 1984). This index is the student's difference score (post - pre) divided by the standard error of measurement. An RC of larger than $+/-1.96$ indicates that treatment produced a significant $(\mathrm{p}<.05)$ change in behavior. TRF raw scores were used for analyses rather than $T$-scores in order to maximize statistical power and take in account the full range of variation in the scales (Achenbach \& Rescorla, 2001). Normative comparisons of TRF data were used to determine whether changes in Mark's T-scores moved from the clinical to the normative range of functioning following consultation.

As indicated in Table 1 (next page), there was a statistically reliable change in behavior from preto post- treatment ( $\mathrm{p}<.05$ ) on the TRF Attention Problems, Aggressive Behavior, Social Problems, and Externalizing behavior scales. Mark's $T$-scores also fell below the borderline clinical cut point to the normative range of functioning for the Attention Problems, Aggressive Behavior, and Social Problems 
syndrome scales $(T=<65)$ and the broad based Externalizing behavior scale $(T=<60)$ following consultation.

\section{Table 1}

Pre- and Post Consultation TRF Scale Scores

Raw Score

Pre

Post

$3 *$

$19 *$

14

11

\section{T-Score}

\begin{tabular}{lrrrr}
\hline Soc & 7 & $3 *$ & 68 & $59 * *$ \\
Attn & 38 & $19 *$ & 70 & $59 * *$ \\
Agg & 14 & $3 *$ & 65 & $55 * *$ \\
Ext & 11 & $3 *$ & 60 & $53 * *$ \\
\hline
\end{tabular}

Soc $=$ Social Problems; Attn = Attention Problems; Agg = Aggressive Behavior;

Ext $=$ Externalizing behavior. ${ }^{*}$ Denotes a statistically reliable change between pre- and postreatment $(\mathrm{p}$ $<.05)$. ** Denotes clinically significant change between pre- and posttreatment syndrome $T$-scores.

Note. The data are from "An evaluation of conjoint behavioral consultation as a model for supporting students with emotional and behavioral difficulties in mainstream classrooms," by L. A. Wilkinson, 2005, Emotional and Behavioural Difficulties, 10,

p. 129. Copyright by 2005 by Sage Publications. Reprinted with permission.

\section{Social Validity}

An adaptation of the Behavior Intervention Rating Scale (BIRS; Von Brock \& Elliott, 1987) was used to assess consultees' perceptions of the acceptability and effectiveness of CBC and the selfmanagement intervention. This instrument has been used to document social validity outcomes in consultation practice and research (Sheridan et al., 2001; Wilkinson, 2005a). Mark's parent and teacher completed the BIRS following the final consultation interview. The higher the ratings, the more acceptable and effective the consultation process and intervention plan. 
On a 6-point Likert scale ranging from Strongly Disagree to Strongly Agree, Mark's parent and teacher reported average acceptability item ratings of 5.83 and 5.63, respectively. This translates to a high level of perceived acceptability. Among the items that consultees endorsed as highly acceptable were "Consultation was an acceptable intervention for the problem," "The problem was severe enough to warrant the use of consultation," "Most parents and teachers will find consultation appropriate for other behavior problems," and "I would be willing to use consultation again."

The consultees' subjective perception of the CBC's effectiveness of yielded average parent and teacher ratings of 5.08 and 5.07, respectively. This suggests that consultees viewed CBC as a highly effective process. Items rated as most effective included "Consultation should produce a lasting improvement," "The child's behavior should remain at an improved level," and "consultation not only improved the child's behavior in the classroom and at home, but in other situations as well."

\section{Treatment Integrity}

The success or failure of a behavioral intervention is largely dependent on the extent to which it is implemented as intended or planned by the change agent (e.g., teacher), or what has been termed treatment integrity (Gresham, 1989). Treatment integrity reflects the accuracy and consistency with which each component of the treatment or intervention plan is implemented. Therefore, it is essential that treatment integrity information be collected when implementing school-based interventions in order to distinguish between ineffective treatments and potentially effective treatments implemented with poor integrity (Gresham, 1989).

In order to enhance the treatment integrity of the consultation process the consultant used detailed protocols to ensure that each interview included the goals and objectives for CBC (see Sheridan et al, 1996). The treatment integrity of the intervention plan was assessed and monitored through direct observation, interviews with consultees, and permanent products. To verify fidelity to the self-management procedure, Mark's teacher was asked to complete a treatment plan checklist by indicating whether each component (e.g., cued student to self-monitor, gave incentive when earned, sent self-recording checklist home for signature) was fully or partially implemented. Checklists, home-school notes, self-recording sheets, and anecdotal records were analyzed during the treatment monitoring interview (CTMI) and at the conclusion of consultation to determine the level of treatment integrity. The consultation team posited that the selfmonitoring program was consistently implemented as planned approximately $90 \%$ of the time, thereby indicting a high level of treatment fidelity.

\section{Case Discussion}

This case study vignette illustrates the effectiveness of ecological systems theory in a relatively new and emerging area of consultation. Despite the constraints and limitations associated with applied research and practice (e.g., threats to internal validity), the data gathered across the baseline, treatment, and follow-up phases provide important and useful information. The intervention package consisting of $\mathrm{CBC}$ and self-management was associated with an immediate and distinguishable improvement in behavioral control (on-task and compliant behavior). The positive behavioral changes demonstrated during $\mathrm{CBC}$ were also maintained over time. Consultees expressed considerable satisfaction with the process (acceptability) and outcomes (effectiveness) of consultation. They consistently agreed that CBC was an acceptable and effective process to use for the students' behavior problems and that most parents and teachers would find the model appropriate for other behavior problems as well. Importantly, Mark's parent 
socially validated $\mathrm{CBC}$ and the treatment plan by reporting concurrent improvement in her children's home behavior, thereby suggesting generalization of treatment effects across settings (Gresham, 2004). Likewise, consultees indicated a strong willingness to use $\mathrm{CBC}$ again and recommended the use of consultation to other parents and teachers.

An important consideration is whether $\mathrm{CBC}$ and self-monitoring produced socially important changes in Mark's classroom behavior. According to the TRF, there was a statistically reliable and clinically meaningful change in his attention problems, noncompliance, and overall externalizing behavior following consultation. The reduction in aggressive behavior is especially salient in that decreases on the TRF aggressive behavior syndrome and broad-based externalizing problems scales are associated with significant improvement in classroom functioning as well as less restrictive educational placement (Mattison \& Spitznagel, 2001). The decrease in Mark's attention problems is also important, further suggesting that $\mathrm{CBC}$ and self-monitoring might be a viable strategy for reducing the challenging behavior associated with ADHD (Barkley, 2006; DuPaul \& Stoner, 2003).

A fundamental goal in school-based behavioral consultation is the demonstration that changes in behavior are related to the systematic implementation of intervention plans and not to other extraneous variables. Treatment plans are developed with the expectation that they will be implemented as intended and not modified by the change agent (treatment integrity). Many failures in school-based consultation can be attributed to consultee resistance and absent or weak treatment integrity, despite an intervention's demonstrated empirical support (Cautilli, Riley-Tillman, Axelrod, \& Hineline, 2005; Gresham, 1989). A noteworthy feature of this case study is the inclusion of a structured treatment monitoring interview (CTMI) designed to promote a collaborative consultant-consultee relationship, increase consultees' problem-solving efforts and shared ownership of the treatment plan, and improve their self-efficacy. Expanding the $\mathrm{CBC}$ model to include a treatment monitoring phase, rather than only brief informal contacts, can be a practical and effective method of providing valuable performance feedback to consultees, thereby lessening resistance, enhancing treatment integrity, and improving generalization (Codding, Feinberg, Dunn, \& Pace, 2005; Tillman, 2000).

\section{Conclusion}

The case study presented here illustrates how $\mathrm{CBC}$ can be a useful vehicle for promoting a shared responsibility between home and school systems and that applying empirically supported interventions within the model can result in acceptable and effective behavioral outcomes. Research clearly indicates that students benefit from home-school partnerships and that parent involvement maximizes the potential of positive treatment effects for children (Christenson, 2004; Christenson \& Sheridan 2001). CBC offers practitioners a structured approach for intervening and engaging educators and families in shared problem solving, which, in turn, has the potential for enhancing children's behavioral competency. The model provides a framework within which professionals can foster a collaborative process with parents and teachers and deliver high quality consultative services to all stakeholders in real world settings. CBC holds considerable promise for improving services to teachers, families, and students by bridging the gap between home and school contexts, promoting shared ownership across systems for problem solution, and strengthening relationships among participants (Sheridan et al., 1996).

\section{References}

Abidin, R. R., \& Robinson, L. L. (2002). Stress, biases, or professionalism: What drives teachers' referral judgments of students with challenging behaviors? Journal of 
Emotional and Behavioral Disorders, 10, 204-212.

Achenbach, T. M., \& Rescorla, L. A. (2001). Manual for the ASEBA School-Age Form \& Profiles. Burlington, VT: University of Vermont, Research Center for Children, Youth, and Families.

American Psychiatric Association (2000). Diagnostic and Statistical Manual of Mental Disorders, Text Revision (4th ed.). Washington, DC: Author

Barkley, R. A. (2006). Attention-deficit hyperactivity disorder: A handbook for diagnosis and treatment (3rd ed.). New York: Guilford Press.

Bramlett, R. K., \& Murphy, J. J. (1998). School psychology perspectives on consultation: Key contributions to the field. Journal of Educational and Psychological Consultation, 9, 29-55.

Bronfenbrenner, U. (1992). Ecological systems theory. In R. Vasta (Ed.), Annals of child development: Revised formulations and current issues (pp. 187-249). London: Jessica Kingsley.

Butler, T. S., Weaver, A. D., Doggett, R. A., \& Watson, T. S. (2002). Countering teacher resistance in behavioral consultation: Recommendations for the school-based consultant. The Behavior Analyst Today, 3, 282-288.

Cautilli, J., Riley-Tillman, Axelrod, S., \& Hineline, P. (2005). Current behavioral models of client and consultee resistance: A critical review. International Journal of Behavioral Consultation and Therapy, 1, 147-164.

Christenson, S. L. (1990). Differences in students' home environments: The need to work with families. School Psychology Review, 19, 505-517.

Christenson, S. L. (1995). Best practices in supporting home-school collaboration. In A. Thomas \& J. Grimes (Eds.), Best practices in school psychology III (pp. 253267). Washington, DC: National Association of School Psychologists.

Christenson, S. L. (2004). The family-school partnership: An opportunity to promote the learning competence of all students. School Psychology Review, 33, 83-104.

Christenson, S. L., Rounds, T., \& Franklin, M. J. (1992). Home-school collaboration: Efforts, issues, and opportunities. In S. L. Christenson \& J. C. Conoley (Eds.), Home-school collaboration: Enhancing children's academic and social competence (pp. 19-51). Silver Spring, MD: National Association of School Psychologists.

Christenson, S. L., \& Sheridan, S. M. (2001). School and families: Creating essential connections for learning. New York: Guilford Press.

Clark, D., \& Fiedler, C. R. (2003). Building family-school relationships during the assessment and intervention process. In M. J. Breen \& C. R. Fiedler (Eds.), 
Behavioral approach to assessment of youth with emotional/behavioural disorders (pp. 561-585). Austin, TX: Pro-Ed.

Codding, R. S., Feinberg, A. B., Dunn, E. K., \& Pace, G. M. (2005). Effects of immediate Performance feedback on implementation of behavior support plans. Journal of Applied Behavior Analysis, 38, 205-219.

Cole, C. L., \& Bambara, L. M. (2000). Self-monitoring: Theory and practice. In E. S. Shapiro \& T. R. Kratochwill (Eds.), Behavioral assessment in schools: Theory, research, and clinical foundations ( $2^{\text {nd }}$ ed.) (pp. 202-232). New York: Guilford.

Cole, C. L., Marder, T., \& McCann, L. (2000). Self-monitoring. In E.S. Shapiro \& T. R. Kratochwill (Eds.), Conducting school-based assessments of child and adolescent behavior (pp. 121-149). New York: Guilford.

Colton, D. L., \& Sheridan, S. M. (1998). Conjoint behavioral consultation and social skills training: Enhancing the play behaviors of boys with attention deficit Hyperactivity disorder. Journal of Educational and Psychological Consultation, 9, 328.

DuPaul, G. J., \& Stoner, G. (2003). ADHD in the schools: Assessment and intervention strategies (2nd ed.). New York: Guilford.

Freer, P., \& Watson, T. S. (1999). A comparison of parent and teacher acceptability ratings of behavioral and conjoint behavioral consultation. School Psychology Review, 28, 672- 684.

Galloway, J., \& Sheridan, S. M. (1994). Implementing scientific practices through case studies: Examples using home-school intervention and consultation. Journal of School Psychology, 32, 385-413.

Gresham, F. M. (1989). Assessment of treatment integrity in school consultation and prereferral intervention. School Psychology Review, 18, 37-50.

Gresham, F. M. (2004). Current status and future directions for school-based behavioral interventions. School Psychology Review, 33, 326-343.

Gresham, F. M., \& Noell, G. H. (1993). Documenting the effectiveness of consultation outcomes. In J. E. Zins, T. R. Kratochwill, \& S. N. Elliott (Eds.), Handbook of consultation services for children: Applications in educational and clinical settings (pp. 249-273). SanFrancisco, CA: Jossey-Bass.

Hoff, K. E., \& DuPaul, G. J. (1998). Reducing disruptive behavior in general education classrooms: The use of self-management strategies. School psychology review, 27, 290-303.

Jacobson, N. S., Follette, W. C., \& Revenstorf, D. (1984). Psychotherapy outcome research: Methods for reporting variability and evaluating clinical significance. Behavior Therapy, 15, 336-352. 
Jones, K. M., Wickstrom, K. F., \& Friman, P. C. (1997). The effects of observational feedback on treatment integrity in school-based behavioral consultation. School Psychology Quarterly, 12, 316-326.

Kratochwill, T. R., \& Bergan, J. R. (1990). Behavioral consultation in applied settings: An individual guide. New York: Plenum.

Kratochwill, T. R., Elliott, S. N., \& Busse, R. T. (1995). Behavior consultation: A five year evaluation of consultant and client outcomes. School Psychology Quarterly, 10, 87-117.

Kratochwill, T. R., \& Stoiber, K. C. (2000). Uncovering critical research agenda for school psychology: Conceptual dimensions and future directions. School Psychology Review, 29, 591-603.

MacLeod, I. R., Jones, K. M., Somers, C. L., \& Havey, J. M. (2001). An evaluation of the effectiveness of school-based behavioral consultation. Journal of Educational and Psychological Consultation, 12, 203-216.

Mattison, R. E., \& Spitznagel. E. L. (2001). Longitudinal use of the Teacher's Report Form in tracking outcome for students with SED. Journal of Emotional and Behavioral Disorders, 9, 86-93.

McDougall, D. (1998). Research on self-management techniques used by students with disabilities in general education settings. Remedial and Special Education, 19, 310-321.

Medway, F. J., \& Updyke, J.F. (1985). Meta-analysis of consultation outcome studies. American Journal of Community Psychology, 13, 489-504.

Noell, G. H., Duhon, G. J., Gatti, S. L., \& Connell, J. E. (2002). Consultation, follow-up, and implementation of behavior management interventions in general education. School Psychology Review, 31, 217-234.

Sattler, J. (2002). Assessment of Children: Behavioral and clinical applications (4th ed.) San Diego, CA: Author.

Shapiro, E. S., \& Cole, C. L. (1994). Behavior change in the classroom: Self-management interventions. New York: Guilford Press.

Shapiro, E. S., Durnan, S. L., Post, E. E., \& Skibitsky Levinson, T. (2002). Self-monitoring procedures with children and adolescents. In M. A. Shinn, H. M. Walker, \& G. Stoner (Eds.), Interventions for academic and behavior problems II: Preventive and remedial approaches (pp. 43-454). Bethesda, MD: National Association of School Psychologists.

Sheridan, S. N. (1997). Conceptual and empirical bases of conjoint behavioral consultation. School Psychology Quarterly, 12, 119-133. 
Sheridan, S. M., Eagle, J. W., Cowan, R. J., \& Mickelson, W. (2001). The effects of conjoint behavioral consultation: Results of a 4-year investigation. Journal of School Psychology, 39, 361-385.

Sheridan, S. M., \& Gutkin, T. B. (2000). The ecology of school psychology: Examining and changing our paradigm for the 21st century. School Psychology Review, 29, 485-502.

Sheridan, S. M., \& Kratochwill, T. R. (1992). Behavioral parent-teacher consultation: Conceptual and research considerations. Journal of School Psychology, 30, 117-139.

Sheridan, S. M., Kratochwill, T. R., \& Bergan, J. R. (1996). Conjoint behavioral consultation: A procedural manual. New York: Plenum.

Sheridan, S. M., Kratochwill, T. R., \& Elliott, S. N. (1990). Behavioral consultation with parents and teachers: Delivering treatment for socially withdrawn children at home and school. School Psychology Review, 19, 33-52.

Sheridan, S. M., \& Steck, M. C. (1995). Acceptability of conjoint behavioral consultation: A national survey of school psychologists. School Psychology Review, 24, 633-647.

Sheridan, S. M., Welch, M., \& Orme, S. F. (1996). Is consultation effective? A review of outcome research. Remedial and Special Education, 17, 341-354.

Stage, S. A., \& Quiroz, D. R. (1997). A met-analysis of interventions to decrease disruptive behavior in public school settings. School Psychology Review, 26, 333-368.

Steege, M. W., Davin, T., \& Hathaway, M. (2001). Reliability and accuracy of a performance based behavioral recording procedure. School Psychology Review, 30, 252-262.

Tillman, C. T. (2000). Generalization programming and behavioral consultation. The Behavior Analyst Today, 1, 30-34.

Von Brock, M. B., \& Elliott, S. N. (1987). The influence of treatment effectiveness information on the acceptability of classroom interventions. Journal of School Psychology, 25, 131-144.

Weiner, R. K., Sheridan, S. M., \& Jenson, W. R. (1998). The effects of conjoint behavioral consultation and a structured homework program on math completion and accuracy in junior high students. School Psychology Quarterly, 13, 281-309.

Wilkinson, L. A. (1997). School-based behavioral consultation: Delivering treatment for children's externalizing behavior in the classroom. Journal of Educational and Psychological Consultation, 8, 255-276.

Wilkinson, L. A. (2003). Using behavioral consultation to reduce challenging behavior in the classroom. Preventing School Failure, 47, 100-105.

Wilkinson, L. A. (2005a). An evaluation of conjoint behavioral consultation as a model 
for supporting students with emotional and behavioral difficulties in mainstream classrooms. Emotional and Behavioural Difficulties, 10, 119-136.

Wilkinson, L. A. (2005b). Supporting the inclusion of a student with Asperger syndrome:

A case study using conjoint behavioural consultation and self-management. Educational Psychology in Practice, 21, 307-326

\section{Author Contact Information:}

Lee A. Wilkinson, Ph.D.

7708 Red River Road,

West Palm Beach, FL 33411

E-mail: lawilkinson@bellsouth.net

Lee A. Wilkinson, EdD, PhD, NCSP is a nationally certified school psychologist and faculty member in the School of Education and Behavioral Studies at Palm Beach Atlantic University; FL. His research interests include behavioral consultation, home-school partnerships, and evidence-based practice in school psychology.

\section{ADVERTISING IN THE INTERNATIONAL JOURNAL OF BEHAVIORAL AND CONSULTATION THERAPY}

The prices for advertising in one issue are as follows:

1/4 Page: \$50.00 1/2 Page: \$100.00 vertical or horizontal Full Page: \$200.00

If you wish to run the same ad in multiple issues for the year, you are eligible for the following discount:

1/4 Pg.: \$40 - per issue

1/2 Pg.: \$75 - per issue -vertical or horizontal

Full Page: \$150.00-per issue

An additional one time layout/composition fee of $\$ 25.00$ is applicable

For more information, or to place an ad, contact Halina Dziewolska via e-mail at: halinadz@hotmail.com 


\title{
Alternate Forms Reliability of the Behavioral Relaxation Scale: Preliminary Results
}

\author{
Duane A. Lundervold and Angel L. Dunlap
}

\begin{abstract}
Alternate forms reliability of the Behavioral Relaxation Scale (BRS; Poppen,1998), a direct observation measure of relaxed behavior, was examined. A single BRS score, based on long duration observation (5-minute), has been found to be a valid measure of relaxation and is correlated with selfreport and some physiological measures. Recently, alternate forms of BRS observation have appeared in the literature; however, it is unknown if alternate forms are reliable relative to the long form observation method. BRS data from 10 adults, taking part in research on Behavioral Relaxation Training (BRT), were examined. Correlation analyses of long form BRS scores, intervalby-interval BRS (very short form: one 60-second; short form: two 60-second; medium form: three 60-second intervals) and composite BRS scores obtained from a single 120- or 180-second observation were conducted. All alternate forms BRS observation methods were robustly associated with long form BRS scores $(\underline{r}=\geq .80, p=.005)$. Alternate forms BRS observation methods provide more flexibility in applied situations without loss of reliability when measuring overt relaxed behavior. Further research needs to examine reliability of alternate forms BRS observation methods using physiological measures and direct observation measures as criterion variables and clinical populations.

Key words: Relaxation training, Behavioral Relaxation Scale (BRS), Behavioral Relaxation Training (BRT).
\end{abstract}

Introduction

Relaxation training has a long history in behavior therapy and behavioral medicine. More recently relaxation has been advocated as a component of applied behavior analysis interventions for individuals with developmental disabilities as a means to manage anxiety and challenging behavior (Lindsay, Baty, \& Michie, 1989; Mullins \& Christian, 2001; Paclawskyj, 2002). The most well known method is Jacobson's classical progressive relaxation (PR) training (Jacobson, 1938; 1970). Wolpe (1958), followed by Paul (1966), abbreviated PR and incorporated it into systematic desensitization. In so doing, PR training was now more easily used in applied settings. Bernstein and Borkovek (1973) standardized abbreviated PR by means of manualization. Regardless, each method of PR targets a reduction in physical tension. Benson (1975) hypothesized that all relaxation procedures result in a general effect of decreased autonomic arousal. Davidson and Schwartz (1976) suggested that cognitive and somatic domains are altered following relaxation. Poppen (1998) conceptualized relaxation as a complex response class involving motor, visceral, observational responses and verbal behavior. Motor behavior involves action of the skeletal muscles. Visceral responding is concerned with homeostatic functions including breathing, temperature, and muscle tension. Observational responses seek out stimuli in the environment (e.g. a quiet park setting) or generate discriminative stimuli (e.g., "seeing" a quiet park setting). Verbal behavior is concerned with overt or covert vocal behavior (e.g., "I am tense") in relation to relaxed behavior. Because multiple modes of responding are involved in relaxation, each mode is in need of assessment to determine the unique and interactive effect of relaxation training procedures on each response channel.

According to Poppen (1998), assessment of actual relaxation is rarely done. The verbal component of relaxation is assessed by simply asking, "How do you feel?" which may be combined with a numerical rating. This question appears to assess what Smith (1999) refers to as a relaxation state (R- 
State), "a psychological state of mind associated with practic ing relaxation and mastering the act of sustaining passive simple focus (p. 5)." Crist, Rickard, Prentice-Dunn, and Barker (1989) developed a 45item relaxation inventory used to assess the feelings and sensations of relaxation. As pointed out by Poppen (1998), verbal report of relaxation may be influenced by the social contingencies of the training situation as well as the covert stimulus about which the trainer is inquiring. Furthermore, research has indicated that verbal report of the extent of relaxation is not differentially sensitive to training or control procedures and is unrelated to physiological measures of decreased arousal (Schilling \& Poppen, 1983). Visceral responding, for example, peripheral temperature, is typically assessed using instruments. Assessment of the motor response component of relaxation has been neglected even though it is the primary mode of behavior under instruction.

Only two instruments have been developed to assess the motor response component of relaxation. Luiselli (1980) developed the Relaxation Checklist to be completed by raters after relaxation training; however, there are no data on its validity. As part of Behavioral Relaxation Training (BRT) procedures (Poppen, 1998), relaxed behavior is assessed using the Behavioral Relaxation Scale (BRS), a partial interval direct observation recording system (Lundervold \& Poppen, 2004; Schilling \& Poppen, 1983; Poppen, 1998). Typically, a 5-minute observation is conducted during which the behaviors are observed and recorded within each 60-second interval. During the first 30-seconds of each interval breathing is counted. In the next 15 -seconds the remaining nine behaviors are observed. The final 15 -seconds are used to score the behaviors as relaxed or unrelaxed. The BRS (and the behaviors that comprise the BRS) have been shown to be a valid measure of relaxation (Norton, Holm, \& McSherry, 1997; Schilling \& Poppen, 1983; Poppen \& Maurer, 1982).

The BRS has been repeatedly used in research employing BRT using the recommended observation procedure (Chung, Poppen, \& Lundervold, 1995; Lundervold \& Poppen, 2004; Raymer \& Poppen, 1985; Schilling \& Poppen, 1983). A percent-relaxed score is calculated based on the entire 5minute observation period. Inter-observer agreement, a measure of the extent to which two observers simultaneously and independently agree on the occurrence of a behavior, for traditional BRS observation is uniformly very good. Poppen (1998) further recommends that repeated 15-minute baseline observations and 5-minute post training observation of relaxed behavior be conducted. Such long baseline conditions and observation periods may be difficult to conduct in applied settings.

Recently, alternate forms of BRS observation have appeared in the literature. A study evaluating the effect of progressive relaxation with a child with autism and aggressive behavior used an alternate form of BRS observation (Mulllins \& Christian, 2001). The BRS was used to assess the effects of progressive relaxation using one 60-second observation (very short form). Medical settings are known to be especially fast-paced work environments and conducting long baseline observations is unlikely. Behavior analysts working in such environments must be able to change their behavior to be successful in such contexts yet obtain valid data (Strasahl, 1998). Lundervold, Pahwa and Lyons (2005; In press) reported the use of Behavioral Relaxation Training for Parkinson's disease-related anxiety disorders. In these studies, observation periods ranged from two to four minutes with BRS scores calculated on an intervalby-interval basis. By altering the duration of the observation period from the standard established and used in past research (Poppen, 1998), Mullins and Christian and Lundervold et al have essentially employed the use of an alternate form of the BRS.

According to Thorndike (1991), alternate forms of tests (observations) are forms of assessment designed according to the same specifications but comprised of separate samples of the behavior to be assessed. Alternate forms of tests or observation must demonstrate that they are reliable with the standard, long form on which they are based (Thorndike, 1991). The length of the observation (test) can significantly influence reliability assuming that the behavior measured is the same. Neither Mullins and Christian or Lundervold et al provide evidence of the reliability of alternate forms BRS observation 
methods relative to the long form BRS. Cone (1998) has advised behavior analysts to integrate traditional psychometric concepts into behavioral assessment to the extent that they are appropriate. Given that past research (Norton et al, 1997; Schilling \& Poppen, 1983; Poppen \& Maurer, 1982) demonstrated the validity of the BRS using long form observation methods, it is important to establish that alternate forms BRS observation are correlated with the long form BRS. Doing so would enable rapid collection of baseline data regarding relaxation using less time consuming alternate forms BRS observation procedures and swift transition to intervention phases. The purpose of this research was to examine the relationship between long form and alternate forms BRS scores obtained from observation periods ranging from very short (60-seconds) to medium (180-seconds) duration.

\section{Method}

\section{Participants}

Data from 10 adults (range 18-44; mean age 33.5, sd 14.8 years) taking part in Behavioral Relaxation Training based research were analyzed. All participants were cognitively intact and $70 \%$ were female. Consent was obtained from all participants before taking part in the research. One participant was taking part in applied research on chronic pain management.

\section{Variables}

The Behavioral Relaxation Scale (BRS) is a direct observation measure of 10 overt relaxed behaviors using a partial interval, time sampling procedure (Poppen, 1998). Each of the 10 behaviors are repeatedly observed and scored over consecutive 60 -second time periods. The criterion variable was the BRS score indexed as percent-relaxed behavior and based on a 5-minute (300-second) observation interval (Poppen, 1998).

\section{Design and analysis}

A group design employing bivariate correlation was used. Pearson correlation coefficients were calculated examining the relation between BRS scores obtained during observation periods of differing duration. In essence, the analysis examined the reliability of very short, short, medium, and long form BRS scores.

\section{Procedure}

BRS scores for each participant based on very short (60-second), short (120-second), medium (180-second), and long forms (300-second) of observation were calculated and extracted from the existing data. All scores were obtained from the first session that a BRS score was obtained. Long form BRS scores were calculated by dividing the number of relaxed behaviors by the total number of relaxed and unrelaxed behaviors $(\mathrm{N}=50)$ multiplied by 100 (Poppen, 1998). Very short form BRS scores (number of relaxed behaviors/10 x 100) were calculated for each participant using the first interval of observation. Short form (i.e., two BRS scores, one each for the first two intervals) and medium form BRS scores (i.e., three BRS scores, one each for the first three intervals) were calculated. In other words, the BRS score for one 60 -second interval was based on a single observation of 10 behaviors. For a 120 -second observation, two BRS scores were calculated, one for each consecutive 60-second interval. Within the 180-second observation, three consecutive BRS scores were calculated, one for each 60-second interval. A single BRS score was calculated based on a 120-second observation interval (composite short form; number of relaxed behaviors/20 x 100) and 180-second interval (composite medium form; number of relaxed behaviors/30 x 100). Composite BRS scores were correlated with long form BRS scores. 


\section{Results and Discussion}

Interval-by-interval BRS scores obtained using the very short form (one 60-second interval observation) were strongly associa ted with the long form (300-second) BRS score

$(\underline{\mathrm{r}}=.93, \mathrm{p}=.001)$. Similarly, BRS scores based on short (two, 60-second interval observations) and medium form (three, 60-second interval observations) methods also were strongly associated with long form BRS scores $(\underline{r}=.93, \underline{p}=.001)$. Finally, composite BRS scores using one 120-second interval $(\underline{r}=$ $.90, \underline{p}=.01)$ or a 180 -second interval $(\underline{\mathrm{r}}=.80, \mathrm{p}=.005)$ were robustly associated with long form BRS scores.

The importance of these preliminary findings lies in the increased flexibility of observation methods used with the BRS in applied settings. Because intervalby-interval BRS scores (very short and short form methods) have been shown to be reliable, these scores can be used to determine baseline levels of relaxed behavior. Rather than three sessions being conducted over three weeks of observation as is the current case, short form BRS observation methods allow clinical behavior analysts to conduct one 3minute observation and reliably determine data trend. More rapid, evidence-based provision of relaxation training is possible. Preliminary results suggest that shortened forms of BRS observation are strongly related to BRS scores obtained over the traditional 5-minute observation recommended by Poppen (1998) and used in research.

While encouraging, results were obtained with a small, largely non-clinical sample. It is well known that results of analog research may not be generalizable to clinical populations. Results must be interpreted very cautiously. In addition, no physiological measures were obtained to provide concurrent validity of abbreviated forms of BRS observation. Replication of this research utilizing a larger clinical sample as well as incorporating use of physiological measures is needed.

\section{References}

Benson, H. (1975). The relaxation response . NY: Morrow.

Bernstein, D. A. \& Borkovek, T. D. (1973). Progressive muscle relaxation. Champaign, IL:Research Press.

Chung, W., Poppen, R., \& Lundervold, D. A. (1995). Behavioral relaxation training for tremor disorders in older adults. Biofeedback and Self-Regulation, 20, 123-135.

Crist, D. A., Rickard, H. C., Prentice-Dunn, S., \& Barker, H. R. (1989). The Relaxation Inventory: Self-report scales of relaxation training effects. Journal of Personality Assessment, 53, 716-726.

Cone, J. D. (1998). Psychometric considerations: Concepts, contents and methods. In A.S. Bellack \& M. Hersen (Eds.), Behavioral assessment (4 ${ }^{\text {th }}$ ed.)(pp. 22-46).

Davidson, R.J. \& Schwartz, G.E. (1976). Psychobiology of relaxation and related states: A multiprocess theory. D.I. Mostofsky (Ed.), Behavioral control and the modification of physiological activity (pp. 200-233). NY: Free Press.

Jacobson, E. (1938). Progressive relaxation (2nd Ed.). Chicago: University of Chicago Press. 
Jacobson, E. (1970). Modern treatment of tense patients. Springfield, IL: Charles C. Thomas Publishers.

Lindsay, W.R., Baty, F.J., \& Michie, A.M. (1989). A comparison of anxiety treatments with adults who have moderate and severe mental retardation. Research on Developmental Disabilities, 10, 129-40.

Luiselli, J. K. (1980). Relaxation training with the developmentally disabled: A reappraisal. Behavior Research With Severe Developmental Disabilities, 1, 191-213.

Lundervold, D.A., Pahwa, R., \& Lyons, K. (2005a). Effect of Behavioral Relaxation Training on comorbid general anxiety disorder and Parkinson's Disease. Manuscript submitted.

Lundervold, D.A., Pahwa, R., \& Lyons, K. (In press). Behavioral Relaxation Training for Parkinson's Disease-related anxiety and dyskinesia. Cognitive and Behavioral Practice.

Lundervold, D.A. \& Poppen, R. (2004). Biobehavioral intervention for older adults coping with essential tremor and related disability. Applied Psychophysiology and Biofeedback, 29, 63-74.

Mullins, J.L., Christian, L. (2001). The effects of progressive relaxation training on the disruptive behavior of a boy with autism. Research on Developmental Disabilities, 22, 449-462.

Norton, M., Holm, J. E., \& McSherry, W. C., II. (1997). Behavioral assessment of relaxation: The validity of a behavioral rating scale. Journal of Behavior Therapy and Experimental Psychiatry, 28, 129-137.

Paclawskyj, T. R. (2002). Behavioral relaxation training (BRT) with children with dual diagnosis. NADD Bulletin, 5, 81-83.

Paul, G. L. (1966). Insight versus desensitization in psychotherapy. Stanford, CA: Stanford University Press.

Poppen, R. (1998). Behavioral relaxation training and assessment ( $2^{\text {nd }}$ Ed.). Thousand Oaks, CA: Sage.

Poppen, R. \& Maurer, G. (1982). Electromyographic analysis of relaxed postures. Biofeedback and Self-Regulation, 7, 491-498.

Schilling, D. \& Poppen, R. (1983). Behavioral relaxation training and assessment. Journal of Behavior Therapy and Experimental Psychiatry, 14, 99-107.

Smith, J.C. (1999). ABC relaxation theory. An evidenced based approach. NY: Springer.

Strosahl, K. (1998). Integrating behavioral health and primary care services: The primary mental health care model. In A. Blount (Ed.), Integrated primary care (pp.139-168). NY: Norton \& Company.

Thorndike, R.M. (1991). Measurement and evaluation in psychology and education (6 $6^{\text {th }}$ ed). Upper Saddle River, NJ: Merrill/Prentice Hall. 
Wolpe, J. (1958). Psychotherapy by reciprocal inhibition. Stanford, CA: Stanford University.

\section{Author Contact Information:}

Duane A. Lundervold

Behavioral Medicine and Biofeedback Laboratory, Department of Psychology, Lovinger 1111, Central Missouri State University, Warrensburg, MO 64093.

Email:Lundervold@cmsu1.cmsu.edu.

\section{ADVERTISING IN THE \\ INTERNATIONAL JOURNAL OF BEHAVIORAL AND CONSULTATION THERAPY}

The prices for advertising in one issue are as follows:

1/4 Page: $\$ 50.00 \quad 1 / 2$ Page: $\$ 100.00$ vertical or horizontal Full Page: $\$ 200.00$

If you wish to run the same ad in multiple issues for the year, you are eligible for the following discount:

1/4 Pg.: $\$ 40$ - per issue

1/2 Pg.: \$75 - per issue -vertical or horizontal

Full Page: \$150.00-per issue

An additional one-time layout/composition fee of $\$ 25.00$ is applicable

For more information, or to place an ad, contact Halina Dziewolska via e-mail at: halinadz@ hotmail.com 


\title{
The Effects of Learn Units on Student Performance in Two College Courses
}

\author{
Ara John Bahadourian, Kai Yung (Brian) Tam, R. Douglas Greer and Marilyn K. Rousseau
}

\begin{abstract}
We report an experiment examining the academic performance of undergraduate students in two special education college courses. The experimenter/professor taught both courses in which he presented curriculum material via written learn units (LUs) (Greer \& Hogin, 1999) or in a lecture format across randomly selected weeks in a 12-week semester. There were a total of 20 students (11 in the Emotional Disturbance course, 9 in the ABA course) primarily juniors and seniors majoring in special education ranging in age from 20 to 48 .

The independent variable consisted of a series of written LUs presented to students in the form of guided notes that were scripted in logical sequence (based upon textbook material). LUs were defined as a series of meshed or interlocking 3-term contingencies 1 for the student and at least 2 for the professor arranged through scripted curricula. During the LU condition, the professor (1) read a phrase or question from the guided notes (with blank lines) that were distributed to students, (2) discussed the phrase or question, (3) exposed the phrase/question and its corresponding answer on the overhead, (4) provided an opportunity for all students to respond by writing/copying the answer, and (5) then immediately consequated their answers by checking their accurate completion of the blank line. During the lecture condition, the professor lectured (from the material obtained from the textbook chapter) without providing any written LUs. The dependent variable was student grade achievement on weekly short answer essay exams.
\end{abstract}

Interobserver agreement for independent scoring of the dependent variable for the ABA exams was $97 \%$. Interobserver agreement for independent scoring of the dependent variable for the ED exams was 95\%. The mean percentage of procedural integrity for the ABA course was $88 \%$ ranging from $83 \%$ to $100 \%$. The mean percentage of procedural integrity for the ED course was $100 \%$.

In the ABA course, the mean percentage correct on exams was $83 \%$ during the LU class sessions and $68 \%$ during the lecture sessions. In the ED course, the mean percentage correct on exams was $84 \%$ during LU class sessions and $74 \%$ during lecture sessions. Social validity measures indicated high student satisfaction with the learn unit instructional procedure. These results were discussed in terms of the potential utility of the learn unit as a microanalytic measure of both teaching and learning particularly for subject matter in higher education containing specificity in terminology (i.e., factual and scientific content). Key Words: Learn Units, Instructional time, active student responding, interobserver agreement

\section{The Effects of Learn Units on Student Performance in Two College Courses}

It is generally agreed that the goals of science are to understand, predict, and control behavior (Berliner, 1990). Consequently, every respected scientific discipline has its corresponding basic unit of measurement which is ultimately responsible for the profession's advancement and improvement (e.g., biology: the "cell," nutrition: "vitamins and calories," chemistry: "molecules," engineering: the "micron").

Unfortunately, the professions of education and school psychology have lacked an accurate and replicable basic unit of measurement which may well account for decades of student underachievement. 
Greer (1994) states that "the identification and use of a primary measure of teaching is essential to the maturation of a science of pedagogy" (p. 161).

The refinement of instructional "time" concepts in relationship to educational outcomes has evolved over decades (Fisher \& Berliner, 1985). Recently, "learn units" have been identified within the field of education: "The learn unit consists of the interlocking operants of instruction that incorporate particular student and teacher interactions that predict whether student behavior will be controlled by particular stimuli and setting events" (p. 161) (Greer, 1994). The learn unit measurement has served to produce better research to help children with various needs (Albers \& Greer, 1991; Kelly \& Greer, 1996; Martinez, 1996; Hogin, 1996; Lindhart-Kelly \& Greer, 1997), improve teacher training procedures (Keohane, 1997; Ingham \& Greer, 1992), and determine more accurate measures of school-wide effectiveness (Greer, McCorkle, \& Williams, 1989; Selinske \& Greer, 1991; Lamm \& Greer, 1991).

To date there have been no studies investigating the effects of learn units on the performance of undergraduate college students: "Obviously, we are far from hard data on the long-range and even shortrange effectiveness of our application of behavioral systems analysis to the college teaching of behavior analysis...We believe that the lecture has been obsolete...We believe that a behavior-analytic view demands or at least suggests something like a learn-unit model of active student responding during classroom instruction" (p. 341) (Malott, Vunovich, Boettcher, \& Groeger, 1995).

In an article entitled "The Wastage in Education" (Samuelson, 1998), the author describes the academic and economic failure of American universities and colleges across the country to effectively produce education students who have basic competence in reading, writing and in their subject area.

Research to improve students' achievement is critical given the fact that (1) college degrees have been devalued because many students who obtain degrees lack fundamental literacy skills, (2) many colleges currently offer remedial courses and are closing schools of education, and (3) increasing teacher salaries have never been shown to improve educational outcomes (Samuelson, 1998).

\section{Instructional Time Research}

The importance of the instructional "time" concept in the determination of educational outcomes has received much attention both in the general education and behavior analytic literatures (Fisher \& Berliner, 1985; Goodman, 1990). Student achievement as a function of instructional time has evolved from the measurement of by-products or inferences to more recently the direct measurement of behavior outcomes (Greer \& Hogin, 1999).

Carroll's (1963) major contribution was his redefinition of "aptitude" as a function of time. In other words, aptitude was not regarded as an intellectual ceiling on what a student can learn but, rather, how long it will take that student to master the academic material given sufficient time. Carroll was credited for transforming the mysterious concept of "motivation" into a time-based concept (Ben-Peretz \& Bromme, 1990). Bloom (1974) expanded Carroll's theory emphasizing the significance of the student's prior learning and the quality of instruction. Bloom's mastery learning was based on the premise that most students could master required content and, therefore, up to $95 \%$ of students in a class have the potential to earn a grade of $\mathrm{A}$ if instruction in terms of the degree to which the presentation, explanation, and sequencing of the task corresponds to the optimum rate (i.e., time needed to reach criterion) for a given learner (Fisher \& Berliner, 1985).

Allocated time or scheduled time is often defined as the time that the state, district, school, or teacher requires or allocates for instruction in a particular content area for the student (Fisher \& Berliner, 1985). 
Although research has repeatedly shown that an increase in allocated instructional time does not necessarily increase student achievement (Fischer et al., 1980; Heward, 1994), schools across the U.S. are currently experimenting with "block scheduling" --the 90s terminology for allocated time (Grossman, 1998).

Engaged time or on-task is "that part of allocated time during which the student is paying attention" (Fisher et al., 1980, p. 9). Some research has demonstrated that increasing a student's engaged time or on-task behavior does not necessarily result in a corresponding increase in the number of academic responses the student emits (Heward, 1994; Harris, 1986). Students in classrooms where no achievement gains were made spent $50 \%$ of available time in noninteractive on-task activities such as silent reading and seatwork (Stallings, 1980).

Academic learning time (ALT) is defined as "the amount of time a student spends engaged in an academic task that she/he can perform with high success" (Fisher et al., 1980, p. 8). Unfortunately, ALT's definition of student engagement does not enable a clear analysis of specific types of academic student responses (Greenwood et al., 1984). Therefore, as a time-based measure, ALT cannot account for the actual number of learning responses in which a student participated during instruction (Heward, 1994).

\section{Opportunity to Respond and Active Student Responding}

By moving away from allocated academic time to engaged or on-task academic time to ALT, educational research gradually recognized the importance of more direct measurement (Greer, 1996; Stallings, 1980). However, "...these measures were still of the appearance of learning (e.g., engagement or on task) and not the measurement of learning outcomes" (p. 140) (Greer, 1996). For example, students could be passively staring at a page of text and still be recorded as being "actively" engaged (Greer \& Hogin, 1999).

Vance Hall and his colleagues coined the term opportunity to respond (OTR) in 1977. The term refers to student responding and participation during instruction (Heward, 1994). OTR has been defined as a measure of the "interaction between: (a) teacher-formulated instructional antecedent stimuli (the materials presented, prompts, questions asked, signals to respond) and (b) their success in establishing the academic responding desired or implied by the materials" (Greenwood et al., 1984, p. 64). Although in the literature many authors differentiate the terms OTR and active student responding (ASR), ASR is actually an intertwined component of OTR: "Student response is the second component of opportunity to respond. Tactics that establish high rates of correct academic responding over periods of instruction by the most students are those providing the greater opportunity. Thus, opportunity is confirmed by the academic behavior produced" (Greenwood et al., 1984, p. 65). In other words, ASR involves opportunities for students to practice the academic task (Hall et al., 1982).

Research has consistently shown that teachers and parents who provide higher numbers of opportunities for student responding produce more student learning (Edmonds, 1979; ; Rosenshine \& Berliner, 1978; Rotholz et al., 1985; Greenwood et al, 1994, Hart \& Risley, 1995). Stanley \& Greenwood (1983) found that instruction for fourth graders in Title 1 and non-Title 1 schools provided infrequent amounts of academic responding time. In fact, ASR time was significantly lower among minority students in Title 1 schools. It appears that inner city preschool students raised in low socioeconomic environments may begin school with less educational experience (i.e., language opportunities) at home and fall further behind as a function of low levels of active academic response time (Delquadri \& Greenwood, 1981; Hart \& Risley, 1995). The implication is that low opportunity instruction (in the form of lecture, media presentations) that requires passive responding produces lower student achievement gains over the course of a school year. 
As Dewey (1916) once aptly stated, "Students learn by doing." The challenge for educators is to identify and use instructional antecedents and methods that increase students' opportunity to respond and thereby occasion more frequent academic responding. Heward (1994) discusses three "low-tech" strategies for increasing the frequency of active student response during group instruction including response cards, choral responding, and guided notes.

Although the OTR research is considered to be probably the most important contribution of the 1984 conference at Ohio State University (Greer, 1994), even this variable lacked a critical component of instruction--the teacher response or consequation to the student's response (Albers \& Greer, 1991; Diamond, 1992).

\section{The Learn Unit}

Although research studies have demonstrated the importance of isolated behavioral tactics such as opportunity to respond and active student responding in regards to improving college students' achievement (Saur, 1995; Baker \& Mulcahy-Ernt, 1992; Tudor \& Bostow, 1991), a more comprehensive measure might account for a combination of several behavioral tactics into one countable unit of measurement. Greer (1994) proposed that the learn unit is the basic unit of instructional measurement for both student and teacher. The learn unit is a comprehensive measurement which includes opportunity to respond, the student's response, the teacher antecedent-consequence, and the student antecedent-consequence in yoked or interlocking three-term contingencies between the teacher and student (Greer, 1996). This interlocking contingency is the least divisible and most effective measurement for both teacher and student thereby serving both as a moment-to-moment student outcome measure as well as a measure of the entire instructional process (Greer, 1996; Hogin, 1996).

Albers and Greer (1991) examined the use of the learn unit in two experiments by examining the effect of increasing the rate of learn unit emissions to three times its baseline rate on student learning. Increases in the presentation rate of learn units were implemented by the researcher prompting the teacher and teaching assistant to increase their presentation rate and assignment of material. Data from the first experiment showed that increasing the rate of learn units resulted in higher rates of correct student responding and lower rates of incorrect responding. Data from the second experiment replicated the results of the first with two other students and further demonstrated that both written and vocal learn unit presentation formats were effective when each was isolated.

Learn units have been found to be the best predictors of student learning. Several studies have demonstrated that higher numbers of learn units consistently result in higher numbers of correct student responses and greater numbers of instructional objectives achieved (Dorow, McCorkle, Williams \& Greer, 1989; Greer et al., 1989, Ingham \& Greer, 1992; Selinski et al., 1991). Ingham \& Greer (1992) analyzed the role of the teacher supervisor in terms of teacher performance via accurate and fluent learn unit presentations. The investigators observed and recorded teacher behavior based on the accuracy of their emission of learn units to students. The findings revealed that when the supervisor delivered flawless verbal and written antecedents, response opportunities, and consequences to the teachers, correct teacher and student responding increased.

The results of Albers \& Greer (1991) and Ingham \& Greer (1992) demonstrated the value of the consequence in the three term contingency and supported the use of the learn unit as the least divisible component of effective instruction that incorporates both student and teacher interaction.

Hogin (1996) found that when the correction feedback of the learn unit required the students to observe their responses to math problems viewing only their responses and the teacher's consequence (in 
the absence of the antecedent), they did not learn the math computation perations. Hogin's study demonstrated the importance of the antecedent in the interlocking three term contingencies that form the learn unit. Kelly \& Greer (1996) examined the effects of increased rates of curriculum based learn units on the assaultive and self-injurious behavior of three students. The results showed that by increasing the rate of learn units, students remained instructionally engaged thereby increasing their rate of correct responding and opportunities for reinforcement.

The uniqueness of the learn unit is the fact that it incorporates the three term contingency of both the student and the teacher forming an evolving unit of measurement that is continuously shaped by the reciprocal behavioral exchanges of each party. In effect, the teacher's future behavior becomes a function of the moment by moment response of the student -- the teacher learns what to do next based upon student responding.

The learn unit proposed by Greer (1994) is the interlocking or yoked operant of both the student and teacher antecedent-behavior-consequence chain which constitutes the basic measure and building block of effective teaching (i.e., teacher productivity) and has been demonstrated to reliably predict student learning outcomes in the fields of education and school psychology (Greer, in press; Greer \& Hogin, 1999; Malott, 1999; Heward, 1994; Malott, Vunovich, Boettcher, \& Groeger, 1995). The learn unit (in conjunction with the measurement of criterion-referenced instructional objectives) is often inseparable from carefully scripted, logically sequenced, and programmed curricula because such curricula help assure or standardize teacher accuracy, unambiguous antecedents, clear response definitions, and delivery of consequences before the teacher moves to subsequent learn unit presentations (Hogin , 1996). In fact, high rates of learn units in the absence of carefully selected and properly designed instructional materials can be meaningless (Greer, 1994; Engelmann, 1992; Heward, 1994). The use of guided notes (Heward, 1994) satisfies the above criteria and may serve as one way to provide frequent response and consequence opportunities in large groups.

There have been no studies to date testing the efficacy of the learn unit in higher education settings. This research study investigated the relationship of the effects of written learn units (presented by a professor in the form of guided notes) and their impact on student test performance in two undergraduate courses.

Participants

\section{METHOD}

The participants were two different intact groups of undergraduate students enrolled in two required courses. The first course was "Techniques of Applied Behavior Analysis" (ABA) and the second was "Teaching Students with Emotional Disturbance" (ED). The courses were taught by the same instructor/experimenter in a special education training program at an urban college. The two courses were comprised of a total of twenty undergraduate students (11 in the ED course, 9 in the ABA course) majoring in special education. There were seven female students and two male students in the ABA course. The class consisted of one Caucasian, three African-American, and six bilingual students of Hispanic background. In the ED course, there were eight female students and three male students. Two of the students in the ED course were also taking the ABA course during the same semester with the experimenter. The ED class was comprised of two Caucasian, four African-American, and five bilingual students of Hispanic origin.

Independent variable 
The independent variable was the presentation of written learn units vis a vis guided note (Heward, 1994) handouts with blank lines. The rationale for using guided notes was to provide students with potential curriculum-based written learn units that were scripted, sequenced, and programmed (Greer $\&$ Hogin, 1999) and which included all components of the learn unit (i.e., frequent opportunities to respond, active student responding, and an opportunity for consequation). The guided notes were discriminative stimuli thereby setting the occasion for curriculum-based learn units: "When teachers present instruction in scripted sequences based on logical analyses or in scripted instruction based on task analyses, operant units are scripted for the teacher. These scripts specify teacher behavior, student behavior...as well as the sequence of steps and objectives...Teaching scripts can specify learn units with students individually or with groups of students" (p. 19) (Greer, in press).

In other words, guided notes were used because the learn unit is a measure of teaching which (a) engages the use of all components of the three-term contingency (one for the student and at least two for the teacher) as a continuous yoked and interlocking operant response between both the student and instructor and (b) requires logical and flawless programmed sequences (Greer \& Hogin, 1999).

The experimenter prepared the guided notes by sequencing and scripting the textbook chapter content resulting in a series of "potential" written learn units (i.e., in the form of sentences or phrases) for all chapters in both textbooks. These were potential LUs because they had to be consequated by (1) the student viewing the answer on the overhead and (2) the professor placing a check mark next to the student's accurate completion of the phrase.

The following is an example of a single learn unit (LU) which is scripted, logically sequenced and programmed providing 1 three-term contingency for the student and 2 three-term contingencies for the professor which was emitted during the first class session in the ABA course:

Student looks at guided note handout

Prof. reads: What is meant by "applied"?

Prof. discusses "applied" in the term ABA and then exposes answer on overhead

Students write/copy answer:The behavior targeted for change is socially important for the person.

Prof. sees students writing

Prof. checks written work on the spot

\section{Professor antecedent}

Student antecedent

Professor behavior

Student behavior

Professor behavior

Student consequence

Professor consequence

Next scripted LU sequence: What is included in the term "behavior" in ABA?

Dependent variable

The dependent variable was student performance (i.e., percentage correct) on a weekly basis as measured by in class exams throughout the 12-week semester for ABA and ED courses. The 
experimenter prepared 22 short answer essay exams (11 for the ABA course, 11 for the ED course) each comprising of eleven questions. The entire content (of all exams for both learn unit and lecture sessions) were always covered during class sessions and the exam content was also available in the textbook chapter. The two textbooks assigned were entitled (1) Applied Behavior Analysis in the Classroom (Schloss \& Smith, 1999) and (2) Understanding and Teaching Emotionally Disturbed Children and Adolescents (Newcomer, 1993).

At the end of the semester, the experimenter asked all students in both courses to answer two questions prepared by the professor to assess social validity of student preferences regarding course format. The questions included (1) What did you find to be most useful to help prepare you for your weekly quiz? and (2) Did you prefer the lecture only classes or lecture with written handouts?

\section{Data Collection Procedures}

Data were collected each week from the two courses by recording weekly percentage correct/incorrect on exam grades. The experimenter read each exam twice to assure accuracy in the grading and scoring of exams. All student grades were graphed on a weekly basis for both courses.

\section{General Procedures (for Learn Unit and Lecture)}

The students in both courses were given a course syllabus on the first day of class. They were informed that they would take an in class short answer essay exam on a weekly basis. All students were made aware of the following instructions: (1) They would have to answer 10 out of 11 questions each week, (2) The experimenter told the students that the exam content would be covered in class a week prior to the exam date, (3) The students were told that the weekly exam content was also covered in the textbook chapter, (4) The students were given the first hour of every 2-hour class session to take their exams, (5) Students were allowed to ask questions as a group regarding clarification of lecture and/or textbook material prior to all exams, (6) Students were advised to purchase and carefully read each textbook chapter in preparation of their weekly exam, (7) Students were encouraged to attend each class session and to take good notes, (8) The chapter exams would be graded by the experimenter and then returned to the student the following week for review by students at the end of the following week's class, (9) Students were encouraged to visit the experimenter during office hours to discuss any questions pertaining to the course, and (10) Students who did not take the exams at the scheduled time were required to take the exam during office hours. These late make-up exams were not included as part of this research data in order to prevent confounding variables such as additional study and practice time, or special knowledge from other students who had already taken the exam. The students were not informed about the research study.

\section{Lecture Procedure}

The instructional sequence during the lecture only condition was a follows: (1) The experimenter lectured by following a scripted sequence of lecture notes but did not provide any written learn units to the students (i.e., there were no student guided note handouts and no overhead transparencies), (2) Students took their own notes based on the lecture material they had heard, (3) The experimenter responded to student questions and comments as in the learn unit condition, (4) The experimenter wrote key terms and clarified concepts on the blackboard, and (5) All exam questions were based on both lecture and textbook material as in the learn unit condition.

\section{Learn Unit Procedure}


The instructional sequence during the learn unit condition was as follows: (1) The experimenter distributed "potential" ( because they were not yet consequated by the professor) written learn units in the form of guided notes with blanks for all students in the ABA and ED courses, (2) The experimenter then placed these notes with their competed answers on overhead transparencies, (3) The experimenter sequentially exposed only the potential learn unit sentence or phrase (i.e., guided note with the answer) on the overhead projector which was relevant to the topic after he finished discussing it (all other potential learn unit sentences were covered), (4) The experimenter then provided the students an opportunity to "actively" respond by copying the information from the overhead onto handouts which consisted of fill-in blank spaces , (5) The experimenter provided immediate written feedback to students by placing check marks as they completed their own notes on these handouts, (6) The experimenter gave students an opportunity to ask questions or make comments, (7) The experimenter then presented the next LU (steps \#3 to \#6 above) and (8) All exams were based on both material covered in class and the textbook chapter.

\section{Experimental Design}

An alternating treatment design across randomly selected weeks throughout the 12-week semester for both courses was used to compare the utility of programmed, sequenced, and scripted LUs in contrast to the lecture format which does not typically provide LUs to students. Greer (in press) states that "the presentation is typically improvised in the lecture format (i.e., antecedent presentations with infrequent response opportunities)" (p. 20).

Interobserver Agreement (IOA)

Independent grading of the weekly exams in both courses were evaluated by the experimenter and a graduate student in the Department of Special Education using sample key or model answers to short answer essay questions to assure grading accuracy. The interobserver agreement for independent grading of the dependent variable for Applied Behavior Analysis exams was 97\%. The interobserver agreement for independent grading of the dependent variable for ED exams was $95 \%$.

Interobserver agreement for the independent variable was assessed by seven graduate students from the same department. They served as observers during LU class sessions to check for procedural reliability in both $\mathrm{ABA}$ and ED courses. The mean percentage of procedural integrity for the ABA course was $88 \%$ ranging from $100 \%$ to $83 \%$. The mean percentage of procedural integrity for the ED course was $100 \%$.

Results

In the ABA course, the total mean percentage correct on exams was $83 \%$ during the LU class sessions and $68 \%$ during the lecture sessions. In the ED course, the total mean percentage correct on exams was $84 \%$ during LU class sessions and $74 \%$ during lecture sessions.

The mean percentage correct on ABA exams for Student A was $81 \%$ during LU classes and 52\% during lecture only classes (equivalent to a letter grade of B as opposed to F), Student B was $73 \%$ during LU classes and $47 \%$ during lecture only classes (equivalent to a le tter grade of $\mathrm{C}$ versus $\mathrm{F}$ ), Student $\mathrm{C}$ was $95 \%$ during LU classes and $77 \%$ during lecture only classes (equivalent to a grade of A versus C), Student D was $63 \%$ during LU classes and $45 \%$ during lecture only classes (equivalent to a grade of D versus $\mathrm{F}$ ), Student $\mathrm{E}$ was $90 \%$ during LU classes and $73 \%$ during lecture only classes (equivalent to a grade of A versus C), Student $\mathrm{F}$ was $87 \%$ during LU classes and $70 \%$ during lecture only classes (equivalent to a grade of B versus C), Student G was $98 \%$ during LU classes and $83 \%$ during lecture only 
classes (equivalent to a grade of A versus B), Student $\mathrm{H}$ was $90 \%$ during LU classes and $81 \%$ during lecture only classes (equivalent to a grade of A versus B), and Student I was $81 \%$ during LU classes and $76 \%$ during lecture only classes (equivalent grade of B versus $\mathrm{C}$.)

The mean percentage correct on ED exams for Student A was 95\% during LU classes and $75 \%$ during lecture only classes (equivalent to a grade of A versus C), Student B was $87 \%$ during LU classes and $68 \%$ during lecture only classes (equivalent to a grade of B versus D), Student $\mathrm{C}$ was $78 \%$ during LU classes and $60 \%$ during lecture only classes (equivalent to a grade of C versus D), Student D was $96 \%$ during LU classes and $81 \%$ during lecture only classes (equivalent to a grade of A versus B), Student E was $90 \%$ during LU classes and $80 \%$ during lecture only classes (equivalent to a grade of A versus B), Student $\mathrm{F}$ was $87 \%$ during LU classes and $78 \%$ during lecture only classes (equivalent to a grade of B versus C), Student G was $95 \%$ during LU classes and $89 \%$ during lecture only classes (equivalent to a grade of A versus B), Student $\mathrm{H}$ was $73 \%$ during LU classes and $68 \%$ during lecture only classes (equivalent to a grade of $\mathrm{C}$ versus D), Student I was $79 \%$ during LU classes and $75 \%$ during lecture only classes (a grade of $\mathrm{C}$ regardless of instructional format), Student $\mathrm{J}$ was $71 \%$ during LU classes and 70\% during lecture only classes (a grade of $\mathrm{C}$ regardless of instructional format), and Student $\mathrm{K}$ was $67 \%$ during LU classes and 69\% during lecture only classes (a grade of D regardless of instructional format).

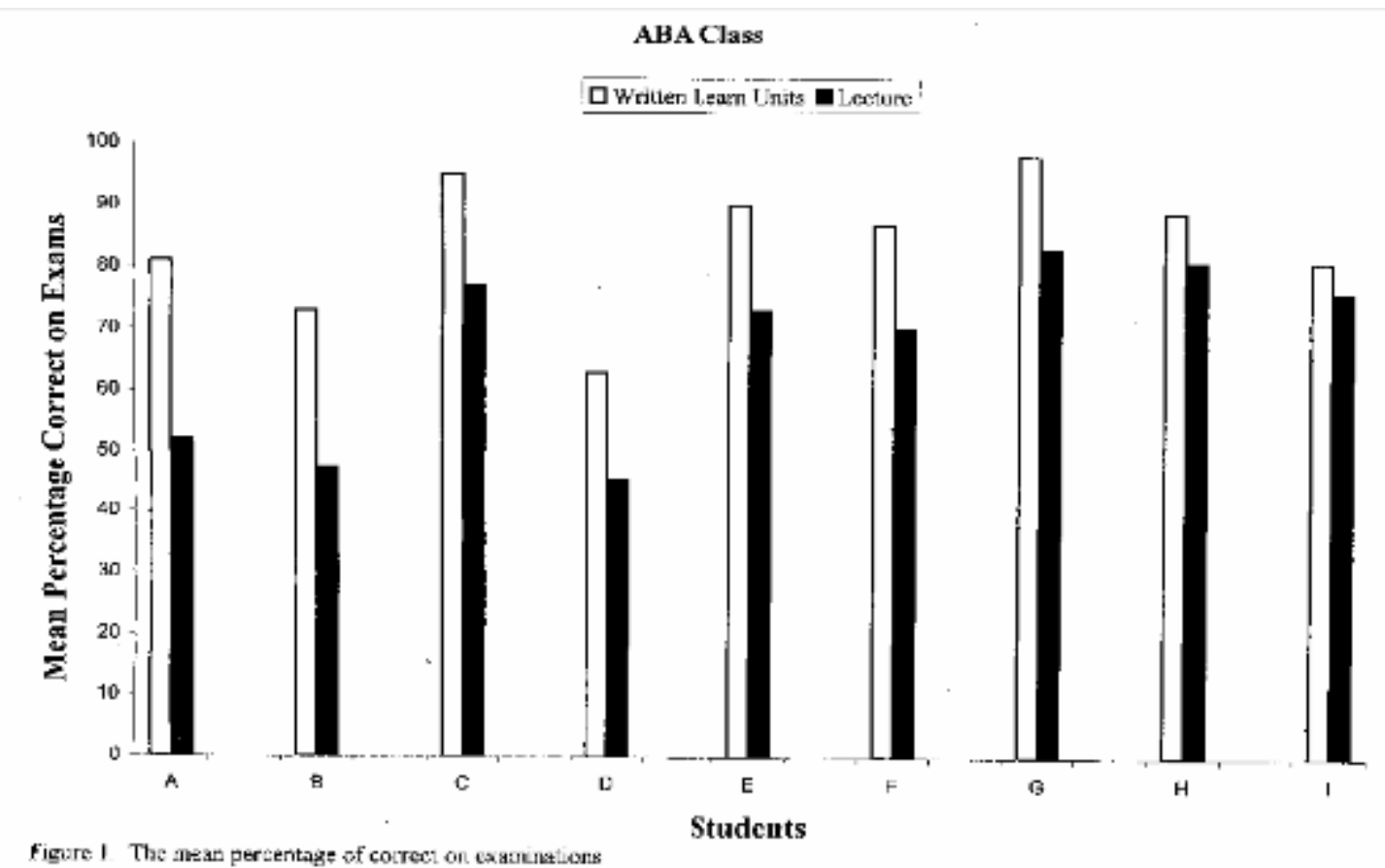




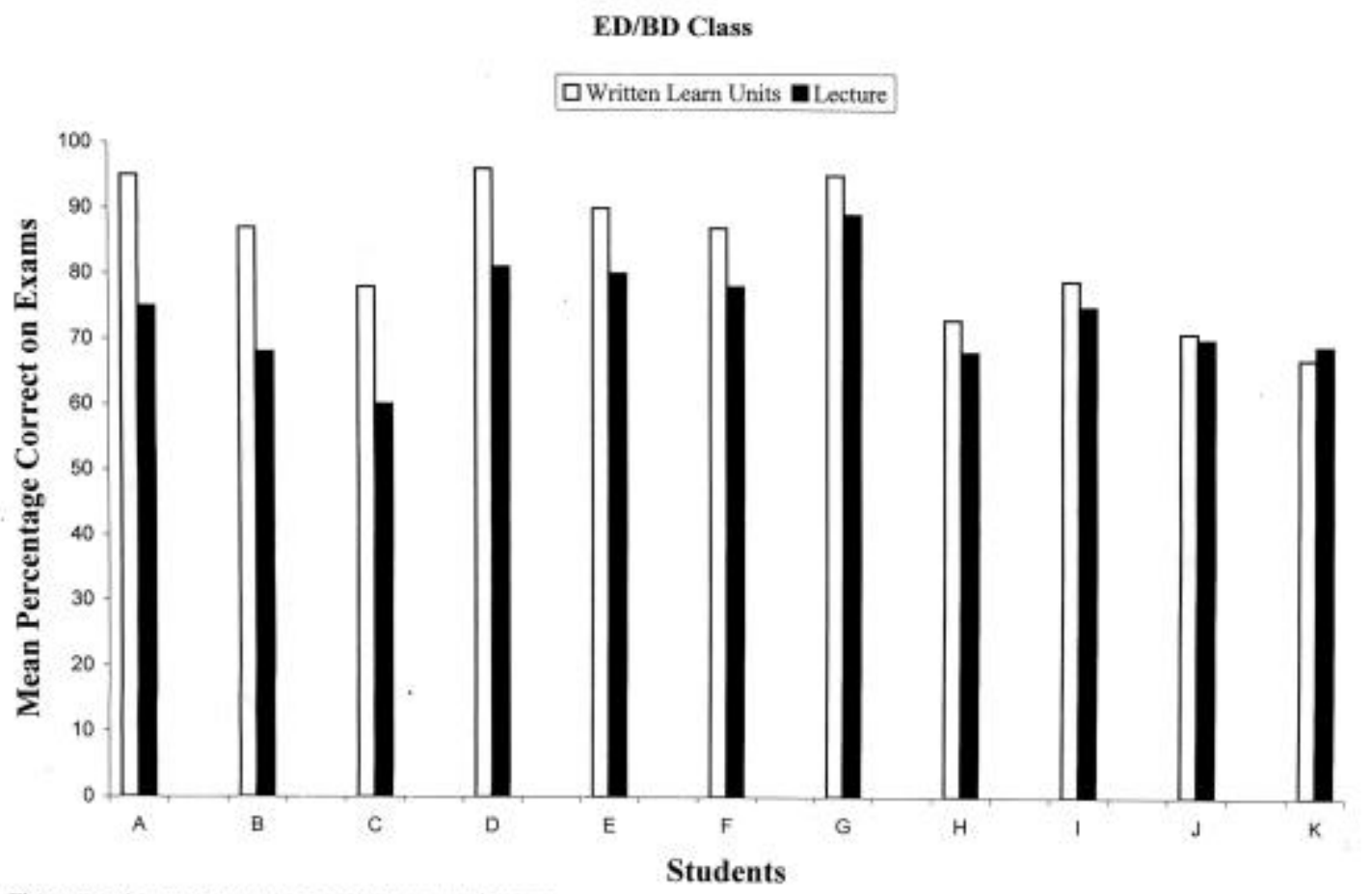

Figure 2. The mean percentage correct on examinations

In the ABA course, the mean percentage correct for all students taking exam \#1 was 79.8 (learn unitbased exam) (exam percentages ranged from 70 to 100), exam \#2 was 60.7 (lecture-based) (exam percentages ranged from 45 to 80), exam \#3 was 75.8 (lecture-based) (exam percentages ranged from 53 to 96), exam \#4 was 83.8 (learn unit-based) (exam percentages ranged from 43 to 100), exam \#5 was 84.3 (learn unit-based) (exam percentages ranged from 70 to 100), exam \#6 was 70.1 (lecture-based) (exam percentages ranged from 24 to 87), exam \#7 was 87.1 (learn unit-based) (exam percentages raged from 70 to 95), exam \#8 was 82.1 (learn unit-based) (exam percentages ranged from 70 to 95), exam \# 9 was 71.3 (lecture-based) (exam percentages ranged from 30 to 95), exam \#10 was 63.1 (lecture-based) (exam percentages ranged from 0 to 100), and exam \#11 was 83.3 (learn unit-based) (exam percentages ranged from 60 to 100).

In the ED course, the mean percentage correct for all students taking exam \#1 was 86.4 (learn unitbased exam) (exam percentages ranged from 40 to 100), exam \#2 was 85.5 (le arn unit-based) (exam percentages ranged from 52 to 100), exam \#3 was 79.9 (learn unit-based) (exam percentages ranged from 55 to 98), exam \#4 was 73.1 (lecture-based) (exam percentages ranged from 43 to 95), exam \#5 was 77.6 (learn unit-based) (exam percentages ranged from 46 to 95), exam \#6 was 77.6 (lecture-based) (exam percentages

ranged from 48 to 98), exam \#7 was 68.9 (lecture-based) (exam percentages ranged from 47 to 91), exam \#8 was 84.0 (learn unit-based) (exam percentages ranged from 65 to 95), exam \#9 was 80.0 (lecturebased) (exam percentages ranged from 60 to 95), exam \#10 was 89.5 (learn unit-based) (exam percentages ranged from 75 to 100) and exam \#11 was 70.0 (lecture-based) (exam percentages ranged from 40 to 100) (see Figure 4).

The results showed that all nine students in the ABA course earned mean test grades that were approximately at least one letter grade higher during class sessions in which written LUs were presented (see Figure 1). Eight out of the eleven students in the ED course also achieved mean test grades that 
were approximately at least one letter grade higher during class sessions in which they had received written LUs (see Figure 2). Overall, a 15-point performance difference was found between mean LU and lecture test grades in the ABA course (Figure 3) whereas only a 10-point performance difference was noted between mean LU and lecture test grades in the ED course.

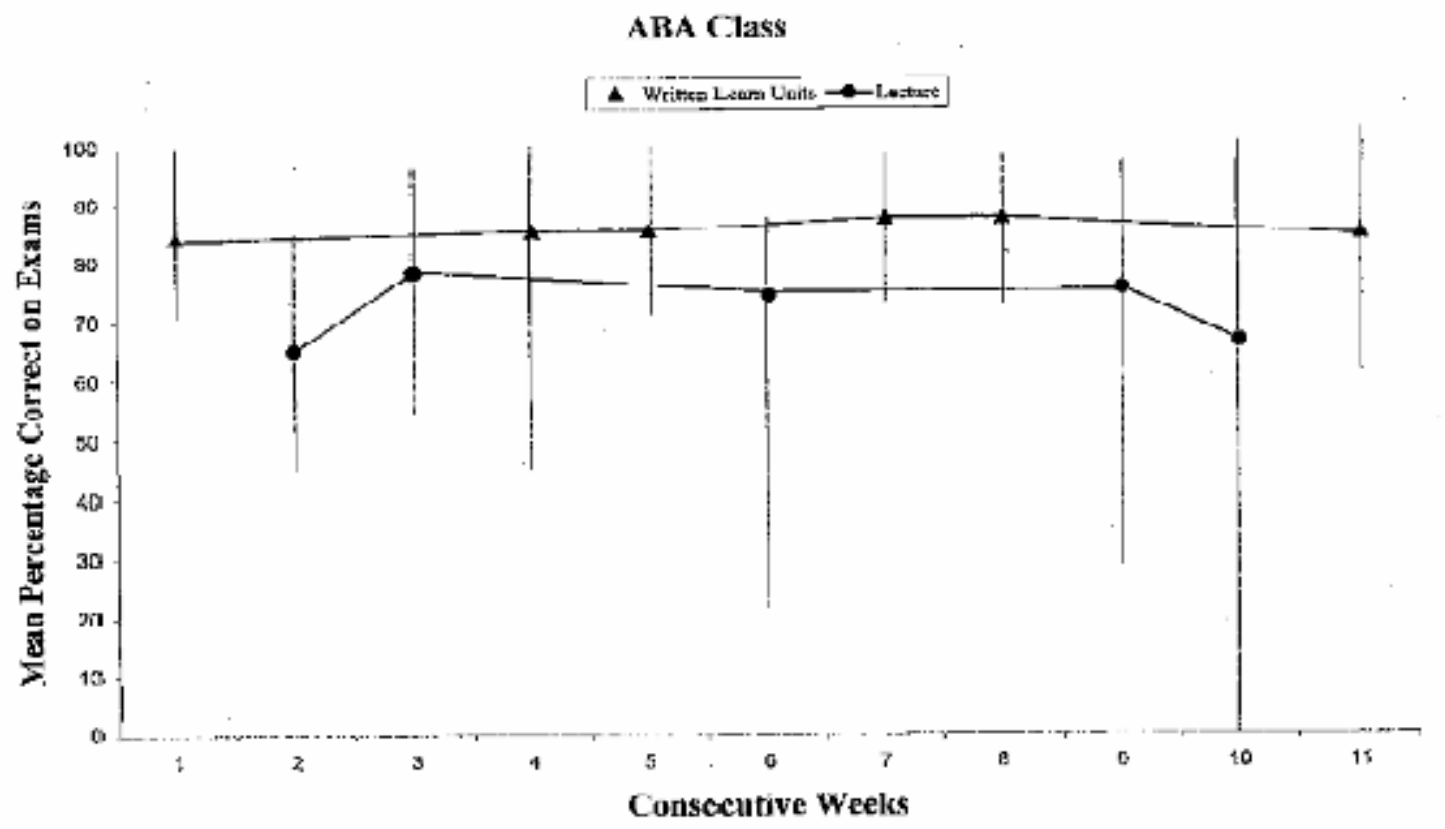

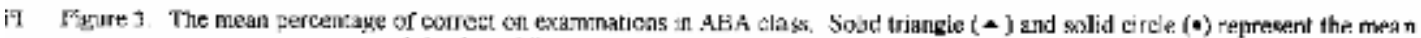
percerity ge sorrect and the dotted linee ropseacal the rasige (----). 


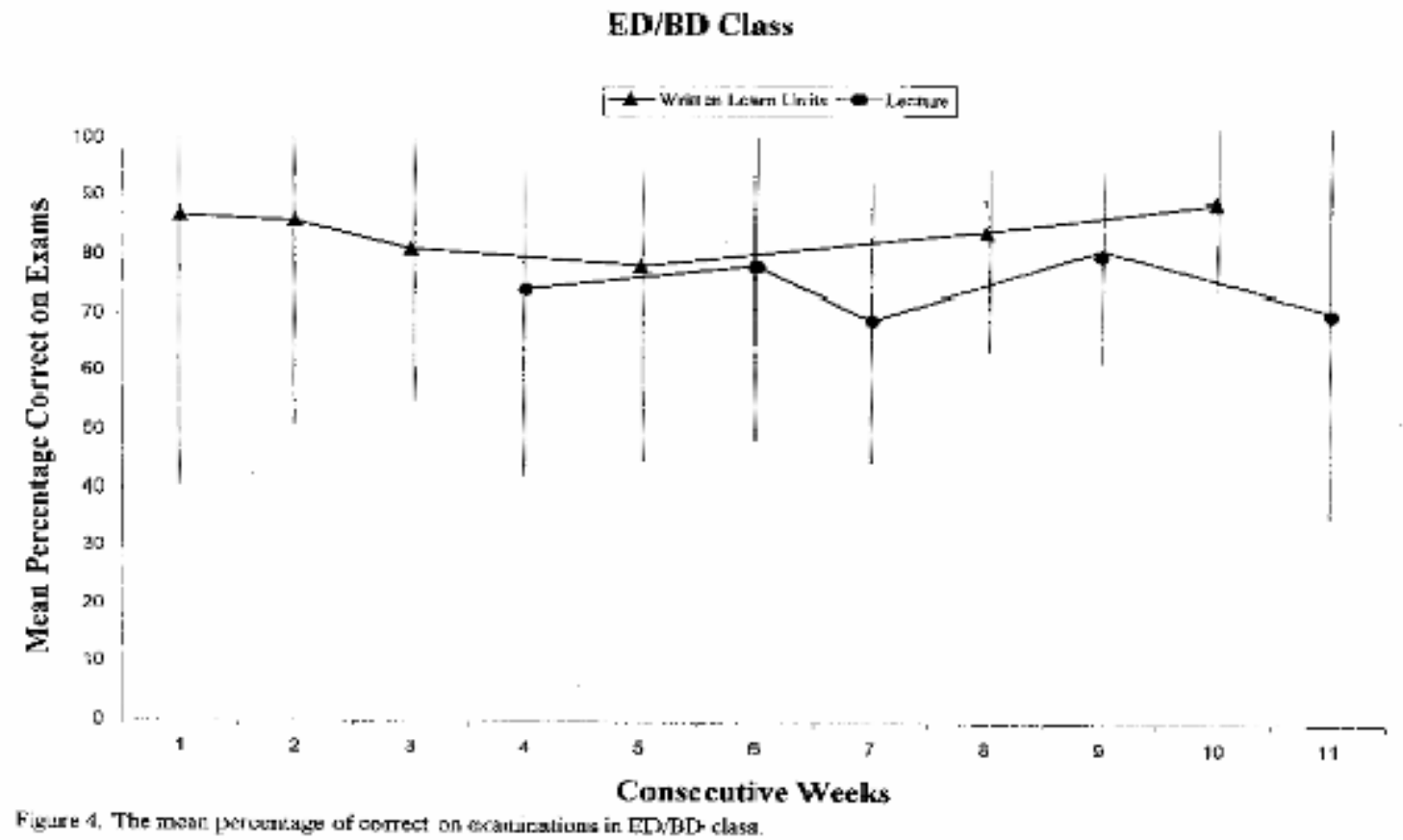

\section{DISCUSSION}

The purpose of this study was to examine the effects of written learn units on the academic achievement of undergraduate students. The measurement of the learn unit includes the interlocking behaviors of student and teacher three-term contingencies. Greer (1994) stated that the three term contingency trial for the student was yoked with the three term contingency trial for the teacher. Consequently, the behavior of the student was contingent upon the behavior of the teacher--i.e., each party "learns" from the other. The three term contingency trial for both student and teacher evolved to reduce the teaching and learning process into its fundamental elements--the smallest measurable unit of teaching and learning: "Because it predicts students' learning, the learn unit is a basic measure of effective teaching and can be used to discriminate between effective and ineffective teaching practices" (p. 30) (Greer, in press).

The learn unit measurement has been reported in the literature to improve a wide range of academic and social behaviors of certified students receiving special education services (Kelly \& Greer, 1996; Martinez, 1996; Lindhart-Kelly \& Greer, 1997; Polirstok \& Greer, 1982; Donley \& Greer; 1993; Lodhi \& Greer, 1989, Keohane, 1997; Hogin, 1996). However, there have been no studies investigating the effects of learn units on the academic performance of students in higher education nor with non-certified students in regular education settings. This study examined the effects of learn units on the test performance of undergraduate students enrolled in a special education university program.

The results demonstrated that for the ABA course, the mean percentage correct on exams was $83 \%$ during the LU class sessions and 68\% during the lecture sessions. In the ED course, the mean percentage correct on exams was $84 \%$ during LU classes and $74 \%$ during lecture classes. In other words, there was a 15-point performance difference between LU- and lecture- based tests for the students in the ABA course whereas only a 10-point performance difference was found in the ED course between LU- and lecture- based tests. 
In contrast to the overall 15-point performance difference between learn unit-based and lecture-based exams in the ABA course, students in the ED course whose grades were not higher on learn unit based exams may be explained by the fact that the textbook content did not specify operational definitions of vocabulary terms (e.g., "educational therapy," "therapeutic process") . Therefore, the grading of ED examinations may have been more subjective, discretionary, and liberal because of this lack of specificity in vocabulary. The implication is that subject matter containing specificity in vocabulary allows for more objective scoring of exams (i.e., assessing only chapter-specific content).

All nine students in the ABA course achieved a mean percentage correct on LU-based tests that was equivalent to at least 1 letter grade higher than they would have received on their performance on lecturebased tests. Eight students out of eleven in the ED course earned a mean percentage correct on LUbased tests that was also equivalent to at least 1 letter grade higher than their lecture-based performance.

College student's academic improvement in this study and their personal satisfaction with written learn unit class sessions (as opposed to lecture sessions) will be discussed in relation to the literature and research in instructional time, opportunity to respond/active student responding, and learn units.

Instructional Time

According to both educational research (Brophy \& Good, 1986) and behavior analysis literature (Greenwood, Hart, Walker, \& Risley, 1994), the critical component of effective schooling is that of maximizing class time in order to expedite student learning. Throughout the ages, researchers in the fields of education and psychology have recognized the obvious relationship between amount of time and learning (Currie, 1884; Carroll, 1963; Bloom, 1968). In fact, Skinner $(1968 ; 1984)$ stated that most of the problems facing education could be solved if student time in school was utilized more efficiently. The goal is to identify a reliable and valid measure (i.e., an independent variable) which will increase the number of correct student responses in less time. Unfortunately, the historical evolution of time measures such as allocated (scheduled) time, engaged time (time on-task), and academic learning time (ALT) have failed to (1) identify specific teacher behaviors and (2) provide a clear analysis of specific types and numbers of academic student responses (Greenwood et al., 1984; Heward, 1994). Today's popular version of allocated time is known as "block scheduling" whereby states across the country are requiring schools to increase class periods from 40 to 66 minutes. More than half of American high schools have currently adopted a schedule that offers longer class blocks: "With rising expectations for student achievement, heightened social and academic needs, and overcrowding, many schools have had to fundamentally rethink how they teach" (Grossman, 1998). Unfortunately, studies of correlations between amount of allocated time and academic achievement have consistently produced non-significant results (Heward, 1994).

The undergraduate students in this study attended weekly classes each for two and a half hour "block" lengths of time during the LU and lecture conditions. Yet the students in both courses learned significantly more (i.e., as measured by their weekly test performance) during the class sessions in which the professor emitted complete and accurate learn units. The number and rate of learn unit presentations by the professor is a specific teacher behavior which can be counted and functionally related to student learning outcomes than merely increasing the time of class periods. The research indicates that unless teachers are trained, they do not automatically emit complete learn units: "In some lectures or lessons, the teacher presents an extensive set of antecedents; at some point a student or students will be questioned" (p. 20) (Greer, in press).

Opportunity to Respond and Active Student Responding 
Although Heward (1994) distinguishes active student responding (ASR) from opportunity to respond (OTR) stating that OTR does not provide an account of discrete learning trials, both ASR and OTR are interdependent measures because opportunity is confirmed by the academic behavior produced by the student (Greenwood et al., 1984, Hall et al., 1982). As part of their definition of OTR, Greenwood et al. (1984) clearly state that the ultimate result in presenting antecedent stimuli (i.e., the materials presented, questions asked, prompts) is their success in establishing the academic responding desired by the curriculum materials. These researchers point out that the importance of OTR is its focus on active (e.g., writing, oral reading) rather than passive responding (e.g., watching the teacher lecture, viewing an overhead transparency presentation). Their study reported that students in the inner-city Title 1 sample engaged in less academic responding during a typical day than did the suburban, high socioeconomic school group. They concluded that teachers who exposed students to "low opportunity to respond instruction" (e.g., lectures) should expect to result in significantly lower achievement gains in their students over the course of a school year. In a major longitudinal study, Hart and Risley (1995) discovered that young children reared in poverty experienced far fewer verbal opportunities to respond resulting in striking disparities in their future vocabulary growth rate and IQ test scores. It is quite likely that the informal instruction received in the home by children from their parents is more effective when the interactions are complete and accurate learn units (Greer, 1996, personal communication).

In relation to ASR research, Heward (1994) concluded that increasing the frequency with which each student makes academic responses has (1) consistently produced better performance on same-day, nextday, and follow-up tests of the material taught, (2) resulted in higher levels of on-task behavior (i.e., reduced levels of off-task, disruptive, and "looking bored" behavior), and (3) been preferred by the great majority of students over traditional instructional formats.

The written learn units in the form of guided notes in this study provided the students with continuous and multiple opportunities to respond and, therefore, to receive immediate consequences for their writing and attending behaviors (i.e., professor's verbal and written corrective feedback, student's viewing correctly written answer on overhead).

\section{The Learn Unit}

The learn unit consists of two or more interlocked three-term contingencies of the teacher and student. The sequence is described by Greer and Hogin (1999) as follows: (1) the attending student serves as the teacher's antecedent, (2) the teacher responds by presenting the student antecedent, (3) the student behaves by responding to the stimulus either correctly or incorrectly which in turn, (4) consequates and serves as an antecedent for the eacher to (5) consequate the student for his or her response. The completion of this single learn unit functions as a consequence for the teacher to present the next learn unit. This type of microanalytic analysis is easily overlooked when instructors deliver lectures.

Greer (1994) suggests that learn units must be considered together with the measurement of criterionreferenced instructional objectives and presented via scripted sequences based on logic al analyses or based upon task analyses. The accuracy, number, and rate of learn units have predicted student learning in programmatic research conducted by behavioral investigators at Teachers College Columbia University. Albers and Greer (1991) studied the effect of increasing learn units presentations to three times their baseline rates with seventh-grade classified students in a remedial math class. Results demonstrated the utility of both written and vocal learn units in producing higher rates of correct academic responding and an increase in the achievement of instructional objectives. These findings were consistent with results obtained by Ingham \& Greer (1992), Selinske et al. (1991), Greer et al. (1989), and Lamm \& Greer (1991). Based on these studies, it was found that increasing the number of learn units that were 
sequenced carefully and that were accurately consequated by teacher and supervisor behaviors led to (1) an increase in correct academic responses, (2) higher numbers of achieved objectives and (3) fewer incorrect responses.

The microanalytic (i.e., decision tree) analyses of written learn units in this study was presented in a group setting by the professor following sequenced scripts available to students both on their desks and viewed on overhead transparencies. The professor monitored the delivery of complete and accurate learn units by (1) providing clear and flawless antecedent curricular stimuli in the form of guided notes, (2) observing students' behavior of notetaking, and (3) consequating students' notetaking after the completion of each phrase (i.e., a single learn unit). The professor did not move on to the next learn unit until each student mastered the specific phrase or sentence as evidenced by their correct answers on their guided notes. During lecture sessions, the professor read a scripted sequence of lecture notes but had no evidence of moment-to-moment mastery of academic content. The initial antecedent for the professor to present curricular stimuli to the student is the student's attentive looking behavior at the professor. Presentation of an antecedent by the professor to the student (e.g., professor points to overhead and reads "The behaviors characteristic of mental illness are caused by organic malfunctions due to___ (") is the professor's response and serves as the antecedent for the student's response. The behavior of writing notes by the student (e.g., copying the answer from the overhead transparency) functions as a consequence for the professor as well as an antecedent for the professor's next response to the student (e.g., reinforcement of the correct response by checking the answer or correction feedback of an incorrect answer). The professor's latter response is the consequence for the student as well as a consequence for the professor (i.e., the student's correct response) to emit the next sequenced learn unit.

In short, the learn unit procedure provided the professor with a micro analytic (i.e., decision tree) analyses and standardized measure for efficiently and continuously assessing and improving student progress throughout two and a half hours of instruction by checking (consequating) each students' written response.

\section{Conclusion}

The data from several sources converge on the finding that a "decision tree" analyses by teachers of the interlocking student/teacher operants is critical to the maturation of a science of pedagogy (Malott et al., 1995; Heward, 1994; Greenwood et al., 1991; Greer \& Hogin, 1999). The research demonstrates that teachers who were effective (i.e., produced high rates of mastery of student objectives and an increase in test performance) presented more student behavior opportunities and consequated student behaviors more than did teachers who were less effective (Albers \& Greer, 1991; Greenwood et al., 1991). Based on the research to date, the learn unit serves the following functions according to Greer (in press): "(1) it is a measure that predicts students' learning for the academic and social behaviors tested in the existing research, (2) because it predicts student learning, the learn unit is a basic measure of effective teaching and can be analyzed to discriminate between effective and ineffective teacher/professor behaviors, (3) the learn unit provides a data base for what teachers/professors need to learn in order to be effective--a scientifically based curriculum for teacher graduate training, and (4) the learn unit with its establishing operations and the students' instructional history provides rule governed operations for solving instructional problems through contingency analyses of student and teacher/professor interlocking behaviors." For example, the only two students $(\mathrm{J}, \mathrm{K})$ in this study who did not improve their test scores on LU-based tests may be explained by instructional histories of significant deficiencies in essay writing skills, motivational variables, and/or competing setting events. In fact, Student $\mathrm{K}$ was experiencing personal health problems along with the deteriorating health and death of his father during the semester whereas Student $\mathrm{J}$ indicated that she had a history of "learning disabilities." 
The conclusion of the most comprehensive and rigorous international comparison ever conducted of academic achievement was reported in February of 1998 by the U.S. Department of Education concluding that the longer students stay in American schools, the farther they academically fall behind their age-mates in most industrialized nations of the world. Throughout the decades, specific as well as vague suggestions for American school reform have been proposed to improve student learning outcomes including (1) increasing academic standards and making a commitment to excellence, (2) increasing the length of class periods (i.e., block scheduling) or the length of the school day, (3) requiring summer school, (4) increasing funding for higher teacher salaries, (5) improving quality of textbooks and computers, (6) empowering teachers and parents, (7) requiring teachers to have undergraduate majors in the subjects they will teach, (8) decentralizing administration, (9) decreasing classroom size, (10) developing professional partnerships between public schools and colleges of education (i.e., consultants), (11) improving the format and quality of tests for children, (12) developing more rigorous tests for teacher certification, (13) increasing the amount or difficulty level of homework, (14) introducing "new and improved" curricula, and (15) providing teachers with experienced mentors and additional preparation periods (Skinner, 1984; Greer, 1996; National Commission on Excellence in Education, 1983). Although all of these suggestions for improving education are important considerations, unfortunately, none of these changes deals with the critical issue of identifying (1) an absolute measure of teaching which can reliably and validly predict learning and (2) specific teacher behaviors functionally related to the measurable improvement of student learning.

The findings reported in this study expand the database of the utility of the learn unit both as a microanalytic measure of teaching and learning as well as an effective independent (intervention) variable not only for students with disabilities (Kelly \& Greer, 1996; Martinez, 1996; Lindhart-Kelly \& Greer, 1997; Keohane, 1997; Hogin, 1996; Albers \& Greer, 1991; Selinske et al. 1991; Lamm \& Greer, 1991) but also for non-classified students in higher education settings. If the utilization of the learn unit measurement is further documented in future studies to improve student outcomes, there will be more accumulated data to substantiate the preliminary finding that the learn unit is the fundamental measure and building block of teaching and learning from pre-K to college (Greer \& Hogin, 1999).

Future investigations of the learn unit in higher education should (1) incorporate end of semester cumulative exams to compare the weekly mean percentage correct on exams to performance maintenance over time on a final exam consisting of both LU- and lecture-based content, (2) distribute guided notes in both LU and lecture conditions but not consequating students' written answers during the lecture condition, (3) collect and analyze the quality and potential improvement of students' notes based on lecture sessions (Peverly, Brobst, Graham, \& Shaw, in press), and (4) test the generalization of the findings of this study by using larger samples of students taking various types of college courses with and without having precise operational definitions of technical terms (e.g., statistics, critical analysis of literature) at other universities consisting of students representing broader ethnic backgrounds.

Future studies may help identify the optimal number, rates, and quality of written and/or vocal learn units in college courses (as opposed to merely increasing block time scheduling) to prevent (1) academic failure and dismissal, (2) drop out, and (3) remedial coursework.

Ultimately, the learn unit has the potential to serve as a universal unit to reliably and validly measure and thereby enhance the teaching, learning, and school satisfaction of classified and nonclassified American students from preschool to college classrooms.

\section{References}

Albers, A., \& Greer, R. D. (1991). Is the three-term contingency trial a predictor of effective instruction? Journal of Behavioral Education, 1, 337-354. 
Baker, L. (1985). Students' lecture notes and their relation to test performance. Teaching of Psychology, 12 (1), 28-32.

Ben-Peretz, M. \& Bromme, R. (Eds.) (1990). The nature of time in schools: Theoretical concepts, practitioner perceptions. New York: Teachers College Press.

Beirne-Smith, M. (1989). A systematic approach for teaching notetaking skills to students with mild learning handicaps. Academic Therapy, 24, 425-437.

Berliner, D. C. (1990). What's all the fuss about instructional time?. In M. Ben-Peretz \& R.

Bromme (Eds.), The Nature of time in schools (pp. 3-35). NY: Teachers College Press.

Bloom, B. S. (1974). Time and learning. American Psychologist, 29, 682-688.

Borg, W. R. (1980). Time and school learning. In C. Denham and A. Lieberman (Eds.), Time to learn (pp. 33-72). CA: National Institutes of Education.

Buskist, W., Cush, D., \& DeGrandpre, M. (1991). The Life and Times of PSI. Journal of Behavioral Education, 1 (2),

Carnine, D. W. (1992). The missing link in improving schools: Reforming educational leaders. Direct Instruction News, 11, pp. 25-35.

Carrier, C. (1983). Notetaking research. Journal of Instructional Development, 6 (3).

Carroll, J. B. (1963). A model of school learning. Teachers College Record, 64 (8).

Diamond, D. (1992). Beyond time on task: Comparing opportunities to respond and learn units to determine an accurate means of measuring educational gains. Unpublished paper. Teachers College, Columbia University.

Engelmann, S., \& Carnine, D. (1982). Theory of instruction: Principles and applications. New York: Irvington.

Fisher, W. F., Berliner, D. C., Filby, N. N., Marliave, R., Cahen, L. S., \& Dishaw, M. M. (1980). Teaching behaviors, academic learning time, and student achievement. In C. Denham \& A. Lieberman (Eds.), Time to learn (pp. 7-22). CA: National Institutes of Education.

Fisher, W. F., \& Berliner, D. C. E. (Eds.) (1985). Perspectives on instructional time. New York: Longham.

Gavlick, M. (1996). Triangulating the relationship among publication productivity, teaching effectiveness, and student achievement, 90, 49-56.

Goodman, L. (1990). Time and learning in the special education classroom. New York: State University of New York Press.

Greenwood, C. R., Delaquardi, J., \& Hall, R. V. (1984). Opportunity to respond and academic 
performance. In W. L. Heward, T. E. Heron, J. Trap-Porter, \& D. S. Hill (Eds.). Focus upon behavior analysis in education (pp. 58-88). Columbus, OH: Charles Merrill.

Greenwood, C. R., Hart, B., Walker, D., \& Risley, T. (1994). The opportunity to respond and academic performance revisited: A behavioral theory of developmental retardation and its prevention. In R. Gardner III, D. M. Sainato, J. O. Cooper, T. E. Heron, W. L., Heward, J. W.., Eschelman, T. A. Grossi (Eds.). Behavior analysis in education: Focus on measurably superior instruction (pp. 213-222). Pacific Grove, CA: Brooks Grove.

Greer, R. D. (1989). A pedagogy for survival. In A. Brownstein (Ed.) Progress in the behavioral sciences (pp. 45-80). Hillsdale, NJ: Erlbaum.

Greer, R. D. (1991). The teacher as strategic scientist: A solution to our educational crisis? Behavior and Social Issues, 1 (2).

Greer, R. D. (1994). The measure of a teacher. In R. Gardner III, D. M. Sainato, J. O. Cooper, T. E. Heron, W. L. Heward, J. W. Eschelman, T. A. Grossi (Eds.). Behavior analysis in education: Focus on measurably superior instruction (pp. 161-171).

Greer, R. D. (1999). Is the learn unit a fundamental measure of pedagogy? The Behavior Analyst, 22, pp.5-16.

Greer, R. D. (1994). A systems analysis of the behaviors of schooling. Journal of Behavioral Education, 4, pp. 255-264.

Greer, R. D., McCorkle, N., \& Williams, G. (1989). A sustained analysis of the behaviors of schooling. Behavioral Residential Treatment, 4, 113-141.

Grossman, K. N. (1998). Schools find learning is all in the timing. Christian Science Monitor, June 2.

H, B. \& Risley, T. R. (1995). Meaningful Differences. MD: Paul Brookes.

Heward, W. L. (1994). Three "low-tech" strategies for increasing the frequency of active student response during group instruction. In R. Gardner III, D. M. Sainato, J. O., Cooper, T. E. Heron, W. L. Heward, J. W. Eschelman, T. A. Grossi (Eds.). Behavior analysis in education: Focus on measurably superior instruction (pp 213-222). Pacific Grove, CA: Brooks Grove.

Hogin, S. (1996). Essential contingencies in correction procedures for increased learning in the context of the learn unit. Unpublished doctoral dissertation, Columbia University, New York.

Hughes, C., \& Suritsky (1994). Note-taking skills of university students with and without learning disabilities. Journal of Learning Disabilities, 27 (1).

Ingham, M. \& Greer, R. D. (1992). Functional relationships between supervisors' observations of teachers in observed and generalized settings. Journal of Applied Behavior Analysis, 25, 153164.

Kelly, T. M. \& Greer, R. D. (1996). Functional relationships between learn units and maladaptive behavior. Manuscript submitted for publication. 
Keohane, D. (1997). A functional relationship between teachers' use of scientific rule governed strategies and student learning. Unpublished doctoral dissertation, Columbia University, New York.

Keller, F. S. (1968). Good-bye, teacher. Journal of Applied Behavior Analysis, 1, 79-89.

Kiewra, K. (1987). Notetaking and review: The research and its implications. Instructional Science, 16.

Kiewra, K., Mayer, R., \& Christensen, M., \& Risch, N. (1991). Effects of repetition on recall and notetaking: Strategies for learning from lectures. Journal of Educational Psychology, 83 (1).

Lamm, N., \& Greer, R. D. (1991). A systematic replication of CABAS in Italy. Journal of Behavioral Education, 1, pp. 427-444.

Lazarus, B. D. (1993) Guided notes: Effects with secondary and post secondary students with mild disabilities. Education and Treatment of Children, 16 (3).

Lindhart-Kelly, R., \& Greer, R. D. (1999). A functional relationship between mastery with a rate requirement and maintenance of learning. Manuscript submitted for publication.

Lodhi, S. \& Greer, R. D. (1989). The speaker as listener. Journal of the Experimental Analysis of Behavior, 51, pp. 353-359.

Polirstok, S. R., \& Greer, R. D. (1986). A replication of collateral effects and a component analysis of a successful tutoring package for inner-city adolescents. Education and Treatment of Children, 9, 101-121.

Malott, R. W., Vunovich, P. L., Boettcher, W., \& Groeger, C. (1995). Saving the world by teaching behavior analysis: A behavioral systems approach. The Behavior Analyst, 2, pp. 341354.

Martinez, R. (1996). Reducing aberrant behaviors of autistic students through effective instruction. Manuscript submitted for publication.

Mithaug, D. E. (1993). Self-regulation theory: How optimal adjustment maximizes gain. Westport, CT: Praeger.

Moxley, R. (1982) Writing and reading in early childhood. NJ: Educational Technology Publications.

Samuelson, R. J. (1998). The wastage in education. Newsweek, August 10, p. 49.

Selinske, J. E., Greer, R. D., \& Lodhi, S. (1991). A functional analysis of the comprehensive application of behavior analysis to schooling. Journal of Applied Behavior Analysis, 24, pp. 107117.

Skinner, B. F. (1968). The technology of teaching. New York: Appleton-Century-Crofts. 
Skinner, B. F. (1984). The shame of American education. American Psychologist, 39 (9), 947954.

Stallings, J. (1980). Allocated academic learning time revisited, or beyond time on task. Educational Researcher, 9, pp. 11-16.

Stanley, S. O., \& Greenwood, C. R. (1983). Assessing opportunity to respond in classroom environments through direct observation: How much opportunity to respond does the minority disadvantaged student receive in school? Exceptional Children, 49, pp. 370-373.

Test, D. W., \& Heward, W. L. (1983). Teaching road signs and traffic laws to learning disabled students. Learning Disability Quarterly, 6(1), pp. 80-83

White, D. M. (1991). Use of guided notes to promote generalized note taking behavior of high school students with learning disabilities. Masters thesis, The Ohio State University.

West, R., \& Hammerlynck, L. (1992). Designs for excellence in education: The legacy of B. F. Skinner. Longmont, CO: Sopris West.

\section{Author contact information:}

Ara John Bahadourian

9 Paulin Blvd.

Leonia, NJ 07605

E-mail: Bahadourian@hotmail.com 


\title{
Problem Solving Treatment for Intellectually Disabled Sex Offenders
}

\author{
Christine Maguth Nezu, Alicia A. Fiore \& Arthur M. Nezu
}

\begin{abstract}
Over the past thirty years, Problem Solving Therapy (PST) has been shown to be an effective treatment for many different problems and patient populations (Nezu, 2004). Among its many clinical applications, PST interventions were developed for persons with intellectually disabilities (ID), where improving problem-solving skills led to adaptive behavioral improvements (Nezu, Nezu, \& Arean 1991). This article provides a rationale and description of the potential benefits of including PST as a treatment for ID sex offenders. Recommendations regarding future research directions are offered.

Key words: Problem Solving Therapy, (PST), Intellectually Disabled, (ID).
\end{abstract}

\section{Introduction}

Among the many adaptations of Problem Solving Therapy (PST; Nezu, 2004), interventions were developed for intellectually disabled (ID) populations, where improving problem-solving skills led to improvements in psychological and adaptive functioning (Nezu, Nezu, \& Arean 1991), and decreases in challenging social behavior. Our clinical experience in providing cognitive behavior therapy (CBT) to sex offenders with intellectual disabilities (ID) and a growing body of literature suggest that PST may potentially serve as an integral part of a multi-component treatment plan for this population.

\section{Sex Offending Defined}

We define a sex offender as an individual who has committed a sex offense or engaged in sex offending behavior (Lanyon, 2001; Nezu, Nezu, Klein, \& Johnson, in press). The term sex offending is a psycholegal one that encompasses a broad set of behaviors, such as nonconsensual sexual conduct with an adult or sexual behavior with a minor (Lanyon, 2001; Nezu, et al., in press). Many individuals identified as sex offenders are also characterized as having deviant sexual interests or diagnosed with specific paraphilias, such as pedophilia or voyeurism. However, having these interests is different from committing a sex offense; some individuals with paraphilias and other deviant sexual interests may never actually engage in sex offending behavior. Likewise, it is possible for some individuals to commit a sex offense in the absence of deviant sexual interests or a diagnosed paraphilia. There is a significant degree of heterogeneity among individuals who commit sex offenses. Individuals who commit such offenses vary across age, race, gender, socioeconomic status, offending history, and a plethora of other variables.

Further adding to the heterogeneity of the sex offending population is the ubiquitous presence of additional, comorbid disorders. Individuals identified as sex offenders may also be diagnosed with other medical or psychiatric diagnoses, including mood, anxiety, or personality disorders, brain injury, physical disabilities, impulse control disorders, sexual dysfunction, developmental disabilities, including mental retardation, or any combination of these (Nezu, et al., in press).

Sex Offenders with Intellectual Disabilities (ID)

Individuals who commit sex offenses and are also diagnosed with ID represent a subset of all offenders, and constitute an estimated 10 to $15 \%$ of the population of sex offenders who 
come to the attention of the courts (Murphy, Coleman \& Haynes, 1983). The prevalence rate is even higher, reaching over $40 \%$, when individuals with borderline intellectual functioning are included (Nezu, Nezu \& Dudek, 1998).

\section{Vulnerability Factors for Sex Offending}

It is generally accepted that sex-offending behavior does not have a single cause but is the result of a general vulnerability that is a combination of risk factors (Marshall, Anderson, \& Fernandez, 1999). Various behavioral and cognitive pathways made up of these risk factors interact to affect an individual's unique vulnerability for engaging in sex offending behavior. Marshall et al., (1999) describe vulnerability as an individual's attitudes, beliefs, cognitions, behavior patterns and emotions, and stress the importance of the role of learning in the development and maintenance of these factors. Deficits or deviance in any one, or a combination, of these areas can increase one's vulnerability, and thus one's risk, for committing a sex offense (Nezu, et al., in press).

The empirical literature provides support for several factors as possible determinants of vulnerability in the general sex offending population. Some of these factors consist of static factors such as individual characteristics, living alone (Marques, Day, Nelson, \& West, 1994), abusive early environments (Seghorn, Prentky, \& Boucher, 1987) and past behavioral patterns of sex offending with a range of victims (Prentky, Knight, \& Lee, 1997). Other risk factors consist of dynamic or treatable characteristics, such as deviant sexual preferences (Hanson, \& Bussiere, 1998), social incompetence (Marshall, Earls, Segal \& Drake, 1983), poor stress management (Marques, et al., 1994; Marshall et al., 1983), cognitive distortions (Ward, Hudson, \& Marshall, 1995), avoidance (Prentky, \& Knight, 1991), psychopathy (Rice, Chaplin, Harris, \& Couts, 1994), lack of motivation, non adherence to treatment (Marshall et al., 1999), and poor problemsolving ability (McMurran, Egan, Richardson, \& Ahmadi, 1999; Nezu, Nezu, Dudek, Peacock, \& Stoll, 2005).

With specific regard to problem solving ability, we investigated the association between various social problem-solving skill components and self-reported sex-offending deviance among a recruited sample of incarcerated child molesters (Nezu et al., 2005). The results provided robust support that self-reported sexual deviance was associa ted with an impulsive and careless problem-solving style.

\section{Vulnerability in Intellectually Disabled Sex Offenders}

Although the empirical literature that provides evidence for the presence of vulnerability factors in ID offenders is much less available than for non-disabled offenders, many authors have indicated that similar vulnerability factors exist for ID sex offenders. In general, these vulnerabilities can be categorized into two types: deviance and deficits. Deviance theories suggest that sex offending behavior is a result of deviant sexual desires learned through conditioning (Marshall et al., 1999; Nezu et. al., in press). Although the scientific support demonstrating the relation of sexually deviant, masturbatory-linked fantasies and sexually deviant behavior is less available for the ID offender population, our own clinical experience suggests that this may represent one important causal factor, and support does exist for non-disabled offender populations (Maguire, Carlisle, \& Young, 1965; Prentky \& Knight, 1991).

Deviant cognitions have also been linked with risk for sex offending, and have been observed in both intellectually disabled and non-disabled sex offenders (Nezu, et al., 1998). For 
example, many offenders tend to distort and minimize their own behavior as well as the intentions and consequences on their victims.

Vulnerability factors categorized as deficits concern factors related to a lack of skills, rather than deviant behavioral or cognitive conditioning. These include poor interpersonal skills, poor coping skills, social incompetence, and poor problem solving. These deficits appear to be quite similar in both ID and non-ID sex offender populations (Marshall, 1999; Murphy, Coleman, $\&$ Haynes, 1983; Nezu, et al., in press). For example, one study reported that specific deficits observed in ID sex offenders included sexual naiveté, poor impulse control, and lack of relationship skills (Day, 1994).

\section{Unique Vulnerability Factors}

Sex offenders with ID also face additional problems and unique vulnerabilities related to their disability. These individuals may have a significant history of developmental factors contributing to their risk for sex offending. In some cases, factors that contributed to the disability (e.g. abuse or negle ct) may also serve as risk factors. For example, we reported elsewhere (Nezu et al., in press) that ID sex offenders may misinterpret socio-sexual cues in their environment, experience deficits in their ability to identify and interpret negative affect or distress, experience deficits in their ability to effectively and appropriately express emotions, as well as experience deficits in social problem solving skills (Nezu, et al., 1998). Finally, persons with ID tend to have less access to resources and services needed to address and remediate such problems.

It may be particularly important for individuals with ID disabilities to have access to training opportunities that will help them cope with the additional, unique set of vulnerability factors they confront. The lives of ID individuals, including their sexual expression, have been controlled by society throughout history. For example, persons with developmental disabilities such as mental retardation have been stereotyped either as innocent, naïve individuals with no sexual desires (Szollos \& McCabe, 1995; Zuker-Weiss, 1994) or as promiscuous, criminal individuals with uncontrollable sexual desires (Lumley \& Scotti, 2001; Kempton \& Kahn, 1991; Szollos \& McCabe, 1995). Social stigma, fears, inaccurate perceptions or negative attitudes towards sexuality in this population have led society to often isolate ID individuals, restrict their sexual behavior, and avoid education about sexuality and intimacy. These factors, in turn, often lead to deficits in sexual knowledge, decreased access to sexual expression, and negative emotions such as anger, frustration, confusion, sadness, and loneliness. As we have previously reported (Nezu et al., 1998), the unique social and environmental factors that contribute to sex offending vulnerability include social stigma and rejection, limited opportunities for social and sexual education, and limited opportunities for learning and participation in adaptive sexual activities. Moreover, ID individuals may have an increased vulnerability due to history of institutionalization and increased likelihood of experiencing sexual victimization themselves (Nezu, et al., 1998). Such problems often require complex and effective solutions. One way to reduce these unique vulnerabilities may be to specifically direct treatment at increasing individuals' abilities to more effectively cope with the problems they face.

\section{Problem Solving}

Problem solving is the cognitive-behavioral process by which individuals attempt to find effective or adaptive solutions to specific problems encountered in their everyday lives (D'Zurilla \& Nezu, 1999; D’Zurilla \& Nezu, in press). This process incorporates overt, purposeful, and conscious efforts to change one's reactions to a problem, to change the problem or situation itself, 
or both, depending on the nature of the problem (e.g. controllable vs. uncontrollable) (Nezu, 2004). In this sense, the goals of problem solving can include changing a problem that may be under one's control (e.g. standing up to a boss who is making unreasonable demands) or increasing coping skills where a problem is not under one's control (e.g. reacting to social or sexual rejection). A problem, or problematic situation, is defined as a present or anticipated task or event that necessitates an effective or adaptive response, but for which there is no such response immediately available or apparent due to existing obstacles or barriers (D'Zurilla \& Nezu, 2001; Nezu 2004). The origin of the demands of a particular problem may lie in the environment (e.g. external barriers to a goal), within the individual being confronted with the problem (e.g. inability to reach a personal goal) or between individuals (e.g. conflicting goals) (Nezu, 2004). The obstacles to an effective or adaptive response, and thus goal attainment, can include uncertainty, ambiguity, lack of resources, novelty of the problem, conflicting demands or skills deficits (Nezu, 2004).

Regarding the causal chain leading to sex offending, problems may be causally linked to internal origins (e.g., deviant thoughts, emotional arousal, learned reactions), or external stressors (e.g., interpersonal problems, lack of training opportunities, life changes), or a combination of both. Moreover, a problem can be a single event (e.g., getting fired from work), a series of related events (e.g., repeated social rejections), or a chronic situation (e.g., social stigmatization; loneliness). The demand in the problematic situation may originate in the environment (e.g., restrictions at a group residence, arguments with supervisors; access to potential victims) or within the person (e.g., viewing a child as seductive; deviant arousal; lack of personal control). A solution, in this model, is defined as any coping response designed to alter the nature of the situation so that it is no longer problematic, one's maladaptive negative reaction to it, or both (Nezu, Nezu \& Perri, 1989). However, not all solutions are effective. According to this definition many destructive or harmful behaviors are viewed as ill-fated solutions, such as substance abuse, withdrawal, or coercive acts toward others. However, an effective solution is one that not only achieves the goal, but also leads to positive consequences and minimal negative consequences. For example, for individual facing an overprotective family, focusing on personal goals and current obstacles toward independence is likely to yield a better problem solution that focusing on exaggerated or inaccurate thoughts of persecution or the family's perceived intention to victimize him. Within a problem-solving conceptualization, sex-offending deviance and behavior reflect a limited and destructive solution to the perpetrator's problems. As such, the solution may provide some relief to an immediate problem (e.g., psychological distress, threats to self-esteem, or sexual tension), but also leads to significant negative consequences for both the victim and offender.

Problem-solving ability is best conceived as comprising a series of specific and interacting cognitive-emotional skills rather than a single, unitary ability. We believe that effective problem solving requires several component processes, each of which makes a distinct contribution toward effective problem resolution. These include (1) problem orientation (e.g., the way one perceives problems, acknowledges and understands their emotional reactions to problems, and assesses their own ability to solve problems), (2) behavioral response styles (e.g., general styles or tendencies regarding the ways one reacts to problems), and (3) rational problemsolving skills (e.g., the extent to which people can accurately define a problem, brainstorm creative solutions, make cost-benefit decisions, implement solutions, and monitor their performance). Each of these problem solving components are discussed below.

\section{Problem orientation}

Social problem-solving ability has, as one component, the psychological set or 
orientation that affects the manner in which people notice, understand, think about, or react to problems in general. With regard to sex offending behavior, common reactions when an offender is exposed to conflict or disappointment include anger, fears of becoming emotionally vulnerable, denial of problems, and grandiose reactions, which may serve to counteract vulnerability. We refer to this general perceptual set as one's problem orientation. This component differs from the other problem-solving component processes, in that it is a motivational process, whereas the other problem-solving processes consist of specific skills and abilities that enable a person to solve a particular problem effectively. It is a set of orienting responses that represent the immediate cognitive-affective reactions of a person when first confronted with a proble $\mathrm{m}$. Where a positive problem orientation has been associated with optimism and an attitude of challenge when facing a problem, a negative orientation has been found to lead to negative affect (e.g., depression, anger, anxiety), impulsive behavior (e.g., aggression) and avoidance motivation (e.g., denial of problems) which can disrupt further problem-solving attempts. The orientation component of problem-solving includes five specific variables: problem recognition (the ability to accurately recognize problems when they occur), problem attribution (the ability to accurately identify the source of the problem verses the pervasive view that problems are always caused by oneself or others), problem appraisal (the ability to view problems as a challenge rather than a threat), and personal control beliefs (and ability to tolerate negative affect and understand their emotional reactions as part of identifying problems; (Nezu, Nezu, Friedman, Houts, \& Faddis, 1999).

\section{Behavioral response styles}

Our definition of problem solving includes a second major component, which concerns the general tendencies, or styles with which people approach their management of life problems. Research has indicated that there are two maladaptive styles that characterize a wide range of mood and behavior disorders. First, an impulsive-careless style is marked by impulsive, hurried, and careless attempts at problem resolution. This may serve as a particular vulnerability among offenders (Nezu, D'Zurilla, \& Nezu, in press). Second, an avoidant style is characterized by procrastination, denial, passivity, and dependency. Each of these problem-solving styles can influence the effectiveness of one's problem orientation as well as all other component skill areas of the problem-solving process listed in the next section.

\section{Rational problem solving skills}

Finally, our definition of problem solving emphasizes the importance of behaviors that are required to direct toward changing the nature of the situation so that it is no longer problematic. Identification of such effective and appropriate solutions or coping efforts is achieved through specific problem-solving tasks, known as rational problem-solving skills. These involve a group of specific skills or goal directed tasks that enable a person to solve a particular problem successfully and can be defined as the rational, planful, systematic, and skillful application of various effective problem-solving principles and techniques. Each task makes a distinct contribution toward the discovery of an adaptive solution or coping response in a problem-solving situation.

Problem definition and formulation refers to the extent to which a person can use feelings as cues, gather all the facts, separate facts from assumptions, and develop goals. Generation of alternatives refers to the ability to withhold judgment and brainstorm creative solutions. Decision-making refers to the ability to estimate the likelihood that a solution will actually achieve desired goals, evaluate one's ability to successfully carry out or implement a given solution, and to weigh personal and social consequences of various alternative solutions. Finally, solution implementation and verification refers to an individual correctly evaluating his ability to 
possess or acquire the requisite skills and willingness to carry out the most effective solutions, self-monitor, and self-reinforce. Thus, this process requires both behavioral enactment and selfmonitoring.

Associated with a conceptual model of social problem solving is a specific clinical intervention -- problem-solving therapy (PST). PST has been applied successfully to people experiencing a wide variety of psychological and emotional difficulties (Nezu, 2004; Nezu, Nezu, \& Arean, 1991). The treatment employs techniques designed to initially target each specific problem-solving component and strategies to help patients practice their new skills, based upon problem-solving components, with real life examples.

\section{Problem Solving Treatment for ID Sex Offenders}

There are no group studies to date that specifically examine the efficacy of PST for the treatment of sex offending behavior in ID individuals. However, one study we conducted in 1991 (Nezu, et al., 1991) was a randomized intervention trial that combined PST, adapted for the dually diagnosed individuals, with assertiveness training. Participants included 28 individuals with a diagnosis of mild mental retardation and a concurrent psychiatric diagnosis, each of whom exhibited maladaptive social behaviors, such as uncontrolled anger, aggressive interpersonal behavior and or destructive behavior. After 10 sessions of assertiveness training and PST, participants showed significant improvements in adaptive functioning, reduction in aggression, and decrease in psychological symptoms and distress. The results of this study suggest that PST may be helpful to offenders who possess similar behavior problems.

One important consideration when adapting PST as an intervention for individuals with developmental disabilities is to optimally tailor the intervention to the intellectual level of the patients receiving treatment. A full description of such guidelines for adapting CBT strategies such as PST can be found in Nezu, Nezu \& Gill-Weiss (1992). These include incorporating strategies to maintain attention, using individuals with ID as teaching models, repetition of sessions, using many concrete examples, and including specific reinforcement for newly learned skills. When such adaptations are used, we have found that individuals diagnosed with mental retardation in even the moderate range of functioning may benefit. Our collective experience suggest that the best way to assess an individual's ability to respond to PST is to provide a brief trial of the intervention for several sessions, using the guidelines indicated above, and a evaluate the presence of any improvement.

Although there are no studies that have evaluated the efficacy of PST as a stand alone intervention for sex offending behaviors, effective programs can be identified that incorporated cognitive and behavioral techniques, including aspects of PST, for reducing behavioral problems in ID sex offenders (Nezu, et. al., in press). For example, Lindsay reported a successful series of CBT studies of group therapy for aggression and anger in developmentally disabled offenders (Lindsay, Neilson, \& Morrison, 1998; Lindsay, Olley, Jack, Morrison, \& Smith, 1998; Lindsay, Marshall, Neilson, Quinn, \& Smith, 1998; Lindsay, Olley, Baillie \& Smith, 1999). Lindsay's investigations consisted of open trials of treatments designed to reduce problems such as child molestation, stalking, and exhibitionism. Griffiths and colleagues (1989) provided a description of an effective CBT program that included covert sensitization to decrease deviant arousal, behavioral techniques such as masturbatory reconditioning to increase arousal to appropriate stimuli, sex education, and social problem solving skills training.

Lund (1992) reported good outcomes for a multi-component residential treatment program. Individual counseling included anger management, discussion of sexually inappropriate 
behavior, cognitive restructuring, processing their own abuse (when appropriate), victim empathy, and problem solving.

As a clinical demonstration of CBT for sex offending, we developed Project STOP, an outpatient program that provided assessment and treatment for men diagnosed with mental retardation and coexisting sex-offending problems (see Nezu, et. al., in press for a full description of the project). Sex offending behaviors included stalking, incest, molestation, rape, other sexual assault, paraphilia, and sexual threat. Patients were treated using various cognitive behavioral strategies and techniques, including PST, in individual, group, and/or family therapy formats.

It is important to note that Project STOP was developed using a broadly defined, CBT approach that evaluated many areas of patient vulnerability including deviant sexual arousal, a functional analysis of current behavioral incidents, deviant cognitive patterns, social and information processing deficits (including problem-solving ability), and coexisting psychological, behavioral, and emotional disorders such as anger, aggressive behavior, depression, anxiety and personality disorders. Consistent with suggestions of previous authors, each individual's treatment was individually designed by integrating assessment data and constructing an individualized case formulation approach to treatment (Nezu, et al., in press; Nezu, Nezu \& Lombardo, 2004; Plaud, Plaud, Kolstoe, \& Orvedal, 2000). Each individual's treatment contained multiple components such as PST and other skills training, contingency management, and procedures to decrease deviant arousal, dependent upon their unique areas of vulnerability. As such, some individuals were prescribed PST as a primary treatment, and others received PST as an adjunctive therapy approach. The results of a program evaluation we conducted of the 25 men in the program over a 3-year period showed significant improvements in treatment targets in individual patients and a low recidivism rate of $4 \%$.

Taken together, we consider the converging literature regarding CBT for sex offending, CBT for persons with ID and aggressive problems, and PST for persons with ID and dual diagnoses, as a strong rationale for the potential use of PST as part of a multi-component treatment for reducing risk in sex offending populations.

\section{A Clinical Case Example of PST with an Intellectually Disabled Sex Offender}

The following clinical case example of "David", a 36-year-old African American man diagnosed with mental retardation illustrates how problem solving can be identified as a vulnerability factor for sex offending behavior and targeted for treatment in order to decrease sexoffending risk.

David was referred by his group residence for aggression and inappropriate sexual behavior, specifically, the sexual molestation of a young boy. He had a significant history of being severely neglected, abused, and institutionalized, as well as of engaging in illegal, aggressive, sexually inappropriate and sexually aggressive behaviors from a young age. At intake, David was prescribed sterile medroxyprogesterone acetate (Depo-Provera) by his physician. The behavioral assessment revealed that David displayed a fair degree of social and adaptive interpersonal skills at his residence as well as functional work skills.

A multimodal, multimatrix assessment resulted in an idiographic case formulation that identified several unique vulnerability factors. Intellectual testing showed that David was functioning in the moderate range of mental retardation, although his adaptive functioning was quite higher. David demonstrated through phallometric assessment measures an absence of deviant arousal, being primarily attracted to adult females. A long history of abuse and neglect, 
and the way in which he had processed these past traumatic life events, served as significant vulnerability factors. For example, David had interpreted these events as his own fault, and developed negative schemas about his self worth. When teased or criticized by others, especially those who were physically smaller or more vulnerable (i.e., children), feelings of fear and anger led to uncontrollable urges to hurt others. Once aroused, these urges often became sexualized. This sequence of events was functionally related to David's past offenses. Assessment of proble m solving factors revealed that David had significant deficits in all rational problem solving skills, as well as an impulsive and careless response style. He viewed himself as being easily overwhelmed by problems and ineffective at solving them, and experienced pronounced symptoms of acute anxiety, anger, and sadness when confronting a problem. He also lacked related skills, such as assertiveness. As a result, David avoided problems such as finding ways to manage his anger when criticized, sexual urges, and even adaptive attraction to peers.

A case formulation that identified these vulnerability factors and the relationships between them pointed to problem solving skills deficits as a primary treatment target, as problem solving was not only a core factor in itself but also appeared to influence the other factors. Intellectual deficits and early victimization likely contributed to David's deficits in social problem solving. In turn, David was unable to utilize effective problem solving to cope with his past abuse as well as current distress, including feelings of anger, anxiety and depression. Due to his past abuse and his inability to solve problems, David experienced intense fear and anxiety during times of any physical arousal. In addition, David's impulsivity and inability to rationally solve problems contributed to his inappropriate expression of fear and intense anger.

A major focus of David's treatment plan included problem-solving skills training, adapted for his intellectual level. Problem-solving skills components were broken down into concrete training modules and presented with many examples and frequent role-play situations, with supportive feedback. The sessions were aimed at inhibiting impulsive behavior and generating alternative, adaptive solutions to provocative situations (e.g. sexual arousal). As a result, he demonstrated significant improvements in his willingness to think about alternative ways to manage such feeling. Additionally, a focus directly on solving his day-to-day problems also resulted in improved anger management and affect labeling. Finally, David was able to decrease feelings of anxiety and hopelessness and develop more accurate understanding of his own past abuse and neglect.

\section{Conclusions}

This article sought to provide a rationale and description of the potential benefits and applicability of PST as part of a multi-component treatment for ID sex offenders. This population has many risk factors in common with the general sex offending population, as well as many additional deficits and vulnerabilities. In some individual offenders, deficits in problem solving skills may stand alone as a dynamic vulnerability factor for sex offending risk, but are most often linked to other deficits or deviant characteristics. However, no studies exist that assess the specific benefits of including PST as one of several important treatment components. There is a need for research that specifically addresses the problem-solving deficits that are functionally operative in sex offending behavior for ID offenders, as well as the use of PST as an effective treatment for the population.

\section{References}

Day, K. (1994) Male mentally handicapped sex offenders. British Journal of Psychiatry, $165,630-639$. 
D'Zurilla, T. J., \& Nezu, A. M. (2001). Problem-solving therapies. In K. S. Dobson (Ed.), The handbook of cognitive-behavioral therapies ( $2^{\text {nd }}$ ed.; pp. 211-245). New York: Guilford.

D'Zurilla, T. J., \& Nezu, A. M. (in press). Problem-solving therapy: A positive approach to clinical intervention (3rd ed.). New York: Springer.

Griffiths, D.M, Quinsey, V. L., \& Hingsburger, D. (1989). Changing inappropriate sexual behavior: A community-based approach for persons with developmental disabilities. Baltimore, MD: Paul H. Brookes Publishing.

Groth, A. N., Burgess, A. W., \& Holstrom, L. L. (1977). Rape: Power, anger, and sexuality. American Journal of Psychiatry, 134, 1239-1243.

Hanson, R.K., \& Bussiere, M.T. (1998). Predicting relapse: A meta-analysis of sex offender recidivism studies. Journal of Consulting and Clinical psychology, 66, 348-362.

Kempton, W. \& Kahn, E. (1991). Sexuality and people with intellectual disabilities: A historical perspective. Sexuality and Disability, 9(2), 93-112.

Lanyon, R.I. (2001) Psychological assessment procedures in sex offending. Professional Psychology: Research and Practice, 32, 253-260.

Lindsay, W. R. (2002). Integration of recent reviews on offenders with intellectua disabilities. Journal of Applied Research in Intellectual Disabilities, 2002, 15, 111-119.

Lindsay, W. R., Marshall, I., Neilson, C., Quinn, K. \& Smith, A. H. (1998). The treatment of men with a learning disability convicted of exhibitionism. Research on Developmental Disabilities, 19, 295-316.

Lindsay, W. R., Neilson, C. Q., \& Morrison, F. (1998). The treatment of six men wit learning disability convicted of sex offenses with children. British Journal of Clinical Psychology, 37, 83-98.

Lumley, V.A. \& Scotti, J.R. (2001). Supporting the sexuality of adults with mental retardation: Current status and future directions. Journal of Positive Behavior Interventions, 3(2), 109-119.

Lund, C. A. (1992). Long term treatment of sexual behavior problems in adolescent and adult developmental disabled persons. Annals of Sex Research, 5, 5-31.

Maguire, R. J., Carlisle, J. M. \& Young, B. G. (1965). Sexual deviations as conditioned behaviour: A hypothesis. Behavior Research and Therapy, 2, 185-190.

Marques, J. D.., Day, D. M., Nelson, C., \& West, M. A. (1994). Effects of cognitivebehavioral treatment on sex offender recidivism: Preliminary results of a longitudinal study. Criminal Justice and Behavior, 21, 28-54.

Marshall, W. L., Anderson, D., and Fernandez, Y. (1999). Cognitive behavioural treatment of sexual offenders. West Sussex, England: John Wiley \& Sons, (pp 93-110). 
Marshall, W.L., Earls, C.M., Segal, Z.V., \& Drake, J. (1983). A behavioral program for the assessment and treatment of sexual aggressors. In K.Craig and R. McMahon (Eds.), Advances in clinical beahvior therapy (pp.148-174). New York: Brunner/Mazel.

McMurran, M., Egan, V., Richardson, C., \& Ahmadi, S. (1999). Social problem-solving in mentally disordered offenders: a brief report. Criminal Behaviour and Mental Health, 9, 315-322.

Murphy, W.D., Coleman, E.M., \& Haynes, M.A. (1983) Treatment evaluation issues with the mentally retarded sex offender. In J.G. Greer \& I.R. Stuart (Eds.), The sexual aggressor: Current perspectives on treatment (pp. 22-41). New York: Van Nostrand Reinhold.

Nezu, C. M., D’Zurilla, T. J., \& Nezu, A. M. (in press). Problem-solving therapy: Theory, practice, and application to sex offenders. In McMurran \& J. Maguire (Eds.), Social problem-solving and offenders: Evidence, evaluation and evolution. Chichester, UK: Wiley.

Nezu, A.M. (2004). Problem Solving and Behavior Therapy Revisited. Behavior Therapy, 35, 1-33.

Nezu, A. M., Nezu, C. M., Houts, P. S., Friedman, S. H., \& Faddis, S. (1999). Relevance of problem-solving therapy to psychosocial oncology. Journal of Psychosocial Oncology, $16,5-26$.

Nezu, A. M., Nezu, C. M., \& Lombardo, E. R. (2004). Cognitive-behavioral case formulation and treatment design: A problem-solving approach. New York: Springer. Currently under translation into Japanese to be published by Seiwa Shoten Publishers, Tokyo, Japan.

Nezu, A. M., Nezu, C. M., \& Perri, M. G. (1989). Problem-solving therapy for depression: Theory, research, and clinical guidelines. New York: Wiley.

Nezu, C. M., Nezu, A. M., \& Arean, P. (1991). Assertiveness and problem-solving therapy for persons with mental retardation and dual diagnosis. Research in Developmental Disabilities, 12, 371-386.

Nezu, C.M., Nezu, A.M., \& Dudek, J.A. (1998) A Cognitive Behavioral Model of Assessment and Treatment for Intellectually Disabled Sexual Offenders. Cognitive and Behavioral Practice, 5, 25-64.

Nezu, C. M., Nezu, A.,M., Dudek, J. A., Peacock, M., \& Stoll, J. (2005). Problem-solving correlates of sexual deviancy among child molesters, Journal of Sexual Aggression $11(1)$.

Nezu, C. M., Nezu, A. M., Klein, T., \& Johnson, M. C. (in press). Sex offending behavior. In J. A. Mulick \& J. W. Jacobson (Eds.), Handbook of Mental Retardation and Developmental Disabilities, New York: Kluwer Academic/ Publishers.

Nezu Nezu, C. M., D’Zurilla, T. J., \& Nezu, A. M. (in press). Problem-solving therapy: Theory, practice, and application to sex offenders. In M. McMurran \& J. McGuire (Eds.), Social 
problem solving and offenders: Evidence, evaluation and evolution.Chichester, UK: Wiley.

Plaud, J. J., Plaud, D M., Kolstoe, P. D., \& Orvedal, M. S. (2000). Behavioral treatment of sexually offending behavior. Mental Health Aspects in Developmental Disabilities, 3, 54-61.

Prentky, R. A., \& Knight, R. A. (1991). Identifying critical dimensions for discriminating among rapists. Journal of Consulting and Clinical Psychology, 59, 643-661.

Prentky, R.A., Knight, R.A., \& Lee, A.F.S. (1997). Risk factors associated with recidivism among extrafamilial child molesters. Journal of Consulting and Clinical Psychology, $65,141-149$.

Rice, M.E., Chaplin, T.C., Harris, G.T., \& Couts, J. (1994). Empathy for the victim and sexual arousal among rapists and nonrapists. Journal of Interpersonal Violence, 9, 435-449.

Seghorn, T.K., Prentky, R.A., \& Boucher, R.J. (1987). Childhood sexual abuse in the lives of sexually aggressive offenders. Journal of the American Academy of Child and Adolescent Psychiatry, 26, 262-267.

Szollos, A.A. \& McCabe, M.P. (1995) The sexuality of people with mild intellectual disability: perceptions of clients and caregivers. Australia and New Zealand Journal of Developmental Disabilities, 20(3), 205-222.

Ward, T., Hudson, S. M., \& Marshall, W. L. (1995). Cognitive distortions and affective deficits in sexual offenders: A cognitive deconstructionist interpretation. Sexual Abuse: Journal of Research \& Treatment, 7, 67-83.

Zuker-Weiss, R. (1994) Sex, mental retardation and ethics. International Journal of Adolescent Medicine and Health, 7(3), 193-197.

\section{Author Contact Information:}

Christine Maguth Nezu, Ph.D., ABPP

Drexel University (CC Campus)

245 N 15th Street, Mail Stop 515

Philadelphia, PA 19102-1192

Email: christine.nezu@drexel.edu 


\title{
A Treatment Study of Mode Deactivation Therapy in an Out Patient Community Setting
}

\author{
Jack A. Apsche, Christopher K. Bass and Alexander Siv
}

\begin{abstract}
This paper is a review of the outpatient data and recidivism for an 18 month post treatment follow-up of Mode Deactivation Therapy (MDT). The follow up data suggests that effects of MDT generalized for over one-year post treatment in these adolescent conduct disordered males in an inpatient therapeutic setting. This research compared the effectiveness of MDT and Treatment as Usual (TAU) as treatments on adolescents with conduct and personality disorders or traits in this sample.
\end{abstract}

Keywords: Mode Deactivation Therapy (MDT), Conduct Disorder, Personality Disorder Out Patient.

\section{Introduction}

One of the criticisms of MDT in academic reviews is that it is a treatment for residential centers and that the clients might have improved on their own by being in a structured environment. Apsche, Bass (2006) published a study completed in an outpatient community setting. They compared six adolescents receiving MDT with seven adolescents receiving TAU in the community.

Another criticism of MDT is the lack of data, suggesting generalization effects. This paper presents the 18 month follow up data for the MDT and TAU sample in a community outpatient setting. Apsche, Bass, Siv (2006) presented data to suggest that MDT was far superior to CBT and SST in producing positive results from a 2 year follow up study of recidivism of male adolescent youths discharges from a residential treatment center.

This paper will review the data from Apsche, Bass (2006), article and add 18 month follow up data. A review of these data suggests that MDT might be an effective methodology in outpatient settings.

\section{METHOD}

\section{Sample Characteristics}

A review of the Apsche, Bass (2006) study showed that data reports for follow up data were calculated form school reports systems. The parent(s) kept general data forms and returned them to the youth agency workers for both groups.

The data was collected by the youth agency and then disseminated.

\section{Review of Research}

A total of 13 male adolescents participated in the study. All subjects were referred to a private outpatient practice for the treatment of aggression. Referrals came from County Juvenile Justice and the Department of Youth and Family Services. In this study, subjects were randomly assigned to one of the two treatment conditions at the time of admission based on available openings in the caseload of the participating clinicians. The two treatment conditions showed similarity in terms of the frequency of Axis I and Axis II diagnoses, age, and racial background. To ensure consistency in the delivery of the two respective treatments, therapists were specifically trained in one of two treatment curriculums/methods. The average length of treatment across conditions was 6 months. 
Condition one: Treatment As Usual (TAU) A total of six male adolescents were assigned to the condition. The group was comprised of 1 African American, 5 European Americans with an average age of 16.1. The principal Axis I diagnoses for this group included Conduct Disorder (2), Oppositional Defiant Disorder (4), and Post Traumatic Stress Disorder (4). Axis II diagnoses for the group included Mixed Personality Disorder (4), Borderline Personality Disorder (1).

Condition two: Mode Deactivation Therapy (MDT): A total of seven male adolescents were assigned to the MDT condition. The group was comprised of 2 African Americans, 5 European Americans with an average age of 16.4. The principal Axis I diagnoses for this group included Conduct Disorder (1),Oppositional Defiant Disorder (3), Post Traumatic Stress Disorder (4), and Major Depressive Disorder, primary or secondary (5). Axis II diagnoses for the group included Mixed Personality Disorder (4), and Borderline Personality Traits (3). The MDT condition used the Mode Deactivation Therapy which is built on the mastery system for youngsters. They move through a workbook at the rate of learning that accommodates their individual learning style. The system is designed to allow the youngster to experience success, prior to undertaking more difficult materials. Initially, the individual needs to be aware of his negative verbalizations and negative thoughts, and record them in his workbook. Through the Case Conceptualization, workbook, and audiotapes, the system allows the youngster to systematically address the underlying conglomerate of personality disorders as well as, the specific didactics necessary, anger/aggression.

\section{Measures}

Three measures were included in this study: School disciplinary referrals, Parent Report and The Child Behavior Checklist (CBCL; Achenbach, 1991).

School records were used to assess disruptive and aggressive behavior in school. Behaviors which were assessed included school suspension, physical altercation, verbal aggression toward peers/others.

The Parent Report Record is a measure used to record aggressive behavior at home. Behaviors recorded included; Sibling altercations, Anger outbursts, and direct intentional disobedience.

The CBCL is a multi-axial assessment designed to obtain reports regarding the behaviors and competencies of 11- to 18-year-olds'. The means and standards are divided into three categories: internalizing (which measures withdrawn behaviors, somatic complaints, anxiety and depression), externalizing (which measures delinquent behavior and aggressive behavior), and total problems (which represent the conglomerate of total problems and symptoms, both internal and external).

\section{FOLLOW-UP DATA}

\begin{tabular}{|l|c|c|}
\hline \multicolumn{3}{|c|}{ Table 1: 18 Month Follow-up Parent Reports Received } \\
\hline & MDT & TAU \\
\hline Sexual Aggression (SA) & 0 & 10 \\
\hline Acting Out (AO) & 3 & 12 \\
\hline $\begin{array}{l}\text { Direct intentional disobedience } \\
\text { (DIB) }\end{array}$ & 6 & 18 \\
\hline
\end{tabular}

Table 2: 18 Month Follow-up School Data Received 


\begin{tabular}{|l|c|c|}
\cline { 2 - 3 } \multicolumn{1}{c|}{} & MDT & TAU \\
\hline Residential Placements (RP) & 0 & 3 \\
\hline School Suspensions (SS) & 3 & 20 \\
\hline School Expulsions (SE) & 1 & 5 \\
\hline
\end{tabular}

\section{RESULTS}

\section{Child Behavior Checklist}

The CBCL means and standards are divided into three categories: internalizing, externalizing, and total problems. There was no significant difference in the pretest means between MDT (Internalization $=73.5$, Externalization $=75.5$ and Total $=74.5$ ) and TAU (Internalization $=73$, Externalization $=75$ and Total $=74)$.

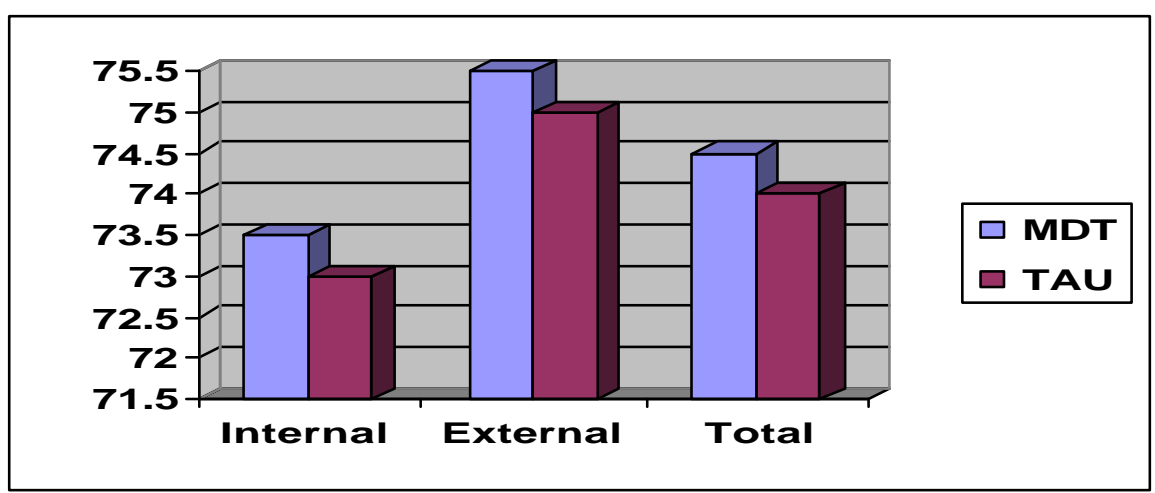

Figure 1. CBCL; Pre treatment mean scores for TAU and MDT groups

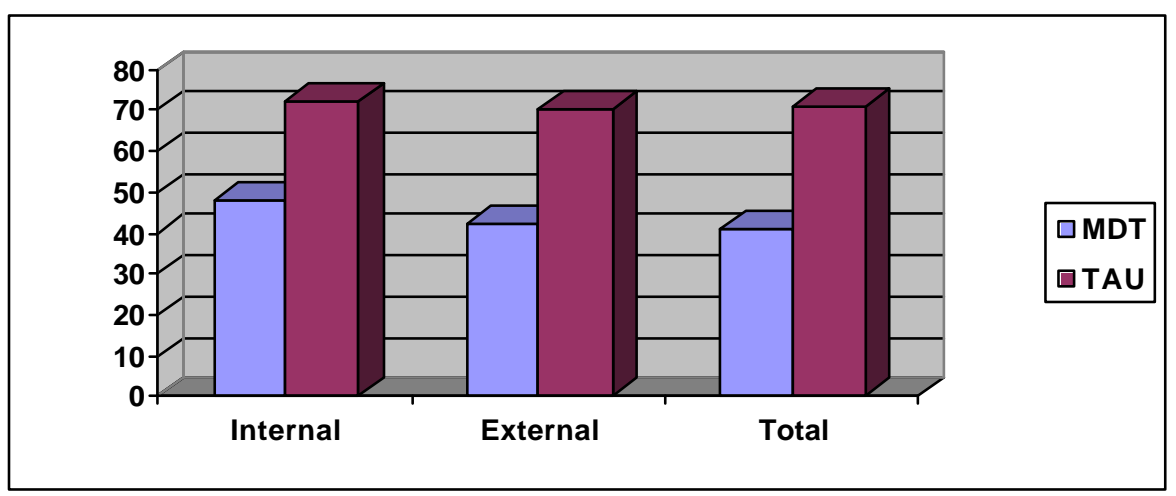

Figure 2. CBCL; Post treatment mean scores for TAU and MDT groups

The post test means showed a statistically significant difference in mean scores. In comparison to the TAU group, the MDT group was superior in reducing all three categories (MDT: Internalization=48.5, Externalization $=43.5$ and Total $=42$; TAU: Internalization $=72$, Externalization $=70$ and Total $=71$ )

\section{The Parent Report Record}

Results on the Parent Report Measure showed no significant difference in the pretreatment recordings of Sibling altercations (SA), Anger outbursts (AO), and direct intentional disobedience (DIB) 
(MDT: $\mathrm{SA}=5$ per week, $\mathrm{AO}=21$ per week, $\mathrm{DIB}=10$; $\mathrm{TAU}: \mathrm{SA}=4$ per week, $\mathrm{AO}=22$ per week and $\mathrm{DIB}=$ $11)$.

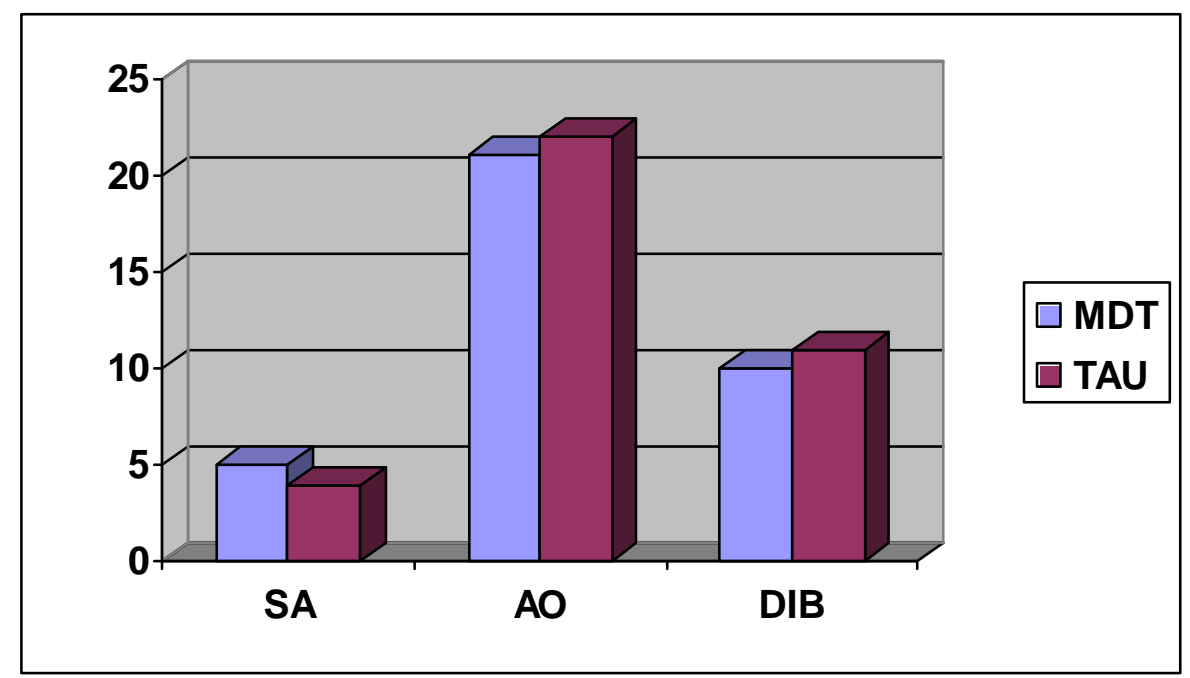

Figure 3. The Parent Report Record: Pre treatment mean scores for TAU and MDT

groups

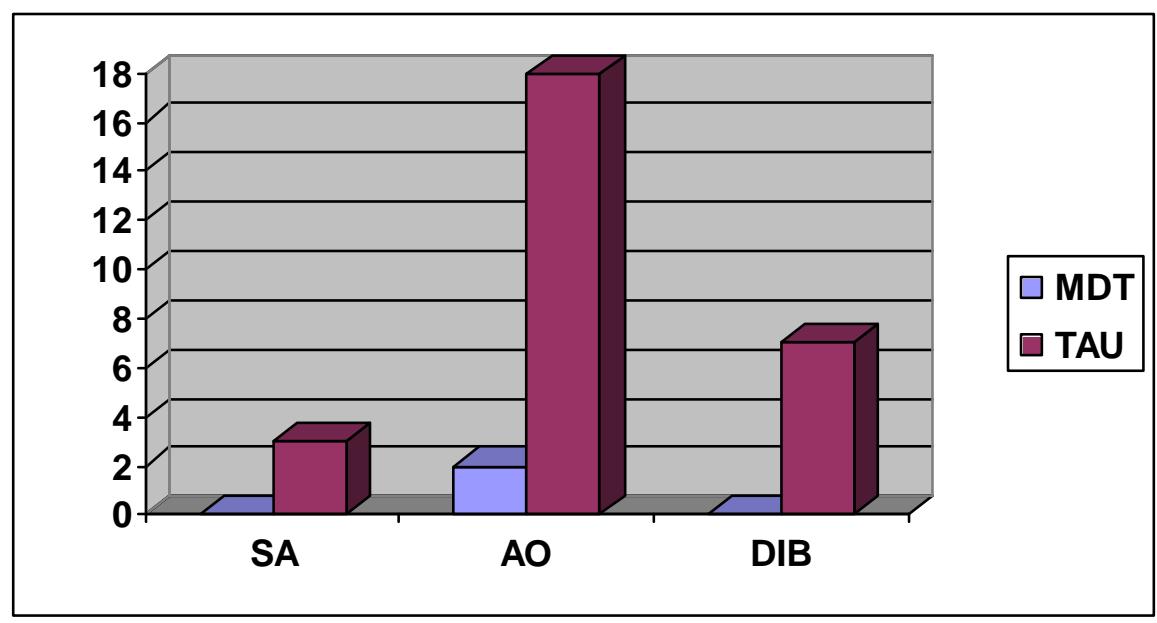

Figure 4. The Parent Report Record: Post treatment mean scores for TAU and MDT groups

Post treatment results on the Parent Report Measure showed a significant difference in the recordings of Sibling altercations (SA), Anger outbursts (AO), and Direct intentional disobedience (DIB) (MDT: $\mathrm{SA}=5$ per week, $\mathrm{AO}=21$ per week, $\mathrm{DIB}=10$; $\mathrm{TAU}: \mathrm{SA}=4$ per week, $\mathrm{AO}=22$ per week and $\mathrm{DIB}=$ $11)$.

\section{School Records}

School records were kept by the school's Principal Discussion Office. The forms tracked aggression and school suspensions. 


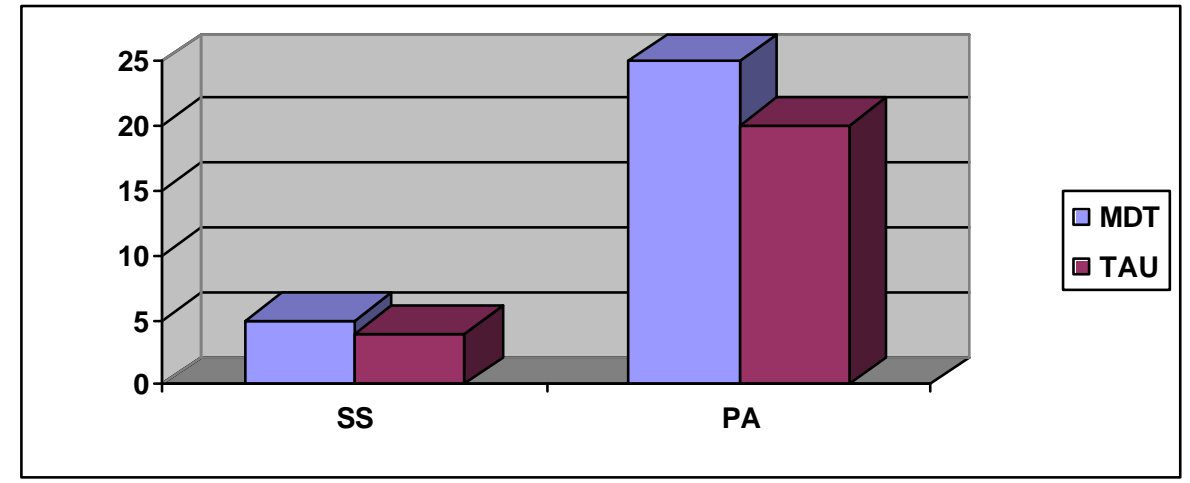

$\mathrm{SS}=$ School Suspension (Pre treatment $\mathrm{MDT}=5, \mathrm{TAU}=4) ; \mathrm{PA}=$ Physical Aggression (Pre Treatment, $\mathrm{MDT}=25, \mathrm{TAU}=20$

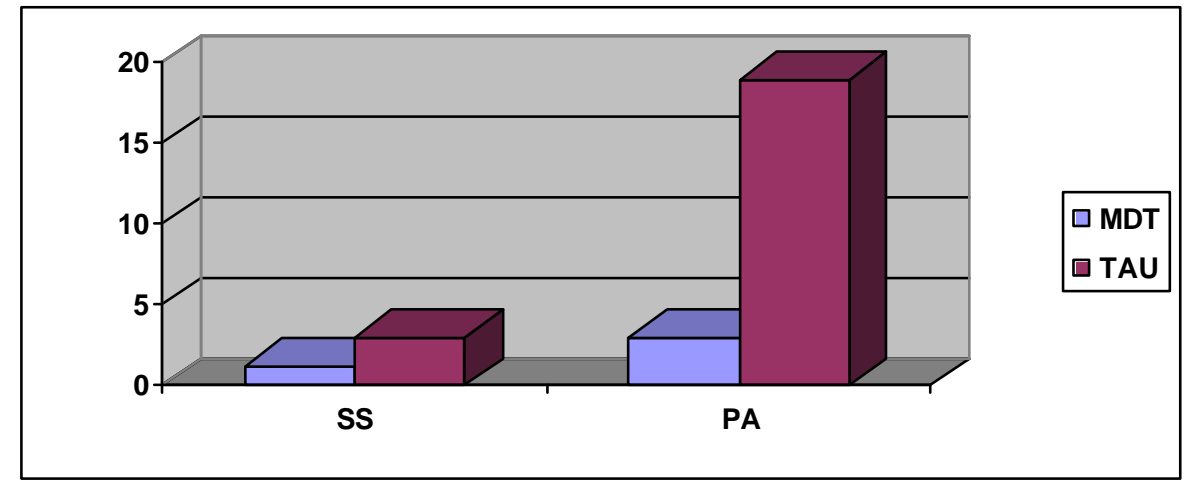

$\mathrm{SS}=$ School Suspension $($ Post treatment MDT= 1.2, TAU=3); PA= Physical Aggression (Post Treatment, MDT $=3, \mathrm{TAU}=19$

\section{Month Follow Results}

\section{Parent Reports Received}




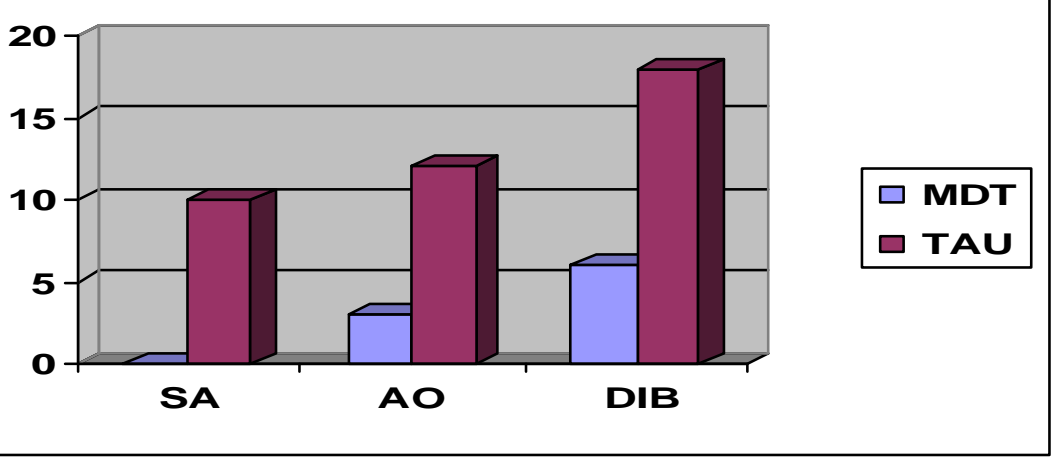

$\mathrm{SA}=$ Sexual aggression (18 Month Follow-up, $\mathrm{MDT}=0$, $\mathrm{TAU}=10$ ); $\mathrm{AO}=$ Acting Out

(18 Month Follow-up, MDT=3, TAU=12); DIB= Direct intentional disobedience

(18 Month Follow-up, MDT=6, TAU= 18)

School Records

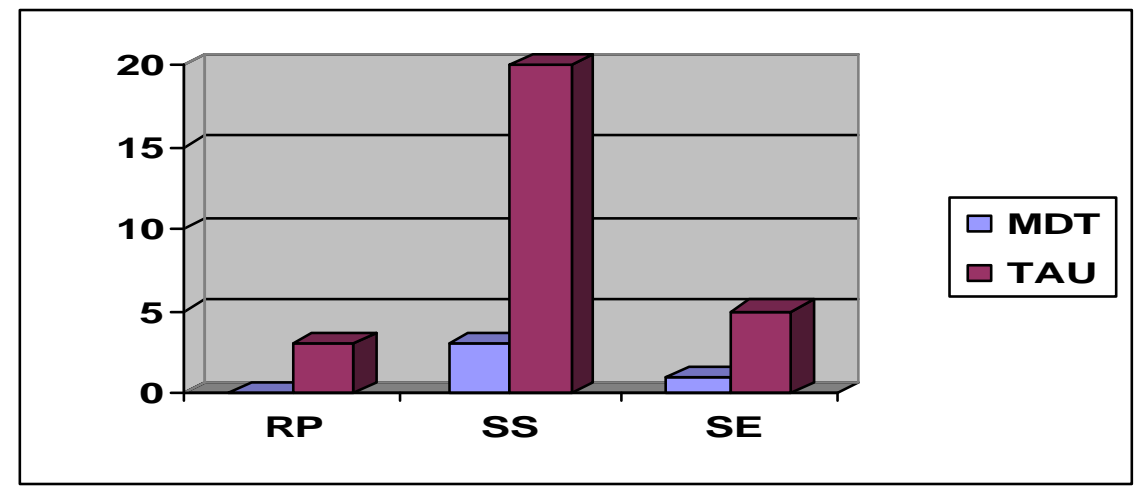

RP = Residential Placement (18 Month Follow-up, MDT=0, TAU=3); SS= School Suspension (18 Month Follow-up, MDT=3, TAU= 20); SE= School Expulsion (18 Month Follow-up, MDT=1, TAU= 5)

Results demonstrate that MDT was superior to TAU in all categories in this study. Results indicate that MDT was statistically significant over TAU in reducing aggressive behavior, defiant behavior, school suspensions, as well as, reducing symptoms of psychological distress as measured by the CBCL. Symptoms such as anxiety and depression were reduced by MDT while some increased with TAU.

Reports by parents and School Administration indicated that the behaviors of the adolescent in MDT showed significant improvement. The TAU group received negative reports by parents and School Administration.

\section{Discussion}

The results suggest that MDT might be an effective treatment for this typology of adolescent in outpatient community settings. The current results also suggest that MDT has generalizable effects from treatment to 18 months post treatment. In this study it was clear that MDT out performed TAU in every category and the treatment effects were far superior for 18 months. It was important to note that none of the adolescents in the MDT group were sent or recommended to residential or correctional settings. This might be important for future research, since residential treatment is costly and often there are many negative side effects reported from lengthy residential treatment, such as, iatrogenic effects of negative learning from peer groups. 
The results also suggest that MDT might be effective in decreasing the clinical symptoms of Axis I disorders in this population which may positively effect the positive follow up data. The clinical symptoms might fuel these negative behaviors and MDT might give the individuals a methodology to self monitor these symptoms. MDT hypothesizes that the modes of the adolescent are constantly charged by perceiving danger and threat which are fueled by their damaged or faulty perceptions (Apsche \& Ward Bailey 2004). These results might validate some of that hypothesis by the results of the 18 month follow up data.

\section{Summary}

MDT was shown to be more effective than TAU in an 18 month study with follow up data. These results suggest that MDT might be effective in treating this type of adolescent in a community setting.

There were several limitations to this treatment research study. There were only thirteen clients in the study, far too few to suggest generalization of effects on the larger population. The assignments of the clients were random in nature, although it did not follow the protocol of a randomized study. Accepting these and other limitations from this type of treatment research, it is important to note the effectiveness of MDT with this population. This study shines light on the MDT treatment tool as a promising approach in the search for effective treatments for adolescents with problems of conduct, opposition and personality.

\section{REFERENCES}

Achenbach, T.M. (1991). Manual for the Child Behavior Checklist and 1991 profile. Burlington, VT: University of Vermont Department of Psychiatry.

Achenbach, T.M. (1991). Child Behavior Checklist, Assessment. Burlington, VT: University of Vermont Department of Psychiatry.

Alford, B.A. and Beck, A.T. (1997). The integrative power of cognitive therapy. New York: Guilford Press.

Apsche, J.A. (2005). Beck's theory of modes. International Journal of Behavioral Consultation and Therapy, 1(1), in press.

Apsche, J.A. (1999). Thought Change Workbook. Portsmouth, VA: Alternative Behavioral services.

Apsche, J.A., Evile, M.M., and Murphy, C.J. (2004). The thought change system: An empirically based cognitive behavior therapy for male juvenile sex offenders. A pilot study. The Journal of Behavior Analysis Today, 5(1), 101-107.

Apsche, J.A. and Ward Bailey, S.R. (2004a). Mode Deactivation Therapy: Cognitive-behavioural therapy for young people with reactive conduct disorders or personality disorders or traits who sexually abuse. In M.C. Calder (Ed.), Children and Young People who Sexually Abuse: New Theory, Research and Practice Developments, pp. 263-287. Lyme Regis, UK: Russell House Publishing.

Apsche, J.A. and Ward Bailey, S.R. (2003). Mode deactivation therapy: A theoretical case analysis (Part I). The Journal of the Behavior Analyst Today, 4(3), 342-353. 
Apsche, J.A. and Ward Bailey, S.R. (2004b). Mode deactivation therapy: A theoretical case analysis (Part II). The Journal of the Behavior Analyst Today, 5(1), 395-434.

Apsche, J.A. and Ward Bailey, S.R. (2004c). Mode deactivation therapy: A theoretical case analysis (Part III). The Journal of the Behavior Analyst Today, 5(3), 314-332.

Apsche, J.A., Bass, C.K., Jennings, J.L., Siv, A.M. (2005). International Journal of Behavior Consultation and Therapy, 1(1), pp. 27-25.

Apsche, J.A., Bass, C.K., Jennings, J.L., Murphy, C.J., Hunter, L.A. Siv, A.M. (2005). International Journal of Behavior Consultation and Therapy. Accepted with revisions.

Apsche, J.A., Bass,C.K.,Murphy,C.J. A comparison of two treatment studies: cbt and mdt with adolescent sex offenders. Journal of Early and Intensive Behavioral Intervention. 1 (2), pp. 179-190. Winter 2004.

Beck, A.T. (1996). Beyond belief: A theory of modes, personality and psychopathology. In P.M. Salkovaskis (Ed.), Frontiers of cognitive therapy, (pp. 1-25). New York: Guilford Press.

Beck, A.T. and Freeman, A. (1990). Cognitive therapy of personality disorders. New York: Guilford Press.

Boesky, L.M. (2002). Juvenile offenders with mental health disorders: Who are they and what do we do with them? Lanham, MD: American Correctional Association.

Dodge, K.A., Lochman, J.E., Harnish, J.D., Petti, G.S. (1997). Reactive and proactive aggression in school children and psychiatrically impaired chronically assaultive youth. Journal of Abnormal Psychology, 106 (1), 37-51.

Henggeler, S.W., Schoenwald, S.K., Borduin, C.M., Rowland, M.D. and Cunningham, P.B. (1998). Multisystemic treatment of antisocial behavior in children and adolescents. New York: Guilford Press.

Johnson, J.G., Cohen, P., Brown, J., Smailes, E.M., and Bernstein, D.P. (1999). Associations between four types of childhood neglect and personality disorder symptoms during adolescence and early adulthood: Findings of a community-based longitudinal study. Archives of General Psychiatry, 14, 171-120.

Kazdin, A.E. and Weisz, J.R. (2003). Evidenced based psychotherapies for children and adolescents. New York: Guilford Press.

Koenigsberg, H.W., Harvey, P.D., Mitropoulou, V., Antonia, N.S., Goodman, M., Silverman, J., Serby, M., Schopick, F. and Siever, L. (2001). Are the interpersonal and identity disturbances in the borderline personality disorder criteria linked to the traits of affective instability and impulsivity? Journal of Personality, 15(4), 358-370.

Kohlenberg, R.J. and Tsai, M. (1993). Functional Analytic Psychotherapy: A behavioral approach to intensive treatment. In W. O'Donahue and L. Krasner (Ed)., Theories of behavior therapy: Exploring behavior change (pp. 638-640). Washington, D.C.: American Psychological Association.

Linehan, M.M. (1993). Treating Borderline Personality disorder: The dialectical approach. New York: Guilford Press. 
Naglieri, J.A., LeBuffe, P.A. \& Pfeiffer, S.I. (1994). Devereux scales of mental disorder. San Antonio: The Devereux Foundation.

Naglieri, J.A., LeBuffe, P.A. \& Pfeiffer, S.I. (1994). Manual of the Devereux scales of mental disorder. San Antonio: The Devereux Foundation.

Nezu, A.M., Nezu, C.M., Friedman, S.H. and Haynes, S.N. (1998). Case formulation in behaviour therapy: Problem-solving and Functional Analytic strategies. In T.D. Eells (Ed.), Handbook of psychotherapy case formulation. New York: Guilford Press.

Patterson, G.R. Etiology and treatment of child and adolescent antisocial behavior. The Behavior Analyst Today. Vol. 3. No.2. pp 55-72.

Swenson, C.C., Henggeler, S.W., Schoenwald, S.K., Kaufman, K.L., and Randall, J. (1998). Changing the social ecologies of adolescent sexual offenders: Implications of the success of multisystemic therapy in treating serious antisocial behavior in adolescents. Child Maltreatment, 3, 330-339.

Young, J.E., Klosko, J.S. and Weishaar, M.E. (2003). Schema therapy: A practitioner's guide. New York: Guilford Press.

\section{Author contact information:}

Jack A. Apsche, Ed.D., ABPP

Apsche Center for Evidenced Based Psychotherapy

111 South Main St

Yardley, PA 19067

215-321-4072

Jackmdt@aol.com

Apschecenter@comcast.net

Christopher K. Bass, Ph.D.

Dept. of Psychology

Clark Atlanta University

207 Knowles Hall

Atlanta, GA 30313

Cbass@cau.edu 


\title{
Community Treatment Programs for Juveniles: A Best-Evidence Summary
}

\author{
Lee A. Underwood, Kara Sandor von Dresner \& Annie L. Phillips
}

\begin{abstract}
A significant challenge facing the juvenile justice system is the task of transitioning and reintegrating juveniles from youth corrections facilities back into the community. This challenge, in part, is related to determining whether the referred community programs are effective. This article summarizes the literature on the effectiveness of community programs for juveniles involved in the justice system, including defining characteristics of evidence-based programs and examining the relationship between youth characteristics and evidence-based practices. Model evidence-based programs are reviewed, providing a description of respective programs, treatment targets, and their outcomes. Limitations of evidence-based programs will be discussed and recommendations for the field will be summarized. Key words: Community programs, juvenile justice, evidence-based programs, delinquents, treatment.
\end{abstract}

\section{Introduction}

The juvenile justice system is overwhelmed with the increasing number of youth who are arrested each year. In 2003 about 2.3 million youth under the age of 18 were arrested and over 130,000 are placed in detention and juvenile correctional facilities (Cocozza, Trupin, \&Teodosio, 2003). As a result, the number of youth who are released back into society is growing; according to the Office of Juvenile Justice and Delinquency Prevention's (OJJDP) Census of Juveniles in Residential Placement, approximately 100,000 youth are discharged from a juvenile correctional facility each year. This estimate is a modest one at best because when compared to adult offenders, juveniles actually spend less time in correctional facilities; therefore the actual percentage of ju veniles returning to the community each year is much greater (Sickmund, 2000). Effective treatment programs are key in youth's successful reintegration back into their homes and communities. Gendreau and Goggin (1996) found that recidivism rates decreased by as much as 25 percent than those youth who did not participate in any institutional or community program. The most effective, however, are evidence based treatment programs as they can reduce recidivism from 25 percent to 80 percent (Gendreau, 1996 \& The National Mental Health Association [NMHA], 2006). This poses a significant challenge to the juvenile justice system for it now has the task of diverting and reintegrating some incarcerated juveniles into some kind of treatment program. While evidence-based community programs are ideal, they are often underused for a variety of reasons. It is often difficult to determine what treatment programs are researched-based (Hoagwood, Burns, Kiser, Ringeisen and Schoenwald, 2001). Once this is done, the characteristics of a program must be complimentary or tailored to juveniles and their presenting problems. This involves properly identifying the youth who are appropriate for program and linking with community resources.

Another challenge that prevents the implementation of model programs is the interchangeable terms that are used in identifying research-based programs and the various definitions these terms hold. Juvenile justice systems must establish a universal language. Frequently used terms when discussing postrelease programs include evidence-based, best practice, research-based and innovative practice. It is critical to exam the similarities and the differences of these types of treatment so that juvenile justice officials can choose evidence-based programs that are complimentary with the specialized needs of each juvenile in the juvenile justice system. Using a common language also helps researchers to further examine the unique characteristics of evidence-based programs (Burns, Hoagwood and Mrazek, 1999 \& Beale \& Jones-Walker, 2004). 
Researchers endorse the idea that evidence-based programs in community settings are more effective than those in residential or institutional settings; however, further examination on the effectiveness of these programs is warranted (Altschuler \& Armstrong 2002; Burns, et al., 1999 \& Steiner, Dunne, Ayres, Arnold, Benedek, Benson, Bernstein, Bernet, Bukstein, Kinlan, Leonard \& McClennan, 1997; Underwood, Barretti, Storms \& Safonte-Strumbolo, 2004; Wood, Trupin, Turner, \& Vander Stoep, 1999).

This article summarizes existing knowledge about evidenced based programs so that researchers, clinicians, and juvenile justice program administrators can choose interventions that are proven to lower recidivism rates. Evidence-based definitional criteria and its characteristics, efficacy and effectiveness will be defined. The importance of implementing or developing evidence-based programs to cater to the unique issues that juveniles bring is highlighted in the relationship between youth characteristics and treatment programs. Model evidence-based community programs are identified with a description of each. Limitations of evidence-based programs will conclude this article.

\section{What is Evidence-Based Practice?}

\section{Defining Evidenced-Based Practices}

There are a variety of definitions for evidence-based practices utilized throughout the fields of juvenile justice and mental health. The National Institute of Mental (2001) and Hoagwood (2003) define evidence-based as a body of knowledge, obtained through scientific method, on the prevalence, the incidence, the risk for mental disorders, and the impact of treatment and services on mental health related issues. In the juvenile justice field, the term "evidence-based" is defined as a body of knowledge, also obtained through scientific method, on the impact of specific practices on targeted outcomes for youth and their families (Hoagwood, et. al, 2001). McDonald (2003) conceptualized that evidence-based programs consists of three characteristics (defined outcomes, measurable outcomes, and practical realities or the rate of recidivism).

The Interdisciplinary Committee on Evidence-based Mental Health Care mandated definitional criteria for evidence-based practice (Weisz, 2001). The committee states that in order for treatment to be determined evidence-based, it must have at least two between group design studies representing the same age group and receiving the same treatment for the same target problem. The National Institute of Mental Health (NIMH) developed a list of research procedures that are consistent with evidence-based practices. These include:

1. Minimum of two control group studies or a large series of single-case design studies.

2. At least two researchers.

3. Utilization of a treatment manual.

4. Therapist training and guidelines.

5. Accurate clinical samples of youth.

6. Clinical significant tests of outcomes.

7. Reviewed functioning and symptom outcomes.

8. Long-term effects after release (Burns 1999).

9. Two or more studies that are superior to medication, placebo or an alternative treatment that is equivalent to an established treatment.

Clearly understanding the definitional criteria related to evidence-based practices allows practitioners to determine which interventions will be more effective in treating youth (Virginia Youth Commission, 2004). 


\section{Determining Effectiveness}

The terms effectiveness and efficacy are often confused. Effectiveness refers to the validity of the intervention when applied in clinical circumstances, whereas efficacy refers to the validity of the intervention under controlled research conditions (Lehman, Godman, Dixon, \& Churchill, 2004). Hoagwood et. al., (2001) suggest that in order for a treatment protocol to be efficacious, two or more studies must show it to be superior to a control condition, one or more experiment must meet the criteria for a well designed treatment, or three single case studies must be conducted. Other indicators of effective programs share characteristics:

1. Reliance upon an empirically validated theory, which addresses the reduction of risk factors.

2. Trained providers with clinical supervisors, who maintain the integrity of the program design.

3. Training/program manuals that are available to all staff members.

4. Validated risk assessments to classify offenders and determine their criminogenic factors.

5. Use of cognitive behavior interventions.

6. Follow-up interviews with youth and their families, which are structured components of the program (Andrews, Bonta \& Hoge, 1990; Gendreau \& Goggin, 1995).

Evidence-based practices should focus on the outcome. Joplin, Bogue, Campbell, Carey, Clawson, Faust, Florio, Wasson, and Woodward (2004) stated that "interventions within corrections are considered effective when they reduce offender risk and subsequent recidivism" (p. 3). Evidence-based practice relies on the following principles:

1. Assessment of actuarial risks/needs. -An ongoing assessment of youths' psychosocial and risk for delinquency needs should be conducted to determine the level of supervision and the types of services needed (Clements, 1996).

2. Enhancement of intrinsic motivation. -Providers should relate to offenders in order to elicit change (Miller \& Rollnick, 2002). Use of motivational interviewing and engagement strategies are helpful in developing rapport and effective relationships.

3. Objective interventions.

-Risk principle: Prioritize supervision and treatment resources for higher risk offenders.

-Need principle: Target interventions to criminogenic needs.

-Responsivity Principle: Be responsive to temperament, learning style, level of motivation, culture, and gender when assigning programs and interventions.

-Dosage: Structure 40-70\% of high-risk offenders' time for at least 
three to nine months.

-Treatment: Integrate treatment into the full sentence/sanction requirements (Taxman \& Byrne, 2001).

4. Rehearsal of skill training. -Providers should include components of role-playing and skill rehearsals in program activities ( McGuire, 2001, 2002).

5. Utilization of positive reinforcement skills.

-Youth tend to respond better and maintain learned behaviors when approached in a positive manner (Higgins \& Silverman, 1999).

6. Initiation of consistent support in surrounding communities.

-Research indicates that effective interventions utilize an offender's surrounding environment in an effort to reinforce new behaviors (Meyers.

Miller, Smith \& Tonnigan, 2002).

7. Assess practices, as well as processes.

-Programs should maintain accurate and detailed information, and the performance staff should be assessed regularly (Milhalic \& Irwin, 2003).

8. Provision of measurable feedback.

-Providing feedback to offenders is essential to the process of enhancing motivation for change and improved outcomes. Providing feedback also provides offenders with accountability of their progress (Alvero et al, 2001).

\section{Intervention Practices}

Crowded facilities, exceptionally high recidivism rates, and the rising costs of incarcerating juveniles are among the factors calling for community-based intervention programs that are supported by the literature (Altschuler, 1998). Common practices include innovative, promising, and best practices.

Innovative or "new idea" programs have never been systematically evaluated, and therefore their effectiveness is undetermined (Hoagwood, 2003). An example of an innovative practice is may include some community-based residential treatment programs. Underwood, Barretti, Storms, and SafonteStrombolo (2004) suggest, "the problem lies in the fact that traditionaloriented residential treatment programs lack a research base to support its effectiveness." (p.12). Practitioners have little empirical research to help guide them in developing more effective practice guidelines for residential treatment programs.

Promising practices are generally thought to be in the early stages of formal evaluation because they have only met two out of four criteria for practices to be effective (Hoagwood, 2003). An example is the Los Angeles County Probation Department's Social Learning Model (SLM) home-based program for high risk and high need gang involved youth on probation (Underwood, 2005). The SLM provides a standardized approach to the method of delivery for treatment. The SLM is designed to positively impact thinking patterns, cognitions, social skills, violent behaviors, and youth and family engagement, all within the context of cultural competency. The six month program is designed to address the needs of males and females ages 14-18, and their families in all service areas. These services include home-based with an intensive family-centered approach. The model integrates principles of cultural competency, ensuring appropriate engagement and human relations strategies. Mutisystemic Therapy (MST) and Functional 
Family Therapy (FFT) are the conceptual frameworks used to guide the practice parameters. The SLM is designed to have treatment providers and probation officers work closely together with gang-involved and violent high-risk youth in: 1) becoming more involved in school, improving moral reasoning, improving skills in handling difficult situations, and engaging in problem solving techniques; and 2) training treatment providers and probation officers in learning effective skills when working with families in further developing their engagement, alliance, and validation skills along with motivational enhancement techniques.

Best practices refer to effective programs. An example of a best practice is the Family Integrated Transitions Program (Trupin \& Stewart, 2004). The Family Integrated Transitions (FIT) Program is an intensive treatment practice. The FIT program draws upon evidence-based operating principles from Multisystemic therapy, Motivational Enhancement therapy, Relapse Prevention, and Dialectical Behavior Therapy. An essential component to FIT is the integration of family in the treatment of the juvenile. A juvenile must be under the age of $171 / 2$ and be placed under supervision for at least four months after release in order to be eligible for FIT's services. This practice is initiated a couple of months before the juvenile's release from an institution, and services continue for an estimate of four to six months. Trupin and Stewart (2004) found that the recidivism rate of juveniles who participated in FIT dropped 27\%, a highly significant decrease in the recidivism rate for this population.

\section{The Relationship Between Youth Characteristics and Evidence-Based Practices}

Many researchers are interested in discovering key attributes of youth in order to determine what program characteristics are more relevant. Behaviors and histories of each youth are quite unique. For example, youth who have been traumatized will have different treatment needs than those who have not been traumatized. Juveniles with significant histories of substance abuse require unique therapeutic interventions that will differ from a juvenile living with a highly structured home. Most juveniles in the justice system will require specialized attention and programming while in community programs (Underwood, Mullan \& Walter, 1997).

The next section provides a review of some key youth characteristics that exemplify the relationship between characteristic and evidence-based practices.

\section{Youth With Histories of Traumatization}

Juveniles vary considerably in their responses to traumatic events. Some youth may experience devastating, horrific events and have few effects, while others may experience minor events and have significant long-term reactions. It is important to understand that many "normal" experiences may be traumatic (e.g., an illness or death in the family) (Prescot, 1997 \& Veysey, 2003). Certain types of experiences increase the likelihood of psychological damage, including being taken by surprise, trapped, and/or exposed to the point of exhaustion (e.g., sleep, hunger, hot or cold); also when certain experiences include physical violation or injury, exposure to extreme violence, and witnessing grotesque death (Veysey, 2003). The degree of psychological damage is indeed related to poor treatment outcomes for youth in both residential and post release rehabilitative programs. These youth tend to be more emotionally vulnerable in their communities and present histories of aggression (Veysey, 2003).

\section{Youth With Co-Occurring Disorders}

Co-occurring disorders occurs when at least one substance abuse disorder can be diagnosed simultaneously with another mental health disorder other than another substance abuse diagnosis. Each type must be determined independent of the other and must not be a cluster of symptoms resulting from the other disorder (Miller, Zweben, Diclemente, \& Grychtarik, 1995). Juveniles with co-occurring disorders often have histories of profound mental health issues and therefore have used drugs or alcohol 
as medications. Since these disorders severely affect their moods, thoughts, and behaviors, juveniles with co-occurring disorders may also be more impulsive and potentially more violent than youth. These behaviors are often unrecognized which deprives these youth from proper treatment because they have been mislabeled.

Youth with co-occurring disorders may be linked with differential longer-term treatment outcomes (Drake, Muesser, Clark and Wallach, 1996; Randall, Henggeler, Pickrel \& Brondino, 1999). Juveniles who have a comorbid externalizing disorders as the coinciding diagnosis with substance abuse are predicted to drop out of high school (Kessler, Foster, Saunder, \& Stang, 1995) and inpatient care (Abram \& Teplin, 1991) whereas juveniles with co-occurring internalizing disorders are predicted to complete inpatient treatment (Kaminer and Frances, 1991). Different mental health diagnosis coupled with substance abuse disorders impacts youth differently than those with only a substance abuse disorder or a mental health disorder. Youth with co-occurring disorders are more likely to engage in higher rates of delinquent behavior, use more drugs and alcohol, and conform to antisocial peer pressure (Randall, et al., 1999; Kessler, et al., 1995).

\section{Family and Environmental Difficulties}

The profiles of juveniles in community programs vividly illustrate a large variety of family and environmental risk factors. Family factors that have been consistently implicated in juvenile justice include, but are not limited to, poor parent-child relationships, neglect, coercive child-rearing (Patterson, Reid \& Dishion, 1992), lack of warmth and affection, inconsistent parenting, violence, sexual abuse, disrupted attachments, and parental substance abuse (Henggeler, 1998).

Various studies have linked delinquent behavior and emotional distress with many different aspects of family functioning. Among the most consistently linked studies, there have been family characteristics suggesting familial antisocial behavior or values, including delinquent behavior as part of the family history, harsh parental discipline, and family conflict (Tolan \& Lober, 1993). Several studies across a range of populations related delinquency and poorly controlled emotional regulation to a lack of parental monitoring, neglect, poor discipline methods, and conflict about discipline (Capaldi \& Patterson, 1996; Farrington, 1989; Gorman-Smith, Tolan \& Henry, 1998; Patterson et al., 1992). Similarly associated are low levels of parental warmth, acceptance and affection, low cohesion, high conflict and hostility, divorce, parental absence, and other losses (Farrington, 1994; Henggeler, Melton, \& Smith, 1992; McCord, 1982).

\section{Ethnic Minority Youth}

Ethnic minority youth, specifically African-American and Latina, are increasingly at risk for entering the juvenile justice system rather than treatment facilities (Bilchick, 1999; Elliot, 1994; Elliot, Tolan \& Loeber, 1993). In 1996, youth of color comprised about one-third of the juvenile population yet accounted for about two-thirds of the incarcerated population (Hamparian \& Leiber, 1997) and possibly more. Many studies fail to differentiate ethnicity from race and Latina's are often counted as white; this makes it impossible to know the accurate number for which youth of color are represented in the juvenile justice system (Poe- Yamagata \& Jones, 2000).

Many factors may contribute to delinquent behavior by youth of color. Complicated social, medical, and psychological factors are among them (Bilchick, 1999; Canino \& Spurlock, 1994). Youth of color are associated with the lack of legitimate job opportunities, increasing social isolation, poor schools, and weak community organizations. Thirty five percent live in not just poor neighborhoods, but "underclass" neighborhoods (Wilson, 1991) where crime rates are extremely high. Most youth of color in the juvenile justice system come from a young, undereducated, single family household headed by a 
single mother. They are likely to be unemployed, truant from school, and to be on welfare (Issacs, 1992). These variables, as well as, others predict that youth of color have limited access to treatment networks and opportunities that would minimize the need for mental health services (Boyd-Franklin, 1991; Issacs, 1992; Osher, Steadman, \& Barr, 2002). They also implicate that the adolescents' parents shared this limited availability of mental health services, thus often providing pathogenic home environments. Each subsequently constitutes risk factors for adolescent and young adulthood crime and violence (Group for the Advancement of Psychiatry, Committee on Preventative Psychiatry, 1999).

Substantial evidence suggests that youth of color who are involved in community programs should have their individualized needs addressed by integrating procedures that influence youth decisionmaking and critical thinking abilities (Boyd, Franklin, 1991; Issacs, 1992; Underwood and Rawles, 2002).

The next section provides a review of several model community programs. These programs have been systematically researched and meet the criteria needed to be classified as evidence-based.

\section{Model Evidence-Based Programs}

The model evidence-based programs described in this section were selected on the basis of a thorough search of the literature (Jose \& Sechrest, 1999; McCord, Widom, \& Crowell, 2001 \& Spencer \& Jones Walker, 2004). The authors have selected community programs with at least some known use in juvenile justice or adolescent clinical settings and some evidence of reliability and other psychometric properties. The following section reviews of model evidence-based programs describe their respective change targets and outcomes.

\section{Multisystemic Therapy (MST)}

Multisystemic Therapy (MST) is considered an intensive family and community based treatment for youth who display antisocial behaviors, which puts them at risk for out-of-home placements. MST has been applied to youth with a variety of clinical problems which consists of: 1) chronic and violent juvenile offenders, 2) substance-abusing juvenile offenders, 3) adolescent sexual offenders, 4) youth in psychiatric crises (homicidal, suicidal, and psychotic), and 5) maltreating families (Randal, Heneggeler, Pickrel \& Brondino, 1999). In treating these particular populations, the ultimate goals of MST programs are to reduce the rates of antisocial behavior, enhance the youth's functioning, and decrease the utilization of out-of-home placements (incarceration and residential treatment). MST's focal point is on the juvenile's surrounding environment (neighborhood, family, peers, school, etc.) and how it contributes to the juvenile's well-being. Service delivery occurs within the home environment and the community. Cortes (2004) states that many authors believe in the effectiveness of home-based family therapy due to the fact that it reduces the attrition rate of families who may not trust the mental health field or may not possess transportation. Home-based services may also benefit the juvenile and his/her family since the family is more at ease. This helps the family in developing better relationships with the therapist, while maintaining some type of control. Home-based services provide more accessible services for low income families (Henggeler, Mihalic, Rone, Thomas \& Timmons-Mitchell, 1998).

MST has a body of research that supports its effectiveness with juveniles involved in post-release programs. Research has shown reductions up to $70 \%$ in long term rates of re-arrest, reductions up to $64 \%$ in out of home placements and improvements in family functioning (Randall, et al., 1999 \& Mulvey, Arthur \& Reppucci, 1993).

\section{Functional Family Therapy (FFT)}


Functional Family Therapy (FFT) is a family-based intervention, which is delivered in a clinical setting. FFT consists of four different phases: Impression, Motivation, Behavior Change, and Generalization phase (Alexander, Pugh \& Parsons, 2000). These phases include assessments of the family, specific interventions utilized throughout the treatment, and the goals of the therapist. FFT's major goal is to enhance the family's communication with each other despite much of the negativity that may be displayed. Other goals include enhancing parenting and problem-solving skills. FFT addresses delinquent behavior, substance abuse, and mental health disorders (Conduct disorder, Oppositional Defiant disorder, and Disruptive Behavior disorder).

FFT provides services for youth between the ages of 6 and 18 years. Recently, components of multi-ethnicity and multicultural have also been incorporated into the program, which is essential to the change process of this population. The outcomes of FFT services have been positive. With less serious juvenile offenders, there has been a 50-75\% reduction in recidivism rates. There has also been a $35 \%$ reduction in recidivism rates for more severe juvenile offenders (Alexander, Pugh \& Parsons, 2000).

\section{Multidimensional Treatment Foster Care (MTFC)}

Multidimensional Treatment Foster Care (MTFC) is an intensive parent training in an effort to enhance parents/guardians with more effective methods of parenting the juvenile when they return home. MTFC places emphasis on utilizing behavioral management methods with juvenile offenders in order to elicit change (Chamberlin \& Mihalic, 1998).

MTFC provides services to juvenile delinquents who are also having difficulties with their families. The program lasts between 6 to 9 months, during which, practitioners focus on assisting juvenile delinquents with reducing criminal behavior, improving school attendance, establishing positive peer relationships, and improving familial relationships. The intensive parenting training continues for 12 months following the termination of services.

There were some notable long-term, positive outcomes found in the review of this program. Chamberlin \& Mihalic (1998) state that $60 \%$ of juvenile offenders spent less time incarcerated during their 12 month follow-up. There were also fewer arrests with these juvenile offenders. Results indicate that these juveniles ran away from their placement three times less often than before receiving the MTFC treatment.

\section{Wrap-Around Milwaukee}

The Wrap-Around Milwaukee program relies upon community services and natural supports for youth and families to achieve positive outcomes (Burns \& Goldman, 1999). The wrap-around approach ensures that youth and families utilize a single individualized treatment plan that connects a youth's strengths and needs with specific services from within home, school and the community. The goal of Wrap Around Milwaukee is to reduce out of home placements. The Wrap-Around Milwaukee approach has been effective in reducing out-of-home placements as well as showing improvements in the social functioning of youth (Burns \& Goldman, 1999).

Effectiveness studies, as measured by the Child and Adolescent Functional Assessment Scale (Hodges, 1995), have demonstrated promising trends. For a group of 300 delinquent youth enrolled in Wraparound Milwaukee, the average score of psychosocial impairment decreased from high levels at the time of enrollment to moderate levels at six months and one year after enrollment in the program. Goldman \& Faw (1999) have also described positive effects. 


\section{Intensive Aftercare Program (IAP)}

The Intensive Aftercare Program (IAP) was designed to assist adolescents with their transition from incarceration back into the community (Altschuler \& Armstrong, 1998). The IAP model consists of five main principles; preparation of juveniles for increased responsibility and freedom, facilitating interaction between the youth and the community, assisting both the offender and community support systems, developing new resources and supports, and monitoring whether the youth and community facilities can effectively work together.

The IAP model has been tested and evaluated in several states, including Colorado, Nevada, and Virginia. Both Caucasian and African-American juveniles were included in the sample of these studies. Due to the fact that this model considers the cultural components, the IAP may have a more positive outcome on the target population.

\section{Mode Deactivation Therapy (MDT)}

Mode Deactivation Therapy (MDT) was developed in response to the difficulty in treating youth with high levels of co-morbidity, which resulted in ongoing resistance to current treatments modalities as well as being considered treatment failures in both the outpatient and residential settings. Apsche, Bass \& Murphy (2004) have demonstrated that MDT is effective in reducing aggression and suicidal ideations within this population. Through the synthesizing of an applied CBT methodology as well as Linehan's work with Dialectical Behavior Therapy (DBT), MDT was developed for youth who displayed a reactive conduct disorder, personality disorders/ traits, and Post Traumatic Stress Disorder symptomology. Apsche and his colleagues have demonstrated the effectiveness of MDT in reducing aggression, specifically with youth who display the aforementioned diagnostic traits (Apsche, et al., 2004; Apsche \& Ward 2004). Apsche \& Siv (2005) further emphasize the need for an efficacious methodology by positing the development of personality disorder traits/features as a coping mechanism by these youth. This methodology encapsulates the needs of these youth who present with a complicated neglect, multiaxial diagnoses, as well as often being the victims of sexual, physical, and/ or emotional abuse.

Mode Deactivation Therapy also includes a series of mindfulness exercises that are specifically designed for these adolescents. Exercises incorporated within the client workbook designed to allow the youth to practice the technique which helps ensure trust, reduce anxiety and increase commitment to treatment as it helps develop mindfulness skills for the youth. The mindfulness skills result in development of the youths heightened awareness of their fears, triggers and beliefs which helps, them to use this new coping strategies in place of the aggressive behaviors.

Several descriptive studies indicate that MDT has been more effective than standardized CBT in the treatment of this population of youth (Apsche \& Ward, 2004). Mode Deactivation Therapy has also been demonstrated as effective in a series of case studies (Apsche, Ward, Evile, 2002) and an empirical study which shows that it was more effective then standard CBT and social skills training (Apsche, Bass, Siv, 2005). Preliminary results of several recent case studies has shown MDT to be effective in reducing suicidal ideation and in reducing fire setting behaviors (Apsche \& Siv, 2005, Apsche, Siv, Bass, 2005). The study of this methodology is important on several levels. The first level being the need to provide evidence based therapy for youth with deficits in multiple areas regarding their mental health issues. Kazdin and Weisz (2003) indicate how aggressive behaviors have an adverse effect not only on the adolescent but also in a variety of social settings such as academics, peer relations, and an increased contact with the juvenile justice system. Providing a methodology which allows increased progress with this difficult population as well as offering hope to both providers and clients is paramount for the benefit of both parties. 


\section{Big Brothers Big Sisters of America (BBBSA)}

Big Brothers Big Sisters of America (BBBSA) is a community-based organization. Services are provided by volunteers of the community, utilizing more of a mentoring relationship. First, all volunteers attend an orientation of the program. Second, volunteers are screened by a written application, a background check, an extensive interview, and a home assessment. Third, the youth is assessed. This process allows the caseworker to learn more about the youth and their parent. Matching the youth and the volunteer is an essential component to the program. Matches are made based on the youth's needs, the parent's preference, and the availability of the volunteer. Supervision is maintained throughout the program.

BBBSA provides services to youth, who are between the ages of 6 and 18 years. The majority of these children come from single parent homes. BBBSA services continue until the eligibility criteria are no longer met or the youth/volunteer makes the decision that they can no longer participate in the program.

After 18 months, the study found that $46 \%$ were less likely to initiate drug and alcohol use. One third of the youth were less likely to hit someone. Youth, who participated in BBBSA, presented a more positive attitude towards their academic behavior and performance. The youth also reported that they had more positive relationships with friends and family (McGill, Mihalic, Grotpeter, 1998).

The next section discusses the limitations of evidence-based practices and offers recommendations for policymakers. A caution about these selections: What is best for one setting-or in the hypothetical circumstances described—might not be best for other settings.

\section{Limitations of Evidence-based Practices}

Researchers rely on rigorous designs and statistical procedures in developing evidence-based programs and interventions. However, there are some limitations to these practices. Researchers find it difficult to conduct a true random study on the outcome and effectiveness of these community based programs oftentimes use a quasi-experimental design in which the control group and experimental group are equivalent, but not randomly chosen. A well designed study that controls for external factors, has a low rate of participant attrition, accurate measurements, and appropria te analysis involves time and money of which most community based programs do not have.

Lack of adequate studies involving minorities raise important concerns when analyzing the effectiveness of evidence-based practices when the sample population is not representative of the actual population. Supporters of evidence-based community programs as treatment alternatives must take into account that some empirically validated interventions were normed on juveniles who may not have represented the heterogeneity of juveniles involved in the justice system. More studies are needed to examine the effectiveness that they may have on youth with specials needs including youth of color, ethnic minorities, females, mentally retarded, developmentally delayed, medically fragile, violent adolescents, and those with mental health issues.

Many at-risk youth present with many complex and unique issues that make it difficult to develop or implement a treatment program. Each intervention will have to be examined to match and tailor it to the developmental stage of the targeted population. The Virginia Commission on Youth (2004) finds that evidence-based practices often fail because of the poor fit with their target audience. There must be a clearly defined rationale and procedure when assessing youth for the appropriateness of their participation in a program. This poses a problem because in order to identify the population that would potentially 
benefit from treatment, youth need to be screened. Many community based treatment programs are understaffed and do not have the funds to implement such screening devises. Training new staff providing ongoing training for staff already involved is also costly, but necessary in order for juveniles are receiving adequate care.

When time, effort, and money well spent are not taken to ensure these measures are being conducted, chances are high that those juveniles will reenter back into the juvenile justice system.

\section{Summary}

This article summarized the literature on the effectiveness of community programs for juveniles involved in the justice system. In examining the literature, this article discusses critical factors in determining the effectiveness of evidence-based practices. In order to provide effective, evidence-based practices, terms associated with evidence-based practices must be defined. This article referred to evidence-base practices as a "body of knowledge, obtained through carefully implemented scientific methods, about the prevalence, incidence, or risk for mental disorders or about the impact of treatments or services on mental health problems" (National Institute of Mental Health (NIMH), 2001).

Evidence-based practices must be tailored to the population that is being treated. These interventions must address certain issues, such as the juvenile's environment, cultural aspects, and their development (physically and mentally).

In light of the advancements made in the area of evidence-based practices, we have argued that juveniles in community programs should receive the same level of services as those juveniles in mental health and substance use programs. Evidence-based practices require the integration of cognitivebehavioral theory, assessment, and treatment interventions. Furthermore, these characteristics for community programs are supported by the literature.

The emergence of evidence-based community programs has encouraged careful analyses on the development of evolving treatment strategies. Short and long-term outcome studies are needed to capture pertinent information for 18 to 36 months after discharge from community programs. The focus of these studies should not only provide measures of technical violations (re-arrests, etc.), but should also provide measures of positive outcomes, such as school attendance, substance use, peer association, and community involvement.

Future longitudinal studies are needed to determine if there are critical youth characteristics related to the most significant change targets. It is critical to focus on trauma, aggression and family violence and its mediating impact on juvenile delinquents. There is a need to further explore innovative programs that are directed towards ethnic minorities. These programs should focus on the role of acculturation and the level of community success and reintegration.

Policymakers must be aware of the impact of evidence-based programs. Funding and policy entities should be held responsible for their actions, supporting an atmosphere where service providers can provide evidence-based practices. Federal sources should highly encourage the use of evidence-based operating principles when considering acceptance of state and county Medicaid plans. Programs that subscribe to evidence-based practices should be held accountable for achieving expected outcomes. All evidence-based practices should be available to the community (Lehman, Goldman, Dixon, \& Churchill, 2004).

\section{References}

Abram, K., \& Teplin, L. (1991). Co-occurring disorders among mentally ill jail detainees: Implications for public policy. American Psychologist, 46 (10), 1036-1045. 
Alexander, J., Pugh, C. \& Parsons, B. (2000). Functional family therapy: In D. Elliot (Series Ed), Blueprints for Violence Prevention (Vol 3). Golden, CO: Venture.

Altschuler, D. (1998). Reintegrating juvenile offenders into the community: OJJDP's intensive community-based aftercare demonstration program.

Altschuler, D., \& Armstrong, T. (1995). Managing aftercare services for delinquents. In B. Glick \& A.P. Goldstein (Eds.), Managing Delinquency Programs That Work. Laurel, MD: American Correctional Association, pp. 137-170.

Altschuler, D., \& Armstrong, T. (1998). Reintegrating high-risk juvenile offenders into communities: Experiences and prospects. Corrections Management Quarterly, 5, 72-88.

Altschuler, D., \& Armstrong, T. (2002). Juvenile corrections and continuity of care in a community context: The evidence and promising direcions. Federal Probation, 66, 2, 72-78.

Alvero, A., Bucklin, B., \& Austin, J. (2001). An objective review of the effectiveness and essential characteristics of performance feedback in organizational settings. Journal of Organizational Behavior Management, 21 (1), 3-29.

Andrews, D.A., Bonta, J., and Hoge, R.D. 1990. Classification for effective rehabilitation: Rediscover psychology. Criminal Justice and Behavior 17:19-52.

Apsche, J.A. (2005). Beck's theory of modes. International Journal of Behavioral Consultation and Therapy, 2,1, in press.

Apsche, J.A. (1999). Thought Change Workbook. Portsmouth, VA: Alternative Behavioral Services.

Apsche, J.A., Evile, M.M., and Murphy, C.J. (2004). The thought change system: An empirically based cognitive behavior therapy for male juvenile sex offenders. A pilot study. The Journal of Behavior Analysis Today, 5, 1, 101-107.

Apsche, J.A., \& Ward Bailey, S.R. (2004a). Mode deactivation therapy: Cognitive behavioral therapy for young people with reactive conduct disorders or personality disorders or traits who sexually abuse. In M.C. Calder (Ed), Children and Young People Who Sexually Abuse: New Theory Research and Practice Developments, pp. 263-287. Lyme Regis, UK: Russell House Publishing.

Apsche, J.A., \& Ward Bailey, S.R. (2003). Mode deactivation therapy: A theoretical case analyses (Part I). The Journal of Behavioral Analyst Today, 4, 3, 342-353.

Apsche, J.A., \& Ward Bailey, S.R. (2004b). Mode deactivation therapy: A theoretical case analyses (Part II). The Journal of Behavioral Analyst Today, 5, 1, 395-434.

Apsche, J.A., \& Ward Bailey, S.R. (2004c). Mode deactivation therapy: A theoretical case analyses (Part III). The Journal of Behavioral Analyst Today, 5, 3, 314-332.

Apsche, J.A., Bass, C.K., Jennings,C.J., Siv, A.M. An empirical comparison between 
two treatments for adolescent males with conduct and personality disorders: Cognitive Behavior Therapy and Mode Deactivation Therapy. International Journal of Behavior Consultation and Therapy. Winter 20051 (1). Pp 27-45.

Apsche,J.A., Bass,C.K., Jennings, J.L., Murphy,C.J., Hunter, L.A., and SIV, A. An empirical study of behavior: A comparison of Mode Deactivation Therapy, Cognitive Behavior Therapy and Social Skills Training. International Journal of Behavior Consultation and Therapy. Spring 2005 1. (2), pp. 113-132.

Apsche, J.A., Bass, C.K., Murphy, C.J. (2004). A comparison of two treatment studies: CBT and MDT with adolescent sex offenders. Journal of Early and Intensive Behavioral Intervention, 1, 2, (Winter)179-190.

Armstrong, T. (2003). Achieving positive results with serious juvenile offenders in a reintegrative framework: Strategies essential for rehabilitative effectiveness with the intensive aftercare program (IAP) model. Retrieved on July 19, 2005, from http://www.csus.edu/ssis/cdcps/OnatiPaperEuropeanVersionRev3_05.pdf.

Beale Spencer, M., \& Jones-Walker, C. (2004). Interventions and services offered to former juvenile offenders reentering their communities. Youth Violence and Juvenile Justice, 2, $1,88-97$.

Bilchik, S. (1999). Minorities in the juvenile justice system. 1999 National Report Series. Juvenile Justice Bulletin. Department of Justice, Washington, D.C. Office of Juvenile Justice and Delinquency Prevention, 1-15.

Botvin, G., Mihalic, S., \& Grotpeter, J. (1998). Blueprints for violence prevention, book five: Life skills training. Boulder, CO: Center for Study and Prevention of Violence.

Bourdin, C. (1999). Multisystemic treatment of criminality and violence in adolescents. Journal of American Academy of Child and Adolescent Psychiatry, 38 (3), 242-249.

Boyd-Franklin, N. (1991). Culturally sensitive treatment of the inner-city AfricanAmerican adolescent: A multi-systemic model. In W. Snyder, \& T. Ooms (Eds.), Empowering families, helping adolescents: Family-centered treatment of adolescents with alcohol, drug abuse and mental health problems. Washington, DC: U.S. Department of Health and Human Services.

Burns, B., Hoagwood, K., and Mrazek, P. (1999). Effective Treatment for Mental Disorders in Children and Adolescents. Clinical Child and Family Psychology Review 2 (4): 199-254. For a report on the proceedings of the NIMH Child and Adolescent Mental Health Services Research Planning Meeting. [Online]. Available: http://www.nimh.nih.gov/childhp. [June 2002].

Burns, B.J., \& Goldman, S.K. (1999). Promising practices in wraparound for children with serious emotional disturbance and their families. Systems of care: Promising practices in children's mental health, 1998 series, volume IV. Washington, D.C.: Center for Effective Collaboration and Practice, American Institutes for Research. 
Canino, I., \& Spurlock, J. (1994). Culturally diverse children and adolescents. New York: Guilford Press.

Capaldi, D. (1992). Co-occurrence of conduct problems and depressive symptoms in early adolescent boys: A 2-year follow-up at grade eight. Development and Psychopathology: 4, 125-144.

Capaldi, D., \& Patterson, G. (1996). Can violent offenders be distinguished from frequent offenders? Prediction from childhood to adolescence. Journal of Research in Crime and Delinquency, 33, 206-231.

Chamberlain, P., \& Mihalic, S. (1998) Blueprints for violence prevention, book eight: Multidimensional treatment foster care. Boulder, CO: Center for the Study and Prevention of Violence.

Clements, C. (1996). Offender classification: Two decades of progress. Criminal Justice and Behavior, 23, 121-143.

Cocozza, J. (1997). Identifying the needs of juveniles with co-occurring disorders. Corrections Today, 147-149.

Cocozza, J. J., Trupin, E., \&Teodosio, L. (2003) Diverting youth with mental health needs from the juvenile justice system: Critical issues and model approaches. Presented at the GAINS TAPA center easy access net/teleconference.

Cortes, L. (2004). Home-based family therapy: A misunderstanding of the role and a new challenge for therapists. The Family Journal: Counseling and Therapy for Couples and Families, 12(2), 184-188.

Department of Justice, Office of Juvenile Justice and Delinquency Prevention. (1999). Minorities in the juvenile justice system. 1999 National Report Series. Juvenile Justice Bulletin. Washington, D.C.: Juvenile Justice Clearinghouse, 1-17.

Drake, R., Mueser, K., Clark, R., \& Wallach, M. (1999). The course, treatment and outcomes of substance disorder in persons with severe mental illness. American Journal of Orthopsychiatry, 66 (1), 42-51.

Farrington, D. (1989). Early predictors of adolescent aggression and adult violence. Violence and Victims, 4, 79-100.

Farrington, D. (1994). Childhood, adolescent, and adult features of violent males. In: Aggressive behavior: current perspectives (pp. 215-240). New York: Plenum Press.

Fulkerson, J., Harrison, P., \& Beebe, T. (1997). Residential behavioral treatment facilities. 1996 Minnesota student survey. Substance Abuse and Mental Health Services Administration. Rockville, MD, 1-33.

Gendreau, P., \& Goggin, C. (1995). The principles of effective intervention with offenders. In A. J. Harland (Ed.), Choosing Correctional Options That Work: Defining the demand and evaluating the supply. Thousand Oaks, CA: Sage. 
Goldman, S.K. \& Faw, L. (1999). Three wraparound models as promising approaches in Burns, B.J. \& Goldman, S.K. (Eds) (1999). Promising practices in wraparound for children with serious emotional disturbance and their families. Systems of care: Promising practices in children's mental health, 1998 series, volume IV. Washington DS: Center for Effective Collaboration \& Practice, American Institutes for Research, (pgs 17-60).

Gorman-Smith, D., Tolan, P., Loeber, R., \& Henry, D. (1998). Relation of family problems to patterns of delinquent involvement among urban youth. Journal of Abnormal Child Psychology, 26(5), 319-333.

Greenbaum, P., Foster-Johnson, L., \& Petrilla, A. (1996). Co-occurring addictive and mental disorders among adolescents: Prevalence Research and Future Directions. American Orthopsychiatry Association.

Greenberg, M., Kusche, C., \& Mihalic, S. (1998). Blueprints for violence prevention, Book Ten: Promoting Alternative Thinking Strategies (PATHS). Boulder, CO: Center for the Study and Prevention of Violence.

Group for the Advancement of Psychiatry, Committee on Preventive Psychiatry. (1999). Violent behavior in children and youth: preventive intervention from a psychiatric perspective. Journal of the American Academy of Child and Adolescent Psychiatry, 38 (3), 235-241.

Hamparian, D., \& Leiber, M. (1997). Disproportionate confinement of minority juveniles in secure facilities: 1996 National Report. Champaign, IL: Community Research Associates.

Henggeler, S., Melton, G., \& Smith, L. (1992). Family preservation using multisystemic therapy: An effective alternative to incarcerating serious juvenile offenders. Journal of Consulting and Clinical Psychology, 60, 953-961.

Henggeler, S., Mihalic, S., Rone, L., Thomas, C., \& Timmons-Mitchell, J. (1998). Blueprints for violence prevention, book six: Multisystemic therapy. Boulder, CO: Center for the Study and Prevention of Violence.

Hoagwood, K., Burns, B., Kiser, L., Ringeisen, H., \& Schoenw ald (2001). Evidencebased practice in child and adolescent mental health services. Psychiatric Services, 52 (9), 1179-1189.

Hodges, K. (1995). CAFAS self-training manual and blank scoring forms. Ypsilanti, MI: Eastern Michigan University Psychology Department.

Isaacs, M. (1992). Assessing the mental health needs of children and adolescents of color in the juvenile justice system. Overcoming institutionalized perceptions and barriers. In J. Cocozza (Ed.), Responding to the mental health needs of youth in the juvenile justice system (pp. 141-163). Seattle, WA: National Coalition for the Mentally Ill in the Criminal Justice System.

Joplin, et al. (2004). Using an integrated model to implement evidence-based practices in corrections. International Community Corrections Association and American Correctional Association, 1-28. 
Josi, D.A., \& Sechrest, D.K. (1999). A pragmatic approach to parole aftercare: Evaluation of community reintegration program for high-risk youthful offenders. Justice Quarterly, 16 (5), 1-80.

Kaminer, Y., \& Frances R. (1991). Inpatient treatment of adolescents with psychiatric and substance abuse disorders. Hospital and Community Psychiatry, 42, 894-896.

Kessler, R., Foster, C., Saunder, W., \& Stang, P. (1995). Social consequences of psychiatric disorders. American Journal of Psychiatry, 152, 1026-1032.

Lehman, A., Goldman, H., Dixon, L., \& Churchill, R. (2004). Evidence-based mental Health treatments and services: Examples to inform public policy. Retrie ved on July 19, 2005, http://www.milbank.org/reports/2004lehman/2004lehman.html.

McCord, J. (1982). A longitudinal study of the link between broken homes and criminality. In: Abnormal offenders delinquency and the criminal justice system. London: Wiley.

McCord, J., Widom, C., \& Crowell, N. (2001). Juvenile Crime, Juvenile Justice. Washington, DC: National Academy Press.

McDonald, C. (2003). Forward via the past? Evidence-based practice as strategy in social work, The drawing board: An Australian review of public affairs, 3 (3), 123-142.

McGill, D., Mihalic, S., \& Grotpeter, J. (1998). Blueprints for violence prevention, book two: Big brothers big sisters of America. Boulder, CO: Center for the Study and Prevention of Violence.

McGuire, J. (2001). What works in correctional intervention? Evidence and practical implications. Pp. 25-43 in Offender rehabilitation in practice: Implementing and evaluating effective programs, edited by D. F. Gary Bernfeld, Alan Leschied. New York, NY: John Wiley \& Sons, LTD.

McGuire, J. (2002). Evidence-based programming today. Paper presented at international community corrections association conference, Boston, MA, November, 2002.

Meyers, R., Miller, W., Smith, J., \& Tonnigan, S. (2002). A randomized trial of two methods for engaging treatment-refusing drug users through concerned significant others. Journal of Consulting and Clinical Psychology, 70 (5), 1182-1185.

Mihalic, S. \& Irwin, K. (2003). Blueprints for violence prevention: From research to real world settings-factors influencing the successful replication of model programs. Boulder, CO: Center for the Study \& Prevention of Violence.

Miller, W. \& Rollnick, S. (2002). Motivational interviewing: Preparing people for change. New York, NY: Guilford Press.

Mulvey, E., Arthur, M., \& Reppucci, N. (1993). The prevention and treatment of juvenile delinquency: A review of the research. Clinical Psychology Review, 13, 133-167.

National Institute of Mental Health. (2001). Blueprint for change: Research on child and adolescent mental health. Report of the National Advisory Mental Health 
Council's Workgroup on Child and Adolescent Mental Health Intervention.

National Mental Health Association. (2006). Treatment works for youth in the juvenile Justice system. www.nmha.org/children/justjuv/treatment.cfm

Olds, D., Hill, P., Mihalic, S., \& O’Brien, R. (1998). Blueprints for violence prevention, book seven: Prenatal and infancy home visitation by nurses. Boulder, CO: Center for the Study and Prevention of Violence.

Osher, F., Steadman, H., \& Barr, H. (2002). A best practice approach to community reentry from jails for inmates with co-occurring disorders: The APIC model. The National GAINS Center. Delmar, New York.

Palmer, T. (1995). Programmatic and non-programmatic aspects of successful intervention: New directions for research. Crime \& Delinquency, 41 (1), 100-131.

Patterson, G., Reid, J., \& Dishion, T. (1992). Antisocial boys: A social interactional approach (Vol. 4). Eugene, OR: Castalia.

Pentz, M., Mihalic, S., \& Grotpeter, J. (1998). Blueprints for violence prevention, book one: The midwestern prevention project. Boulder, CO: Center for the Study and Prevention of Violence.

Poe- Yamagata, E., Jones, M. (2000). And justice for some. Building Blocks for Youth.

Prescot, L. (1997). Adolescent girls with co-occurring disorders in the juvenile justice system. Delmar, NY: The National GAINS Center.

Randall, J., Henggeler, S., Pickrel, S., \& Brondino, M. (1999). Psychiatric comorbidity and the 16-month trajectory of substance-abusing and substance-dependent juvenile offenders. Journal of the American Academy of Child and Adolescent.

Sickmund, M. 2000. Census of Juveniles in Residential Placement Databook. Fact Sheet. Washington, DC: U.S. Department of Justice, Office of Justice Programs, Office of Juvenile Justice and Delinquency Prevention. FS-200008.

Spencer, M., \& Jones-Walker, C. (2004). Interventions and services offered to former juvenile offenders reentering their communities: An analysis of program effectiveness. Youth Violence and Juvenile Justice, 2, 88-97.

Steiner, J., Dunne, J., Ayres, W., Arnold, V., Benedek, R., Benson, S., et al. (1997). Practice parameters for the assessment and treatment of children and adolescents with conduct disorder. Journal of the American Academy of Child and Adolescent Psychiatry, 36, 122-140.

Taxman, F. \& Byrne, J. (2001). Fixing broken windows probation together. Perspectives, Spring, 23-29.

Thompson, L, Riggs, P., Mikulich, S., \& Crowley, T. (1996). Contribution of ADHD symptoms to substance problems and delinquency in conduct-disordered adolescents, Journal of Abnormal Child Psychology, 24, 325-347. 
Tolan, P., \& Loeber, R. (1993). Antisocial behavior. In: Handbook of clinical research and clinical practice with adolescents (pp. 307-331). New York: Wiley.

Underwood, L.A. (2005). Los Angeles County Probation Social Learning Model for High Risk and High Need Youth in Community Programs. Unpublished Document.

Underwood, L.A., Barretti, L., Storms, T.L., Safonte-Strumbolo, N. (2004). A review of clinical characteristics and residential treatments for adolescent males with mental health disorders: A promising program_A review of clinical characteristics and residential treatments for adolescent males with mental health disorders: A promising program Journal of Trauma, Violence and Abuse, 5, 3, 199-242.

Underwood, L., Mullan, W., \& Walter, C. (1997). We built them and they came: New insights for managing Ohio's aggressive juvenile offenders with mental illness. Corrections Management Quarterly, 1(4), 19-27.

Underwood, L., \& Rawles, P. (2002). Screening and assessing African-American youth involved in the juvenile justice system: Practical Considerations, Juvenile Correctional Mental Health Report, 2 (4), 49-50, 56-62.

Veysey, B. (2003). Adolescent girls with mental health disorders involved with the juvenile justice system. National Center for Mental Health and Juvenile Justice. Delmar, New York.

Virginia Youth Commission (2004). Evidence-based treatments. Retrieved on July 19, 2005, from http://coy.state.va.us/Modalities/evidence.htm.

Waldron, H., Slesnick, N., Peterson, T., \& Turner, C. (2001). Treatment outcomes for adolescent substance abuse at 4-and 7-month assessments, Journal of Consulting and Clinical Psychology, 69 (5), 802-818.

Weinberg, N., Rahdert, E., Colliver, J., \& Glantz, M. (1998). Adolescent substance abuse: A review of the past 10 years. Journal of the American Academy of Child and Adolescent Psychiatry, 37, 252-261.

Weisz, J.R. (2001). Lab-clinic differences and what we can do about them: Linking research and practice to enhance our public impact. Newsletter of the Division of Clinical Child Psychology.

Wood, P., Trupin, A., Vander Stoep, A. (1999). The community transition of incarcerated mentally ill youth: An outcome study. Washington State Department of Social and Health Services. Seattle, WA.

Wilson, W. (1991). Studying inner-city social dislocation. American Sociological Review, $56,1-14$.

\section{Author Note}

Lee A. Underwood, Psy.D. Licensed Clinical Psychologist, Regent University and the National Center for Mental Health and Juvenile Justice (NCMHJJ). 
Dr. Lee A. Underwood serves as an Assistant Professor with Regent University School of Psychology and Counseling and is a Senior Consultant for the National Center for Mental Health and Juvenile Justice, an affiliate of Policy Research Associates (PRA).

Kara Sandor von Dresner, MA, CGS is a Psy.D. student in the Clinical Psychology at Argosy University/Washington DC. She also serves as a Program Consultant for USA Consulting Group.

Annie L. Phillips, MA is a graduate of Regent University School of Psychology and Counseling and is a doctoral student in the Counseling Psychology at Walden University.

\title{
Author Contact Information:
}

\section{Dr. Lee A. Underwood \\ Regent University, 1000 University Drive Virginia Beach, VA 23464 \\ Email: leeunde@regent.edu.}

\section{ADVERTISING IN THE INTERNATIONAL JOURNAL OF BEHAVIORAL AND CONSULTATION THERAPY}

\author{
The prices for advertising in one issue are as follows: \\ 1/4 Page: \$50.00 1/2 Page: \$100.00 vertical or horizontal Full Page: \$200.00 \\ If you wish to run the same ad in multiple issues for the year, you are eligible for the following discount: \\ 1/4 Pg.: \$40 - per issue \\ 1/2 Pg.: \$75 - per issue -vertical or horizontal \\ Full Page: \$150.00-per issue \\ An additional one time layout/composition fee of \$25.00 is applicable
}

For more information, or to place an ad, contact Halina Dziewolska via e-mail at: halinadz@ hotmail.com 


\title{
Dodo-Bird or Dressing up the Pig and the Politics of Psychotherapy: A Reply to Vandenberghe and de Sousa (2005)
}

Joseph Cautilli, Ph.D.

\begin{abstract}
It is fitting that the concept of all having one and having prizes is attributed to the DodoBird. The dodo was a flightless bird. In shape and form it was similar to the modern turkey. The dodo was native to Mauritius, where it lived for thousands of years before domestic animals brought to Mauritius hunted it to extinction. The last live specimen was seen in 1681. The words of the dodo-bird having been long extinct are the perfect way to reflect on Smith, Glass and Miller (1980).

Key words: Dodo bird, placebo treatments, attention control, control group, meta-analysis.
\end{abstract}

\section{Introduction}

If the reader will pardon my indulgence, most biologists thought that coelacanths had been extinct for 70 million years until 1938 when fishermen of South Africa were found to have been regularly catching and eating them. I am equally shocked to see Vandenberghe and de Sousa have resurrected the Dodo-bird again based on Smith, Glass and Miller (1980). But it is really not the dodo at all but a dressed up pig.

Let me rehash three well know arguments about the meta-analysis conducted by Smith and colleagues:

1. The first is that Smith and colleague's (1980) table of treatments list placebo treatment and attention control as active treatments. Why would this occur? Simple the formula for meta-analysis for a continuous outcome is reported as the difference between the treatment mean and the control mean divided by the standard deviation in the control group.

$$
\hat{\theta}_{i}=\frac{\bar{x}_{r}-\bar{x}_{c}}{\bar{s}_{c}}
$$

If one moves the placebo treatment over to the control side, then the whole meta-analysis reports no-effect for psychotherapy. This statistical slight of hand was first reported by Prioleau, Murdock \& Brody (1983) and echoed by others since then (e.g., Cautilli \& Skinner, 2001).

2. Even if one buys that placebo treatment is a treatment, and then a fair report of metaanalysis would be that no form of psychotherapy is better then any other form including placebo control treatment. I believe even Eysenk (1952, 1983, 1994) would have supported this conclusion. So why is this not mentioned? Glass (2000) offers some insight "Psychologists tended to fixate on the fact that the analysis gave no warrant to any claims that one type or style of psychotherapy was any more effective than any other: whether called "behavioral" or "Rogerian" or "rational" or "psychodynamic," all the 
therapies seemed to work and to work to about the same degree of effectiveness." (p. 3). Mays and Franks (1980 in discussing possible deleterious effects of psychotherapy placed such discussions squarely on the need of an emerging profession to justify itself by showing it was "safe" and "effective" to the insurance industry and federal funders.

3. One final issue, Vaudenberghe and colleagues (2005) argue that Smith et al (1980) places further interest into the therapeutic relationship. This is certainly not how Cronbach (1982) saw it. He argued that Smith and colleagues stripped psychotherapy of context. It did not matter if you liked your therapist, if your problem had been occurring one week, one moth, one year fifty years, it did not matter if the treatment was a week or a month this thing called psychotherapy worked.

My argument is not that le gitimate meta-analysis cannot be accomplished, but that in a world with multiple contingencies operating on each scientist careful review of the methods and procedures is needed. Nor is my argument that functional analytic psychotherapy (Kohlenberg and Tsai, 1991) is not effective. From my perspective, forty years of considerable research exists to support the notion of building report and targeting clinically relevant behavior in session with behavioral principles such as reinforcement and extinction (see a brief review in Cautilli, Tillman, Axelrod and Hineline, 2005) as done in functional analytic psychotherapy (Kohlenberg and Tsai, 1991). My point is simply that Smith and colleagues dressed up the pig to sell her to governments and the insurance industry.

The field of psychotherapy is past the need to self-justify. We need to take an honest look at our past and recognize what was science and what was politics.

\section{References}

Cautilli, J., Riley-Tillman, T.C., Axelrod, S. \& Hineline, P. (2005). The role of verbal conditioning in third generation behavior therapy. The Behavior Analyst Today, 6(2), 137-146.

Cautilli, J. \& Skinner, L. (2001). Toward a functional analysis of "scientific" verbal behavior: A preliminary essay. The Behavior Analyst Today, 2(3), 250-252.

Cronbach, L.J. (1982). Prudent Aspirations for Social Inquiry. Chapter 5 (Pp. 61-81) in Kruskal, W.H. (Ed.), The social sciences: Their nature and uses. Chicago: The University of Chicago Press.

Eysenck, H.J. (1952). The effects of psychotherapy: An evaluation. Journal of Consulting Psychology, 16, 319-324.

Eysenck, H.J. (1983). The benefit of psychotherapy. Behavior Research and Therapy, 21, 315320.

Eysenck, H.J. (1994). The outcome problem in psychotherapy: What have we learned? Behavior Research and Therapy, 32, 477-495

Glass, G.V. (2000). Meta-Analysis at 25 http://glass.ed.asu.edu/gene/papers/meta25.html downloaded on 10/6/05. 
Kohelnerg, R.J. \& Tsai, M. (1991). Functional analytic psychotherapy: Creating intense and curative relationships. New York: Plenum Press.

Mays, D.T. \& Franks, C.M.(1980). Getting worse: Psychotherapy or no treatment: The jury should still be out. Professional Psychology, 11, 78-92.

Prioleau, L., Murdock, M., \& Brody, N. (1983). An analysis of psychotherapy versus placebo studies. The Behavioral and Brain Sciences, 6, 275-282.

Smith, ML., Glass, G.V., and Miller, T.I. (1980). The benefits of psychotherapy. Baltimore: John Hopkins University Press.

Vandenberghe, L. \& de Sousa, A.C. (2005). The dodo-bird debate, empirically supported relationships and functional analytic psychotherapy. International Journal of Behavioral Consultation and Therapy, 1(4), 323-328.

\section{Author Contact Information:}

\section{Joe Cautilli, Ph.D.}

Children Crisis Treatment

1823 Callowhill St.

Philadelphia, Pa. 19130

\section{ADVERTISING IN THE \\ INTERNATIONAL JOURNAL OF BEHAVIORAL AND CONSULTATION THERAPY}

The prices for advertising in one issue are as follows:

1/4 Page: $\$ 50.00 \quad 1 / 2$ Page: $\$ 100.00$ vertical or horizontal Full Page: $\$ 200.00$

If you wish to run the same ad in multiple issues for the year, you are eligible for the following discount:

1/4 Pg.: \$40 - per issue

1/2 Pg.: \$75 - per issue -vertical or horizontal

Full Page: \$150.00-per issue

An additional one time layout/composition fee of $\$ 25.00$ is applicable

For more information, or to place an ad, contact Halina Dziewolska via e-mail at: halinadz@hotmail.com 